MARCOSIRIS AMORIM DE OLIVEIRA PESSOA

ARQUITETURA DE SISTEMA DE PLANEJAMENTO E CONTROLE DA PRODUÇÃO NO CONTEXTO DE EMPRESA VIRTUAL

São Paulo 
MARCOSIRIS AMORIM DE OLIVEIRA PESSOA

\section{ARQUITETURA DE SISTEMA DE PLANEJAMENTO E CONTROLE DA PRODUÇÃO NO CONTEXTO DE EMPRESA VIRTUAL}

Tese apresentada à Escola Politécnica da Universidade de São Paulo para obtenção do título de doutor em Ciências

São Paulo 
MARCOSIRIS AMORIM DE OLIVEIRA PESSOA

\section{ARQUITETURA DE SISTEMA DE PLANEJAMENTO E CONTROLE DA PRODUÇÃO NO CONTEXTO DE EMPRESA VIRTUAL}

Tese apresentada à Escola Politécnica da Universidade de São Paulo para obtenção do título de doutor em Ciências

Área de concentração:

Engenharia de Controle e Automação Mecânica

Orientador:

Paulo Eigi Miyagi

Co-orientador:

Fabrício Junqueira

São Paulo 
Este exemplar foi revisado e alterado em relação à versão original, sob responsabilidade única do autor e com a anuência de seu orientador.

São Paulo, de de 2015

Assinatura do autor

Assinatura do orientador

\section{Catalogação-na-publicação}

Pessoa, Marcosiris Amorim de Oliveira

Arquitetura de sistema de planejamento e controle da produção no contexto de empresa virtual / M.A.O. Pessoa. --ed.rev.--São Paulo, 2015.

$171 \mathrm{p}$.

Tese (Doutorado) - Escola Politécnica da Universidade de São Paulo. Departamento de Engenharia Mecatrônica e de Sistemas Mecânicos.

1. Planejamento da produção (Sistemas) 2. Controle da produção (Sistemas) 3. Empresa virtual 4. Janela de tempo 5. Programação de restrições I. Universidade de São Paulo. Escola Politécnica. Departamento de Engenharia Mecatrônica e de Sistemas Mecânicos II. t. 


\section{DEDICATÓRIA}

Aos meus pais Sonia e Bernardo-i.m.

À minha esposa Simone

Ao meu filho Marcosiris

Ao meu grande amigo Levi Arruda - i.m. 


\section{AGRADECIMENTOS}

Agradeço primeiro a Deus por tudo, por sempre ter me ajudado, pelas pessoas que estão ao meu redor e pela vida, muito obrigado meu Senhor.

Aos meus orientadores Prof. Dr. Paulo Eigi Miyagi e Prof. Dr. Fabrício Junqueira, pela constante orientação, apoio, amizade e incentivos para o desenvolvimento deste trabalho.

Ao Prof. Dr. Diolino José dos Santos Filho por sua amizade, incentivos, apoio, e orientações tanto acadêmicas quanto pessoais.

À minha esposa que sempre me apoiou, entendeu a minha ausência, suportou algumas férias em casa enquanto eu estava escrevendo partes da Tese, algum artigo ou projeto, ao meu filho que teve que esperar tanto tempo para nascer, espero que ele entenda que eu não teria o tempo necessário para dar toda atenção que ele merece, aos meus pais que sempre me apoiaram, e a todos os meus parentes e amigos que me apoiaram e entenderam a minha ausência no decorrer deste trabalho.

Aos amigos do Laboratório de Sistemas de Automação (LSA) pelas sugestões e contribuições, em especial ao Caio Fattori, Osvaldo Asato, Francisco Yastami, Cristina Matsusaki, José Isidro Garcia, Percy Kaneshiro, Roy Andres, Samira Souit, Reinaldo Squillante Junior, André Cavalheiro, Jeferson de Souza, Maurício Blos, Robson Marinho, Edson Watanabe, e a todos do LSA pelo apoio e pela amizade.

À Escola Politécnica da USP por ser um centro de excelência e, em especial ao Departamento de Engenharia Mecatrônica e de Sistemas Mecânicos, que institucionalmente viabilizaram este trabalho. Aos Chefes do Departamento de Engenharia Mecatrônica e de Sistemas Mecânicos que apoiaram este trabalho: Prof. Dr. Lucas Antonio Moscato, Prof. Dr. Julio Cezar Adamowski e Prof. Dr. Emílio Carlos Nelli Silva.

Aos Professores da primeira turma (1998-2000) do curso de especialização em Automação e Informática Industrial do Programa de Educação Continuada em Engenharia (PECE) da Escola Politécnica da USP: Prof. Dr. Diolino José dos Santos Filho, Prof. Dr. José Reinaldo Silva, Prof. Dr. Marcos Ribeiro Pereira Barretto, Prof. Dr. Newton Maruyama e Prof. Dr. Fabio Gagliardi Cozman. Seus profundos conhecimentos sobre os assuntos lecionados e algumas conversas sobre pesquisas que me fizeram refletir e me estimularam a continuar estudando, só que eles me mostraram que o estudo deveria ser mais aprofundado e num nível de pesquisa. Vocês foram o exemplo para eu fazer o mestrado.

A todos os professores e funcionários do Departamento de Engenharia Mecatrônica e de Sistemas Mecânicos que sempre me forneceram suporte, amizade e apoio.

À Profa. Dra. Izabel Fernanda Machado pelo seu grande exemplo de determinação e força. 
Aos coordenadores, professores e funcionários do Programa de Pós-Graduação em Engenharia Mecânica da Poli-USP, pelo apoio, amizade e suporte financeiro para participação nos congressos internacionais.

Aos professores do Departamento de Engenharia Mecânica que me apoiaram.

Agradeço a FAPESP, CNPq e CAPES que apoiam o programa de Pós-Graduação em Engenharia Mecânica da Poli-USP.

Agradeço a todos os professores que de forma direta ou indireta contribuíram para a minha formação.

O mestrado me abriu os olhos, o doutorado me abriu a mente. 


\section{RESUMO}

Em um mercado global, tem sido observada a tendência para a dispersão geográfica das fábricas. Esta dispersão é motivada pela oportunidade de explorar as vantagens locais, sob diferentes pontos de vista. Essa estrutura também permite a interação mais intensa entre plantas de diferentes empresas produtivas. Neste sentido, o conceito de Empresa Virtual (EV) é fundamental para explorar novas estratégias de negócios, tais como "foco nas competências essenciais", "orientação máxima para o cliente" e "produção distribuída". No entanto, nesta nova estrutura produtiva, há novos requisitos para o planejamento e para o estabelecimento da data de entrega dos pedidos. Um sistema de Planejamento e Controle da Produção (PCP) convencional utiliza uma arquitetura hierárquica, o que não atende o requisito de autonomia das empresas parceiras. Para atender a essas novas exigências, este trabalho apresenta uma arquitetura de sistemas de planejamento e controle da produção no contexto de EV.

Na proposta são utilizados os conceitos de "janelas de tempo" em conjunto com "propagação de restrições" para atender os requisitos de prazo de entrega de produtos. Estes dois conceitos têm sido amplamente utilizados na literatura relacionada a sistemas de planejamento convencionais, no entanto, não no contexto de EV. Nesta abordagem, as "janelas de tempo" delimitam o intervalo de alocação das tarefas nos sistemas de produção envolvidos, enquanto as "restrição de capacidade" identificam "janelas de tempo" factíveis considerando a importância da data de

vencimento do pedido. É apresentado um exemplo da utilização da arquitetura e um exemplo de implementação. Este trabalho engloba EVs com empresas parceiras de diversos tipos de produção (produção em lotes e produção discreta). É utilizado o Production Flow Schema (PFS) para modelagem dos processos produtivos segundo uma abordagem hierárquica, com base em sucessivos refinamentos para construir o modelo de forma progressiva e estruturada onde as propriedades do modelo ficam asseguradas por construção. Este refinamento gera sub-grafos em Rede de Petri, que são utilizados para a análise e o controle do processo produtivo.

Palavras-chave: Sistemas de planejamento da produção. Sistemas de controle da produção. Empresa virtual. Janela de tempo. Programação de restrições. 


\begin{abstract}
In a global market, the trend for geographical dispersion of manufacturing plants has been observed. This dispersion is motivated by the opportunity to exploit local advantages under different viewpoints. This structure also allows for more intense interaction between plants of different productive enterprises. In this sense, the concept of Virtual Enterprise (VE) is fundamental to explore new business strategies such as "focus on core competencies", "maximal customer orientation" and "distributed production". However, in this new productive structure, there are new requirements for planning and for establishing the delivery date of the orders. $A$ conventional Production Planning and Control system (PPC) uses a hierarchical architecture, which does not meet the requirement of autonomy of the partners companies. To address these new requirements, this work introduces a Production Planning and Control System Architecture in EV context.

In the proposal are used the concepts of "time windows" and "constraint propagation" to meet the deadline requirements of product delivery. These two concepts have been widely used in the literature relating to conventional planning systems, however, not in the EV context. In this approach, the "time windows" delimit the allocation range of tasks in production systems involved, while the "capacity constraint" identify the feasible "time window" considering the importance of the ordes due date. An example of using the architecture and an implementation is presented. This work includes EVs with partner companies of various types of production (production batch and discrete manufacturing). Production Flow Schema (PFS) is used for modeling the processes according to a hierarchical approach based on successive refinements to construct progressive and structured model where the properties of model are ensured by construction. This refinement generates sub-graphs in Petri Net, which are used for the analysis and control of the production process.
\end{abstract}

Keywords: Production planning systems. Production control systems. Virtual enterprise. Time windows. Constraint programming 


\section{LISTA DE FIGURAS}

Figura $1 \quad$ Ciclo para desenvolvimento da pesquisa. . . . . . . . . . . . . . . 23

Figura 2 Ciclo para o desenvolvimento considerado nesta pesquisa. . . . . . . . 24

Figura 3 Níveis de engajamento das interações. . . . . . . . . . . . . . . . . . 26

Figura $4 \quad$ Classificações das redes colaborativas. . . . . . . . . . . . . . . . . . . . 29

Figura 5 Redes de entidades direcionadas à oportunidade. . . . . . . . . . . . . . 29

Figura 6 Exemplo de EV. . . . . . . . . . . . . . . . . . . . . . . . 31

Figura 7 Taxonomia das EVs. . . . . . . . . . . . . . . . . . . . . 33

Figura $8 \quad$ Principais atores de uma EV e interação entre eles. . . . . . . . . . . 35

Figura 9 Ciclo de vida das EVs. . . . . . . . . . . . . . . . . . . . . . . . . 36

Figura $10 \quad$ Estágios evolutivos dos sistemas de PCP. . . . . . . . . . . . . . . . . . 38

Figura $11 \quad$ Instantes principais de uma "janela de tempo". . . . . . . . . . . . . . 45

Figura 12 Diagrama de hierarquia funcional. . . . . . . . . . . . . . . . . 56

Figura $13 \quad$ Modelo de hierarquia de equipamento . . . . . . . . . . . . . . . . 58

Figura $14 \quad$ Modelo funcional de fluxo de dados. . . . . . . . . . . . . . . . . . 60

Figura 15 Modelo de objetos referente à capacidade da produção. . . . . . . . . 60

Figura $16 \quad$ Representação de uma Rede de Petri. . . . . . . . . . . . . . . . . . . 62

Figura $17 \quad$ Representação em RdP de dois processos em sequência. . . . . . . . . . 65

Figura 18 Representação do paralelismo em RdP de duas atividades com a mesma condição inicial. . . . . . . . . . . . . . . . . . . 66

Figura $19 \quad$ Representação em RdP da sincronização de duas atividades. . . . . . . 66

Figura $20 \quad$ Representação em RdP do conflito entre duas atividades. . . . . . . . 67

Figura 21 Representação em RdP do compartilhamento de recursos entre duas atividades. . . . . . . . . . . . . . . . . . . . . . . . . 67

Figura $22 \quad$ Exemplo de PFS com identificação de seus elementos construtivos. . . 69

Figura $23 \quad$ Elemento Atividade do PFS e um possível detalhamento em RdP. . . . 70

Figura $24 \quad$ Elemento Distribuidor do PFS e um possível detalhamento em RdP. . . 70

Figura $25 \quad$ Representação do sistema de movimentação de materiais. . . . . . . . . 70

Figura 26 Representação em PFS do sistema da Fig. 25/indicando o deslocamento

do transportador no trilho, deslocando-se de forma circular pelas
estações. . . . . . . . . . . . . . . . . . . . 71

Figura 27 Modelo em RdP do transporte entre duas estações. . . . . . . . . . . . 72

Figura $28 \quad$ Modelo em RdP da [Parada em Z]. . . . . . . . . . . . . . . . . . . . . . 72

Figura 29 Modelo em RdP da Interface com o Transportador. . . . . . . . . . . 72

Figura 30 Modelo em RdP da Estação. . . . . . . . . . . . . . . . . . . . . . . 73 
Figura $31 \quad$ Modelo em RdP do Transportador. . . . . . . . . . . . . . . . 73

Figura $32 \quad$ Abstração em relação ao Modelo de hierarquia de equipamento. . . . . 75

Figura 33 Funções consideradas na arquitetura proposta em relação ao Modelo funcional empresa-controle da ISA95. . . . . . . . . . . . . . . . 77

Figura $34 \quad$ Simplificação do chão de fábrica e da produção de $E A$. . . . . . . . . . 78

Figura $35 \quad$ Simplificação do chão de fábrica e da produção de $E B$. . . . . . . . . . 78

Figura $36 \quad$ Simplificação do chão de fábrica e da produção das EPs na $E V$. . . . 79

Figura $37 \quad$ PFS do processo produtivo da EV referente à Fig. [36. . . . . . . . . . . . 79

Figura $38 \quad$ Primeiro Refinamento do PFS. . . . . . . . . . . . . . . . . . . . . . 80

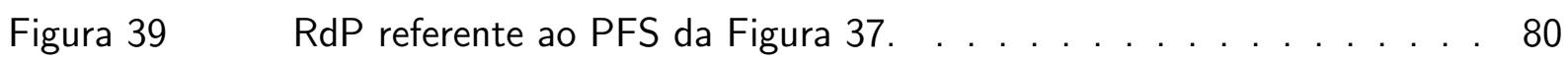

Figura 40 "Janelas globais" de uma EV que recebe informações somente do produto a ser entregue pela EV. . . . . . . . . . . . . . . . . . . 81

Figura $41 \quad$ "Janelas locais" de EP1 referentes ao fluxo codificado do processo da Figura 37. . . . . . . . . . . . . . . . . . 81

Figura 42 "Janelas locais" de EP2 referentes ao fluxo codificado do processo da Figura|37| . . . . . . . . . . . . . . . . . . . 82

Figura $43 \quad$ PFS do processo produtivo de uma EV com informações do fluxo codificado do processo produtivo completo. . . . . . . . . . . . . 82

Figura $44 \quad$ RdP referente ao PFS do fluxo codificado do processo apresentado na Figura 43. . . . . . . . . . . . . . . . . . 82

Figura $45 \quad$ "Janelas globais" referentes ao fluxo codificado do processo produtivo completo ilustrado na Figura 43 . . . . . . . . . . . . . . . 82

Figura $46 \quad$ "Janelas locais" da EP1 referentes ao fluxo codificado do processo produtivo completo ilustrado na Figura 43 [. . . . . . . . . . . . 83

Figura 47 "Janelas locais" da EP2 referentes ao fluxo codificado do processo produtivo completo ilustrado na Figura 43 . . . . . . . . . . . . . 83

Figura 48 Simplificação do chão de fábrica de uma EV em que suas EPs tenham relação de consumo. . . . . . . . . . . . . . . . . . . . . . . . . . . 84

Figura $49 \quad$ PFS do fluxo codificado do processo produtivo de uma EV em que suas

EPs tenham relação de consumo. . . . . . . . . . . . . . . . . . 84

\begin{tabular}{ll|l|l|l|l|}
\hline Figura 50 & RdP referente ao PFS da Figura & 49 & apresentando a sincronização ne-
\end{tabular}

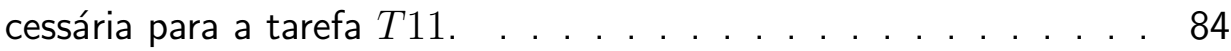

Figura $51 \quad$ "Janelas globais" referentes à Figura 49, . . . . . . . . . . . . . . . . . 85

Figura 52 "Janelas locais" da EP1 referentes ao fluxo codificado do processo ilustrado pelo PFS da Figura 49 . . . . . . . . . . . . . . . . . . . 85 
Figura 53 "Janelas locais" da EP2 referente ao fluxo codificado do processo ilustrado pelo PFS da Figura 49 ] . . . . . . . . . . . . . . . . . . . 85

Figura $54 \quad$ Tipos de "Janelas globais" referente ao fluxo codificado do processo produtivo representado pelo PFS da Figura 49 . . . . . . . . . . . . 86

Figura 55 "Janelas" atualizadas da EP2 depois da alocação de T20 e das propagações de restrições. . . . . . . . . . . . . . . . . . . . . 86

Figura 56 "Janelas atualizadas" da EP1 depois das propagações de restrições. . . 87

Figura 57 Arquitetura proposta. . . . . . . . . . . . . . . . . . . 88

Figura $58 \quad$ Diagrama caso de uso do "Serviço de Pedidos". . . . . . . . . . . . . . . . 89

Figura 59 Diagrama caso de uso do "Serviço de Gerenciamento de Requisições". . 90

Figura 60 Diagrama caso de uso do "Serviço de Dados". . . . . . . . . . . . . . . . 91

Figura $61 \quad$ Diagrama caso de uso do "Serviço de Planejamento Virtual". . . . . . . . 94

Figura 62 Diagrama caso de uso do "Serviço de Planejamento Local". . . . . . . . 95

Figura $63 \quad$ Fluxograma das etapas de funcionamento do sistema de PCP para EV. 96

Figura 64 Fluxograma das etapas necessárias para a implementação da arquitetura proposta de sistema de PCP para EV. . . . . . . . . . . . . 100

Figura $65 \quad$ EV e seus respectivos parceiros. . . . . . . . . . . . . . . . . . 101

Figura 66 Representação em PFS do fluxo codificado do processo produtivo completo referente à Figura $65 \mid$ e Tabela $5 \mid]$. . . . . . . . . . . . . . . . 103

Figura $67 \quad$ Representação da RdP da Figura 66, . . . . . . . . . . . . . . . . . . 103

Figura 68 Representação em PFS e RdP do fluxo codificado do processo pro-

dutivo simplificado (quando a EV recebe informações somente dos

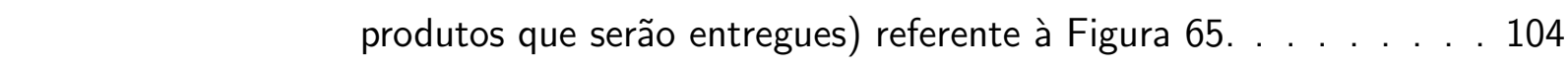

Figura 69 "Janelas globais" geradas para a EV pelo "Serviço de Planejamento Virtual". . . . . . . . . . . . . . . . . . . 106

Figura 70 "Janelas locais" geradas para a EP1 pelo Serviço de Planejamento Virtual.107

Figura 71 "Janelas locais" geradas para a EP2 pelo Serviço de Planejamento Virtual.108

Figura 72 "Janelas locais" geradas para a EP3 pelo Serviço de Planejamento Virtual.109

Figura 73 "Janelas locais" de EP1 após alocação de T30. . . . . . . . . . . . . 112

Figura 74 "Janelas locais" de EP2 após alocação de T20. . . . . . . . . . . . . 113

Figura 75 "Janelas locais" de EP2 após a $1^{a}$ atualização das informações recebidas de EP1. . . . . . . . . . . . . . . . . . . . . . . . . . . . . . . . . . 114

Figura 76 "Janelas locais" de $E P 1$ após a $1^{a}$ atualização das informações recebidas de EP2. . . . . . . . . . . . . . . . . . . . . . . . . . . . . . . . . . . . . . 115

Figura 77 "Janelas locais" de EP2 após alocação de $T 32, T 40$, e T50. . . . . . . 116 
Figura 78 "Janelas locais" de $E P 1$ após a $2^{a}$ atualização das informações recebi-

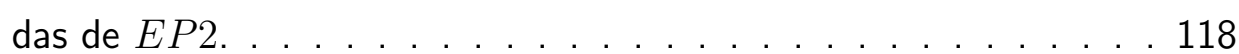

Figura 79 "Janelas locais" e alocação final de EP1. . . . . . . . . . . . . . 119

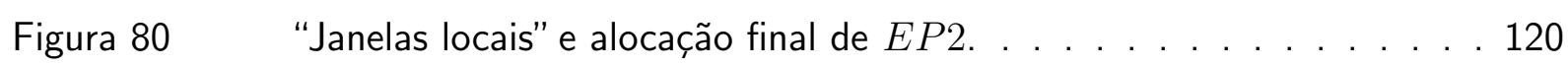

Figura 81 "Janelas locais" e alocação final de EP3. . . . . . . . . . . . . 121 


\section{LISTA DE TABELAS}

Tabela 1 Relação das tarefas com o processo de produção e os recursos de $E A$. 78

Tabela $2 \quad$ Relação das tarefas com o processo de produção e o recurso de $E B$. . 78

Tabela $3 \quad$ Características das EV contempladas por alguns trabalhos apresentados na literatura. . . . . . . . . . . . . . . . . . . . . . . . . 97

Tabela 4 Atribuição e disponibilidade das EPS. . . . . . . . . . . . . . . . . . . 102

Tabela 5 Pedidos e suas respectivas data de entrega. . . . . . . . . . . . . . . . 102 
API

APS

B2MML

CBS

CIM

CORBA

DBMS

E-MFG

EE

EP

ERP

EV

FIS

IIS

MES

MESA

MRP

MRP-II

NIS

ORBs

OV

PCP

PFS

PMEs

RDF

$\operatorname{RdP}$

SDED

SEDs

SPFs

SQL

STN

$\mathrm{TL}$

TV
Application Programming Interface

Advanced Planning and Scheduling

Business-to-Manufacturing Markup Language

Constraint Based Search

Computer Integrated Manufacturing

Common Object Request Broker Architecture

Data Base Management System

Enhanced Mark Flow Graph

Empresa Estendida

Empresa Parceira

Enterprise Resource Planning

Empresa Virtual

Finite Intermediate Storage

Internet Information Services

Manufacturing Execution Systems

Manufacturing Enterprise Solutions Association

Material Requirement Planning

Manufacturing Resource Planning

No Intermediate Storage

Object Request Brokers

Organização Virtual

Planejamento e Controle da Produção

Production Flow Schema

Pequenas e Médias Empresas

Resource Description Framework

Rede de Petri

Sistemas Dinâmicos a Eventos Discretos

Sistemas a Eventos Discretos

Sistemas Produtivos Flexíveis

Structured Query Language

State-Task Network

Tempo de Liberação

Time Virtual 


$\begin{array}{ll}\text { UDDI } & \text { Universal Description Discovery and Integration } \\ \text { UIS } & \text { Unlimited Intermediate Storage } \\ \text { UML } & \text { Unified Modeling Language } \\ \text { VS } & \text { Visual Studio } \\ \text { WCF } & \text { Windows Communication Foundation } \\ \text { WIP } & \text { Work in Progress } \\ \text { WS } & \text { Web Service } \\ \text { XML } & \text { eXtensible Markup Language } \\ \text { ZW } & \text { Zero Wait }\end{array}$




\section{LISTA DE SÍMBOLOS}

$\begin{array}{ll}\text { Est } & \text { Instante de início mais cedo } \\ L f t & \text { Instante de término mais tarde } \\ E f t & \text { Instante de término mais cedo } \\ T p & \text { Tempo de Processamento } \\ L s t & \text { Instante de início mais tarde } \\ \Omega & \text { Conjunto de operações } \\ E s t_{\Omega} & \text { Menor instante de início mais cedo do conjunto de operações } \Omega \\ L f t_{\Omega} & \text { Maior instante de término mais tarde do conjunto de operações } \Omega \\ T p_{\Omega} & \text { Soma dos tempos de processamento das operações pertencentes a } \Omega \\ E s t_{A} & \text { Instante de início mais cedo da operação } A \\ L f t_{A} & \text { Instante de término mais tarde da operação } A \\ T p_{A} & \text { Tempo de processamento da operação } A \\ u . t . & \text { Unidade de tempo }\end{array}$




\section{SUMÁRIO}

1 INTRODUÇÃO $\ldots \ldots \ldots \ldots$

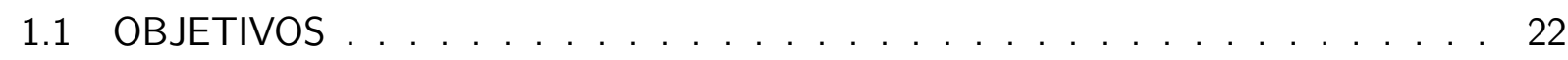

1.2 MATERIAIS E MÉTODOS . . . . . . . . . . . . . . . 23

1.3 ORGANIZAÇÃO DO TRABALHO . . . . . . . . . . . . . . . 24

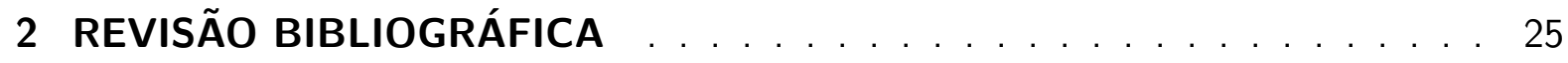

2.1 REDES COLABORATIVAS DE EMPRESAS . . . . . . . . . . . . . 25

2.2 EMPRESA VIRTUAL . . . . . . . . . . . . . . . . . . 30

2.2.1 Características comuns de uma EV . . . . . . . . . . . . . . . . . . 31

2.2 .2 Funções dos participantes $\ldots \ldots \ldots \ldots \ldots \ldots$

2.2 .3 Ciclo de vida da EV . . . . . . . . . . . . . . . . . . . . . . 36

2.3 SISTEMAS DE PLANEJAMENTO E CONTROLE DA PRODUÇÃO (PCP). . . . 38

2.3.1 Evolução dos sistemas de planejamento e controle da produção . . . . . 38

2.3.2 Sistemas avançados de planejamento e programação (APS) . . . . . . 40

2.3.3 Capacidades e Restrições na Programação de Produção . . . . . . . . 44

2.3.4 Geração da programação da produção considerando as restrições . . . . 51

2.3 .5 Sistemas de PCPs em EVs . . . . . . . . . . . . . . . . . 52

2.4 PROPOSTAS DE EVS UTILIZANDO WEB SERVICE . . . . . . . . . . . . . 54

2.5 MODELOS E TERMINOLOGIAS PARA AS INTERFACES DE SISTEMAS DE

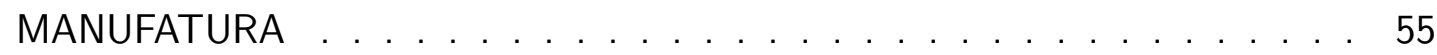

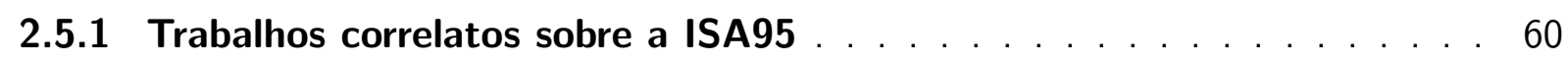

2.6 REDE DE PETRI . . . . . . . . . . . . . . . . . . . . . . . . . . . 62

2.6 .1 Formalização . . . . . . . . . . . . . . . . 63

2.6 .2 Características dos SEDs . . . . . . . . . . . . . . . 65

2.6.3 Metodologia PFS/RdP (Production Flow Schema/Rede de Petri) . . 68

2.7 SINTESE DO CAPITULO . . . . . . . . . . . . . . . . . . . . . . . . . . 73

3 ARQUITETURA PROPOSTA $\ldots \ldots \ldots \ldots$

3.1 ADEQUAÇÃO DA ARQUITETURA PROPOSTA COM A ANSI/ISA-95 . . . . . 75

3.2 MODELAGEM DA EV E GERAÇÃO DE SUAS JANELAS DE TEMPO . . . . . 77

3.3 ARQUITETURA DE SISTEMA DE PLANEJAMENTO E CONTROLE DA PRODUÇÃO NO CONTEXTO DE EV . . . . . . . . . . . . . . . . . 87

3.4 PROCEDIMENTOS DE IMPLEMENTAÇ̃̃O . . . . . . . . . . . . . . . 97

4 EXEMPLO DE APLICAÇÃO . . . . . . . . . . . . . . . . . 101 


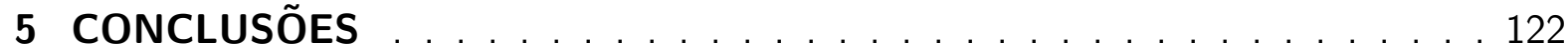

Referências . . . . . . . . . . . . . . . . . . . . . 125

Apêndice A - Geração das Janelas de Tempo . . . . . . . . . . . . . . . . 137

Apêndice B - Heurísticas Utilizadas . . . . . . . . . . . . . . . . . . . . . 142

Apêndice C - Exemplo de implementação no Laboratório de Sistemas de Automação (LSA) . . . . . . . . . . . . . . . . . . . . 146

Apêndice D - Documentação das tabelas criadas na implementação no LSA . 160

Apêndice E - Conversão da rede estado tarefa em PFS $\ldots \ldots \ldots$ 


\section{INTRODUÇÃO}

O mercado global está cada vez mais competitivo e isso pressiona as empresas por mudanças e aprimoramentos em seus sistemas produtivos. Um dos motivos desse aumento da competição entre empresas é que os consumidores estão mais exigentes, buscando personalização dos produtos (ESPOSITO; EVANGELISTA, 2014). Além disso, os processos produtivos que antes podiam ser focados apenas na minimização dos custos de produção têm, agora, que considerar o pleno atendimento dos diferentes tipos de consumidores por meio da diversificação de produto e atendendo rigorosamente as datas de entrega (ESPOSITO; EVANGELISTA, 2014). Conforme Jardim-Goncalves, Grilo e Popplewell (2014), o aumento da diversidade de produtos é devido à natureza volátil dos requisitos. Portanto, para atender as demandas atuais do mercado, é necessário projetar sistemas produtivos com elevado nível de flexibilidade, capazes de produzirem simultaneamente uma variedade de produtos. Esse tipo de flexibilidade pode ser obtido com maior número de recursos (máquinas, por exemplo), que, de modo geral, eleva os custos envolvidos, ou envolvendo um compartilhamento mais eficaz de recursos. Estes fatores criam novos padrões de eficiência a serem atendidos pelos sistemas produtivos (MELO, 2011).

Numa estrutura de sistema produtivo convencional, o atendimento destes novos padrões é praticamente inviável devido aos custos necessários para assegurar um altíssimo grau de versatilidade do sistema. Assim, as empresas procuram novas formas de se organizarem, de modo que cada uma possa focar no que faz de melhor. Desta forma a colaboração entre as empresas torna-se a resposta para este desafio, demonstrando a importância das redes colaborativas (CAMARINHA-MATOS et al., 2009; ROJAS et al., 2012). É nesse contexto que surge a ideia de uma Empresa Virtual (EV). As empresas, em especial as pequenas e médias (PMEs), que participam de EVs, têm acesso aos recursos como se fossem uma grande empresa, entretanto conservam a agilidade e independência de uma pequena empresa (BROWNE; ZHANG, 1999; HSIEH; LIN, 2012).

A EV é uma aliança temporária entre empresas que se unem para atingir um objetivo comum (CAMARINHA-MATOS; PANTOJA-LIMA, 2001; LIU; RAAHEMI; BENYOUCEF, 2011). Esta união envolve uma cooperação, em geral apoiada numa rede de comunicação eficiente, e esta nova organização deve ter a capacidade de fornecer rapidamente produtos competitivos para o mercado (LIU; RAAHEMI; BENYOUCEF, 2011). A cooperação no contexto de EV requer mudanças nos conceitos envolvidos na troca de dados utilizados pelas empresas (DURUGBO; RIEDEL, 2013). Estas mudanças estão relacionadas com a fusão temporária de empresas e o compartilhamento de informações entre elas (GUO et al., 2010). A EV depende muito da efetiva colaboração entre seus membros para compartilhar seus conhecimentos, habilidades, 
competências e recursos (CAMARINHA-MATOS; PANTOJA-LIMA, 2001; DURUGBO; RIEDEL, 2013) e, como um meio para implementar a comunicação entre as partes visando essa colaboração, o web service (WS) é utilizado (LI; WEI, 2014). Utilizando o WS em conjunto com o padrão XML (eXtensible Markup Language) para troca de mensagens, é possível tratar as discrepâncias na forma de descrição das informações entre os sistemas produtivos das empresas de uma EV (HUANG; LAN; YANG, 2009). Entretanto, deve-se destacar que essa solução é apenas um meio para viabilizar o objetivo da EV, que é o atendimento das demandas do consumidor em relação a vários aspectos, sendo que, dentre eles, o prazo de entrega é fundamental. Desta forma, um sistema de "planejamento e controle da produção" (PCP) torna-se fundamental para assegurar o desempenho da EV (ZHOU; RISTIC; BESANT, 2000; DING; GAO; LUO, 2009). Neste contexto, Goulart (2000) destaca que existe uma lacuna para formação de EVs voltadas a produtos manufaturados, que é referente à carência de métodos adequados para executar o PCP.

O sistema de PCP deve tratar de forma eficaz não apenas os casos em situações normais de operação, mas também a ocorrência de distúrbios e outras situações inesperadas neste tipo de sistema produtivo (DING; GAO; LUO, 2009). Entretanto, a implementação dos sistemas de PCP não é uma tarefa trivial (HUANG et al., 2013), pois em especial a EV é caracterizada pela autonomia, distribuição e cooperação entre empresas (ZHOU; RISTIC; BESANT, 2000), o que não costuma ser considerada por sistemas de PCP convencionais (WALTERS, 2005). De acordo com Rojas (2010), o paradigma de EV desafia a maneira com que os sistemas de manufatura são planejados e gerenciados. Numa EV, as atividades de PCP tornam-se mais complexas pois precisam ser realizadas tanto dentro das empresas, como em toda a cadeia produtiva, de forma integrada, a fim de atingir os níveis exigidos de desempenho. De acordo com Pessoa et al. (2012), o PCP de uma EV é um grande desafio para o seu sucesso devido à complexidade de integração de recursos de diferentes empresas, isto é, o ajuste das capacidades dos parceiros e a definição comum de prazos.

Um sistema produtivo é organizado em níveis hierárquicos e o sistema de PCP envolve questões estratégicas da empresa (ZADEH; AFSHARI; KHORSHID-DOUST, 2014), pois representa o primeiro elo entre o nível de decisões estratégicas e os níveis de execução dos processos produtivos. O sistema de PCP traduz as estratégias em planos táticos e operacionais concretos. As funções típicas dos sistemas de PCP incluem o planejamento de requisição de materiais, o gerenciamento da demanda, o planejamento de capacidade, a programação da produção e o controle das operações de produção (STEVENSON; HENDRY; KINGSMAN, 2005).

De acordo com Maravelias e Sung (2009) a integração entre planejamento de capacidade e programação da produção é um problema não trivial. Isto, devido ao desafio de modelar 
as restrições dos recursos numa rede de processos, a dificuldade de comunicação (compartilhamento) de objetivos entre as áreas, e a diferença entre as respectivas escalas de tempo (MARAVELIAS; SUNG, 2009). Estas dificuldades evidenciam a necessidade de se definir uma Arquitetura de Sistema de planejamento e controle de produção sob a visão de Empresa Virtual, isto é, uma arquitetura onde o foco é a integração das funções de PCP de diferentes empresas que compõem a EV. Essa arquitetura deve necessariamente considerar as capacidades específicas de cada empresa parceira para estabelecer os prazos para as atividades a serem realizadas, pois, apesar da Empresa ser Virtual, ela integra várias empresas que operam num ambiente real de produção.

Num ambiente real de produção, cada empresa costuma utilizar um software de gestão que mais se adapta às suas necessidades. Entretanto, quando existe a necessidade de integrações entre diferentes softwares de gestão, ou entre diferentes aplicações, aparecem as dificuldades de interação. Desta forma, as normas e os esquemas de informações de produção desempenham um papel importante referente ao compartilhamento de informação e integração de aplicações empresariais e de produção heterogêneas (ZHANG et al., 2011). É neste contexto que normas como a ANSI/ISA-95 (ANSI, 2010) foram desenvolvidas. A ANSI/ISA-95, em especial, é uma norma que foi desenvolvida para estabelecer uma terminologia consistente para integração de sistemas corporativos e de controle. Nesta norma as informações e os modelos operacionais servem como base para definir a funcionalidade da aplicação e o uso de informação entre os sistemas de negócios de uma empresa e seus sistemas de controle de fabricação (DOBREV; GOCHEVA; BATCHKOVA, 2008). Apesar da norma ANSI/ISA-95 não ter sido utilizada antes num contexto de $E V$, ela se apresenta como válida também na integração destes sistemas.

Uma EV pode ser composta por empresas parceiras que tenham diferentes tipo de produção, ou seja, produção contínua, produção em lotes e produção discreta. Uma das formas utilizadas para representar os fluxos destes diferentes tipos de processos é a STN (State-Task Network) apresentada por Kondili, Pantelides e Sargent (1993), e frequentemente utilizada em problemas de planejamento e programação da produção (RODRIGUES, 2000; RODRIGUES et al., 2004; MARAVELIAS, 2009; SHAIK et al., 2009; BOSE; BHATTACHARYA, 2009; MONIZ; BARBOSA-POVOA; SOUSA, 2013). A STN representa o processo físico de produção de: tarefas contínuas, semicontínuas e em lotes, tal como definido na receita do produto. A STN facilita a visualização do processo do produtivo. Entretanto, ela é uma descrição estática, não permite a análise da dinâmica da evolução de processos por técnicas de simulação, o que é fundamental no contexto de EV, onde diferentes cenários e situações são constantemente alteradas. A simulação é importante pois possibilita a realização de uma análise comportamental do modelo para verificar e validar se ele atende adequadamente os requisitos funcionais. Por outro lado, pode-se explorar uma metodologia de conversão da rede estado tarefa para o PFS 
(Production Flow Schema) que é utilizado para modelagem de sistemas produtivos segundo uma abordagem hierárquica, com base em sucessivos refinamentos para construir o modelo de forma progressiva e estruturada onde as propriedades do modelo ficam asseguradas por construção. Este detalhamento gera sub-grafos em Rede de Petri, que podem ser utilizados para a simulação e o controle do processo produtivo (MELO et al., 2008; MELO et al., 2010; MELO; JUNQUEIRA; MIYAGI, 2010).

As pesquisas por arquiteturas, metodologias, modelos, ferramentas e infra-estruturas de suporte referente às EVs são relativamente recentes (ESPOSITO; EVANGELISTA, 2014). Nesta tese o termo arquitetura se refere a arquitetura de software que conforme Bass, Clements e Kazman (2012), engloba um conjunto de decisões sobre a organização de um sistema de software que inclui a seleção dos elementos estruturais, as interfaces que compõem o sistema, o comportamento e composição dos elementos estruturais. Em consulta recente nas bases de dados como: Web of Science, Scopus, SIBiUSP, DSpace@MIT e EThos, de 1991 até o momento, entre ao trabalhos publicados, constatou-se uma ausência de trabalhos sobre arquitetura de EV considerando o PCP.

\subsection{OBJETIVOS}

O objetivo deste trabalho é de desenvolver uma arquitetura de sistema de planejamento e controle da produção sob a visão de Empresa Virtual. A arquitetura deve assegurar a integração do planejamento global da EV ajustando as diferentes capacidades dos parceiros, possibilitando que tenham a liberdade de escolha nos métodos de programação da produção local, permitindo um melhor controle dos processos produtivos de acordo com os prazos de entrega de produtos da EV, e ser coerente com as normas de integração existentes, como por exemplo a ANSI/ISA95. Desta forma é necessário analisar e reinterpretar parte da norma ANSI/ISA-95, que não atende os requisitos de EV, a esta arquitetura. Esta arquitetura visa a resolução de problemas de planejamento e controle da produção em EVs de forma colaborativa, e distribuída, e deve permitir uma programação da produção de forma descentralizada. Como o foco é o sistema de planejamento e controle da produção em EV, e o State-Task Network (STN) é uma forma de modelar problemas de produção mas não possibilita o seu controle, deve-se especificar também procedimentos que permitam utilizar o Production Flow Schema (PFS) no lugar do STN possibilitando, desta forma, a análise da dinâmica do processo produtivo e o controle do processo. 


\subsection{MATERIAIS E MÉTODOS}

Está é uma pesquisa de natureza aplicada, na qual são utilizadas as teorias abordadas nas referências bibliográficas de forma a contribuir com a solução de problemas relacionados ao planejamento nas EVs. Seu resultado pode ser utilizado por pesquisadores que desejarem complementar os estudos sobre EVs e por grandes e pequenas empresas, independente do tipo de manufatura e da localização da empresa que pretendem formar uma EV. As informações foram pesquisadas e coletadas em livros, artigos científicos e na norma ANSI/ISA95. As principais bases utilizadas foram o Scopus (SCOPUS, 2014), Web of Knowledge (KNOWLEDGE, 2014), Sistema Integrado de Bibliotecas da Universidade de São Paulo (SIBIUSP, 2014), DSpace@MIT (base de dados das teses do Massachusetts Institute of Technology) (DSPACEQMIT, 2014), Ethos (base de dados de teses das Universidades Britânicas) (ETHOS, 2014), e Biblioteca Digital da Unicamp (UNICAMP, 2014).

A pesquisa é descritiva, ou seja, procurou-se definir o problema; descrever em detalhes as partes e suas relações; estudar e aplicar técnicas para solução do problema e produzir uma sistemática e aplicá-la.

Esta proposta segue a metodologia de projetos apresentada em Jensen (1992), que envolve três aspectos diferentes (Figura 1): aspectos teóricos, ferramentas e aplicações, que são abordados de forma cíclica e repetitiva. Para solucionar os problemas detectados nas aplicações, estudam-se os aspectos teóricos relacionados, propondo uma revisão das abordagens, modificações e aperfeiçoamentos. Por meio do desenvolvimento de novas ferramentas, aplicam-se as modificações realizadas nos aspectos teóricos aos problemas das aplicações.

Figura 1 - Ciclo para desenvolvimento da pesquisa.

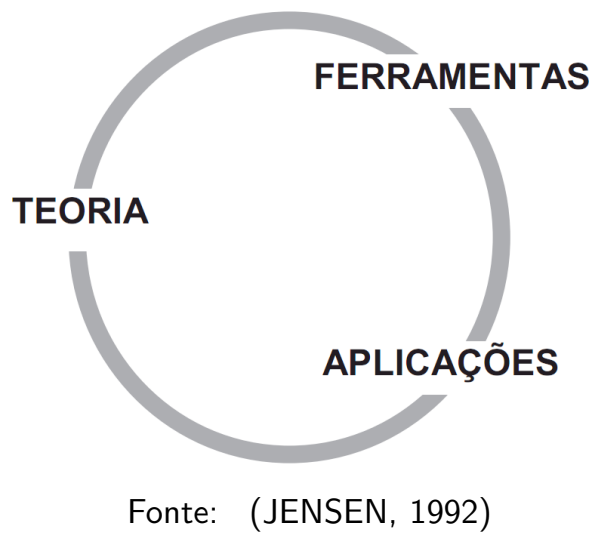

É uma abordagem de engenharia que, neste trabalho, considera os aspectos formais associados à definição de modelos, os métodos de análise aplicáveis via ferramentas computacionais existentes e as aplicações em processos industriais como motor de desenvolvimento e concepção de novos paradigmas. Os três aspectos identificados em Jensen (1992) evoluem simultane- 
amente, condicionando-se mutuamente. Os desenvolvimentos nas três áreas identificadas se beneficiam das sinergias resultantes das atividades em cada uma das outras duas áreas. A Figura 2 sintetiza as principais referências do presente trabalho.

Figura 2 - Ciclo para o desenvolvimento considerado nesta pesquisa.

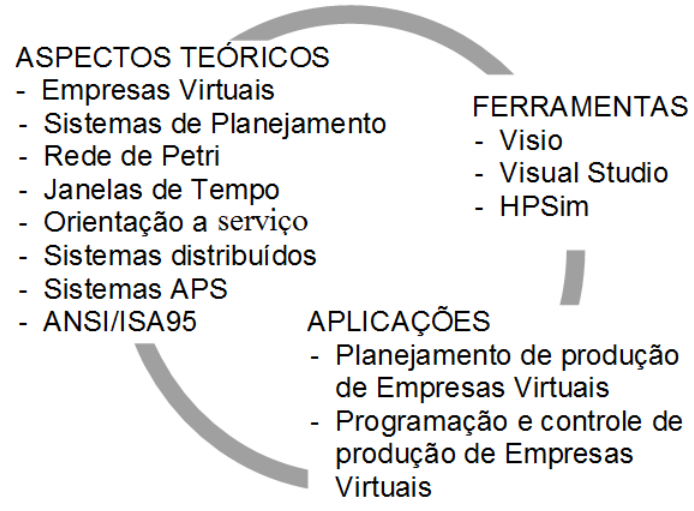

\subsection{ORGANIZAÇÃO DO TRABALHO}

O capítulo 2 sintetiza uma revisão bibliográfica sobre os principais conceitos, teorias e ferramentas utilizadas no desenvolvimento deste trabalho, sendo elas: Redes Colaborativas, EVs, sistemas de PCP para EVs, Sistemas APS (Advanced Planning and Scheduling), aplicação de "janelas de tempo", norma ANSI-ISA 95, rede de Petri e o Production Flow Schema. A arquitetura proposta é apresentada no capítulo 3. O exemplo de aplicação é apresentado no capítulo 4. O capítulo 5 apresenta as conclusões e trabalhos futuros. $\mathrm{O}$ apêndice $\mathrm{A}$ apresenta um exemplo do procedimento para a geração de "janelas de tempo"; o apêndice B apresenta as heurísticas de scheduling utilizadas neste trabalho; o apêndice $C$ apresenta uma implementação da arquitetura proposta utilizando o software free OPenBravo no Laboratório de Sistemas de Automação (LSA) do Departamento de Engenharia Mecatrônica e de Sistemas Mecânicos (PMR) da EP-USP; o apêndice D apresenta a documentação das tabelas que foram implementadas no OpenBravo, e o apêndice E apresenta, um exemplo da conversão de STN para PFS. 


\section{REVISÃO BIBLIOGRÁFICA}

\subsection{REDES COLABORATIVAS DE EMPRESAS}

A "rede colaborativa" é constituída por uma variedade de entidades (por exemplo, organizações e pessoas) que são em grande parte autônomas, geograficamente distribuídas e heterogêneas em termos de: ambiente operacional, cultura, capital social, e objetivos (CAMARINHAMATOS; AFSARMANESH, 2006; CAMARINHA-MATOS et al., 2009). Esta entidades colaboram entre si para melhor atingir os objetivos comuns ou compatíveis, e cujas interações são suportadas por uma rede de computadores (DURUGBO; RIEDEL, 2013).

Existem várias formas de "redes colaborativas" de empresas. Entretanto, as diferentes formas possuem as seguintes características em comum (CAMARINHA-MATOS; AFSARMANESH, 2006):

- Redes compostas por organizações e pessoas, com uma grande autonomia, geograficamente distribuída, heterogênea em termos de seus ambientes de operações, culturas, capital social e metas;

- Os participantes colaboram para atingir objetivos comuns ou metas compatíveis;

- A interação entre os participantes é feita sobre redes de computadores.

$\mathrm{Na}$ "rede colaborativa" os participantes colaboram entre si, mas apesar das pessoas conhecerem o que é colaboração, este tipo de interação é frequentemente confundido com cooperação, e não se consegue distinguir um conceito do outro (CAMARINHA-MATOS; AFSARMANESH, 2006). Em Camarinha-Matos e Afsarmanesh (2006) foram propostas as seguintes definições para os tipos de interação:

- Trabalho em rede - Envolve apenas a comunicação e a troca de informações entre os participantes;

- Redes coordenadas - Além da comunicação e da troca de informações, envolve o alinhamento/alteração das atividades de forma a atingir um resultado mais eficiente para todos os participantes. Os participantes podem ter metas diferentes;

- Cooperação - Além da comunicação, troca de informações, e alinhamento/alteração, envolve compartilhamento de recursos de forma a alcançar metas compatíveis. A cooperação é alcançada pela divisão dos trabalhos entre os participantes, e cada participante tem o seu objetivo especifico; 
- Colaboração - É um processo mais exigente do que a cooperação, os participantes compartilham informação, recursos e responsabilidades para que juntos consigam planejar, implementar e avaliar um conjunto de atividades de forma a alcançar um objetivo comum.

É importante entender os diferentes níveis de engajamento de interação. A Figura 3 relaciona os níveis das interações com os níveis de engajamento de interação. Cada mudança de nível agrega o conceito do nível mais baixo, desta forma a colaboração contém todos os outros conceitos.

Figura 3 - Níveis de engajamento das interações.

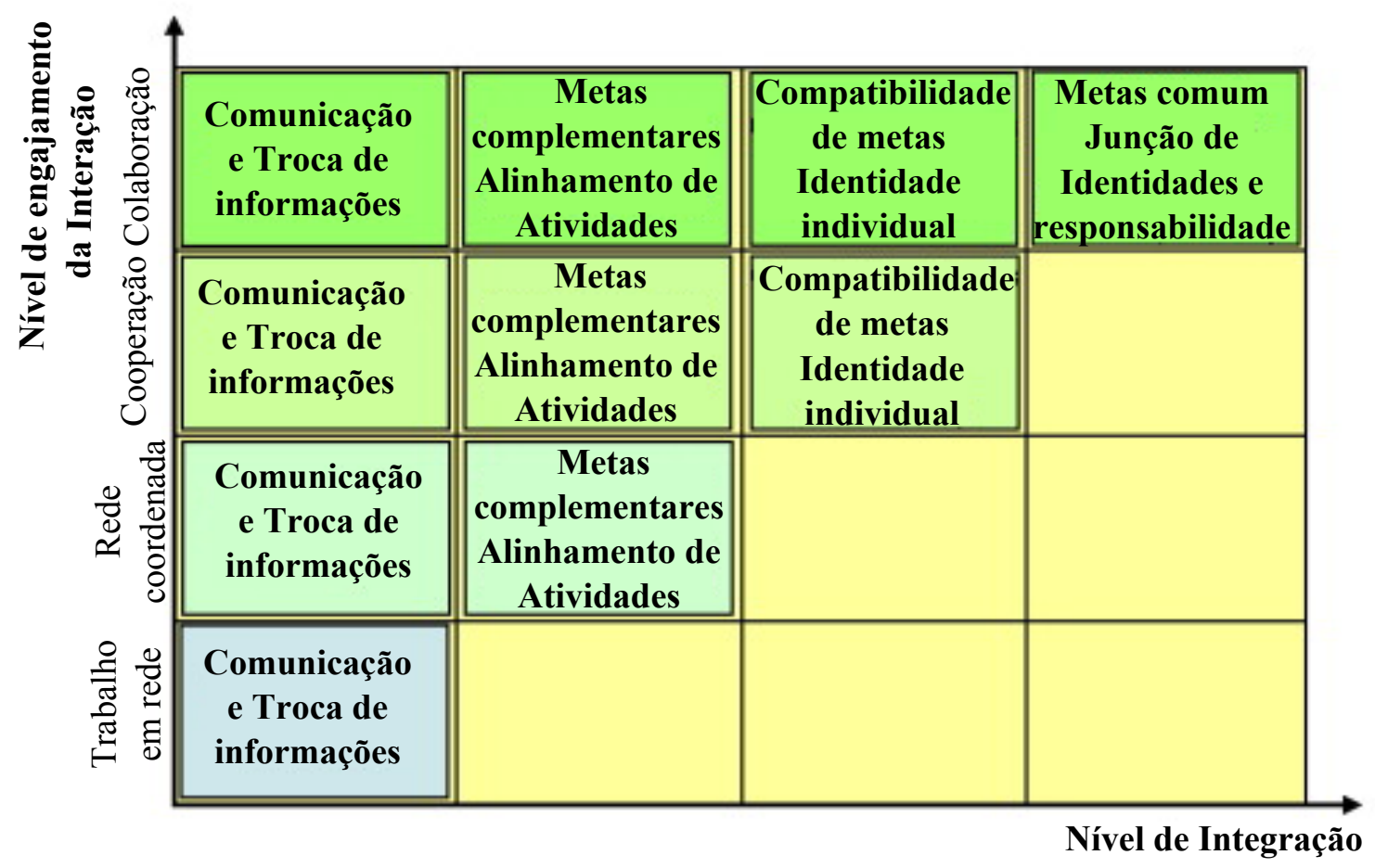

Fonte: (CAMARINHA-MATOS et al., 2009)

Frequentemente os domínios distintos utilizam diferentes terminologias, percebendo a necessidade de uma uniformização de termos. Em Camarinha-Matos et al. (2009) foram propostas as seguintes uniformizações:

A "Rede Colaborativa" é dividida em dois níveis organizacionais:

- Redes orientadas a negócios implica em algum tipo de organização sobre as atividades de seus participantes, existem regras e alguma liderança;

- Rede ad-hoc não são orientadas a negócios. Nesta rede as pessoas ou organizações se tornam voluntárias para colaborar, ajudando em alguma causa social, ou referente a algum desastre natural.

As "Redes orientadas a negócios" diferem pelo tipo de propósito, são eles: 
- Redes com estratégias a longo prazo, onde existe certamente cooperação entre os seus parceiros, mas nem sempre existe colaboração;

- Redes orientadas a objetivos onde existe uma intensa colaboração entre os parceiros para atingir os objetivos comuns.

As "Redes com estratégias a longo prazo" são dividas em duas categorias:

- Ambiente criador de OV (Organização Virtual), representa uma associação de organizações e suas respectivas instituições de apoio, que aderem a um termo de cooperação de longo prazo. Adotam princípios operacionais e infraestruturas em comum. O objetivo principal é de aumentar a sua preparação para uma rápida configuração de alianças temporárias para a colaboração numa potencial OV. Pode ser classificada como:

- Grupo industrial consiste num grupo de empresas que estão localizadas tipicamente numa mesma região geográfica e que operam um setor de negócios em comum. Estas empresas se unem para se tornarem mais competitivas numa região geográfica maior;

- Laboratórios virtuais colaborativos representam uma aliança de organizações autônomas de pesquisa onde cada organização tem os seus recursos próprios, possibilitando que seus pesquisadores, dispersos geograficamente, possam ser reconhecidos e considerados para participar de oportunidades de colaboração na resolução de problemas;

- Distrito industrial é semelhante ao Grupo industrial, entretanto outras instituições locais (agências de desenvolvimento, instituições acadêmicas e de pesquisa) podem participar;

- Rede de resgate de desastres é uma aliança estratégica de organizações governamentais e não governamentais especializadas em operações de resgate no caso de desastres;

- Ecossistema de negócios representam redes que tentam preservar espécies locais, tradição, e cultura; frequentemente são beneficiadas por incentivos do governo local.

- Comunidade profissional virtual é uma aliança de longo prazo formada por profissionais individuais que fornecem um ambiente ágil para os Times Virtuais (TVs).

As "Redes orientadas a objetivos" são dividas em duas categorias: 
- Rede direcionada à oportunidade. Ela é dinamicamente formada para responder a uma oportunidade de colaboração e é dissolvida quando o objetivo é alcançado. Pode ser classificada como:

- Time Virtual (TV), ou equipe virtual. Uma aliança temporária formada por pessoas e não por organizações, que compartilham habilidades ou recursos de forma a responderem melhor às oportunidades de negócios (visando lucro). Os profissionais trabalham em conjunto para realizarem uma consultoria, um projeto, etc;

- Organização Virtual (OV). Uma aliança temporária de empresas que compartilham habilidades ou recursos de forma a responderem melhor às oportunidades. Não é limitada a uma aliança de empresas para obter lucros;

- Empresa Estendida (EE). Quando uma empresa dominante estende os seus limites para todos ou alguns fornecedores;

- OV dinâmica é uma OV criada por um curto espaço de tempo;

- Empresa Virtual (EV). É um caso particular de OV, é uma aliança temporária de empresas que compartilham habilidades ou recursos de forma a responderem melhor às oportunidades de negócios, sempre visando lucro.

- Rede direcionada à produção contínua. São redes de duração de longo prazo e são relativamente estáveis em relação à mudança dos participantes. Existe uma definição clara dos papéis dos membros ao longo da cadeia de valor. Pode ser classificada como:

- Cadeia dinâmica de suprimentos. Uma rede estável de longo prazo, onde existem regras claras sobre a participação/fornecimento de cada empresa, envolvendo todas as etapas desde o desenvolvimento do produto até a entrega ao consumidor. O nível de estabilidade das organizações pode mudar de acordo com o tipo e a dinâmica da cadeia de suprimentos, nas quais os participantes podem ser mudados com mais frequência.

- Governo virtual, ou Governo Eletrônico, é uma aliança de organizações governamentais que agrupam seus serviços por meio de redes de computadores no intuito de fornecer aos cidadãos serviços integrados numa única interface.

A Figura 4 apresenta as classificações das redes colaborativas. A linha pontilhada apresenta o domínio deste trabalho e o bloco destacado, a EV, que é o escopo deste trabalho. 
Figura 4 - Classificações das redes colaborativas.

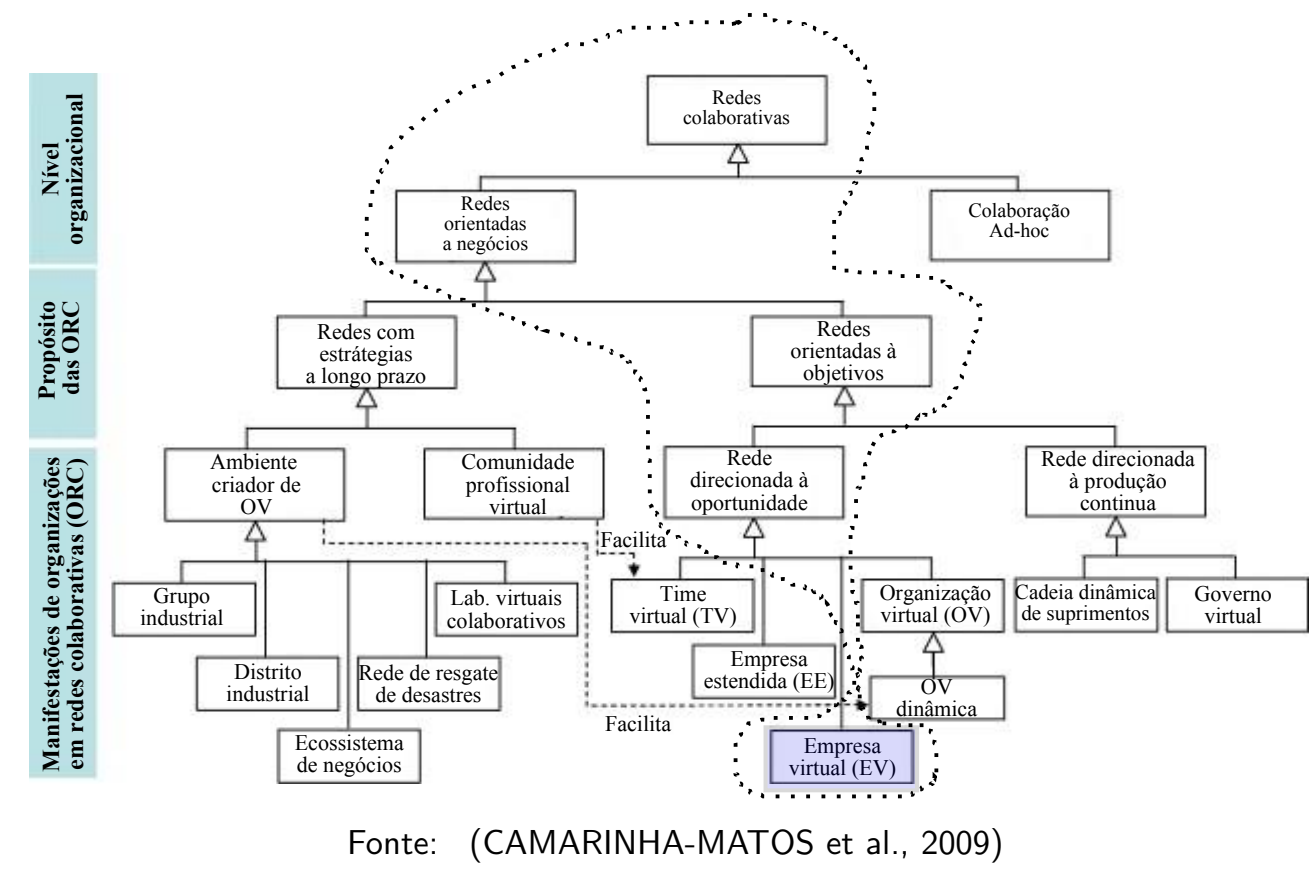

Como é possível verificar pela Figura 4, a EV é uma "Rede Colaborativa" do tipo "Redes orientadas a negócios", "orientada a objetivos", e "direcionada a oportunidades".

A Figura 5 apresenta as diversas redes de entidades direcionadas a oportunidades e suas respectivas relações.

Figura 5 - Redes de entidades direcionadas à oportunidade.

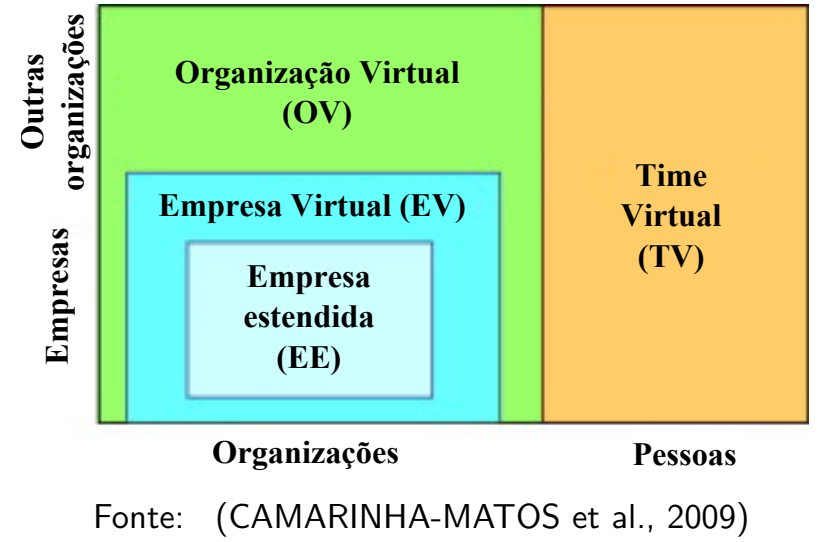

Conforme o texto apresentado, verifica-se que a EV é composta por organizações, com uma grande autonomia, geograficamente distribuída, onde existe uma intensa colaboração entre os participantes para atingir objetivos comuns, sempre visando lucro. A interação entre os participantes é feita sobre redes de computadores. A EV é uma aliança temporária de empresas que compartilham habilidades ou recursos de forma a responderem melhor às oportunidades de negócios. Ela é dinamicamente formada para responder a uma oportunidade de colaboração e é dissolvida quando o objetivo é alcançado. Na seção a seguir são apresentados mais detalhes 
sobre Empresas Virtuais (EVs).

\subsection{EMPRESA VIRTUAL}

As EVs são alianças de processos de negócios independentes ou empresas onde cada participante contribui com suas "competências essenciais" em áreas como projetos, manufatura e distribuição (CUNHA; PUTNIK, 2006; BECKETT, 2008; CAO; HOFFMAN, 2011; ESPOSITO; EVANGELISTA, 2014). Neste cenário, o projeto, o desenvolvimento, o transporte, a manufatura e a estocagem dos produtos podem estar distribuídos geograficamente (LIANG et al., 2008). Esta aliança é temporária e é formada para explorar as rápidas mudanças do mercado (CAO; HOFFMAN, 2011; ESPOSITO; EVANGELISTA, 2014). Conforme Yang et al. (2012) um dos desafios das EVs é o de aumentar a autonomia das Empresas parceiras (cada empresa participante).

O conceito de EV foi proposto em 1991 num relatório sobre "Estratégia da empresa de manufatura do século 21" (NAGEL; DOVE, 1991), onde foi apresentada uma nova estratégia de "Manufatura ágil" para ajudar a indústria americana na competição industrial do século XXI. A idealização partiu do escritório do Secretário de Defesa da Tecnologia de Manufatura (MANTECH) com o apoio do lacocca Institute da Lehigh University. Segundo o relatório, o termo "Manufatura ágil" se refere a um sistema de manufatura com capacidade extraordinária para satisfazer as necessidades de mudança rápida do mercado, um sistema capaz de aceitar rapidamente as mudanças de modelos de produto ou de linhas de produtos, de preferência com resposta em tempo real à demanda dos clientes. O termo utilizado inicialmente para EV foi o de "Companhia Virtual".

Conforme Camarinha-Matos e Afsarmanesh (1999), a pesquisa sobre EV representa uma área complexa, de grande escala e multidisciplinar, que envolve distribuição de atividades, heterogeneidade dos componentes, e agentes autônomos. A Figura 6 apresenta um exemplo de EV.

De acordo com Huang e Zhu (2011) existem três tipos de EVs:

- EV baseada em virtualização de funções. Segundo Applegate, McKenney e McFarlan (1999), a EV é uma entidade que só mantém funções de coordenação, controle e gerenciamento das atividades dos recursos. Todas as outras atividades são terceirizadas (por exemplo, atividade de produção), ou seja, a EV neste caso não produz fisicamente nenhum produto, somente coordena as atividades, temos como exemplo a Nike.

- EV baseada em virtualização de forma. Conforme Desanctis e Monge (1999) a EV é uma coleção de entidades distribuídas geograficamente, funcionalmente e/ou culturalmente 
que são interligadas por meio eletrônico de comunicação e dependem de relações laterais e dinâmicas para sua coordenação, temos como exemplo a Amazon.com.

- EV baseada em virtualização de recursos. Conforme CAMARINHA-MATOS et al. (1998) a EV é uma aliança temporária de empresas que se unem para compartilhar recursos e competências, de forma a fornecer respostas rápidas às oportunidades do mercado. A sua cooperação é suportada por redes de computadores, temos como exemplo a Metersbonwe.

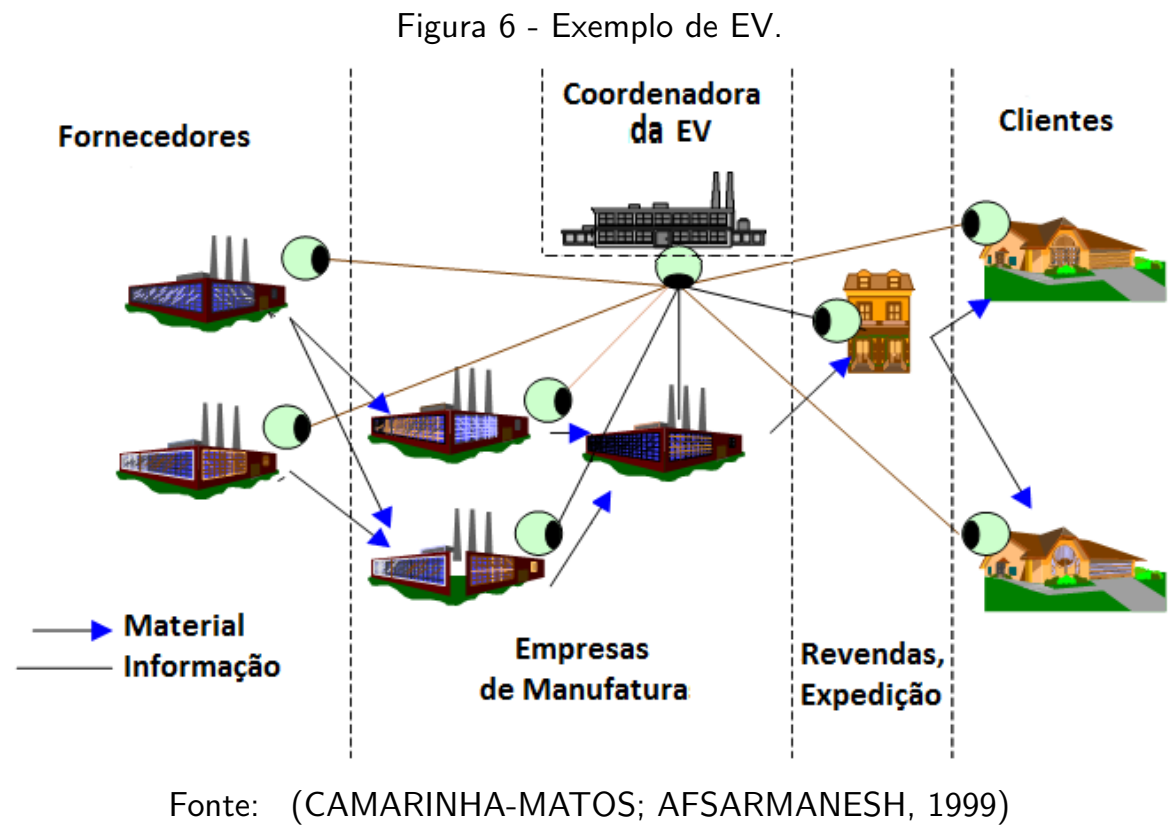

\subsubsection{Características comuns de uma EV}

As principais características orientadas ao ambiente e recursos, e orientadas a processos das EV são (MARTINEZ et al., 2001; CAMARINHA-MATOS; AFSARMANESH, 2003; BARBINI; ATRI, 2005):

- Orientadas ao ambiente e recursos:

- Cooperação orientada ao mercado: A EV é preparada para explorar oportunidades específicas de negócios. Existe uma ligação relevante entre os parceiros, onde os principais pontos de coesão são a cultura empresarial em comum e uma forte orientação aos resultados.

- Complementaridade: Cada parceiro se destaca em sub-processos particulares, ou têm um conhecimento vital sobre parte do processo, produto ou mercado. As interdependências entre os membros têm que ser identificadas e gerenciadas de forma a conseguir criar uma única combinação de recursos, habilidades e conhecimentos. 
- Participação dinâmica: As organizações podem se conectar e desconectar da rede facilmente. A EV deve ter a capacidade de fornecer soluções de backup para permitir a substituição de parceiros desconectados.

- Independência legal e econômica entre parceiros: A rede de empresas não é baseada em acordos estratégicos entre parceiros. Normalmente o poder econômico é compartilhado na rede, não existindo uma empresa centralizadora.

- Compartilhamento de recursos/processos: Os parceiros trabalham em conjunto, integrando processos de negócios e compartilhando recursos, em particular, dados, informações e conhecimento.

- Orientadas a processos:

- Limitação de tempo: Normalmente a EV é destinada à realização de oportunidades de negócios de curto ou médio prazo.

- Transparência: A realização dos objetivos de cooperação é baseada na disponibilidade de meios de comunicação das informações por parte dos parceiros. Entretanto, a EV tem que assegurar que os parceiros protejam o acesso às suas informações confidenciais.

- Polimorfismo: As estruturas organizacionais dependem do tipo de oportunidade a explorar e das características dos parceiros, entretanto, não é possível criar uma estrutura organizacional universal para todas as EVs.

- Automação: Com a utilização de sistemas integrados de informação, as informações entre os parceiros são compartilhadas e associadas à dispositivos mecatrônicos que cooperam para a produção de itens.

Em Camarinha-Matos e Afsarmanesh (1999) os ambientes das EVs foram classificados de acordo com a duração, topologia, participação, coordenação e visibilidade. A Figura 7 apresenta a taxonomia das EVs.

Duração

- Negócio único. A EV é estabelecida para uma oportunidade única de negócio, e é dissolvida no final do processo. É necessária uma infraestrutura de apoio à criação e dissolução de EVs.

- Aliança a longo prazo. Elas podem durar por um número indeterminado de processos de negócios ou por um período especificado de longo prazo. É necessária uma infraestrutura de apoio para a definição de processos de negócios e supervisão. 
Figura 7 - Taxonomia das EVs.

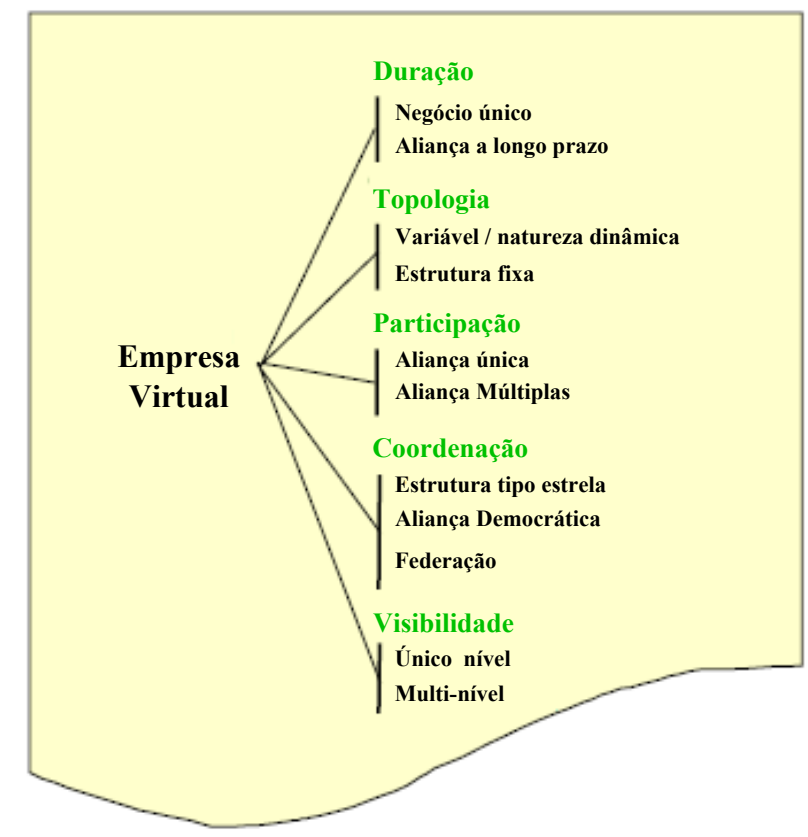

Fonte: (CAMARINHA-MATOS; AFSARMANESH, 1999)

\section{Topologia}

- Variável/natureza dinâmica, onde algumas empresas podem entrar ou sair da EV de acordo com as fases do processo de negócio ou outros fatores de mercado. Neste caso, pode-se requerer funcionalidades específicas de pesquisa e seleção de parceiros (fornecedores e prestadores de serviço), manutenção de diretórios de fornecedores e apoio aos procedimentos de fusão ou saída de parceiros. É possível também utilizar uma interação temporária com outras empresas que não pertencem à EV (fornecedores ou clientes ocasionais por meio de mecanismos de comércio eletrônico).

- Estrutura fixa. Com pouca variação em relação de mudanças de fornecedores ou clientes durante o ciclo de vida da EV.

\section{Participação}

- Aliança única, quando os parceiros podem participar somente de uma única EV (associação exclusiva).

- Aliança múltipla, os parceiros podem se associar a várias EVs. Neste caso a infraestrutura de suporte deve lidar com uma cooperação específica e as regras de visibilidade de informações devem preservar os requisitos (dados sigilosos) de cada participante individual. 
Coordenação

- Estrutura tipo estrela. Existe uma empresa dominante "rodeada" pelas outras empresas fornecedoras. A empresa dominante define "as regras do jogo", e impõe as suas próprias normas sobre os outros em termos dos modelos de processos de negócios, mecanismos de intercâmbio de informações e direitos de acesso.

- Aliança democrática. Todos os parceiros cooperam numa base de igualdade, preservando sua autonomia, mas unindo suas competências essenciais. Entretanto mesmo neste caso, um parceiro (coordenador) pode ser necessário para administrar as informações gerais sobre a associação da EV, e para monitorar a estrutura organizacional e os princípios de cooperação solidária.

- Federação. Existe uma estrutura de coordenação e gestão conjunta de recursos e competências. Todos parceiros podem ter o mesmo poder.

\section{Visibilidade}

É relacionada com a Topologia e com a Coordenação em relação ao aspecto de visibilidade, ou seja, "quão longe" ao longo da rede um parceiro pode "ver" a configuração da EV.

- Único nível, um parceiro somente consegue ver os seus vizinhos diretos (fornecedores, clientes).

- Multi-nível, um parceiro pode ter alguns direitos de visibilidade de informações em relação aos outros (não diretamente relacionado), o que pode levar a uma operação mais otimizada da EV. A monitoração do atendimento de pedidos, planejamento, programação/reprogramação, a distribuição de carga de trabalho e gerenciamento de recursos otimizados são exemplos de supervisão e coordenação de tarefas avançadas da EV que exigem uma visibilidade multi-nível.

\subsubsection{Funções dos participantes}

Conforme Camarinha-Matos e Afsarmanesh (1999), uma empresa pode desempenhar diferentes funções durante as várias fases do ciclo de vida da EV. Em outras palavras, podem ser encontrados vários tipos de atores na EV ou no entorno dela conforme ela evolui no tempo. A Figura 8 apresenta o exemplo de uma EV e os seus principais atores, composto por exemplo: um usuário final, dois fornecedores de serviços, e um exemplo de interação entre os atores. 
Figura 8 - Principais atores de uma EV e interação entre eles.

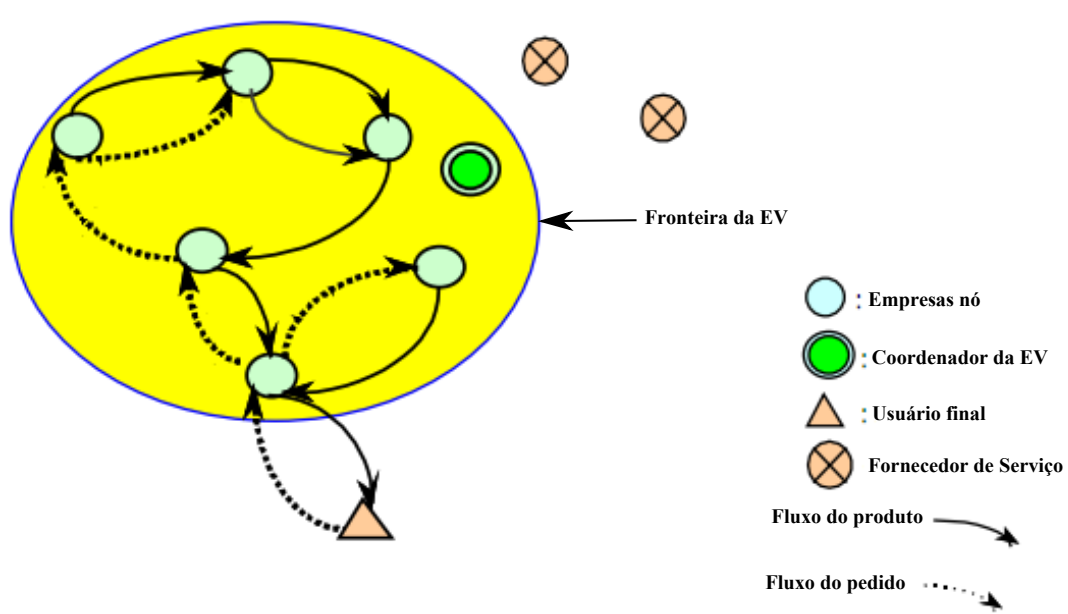

Fonte: (CAMARINHA-MATOS; AFSARMANESH, 1999)

Os principais atores de uma EV são:

- Empresas "nós", empresas parceiras (EPs), são empresas com diferentes habilidades participando e constituindo os "nós" da EV. Suas principais funções incluem:

- Tratar o primeiro contato feito por um cliente (usuário);

- Estabelecer contato e interação segura com os outros "nós";

- Cumprir as atividades e carga de trabalho (definidas em seus contratos), de acordo com o objetivo comum da EV;

- Gerenciar os seus direitos de visibilidade de informações locais, de forma a proteger tanto o seus próprios interesses quanto os da EV;

- Participar e trocar informações e materiais necessários para a cooperação e programação da produção em pedidos com os outros membros dos "nós".

- Coordenador da EV, é o componente que regula as atividades relacionadas à EV. O coordenador pode ser um "nó" especializado na coordenação e adicionado na EV, ou pode ser uma empresa "nó" já participante. O coordenador é responsável pelas seguintes tarefas:

- Registrar novas empresas na rede;

- Auxiliar uma nova empresa na instalação e configuração da infraestrutura de suporte;

- Manter as informações do diretório de rede da EV;

- Reconfigurar a EV, se necessário, e distribuir informações sobre a sua evolução na rede; 
- Testemunhar quando as empresas necessitam de um apoio em negociações com outras empresas;

- Supervisionar e coordenar as diferentes atividades de acordo com o objetivo comum;

- Supervisionar e auxiliar as empresas que estão saindo da EV.

- "Nó" de diretório de rede. Várias EVs podem coexistir em rede, ou seja, um "nó" na rede pode pertencer a várias EVs.

- Broker. Este é o papel desempenhado por uma empresa que inicia/cria uma EV e procura os parceiros. Este não é necessariamente o Coordenador da EV.

\subsubsection{Ciclo de vida da EV}

Devido à natureza dinâmica e temporária das EVs, é importante compreender o seu ciclo de vida (CAMARINHA-MATOS; AFSARMANESH, 1999; MARTINEZ et al., 2001; CAMARINHAMATOS et al., 2009; XIAOYONG; ZHI; YONGHONG, 2010). A Figura 9 apresenta o ciclo de vida das EVs.

Figura 9 - Ciclo de vida das EVs.

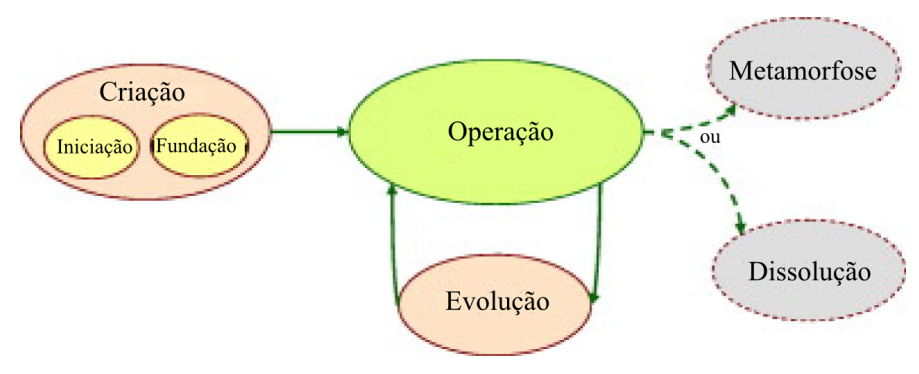

Fonte: (CAMARINHA-MATOS et al., 2009)

\section{Criação}

A criação é a etapa onde a EV é iniciada e configurada. Nesta fase são estabelecidos os objetivos da EV. Ela pode ser dividida em duas fases:

- Iniciação e recrutamento. Fase que lida com o planejamento estratégico e incubação inicial da EV. Esta envolve a identificação da oportunidade de negócios, análise das competências requeridas, a busca e avaliação de parceiros.

- Fundação. Fase que lida com a constituição e o início das atividades. Envolve as negociações e acordos entre possíveis parceiros, assinatura de contrato preliminar, elaboração 
de proposta conjunta com os parceiros. Nesta fase tem que ser definido o papel de cada participante, suas responsabilidades, e os acordos financeiros.

Operação

É a fase em que a EV realiza o seu processo de negócio regularmente a fim de alcançar o seu objetivo comum. Nesta fase se exige as seguintes funcionalidades:

- Mecanismos de segurança de troca de dados;

- Compartilhamento e direitos de visibilidade das informações;

- Gerenciamento de pedidos e processamento de pedidos incompletos;

- Planejamento dinâmico e distribuído, sequenciamento da produção;

- Gerenciamento de tarefas distribuídas;

- Elevado nível de coordenação de tarefas.

Evolução

Quando existem mudanças evolutivas na sociedade, nos papéis dos parceiros, ou em princípios operacionais diários.

Metamorfose

Quando existem mudanças interruptivas na sociedade, nos objetivos e nos princípios, conduzindo a uma nova forma de EV.

Dissolução

Esta é a fase final da EV, onde ela cessa as suas atividades. Existem duas situações que podem causar a dissolução da EV: a realização bem sucedida de todos os seus objetivos, ou quando parceiros envolvidos decidem pela interrupção de sua participação.

Existe uma lacuna nas pesquisas sobre EVs voltadas a produtos manufaturados, que é referente à carência de métodos adequados para executar o PCP (PESSOA et al., 2012), mesmo com o PCP sendo fundamental para assegurar o desempenho da EV (ZHOU; RISTIC; BESANT, 2000; DING; GAO; LUO, 2009). No intuito de diminuir esta lacuna, o foco deste 
trabalho são as funcionalidades do planejamento e controle da produção na fase de operação em EVs baseadas em virtualização de recursos.

A seção a seguir apresenta uma descrição sobre sistemas de Planejamento e Controle da Produção, as heurísticas utilizadas nestes sistemas e uma rede gráfica utilizada para modelar problemas de sequenciamento da produção.

\subsection{SISTEMAS DE PLANEJAMENTO E CONTROLE DA PRODUÇÃO (PCP)}

Os sistemas de Planejamento e Controle da Produção (PCP) são sistemas que integram as operações de produção com o propósito de melhorar o desempenho de produção com baixo custo. Eles otimizam a alocação de recursos da produção e respondem rapidamente às mudanças de demanda de produção (ZADEH; AFSHARI; KHORSHID-DOUST, 2014).

\subsubsection{Evolução dos sistemas de planejamento e controle da produção}

Os sistemas de PCP visavam inicialmente apenas a reposição de itens. Adotava-se uma abordagem histórica para prever a demanda futura, ou seja, assumia-se que os dados anteriores eram representativos da demanda futura. Se em algum momento o nível de estoque ficasse abaixo do esperado, eram feitos novos pedidos ou eram feitas novas ordens de produção, sempre com quantidades fixas. Tudo era feito manualmente, até que os computadores (tipo mainframe) começaram a ser comercializados em meados de 1960 (RONDEAU; LITTERAL, 2001). A Figura 10 apresenta os estágios evolutivos dos sistemas PCP e as forças que impulsionaram para a evolução.

Figura 10 - Estágios evolutivos dos sistemas de PCP.

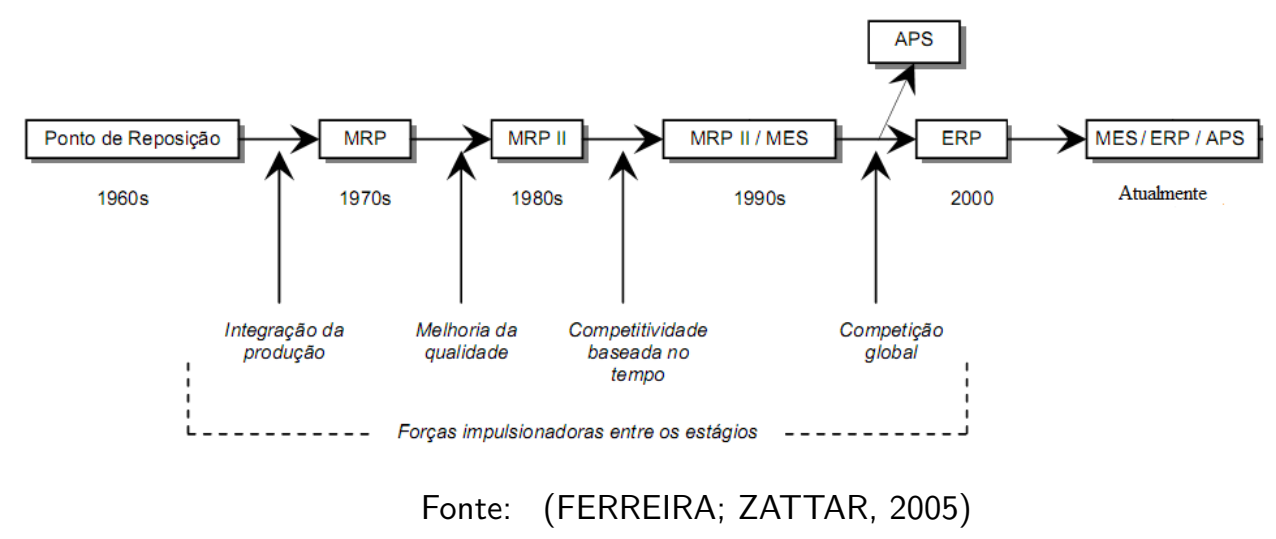

Em 1970 foram introduzidos os sistemas Material Requirement Planning (MRP). Os sistemas MRP são direcionados para lidar com a requisição de materiais. Sua lógica é baseada na identificação de todas as partes que compõem os produtos finais, e analisa-se nível por 
nível a necessidade de matéria-prima ou componentes. O sistema comparava periodicamente a demanda versus o inventário e assumia que os seus recursos tinham capacidade infinita (FERREIRA; ZATTAR, 2005).

Em meados de 1980 foram introduzidos os sistemas Manufacturing Resource Planning (MRP-II). Os sistemas MRP-II são mais amplos que o MRP, incluindo este como um componente. Possuem funções integradas como: previsão de demanda, processamento de pedidos, programação de clientes, listas de material, entre outras (FERREIRA; ZATTAR, 2005).

Em meados de 1990 foram introduzidos os sistemas Manufacturing Execution Systems (MES). Os sistemas MES representam o desenvolvimento de uma interface entre os sistemas MRP-II da empresa, seu chão de fábrica, e os sistemas de controle dos dispositivos (RONDEAU; LITTERAL, 2001). Os sistemas MES nasceram como uma resposta à necessidade da empresa de satisfazer os requisitos dos mercados a partir dos pontos de vista de: reatividade, qualidade, respeito de normas, e redução de custos e prazos (UGARTE; ARTIBA; PELLERIN, 2009).

Os sistemas Enterprise Resource Planning (ERP) foram introduzidos em meados de 2000 (RONDEAU; LITTERAL, 2001; FERREIRA; ZATTAR, 2005). Os ERPs são sistemas de gestão de empresas e visam a integração de informações inter-relacionadas em toda a organização. O ERP é baseado no conceito de identificação e implementação de um conjunto de melhores práticas, procedimentos e ferramentas que diferentes funções de uma empresa podem empregar para atingir a excelência organizacional, por meio da integração de informações. O ERP possui as funções do MRP-II, e o uso efetivo de sistemas ERP ajuda as empresas a melhorar seu desempenho empresarial (LIU et al., 2002).

Os sistemas avançados de planejamento e programação (Advanced Planning and Scheduling - APS) surgiram no final da década de 90 e utilizam o conceito de programação de atividades que utilizam recursos com capacidade finita. Os APS exploram técnicas de simulação de programação da produção e contemplam restrições de matérias-primas, quebras de máquinas, e permitem o tratamento de prioridades (FERREIRA; ZATTAR, 2005) e (HVOLBY; STEGER-JENSEN, 2010). Os sistemas APS foram concebidos para melhorar radicalmente a funcionalidade de planejamento em comparação com os sistemas de Manufacturing Resource Planning (MRPII) e Enterprise Resource Planning (ERP). Entretanto, para que tenham um bom resultado, é essencial que o responsável pela programação da produção esteja familiarizado com as funcionalidades do APS, de forma a fazer uma configuração cuidadosa dos muitos parâmetros de planejamento incluindo casos de conflito (HVOLBY; STEGER-JENSEN, 2010). De acordo com Hadaya e Pellerin (2008), um grande número de empresas está adotando os sistemas APS para apoiar o planejamento e a programação de suas atividades produtivas.

Desde 2010 os sistemas MES, ERP, e APS são considerados sistemas complementares no 
intuito de contribuir para aumentar a eficiência das empresas (HVOLBY; STEGER-JENSEN, 2010, COTTYN et al., 2011).

\subsubsection{Sistemas avançados de planejamento e programação (APS)}

Conforme Lee, Jeong e Moon (2002), os APS são muito importantes para a sobrevivência das empresas em que o cumprimento da data de entrega dos produtos é essencial. Com os sistemas APS, as empresas podem otimizar suas cadeias de suprimentos para reduzir custos, melhorar as margens de produtos, baixar os estoques e aumentar o rendimento de fabricação. De acordo com Gimeno e Rodrigues (2002) os sistemas APS podem ser vistos como tendo dois objetivos principais interligados: (1) a obtenção rápida de soluções da programação da produção a partir dos dados de planejamento; e (2) possibilitar ao responsável pelo planejamento simular os resultados da programação em função dos dados do planejamento.

Os sistemas APS tratam a alocação de recursos de produção, de forma que as restrições e os objetivos de produção sejam satisfeitos (MOON; KIM; GEN, 2004; LIN et al., 2007). Estes sistemas permitem tratar o sequenciamento de produtos multinível, ou seja, produtos formados por sub-produtos (WIERS, 2009). Os sistemas APS tornaram-se uma ferramenta importante para a programação e controle da produção, pois eles geram planos de produção mais realísticos e confiáveis, e possibilitam a realização de simulações de diferentes planos de produção antes de gerar as ordens de produção (HVOLBY; STEGER-JENSEN, 2010).

A seguir são apresentadas algumas estratégias de programação de produção (PP) mais utilizadas em sistemas APS comerciais (PESSOA, 2004; CHEN; JI; WANG, 2011; PESSOA et al., 2013; PESSOA et al., 2014).

\section{Heurísticas de programação de produção em sistemas APS}

Alocação por ordens de produção

Nesta estratégia programam-se as ordens de produção no tempo, sendo que todas as operações que compõem uma ordem de produção são programadas numa única etapa. Para tanto, utiliza-se uma lista de ordens de produção previamente ordenada por prioridades ou ordenada pela data de entrega inserida no sistema, e uma lista ordenada de recursos disponíveis (PESSOA et al., 2013; PESSOA et al., 2014).

Programam-se todas as operações da primeira ordem de produção, em seguida, programamse as da segunda, e assim por diante, até que não exista mais ordens. Cada operação é programada no primeiro instante de tempo disponível do primeiro recurso habilitado para o 
processamento da operação. Desta forma, quando uma operação está habilitada em mais de um recurso, ela é programada para alocar o recurso da lista de recursos que estiver disponível mais cedo (seguindo a ordem declarada da lista de recursos em caso de empate) .

As prioridades podem ser de produtos, onde se escolhe para programar o produto mais priorizado, ou pode ser por data de entrega, onde se programa primeiro os produtos que serão entregues mais cedo.

As heurísticas APS de programação de produção por ordens de produção são (PESSOA et al., 2013; PESSOA et al., 2014):

- Programação da produção no instante mais cedo. Partindo do início do horizonte de planejamento. É uma programação da produção no sentido da evolução do tempo, começando pela primeira operação da primeira ordem até chegar na última operação da última ordem;

- Programação da produção no instante mais tarde, partindo das datas de entrega das ordens de produção. É uma programação da produção em sentido contrário à evolução do tempo, iniciando a programação pela data de entrega das ordens. Programa-se inicialmente a última operação da ordem de menor prioridade ou da última ordem declarada, até chegar na primeira operação da ordem de maior prioridade ou a primeira declarada;

- Bidirecional, esta heurística parte da programação de todas as ordens de produção na máquina gargalo. Consiste em: i) programar inicialmente todas as ordens de produção no instante mais cedo ou no instante mais tarde, ii) fixar as operações que estão programadas para o recurso gargalo, iii) retirar da programação todas as operações que não estão fixas, iv) uma re-programação no instante mais tarde das operações precedentes às operações fixas e uma re-programação no instante mais cedo das operações posteriores às operações fixas, v) uma realocação no instante mais cedo ou mais tarde das operações restantes (operações que não tenham relação direta com as operações fixadas). Esta heurística é útil quando está bem definido qual é o recurso gargalo. Nela priorizam-se as ordens que utilizam os recursos gargalos programando-as antes das outras ordens de produção, independentemente de qual seja a ordem de declaração ou do ordenamento da lista de prioridades das ordens de produção.

Estas heurísticas podem dar lugar a soluções na forma, por exemplo, de cartas de Gantt 1 , que apresentam intervalos de tempo não utilizados entre operações sucessivas da mesma ordem de produção. Isto implica em um tempo de espera desnecessário entre operações da mesma

\footnotetext{
${ }^{1}$ As cartas de Gantt são gráficos utilizados como ferramenta de planejamento de produção. Elas apresentam as tarefas a produzir, os recursos e a linha de tempo de produção (WILSON, 2003).
} 
ordem de produção, e também na existência de estoques intermediários desnecessários. As estratégias adicionais que visam eliminar estes tempos de espera desnecessários são conhecidas como estratégias de minimização da produção em processo (Min Work in Progress - Min WIP) para frente (forward) ou para trás (backward) (PESSOA, 2004). Estas duas estratégias são similares, e elas têm em comum o fato de construir a carta de Gantt em dois passos:

- Minimização do tempo de espera para frente. Esta heurística é dividida em dois passos: o primeiro é idêntico à programação de recursos por ordens de produção no instante mais cedo. O segundo consiste em fixar a última operação da ordem de produção (de acordo com a declaração ou com a prioridade da ordem de produção) e deslocar as operações anteriores visando minimizar o tempo de espera entre as operações;

- Minimização do tempo de espera para trás. Esta heurística possui dois passos como no caso anterior: o primeiro é semelhante à programação de recursos por ordem de produção no instante mais tarde. Neste, inicia-se a programação da produção pela última operação da ordem de maior prioridade ou da primeira declarada. No segundo passo, fixa-se a primeira operação da ordem e desloca as operações seguintes, tentando assim, minimizar o tempo de espera entre operações.

Programação da produção por operações (heurística APS Relógio)

Nesta estratégia a carta de Gantt é construída utilizando um mecanismo de relógio, que avança programando as operações em sentido da evolução no tempo. Esta estratégia programa as operações em função da lista de liberação de recursos (sempre alocando a partir do primeiro recurso da lista), independentemente da ordem de produção à qual pertençam (PESSOA et al., 2013; PESSOA et al., 2014).

A lista de liberação de recursos é associada à lista de recursos ordenados de forma crescente no tempo. Utiliza-se o instante de tempo de liberação $(T L)$ do recurso, ou seja; o instante em que o recurso está liberado isto é, disponível para alocação. Inicialmente, todos os recursos disponíveis estão no mesmo instante de liberação $(T L=0)$, assim inicia-se a lista de tempos de liberação dos recursos de acordo com a ordem em que os recursos foram declarados no sistema. Após cada operação programada, atualiza-se o tempo de liberação $(T L)$ do recurso em que foi programada, e reordena-se a lista de liberação de recursos com o novo valor. Uma vez escolhido um recurso, é necessário identificar a operação programada, dado que podem existir várias operações que podem necessitar do recurso. Esta heurística pode efetuar a programação da produção de duas formas:

- Programação da produção de acordo com a lista de ordens de produção. Programa-se de 
acordo com a prioridade das ordens de produção fornecida pelo responsável da programação de produção. Para cada ordem de produção é utilizada a sequência ordenada de operações que compõem a ordem (precedência entre operações). Programa-se a primeira operação possível de ser executada com o recurso escolhido pelo $T L$.

- Programação da produção utilizando regras heurísticas de seleção. Neste caso são utilizados diversos critérios para a escolha da operação a ser programada, dentre eles: i) razão crítica; ii) tempo de processamento; iii) tempo de preparação; iv) data de entrega; e v) atributos. Os valores podem ser utilizados em ordem crescente ou decrescente e ainda pode ser utilizado mais de um critério para a escolha da operação.

Estes critérios são aplicados sobre as operações disponíveis no recurso alocado que tem o menor tempo de liberação $(T L)$. As principais regras heurísticas utilizadas são descritas a seguir:

- A razão crítica $(R C)$ é o quociente entre: i) o tempo restante até a data de entrega da ordem de produção, isto é, o tempo da data de entrega subtraído do tempo de liberação do recurso em que será alocada a operação e ii) o tempo necessário para completar a ordem de produção isto é, o tempo de processamento total da ordem subtraído da soma dos tempos das operações já programadas. Quanto menor for o valor, mais crítica é a ordem de produção. Escolhendo a operação da ordem de produção mais crítica, busca-se diminuir a possibilidade de atraso das ordens de produção;

- A heurística de tempo de processamento escolhe a operação considerando os tempos de processamento das operações candidatas. Pode, por exemplo, escolher a operação que demora menos, o que pode ser útil para processar o maior número de operações primeiro e deixar as mais demoradas por último;

- A heurística de tempo de preparação (Setup) prioriza as operações de acordo com o tempo de preparação do recurso para processar cada operação.

- A heurística de data de entrega escolhe a operação de acordo com a data de entrega da ordem de produção. Pode-se, por exemplo, escolher a operação que pertença à ordem que tenha que ser finalizada mais cedo, buscando-se evitar atrasos na entrega dos produtos;

- A heurística de atributos escolhe a operação de acordo com atributos introduzidos pelo responsável da programação da produção. 


\subsubsection{Capacidades e Restrições na Programação de Produção}

Em problemas de produção com datas de entrega, é possível determinar, para cada operação necessária para atender a demanda, o instante de tempo mais tarde em que esta operação deve estar pronta. Este cálculo é um dos pontos essenciais da técnica MRP. Os instantes de tempo a partir dos quais as matérias-primas ou os produtos intermediários estão disponíveis, permite determinar o instante de início mais cedo em que cada operação pode ser alocada. Este instante de início mais cedo (earliest starting time-Est) e o instante de término mais tarde (latest finishing time- $L f t$ ) definem a "janela de tempo" da operação. Desta forma, a "janela de tempo" é o intervalo de tempo em que uma operação pode ser alocada e executada de forma a garantir a factibilidade do prazo de entrega dos produtos finais. O uso das "janelas de tempo" permite uma análise preliminar de viabilidade de uma ordem de produção, possibilitando verificar se as demandas e as datas de entregas dos pedidos são possíveis de serem cumpridas (RODRIGUES; RIECHI, 2005; RODRIGUES; RIECHI, 2007).

Para calcular as "janelas de tempo" é necessário que sejam fornecidos os seguintes dados: i) a receita do produto, ou seja, as operações que compõem o produto, suas ordens de precedências, os recursos habilitados para produção do produto com seus tempos de produção; ii) as demandas de produtos finais e suas datas de entrega; iii) a disponibilidade temporal das matérias-primas; iv) a disponibilidade temporal de recursos; e v) os estoques existentes de produtos finais e intermediários.

As "janelas de tempo" são geradas em duas etapas: a primeira é um procedimento de explosão de requisitos para trás; a segunda é um procedimento de explosão para frente que utiliza a informação de disponibilidade de matérias-primas. A primeira etapa utiliza a demanda de produtos finais para calcular o número de lotes que cada operação necessita para cumprir com a quantidade a produzir e seus tempos de término mais tarde $(L f t)$. Esta etapa fornece a quantidade mínima de matérias-primas necessárias. A segunda etapa utiliza a informação de disponibilidades de matérias-primas, fornecidas pelo responsável do planejamento, para calcular o instante de início mais cedo da cada lote (Est). O plano de disponibilidade de matéria-prima, fornecido pelo responsável do planejamento, deve satisfazer o plano mínimo calculado pela explosão para trás.

A segunda etapa é uma explosão para frente, partindo das informações de disponibilidade de matéria-prima introduzidas pelo responsável do planejamento. A explosão para frente é utilizada para determinar os instantes de início mais cedo dos lotes das operações. As explosões para trás e para frente geram os instantes de início mais cedo (Est) e os instantes de término mais tarde dos lotes $(L f t)$, criando assim as "janelas de tempo" dos lotes. Os quatro instantes principais de uma "janela de tempo" (Figura 11) são: 
- Instante de início mais cedo $(E s t)$. É o instante mais cedo que um lote pode ser iniciado na "janela de tempo";

- Instante de término mais tarde $(L f t)$. É o instante de término mais tarde que um lote deve ser finalizado na "janela de tempo";

- Instante de término mais cedo $(E f t)$. É o instante de término mais cedo que um lote pode ser finalizado na "janela de tempo". Ele é definido pela soma do Est com o tempo de processamento do lote $(T p)$;

- Instante de início mais tarde (Lst) . É o instante de início mais tarde que um lote deve ser iniciado na "janela de tempo". Ele é definido pelo $L f t$ subtraido do $T p$ do lote.

Figura 11 - Instantes principais de uma "janela de tempo".

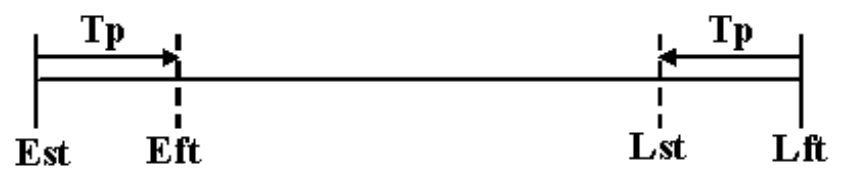

Propagação de restrições

A propagação de restrições é o mecanismo responsável por manter os limites das "janelas de tempo" (Est e $L f t$ ) de todos os lotes compatíveis com as restrições de produção (CASEAU; LABURTHE, 1994). Os principais casos de propagação de restrições são:

- Restrições de capacidade (recurso unitário), onde as operações atribuídas ao mesmo recurso não podem se sobrepor;

- Restrições de precedência por receita, o instante de início mais cedo da operação consumidora (operação antecedente que consome determinado insumo) deve ser igual ou maior que o instante de término mais cedo da operação produtora (operação precedente que produz determinado produto), e o instante de término mais tarde da operação produtora deve ser menor ou igual ao instante de início mais tarde da operação consumidora;

- Restrições por monotonicidade: serão produzidos consecutivamente os lotes da mesma operação que estejam atribuídos ao mesmo recurso, isto quando for necessário mais de um lote para produzir a quantidade requisitada;

- Restrições de armazenagem. 
Restrições de capacidade

A restrição de capacidade garante que as operações não se sobreponham no tempo, ou seja, não é possível executar duas operações ao mesmo tempo no mesmo recurso. Para garantir esta restrição, existem duas situações que podem levar a modificações nas "janelas de tempo":

- "Janela de tempo" com um intervalo de tempo que obrigatoriamente será utilizado pela operação (slots of total reliance) (SADEH, 1991);

- "Janelas de tempo" com um ordenamento obrigatório entre si.

A primeira situação acontece quando uma "janela de tempo" tem um intervalo que será obrigatoriamente utilizado por uma operação. Isto acontece quando na "janela de tempo" tem-se $E f t>L s t$, gerando assim um intervalo obrigatoriamente utilizado (SADEH, 1991). Neste caso é necessário excluir este intervalo das "janelas de tempo" das outras operações que o contenham, evitando assim sobreposição de operações. A exclusão deste intervalo das outras "janelas de tempo" gera aumentos de Est, ou diminuições de $L f t$ ou "janelas de tempo" disjuntas.

A segunda situação é quando existem ordenamentos obrigatórios entre operações. Os ordenamentos obrigatórios entre operações são necessários quando apesar de ser possível alocar as operações com "janelas de tempo" competindo entre si pelo mesmo recurso, é obrigatório um ordenamento entre as operações para que a programação seja factível. É possível generalizar o ordenamento entre operações para um ordenamento entre uma operação $A$ e um conjunto de operações que competem pelo mesmo recurso. As condições que deduzem esse ordenamento foram apresentadas em Bel et al. (1989), e Caseau e Laburthe (1995). Neste tipo de ordenamento existem duas possibilidades: i) quando a operação $A$ pertence ao conjunto de operações (edge finding); e ii) quando a operação $A$ não pertence ao conjunto de operações (exclusão).

Para um conjunto de operações $\Omega$, o Est $t_{\Omega}$ é definido como o mínimo $E s t$, e o $L f t_{\Omega}$ é definido como o máximo $L f t$ das operações pertencentes a $\Omega$, o tempo de processamento $T p_{\Omega}$ é a soma dos tempos de processamento das operações pertencentes a $\Omega$.

A) Edge finding: Ordenamento entre a operação $A$ e um conjunto de operações $\Omega(A \in \Omega)$

Neste caso toda a "janela de tempo" da operação $A$ está contida no intervalo formado pelo conjunto $\Omega$, ou seja; $E s t_{A} \geq E s t_{\Omega}$ e $L f t_{A} \leq L f t_{\Omega}$. Este problema não é factível se não for possível programar as operações pertencentes a $\Omega$ entre o intervalo limite das "janelas de tempo" de $\Omega$, ou seja, se $L f t_{\Omega}-E s t_{\Omega}<T p_{\Omega}$, o problema não é factível. Se o problema for factível, é possível deduzir ordenamentos nos dois casos: se a operação $A$ não precede; ou não segue o conjunto remanescente $\{\Omega-A\}$. 
A operação $A$ não precede o conjunto remanescente $\{\Omega-A\}$ se o intervalo entre o instante de início mais cedo de $A$ e o instante de término mais tarde de $\Omega$ for menor que o tempo de processamento de $\Omega$, ou seja, não é possível programar todas as operações de $\Omega$ entre o intervalo do instante de início mais cedo de $A$ e o instante de término mais tarde de $\Omega$. A equação 1 representa essa condição.

$$
L f t_{\Omega}-E s t_{A}<T p_{\Omega}
$$

Nesse caso o ordenamento implica no aumento no valor de $E s t_{A}$, ou seja:

$$
E s t_{A} \geq \min _{i \in \Omega, i \neq A}\left(E s t_{i}+T p_{i}\right)
$$

A operação $A$ não segue o conjunto remanescente $\{\Omega-A\}$ se o intervalo entre instante de início mais cedo de $\Omega$ e o instante de término mais tarde de $A$ for menor que o tempo de processamento de $\Omega$, ou seja, não é possível programar todas as operações de $\Omega$ entre o intervalo do instante de início mais cedo de $\Omega$ e o instante de término mais tarde de $A$. A equação 3 representa esta condição.

$$
L f t_{A}-E s t_{\Omega}<T p_{\Omega}
$$

Neste caso o ordenamento implica na diminuição no valor de $L f t_{A}$, ou seja:

$$
L f t_{A} \leq \max _{i \in \Omega, i \neq A}\left(L f t_{i}+T p_{i}\right)
$$

B) Exclusão: Ordenamento entre a operação $A$ e um conjunto de operações $\Omega(A \notin \Omega)$

Neste caso a "janela de tempo" da operação $A$ está parcialmente contida no intervalo formado pelo conjunto de $\Omega$. Definindo $\Phi=\Omega \cup A$ o problema não é factível se não for possível programar todas as operações pertencentes a $\Phi$ entre o intervalo limite das "janelas de tempo" de $\Phi$, ou seja, se $L f t_{\Phi}-E s t_{\Phi}<T p_{\Omega}+T p_{A}$, o problema não é factível. Se o problema for factível, é possível verificar se: i) a operação $A$ não precede o conjunto $\{\Omega-A\}$ ou ii) a operação $A$ não segue o conjunto $\{\Omega-A\}$.

i) Operação $A$ não precede o conjunto $\{\Omega-A\}$.

A operação $A$ não precede o conjunto $\{\Omega-A\}$ se o intervalo entre o instante de início mais cedo de $A$ e o instante de término mais tarde de $\Omega$ for menor que a soma do tempo de processamento de $\Omega$ e o tempo de processamento de $A$, ou seja, se não for possível programar todas as operações de $\Omega$ e a operação $A$ entre o intervalo do instante de início mais cedo de $A$ e o instante de término mais tarde de $\Omega$. A equação 5 representa essa condição. 


$$
L f t_{\Omega}-E s t_{A}<T p_{\Omega}+T p_{A}
$$

Neste caso o ordenamento implica no aumento no valor de $E s t_{A}$, ou seja:

$$
E s t_{A} \geq \min _{i \in \Omega}\left(E s t_{i}+T p_{i}\right)
$$

Adicionalmente, se não for possível programar todas as operações de $\Omega$ e a operação $A$ entre o intervalo do instante de início mais cedo de $\Omega$ e o instante de término mais tarde de $\Omega$, ou seja, se $L f t_{\Omega}-E s t_{\Omega}<T p_{\Omega}+T p_{A}$, a operação $A$ não pode ser processada entre as operações $i$ pertencentes a $\Omega$. Neste caso, como é sabido que $A$ não precede o conjunto $\Omega$, conclui-se que $\Omega$ precede $A$. Sendo assim, esse ordenamento implica que o instante de início mais cedo de $A$ tem que ser maior ou igual ao instante de término mais cedo do conjunto $\Omega$, ou seja:

$$
E s t_{A} \geq E s t_{\Omega}+T p_{\Omega}
$$

Nesse caso o ordenamento também implica que é necessário que os instantes de término mais tarde das operações $i$ pertencentes a $\Omega$ sejam menores ou iguais ao instante de início mais tarde da operação $A$, ou seja:

$$
L f t_{i} \leq L f t_{A}-T p_{A} \quad \forall i \in \Omega
$$

Caso a operação $A$ possa ser processada entre as operações $i$ pertencentes ao conjunto $\Omega$, a conclusão que $\Omega$ precede $A$ é obtida se a operação $A$ seguir qualquer operação $i \in \Omega$, ou seja, $E s t_{A}+T p_{A}>L f t_{i}-T p_{i} \forall i \in \Omega$. Sendo assim, o ordenamento entre as operações também implica que as restrições das equações 7 e 8 sejam respeitadas.

ii) Operação $A$ não segue o conjunto $\{\Omega-A\}$

A operação $A$ não segue o conjunto $\{\Omega-A\}$ se o intervalo entre o instante de início mais cedo de $\Omega$ e o instante de término mais tarde de $A$ for menor que a soma do tempo de processamento de $\Omega$ e de $A$, ou seja, não é possível programar todos as operações de $\Omega$ e a operação $A$ entre o intervalo do instante de início mais cedo de $\Omega$ e o instante de término mais tarde de $A$. A equação 9 representa essa condição.

$$
L f t_{A}-E s t_{\Omega}<T p_{\Omega}+T p_{A}
$$

Neste caso o ordenamento implica que é necessário aumentar o valor de $L f t_{A}$, ou seja:

$$
L f t_{A} \geq \max _{i \in \Omega}\left(L f t_{i}+T p_{i}\right)
$$


Adicionalmente, se não for possível programar todas as operações de $\Omega$ e a operação $A$ entre o intervalo do instante de início mais cedo de $\Omega$ e o instante de término mais tarde de $\Omega$, ou seja; $L f t_{\Omega}-E s t_{A}<T p_{\Omega}+T p_{A}$, a operação $A$ não pode ser processada entre as operações $i$ pertencentes a $\Omega$. Neste caso, como é sabido que $A$ não segue o conjunto $\Omega$, conclui-se que $A$ precede $\Omega$. Sendo assim, este ordenamento implica que o instante de término mais tarde de $A$ tem que ser menor ou igual ao instante de início mais tarde do conjunto $\Omega$, ou seja:

$$
L f t_{A} \leq L f t_{\Omega}-T p_{\Omega}
$$

Neste caso o ordenamento entre operações também implica que é necessário que os instantes de início mais cedo das operações $i$ pertencentes a $\Omega$ sejam maiores ou iguais ao instante de término mais cedo da operação $A$, ou seja:

$$
E s t_{i} \geq E s t_{A}+T p_{A} \quad \forall i \in \Omega
$$

Caso a operação $A$ possa ser processada entre as operações $i$ pertencentes ao conjunto $\Omega$, a conclusão que $A$ precede $\Omega$ é obtida se a operação $A$ preceder qualquer operação $i \in \Omega$, ou seja, $L f t_{A}-T p_{A}<E s t_{i}+T p_{i} \forall i \in \Omega$. Sendo assim, o ordenamento entre as operações também implica que as restrições das equações 11 e 12 sejam respeitadas.

Restrições de precedência por receita

Como a operação produtora precede a operação consumidora, é necessário utilizar restrições entre os inícios e fins das "janelas de tempo" das operações envolvidas por precedências. As restrições consideradas são:

- restrição entre o instante de início mais cedo da "janela de tempo" da operação consumidora e o instante de término mais cedo da operação produtora, ou seja,

$$
\text { Est }_{\text {consumidora }} \geq E f t_{\text {produtora }}
$$

- restrição entre o instante de término mais tarde da operação produtora e o instante de início mais tarde da operação consumidora, ou seja,

$$
L f t_{\text {produtora }} \leq L s t_{\text {consumidora }}
$$


Restrições por monotonicidade

As restrições de monotonicidade consideram que se forem necessários várias lotes da mesma operação e se eles forem produzidos no mesmo processador, estes lotes podem ser considerados como lotes consecutivos. Para representar esta condição é necessário que:

$$
\begin{aligned}
& E s t_{\text {lote }+1} \geq E s t_{\text {lote }}+T p \\
& L f t_{\text {lote }} \leq L f t_{\text {lote }+1}-T p
\end{aligned}
$$

Restrições de armazenagem

Considera-se aqui três tipos de armazenagem:

- Ilimitada (UIS - unlimited intermediate storage)

- Limitada (FIS - finite intermediate storage)

- Inexistente (NIS - no intermediate storage)

A armazenagem do tipo UIS considera que existe capacidade de armazenagem ilimitada, e sendo assim não há nenhuma restrição a ser imposta ao problema. Os outros tipos de armazenagem serão descritos a seguir.

\section{Armazenagem Limitada (FIS)}

A armazenagem limitada é utilizada quando existe limitação de capacidade de estocagem do produto processado. Neste caso as "janelas de tempo" das operações produtoras estão interligadas com as "janelas de tempo" das operações consumidoras de forma que não seja ultrapassada a capacidade de estocagem. Uma descrição mais detalhada pode ser encontrada em Rodrigues (2000).

\section{Armazenagem inexistente (NIS)}

Neste tipo de restrição não existe local para armazenar o produto processado. Entretanto o produto pode ficar retido no recurso que o produziu até que exista demanda para ele, ou até que o recurso seja requisitado por outra operação. Em Rodrigues (2000) tem-se uma descrição detalhada.

As restrições apresentadas são utilizadas num mecanismo de propagação de restrições. Cada vez que uma operação é programada, o mecanismo propaga todas as restrições para as "janelas de tempo" das operações que ainda não foram programadas. Quando existe uma propagação de restrição, esta pode gerar recortes no instante de início mais cedo ou no instante de término mais tarde da "janela de tempo". O recorte é um aumento no instante de início mais cedo 
(EST), ou uma diminuição no instante de término mais tarde ( $L F T)$. Uma das funções do mecanismo de propagação é manter os limites das "janelas de tempo" atualizados, ou seja, dentro de limites reais, e não é possível prever os recortes que o mecanismo irá fazer. Caso algum recorte não seja factível, ou seja, o tempo de processamento da operação for maior que o tamanho da "janela de tempo", o sistema de planejamento e programação da produção deve enviar uma mensagem de não factibilidade e as "janelas de tempo" não são geradas.

\subsubsection{Geração da programação da produção considerando as restrições}

A busca orientada por restrições (Constraint Based Search-CBS) é uma estratégia de busca em árvore, onde os "nós intermediários" são soluções parciais do problema de programação da produção e os "nós finais" representam soluções completas do problema (SADEH, 1991). Uma decisão de programação leva de um "nó" pai a um "nó" filho.

A programação decide o momento em que uma operação é iniciada e o ordenamento define uma relação de precedências entre duas operações. No primeiro caso, o problema de programação está resolvido quando se tem uma solução que engloba todas as operações. Neste caso, o instante específico em que a operação inicia e termina é conhecido, e a partir destes é obtida a Carta de Gantt diretamente. No segundo caso, de ordenamento, o problema de programação está finalizado quando todas as relações de precedências entre as operações estão fixadas.

A busca orientada por restrições tem como características principais a utilização de procedimentos para determinar a decisão de programação em cada "nó" e a utilização de técnicas de propagação de restrições após cada decisão de programação para reduzir a árvore de busca. $\mathrm{O}$ processo heurístico da busca orientada pelas restrições é composto por vários componentes: o "nó" da árvore que será escolhido para a abertura (passagem do "nó" pai para o "nó" filho), a(s) operações(s) que serão escolhidas pelo cenário representado e a decisão de programação sobre esta(s) operações(s) (SADEH, 1991).

Sua principal característica é que o processo de busca é orientado pelos gargalos do processo, onde o gargalo é originado pela competição entre operações por um mesmo recurso. Após a detecção do gargalo, procede-se à escolha da(s) operações(s) sobre as quais serão tomadas as decisões de ordenamento. As regras utilizadas para esta escolha são conhecidas na literatura por heurísticas de ordenação variável (variable ordering heuristics) e as decisões tomadas sobre a(s) operações(s) escolhida(s) são conhecidas como heurísticas de ordenação por valor (value ordering heuristics) (SADEH, 1991; SMITH; CHENG, 1993).

A outra característica importante das estratégias $C B S$ é a utilização dos mecanismos de propagação de restrições que são ativados após cada decisão de programação, ou quando al-

guma "janela de tempo" sofre um recorte devido à propagação de restrições. Estes mecanismos 
propagam as restrições entre as "janelas de tempo", gerando novos cenários para o problema, e mantendo sempre as "janelas de tempo" atualizadas. Esse mecanismo é o responsável pela redução das "janelas de tempo", gerando também uma redução no espaço de busca na árvore. Tratando-se de uma busca em árvore, é necessário manter informações adequadas para permitir uma volta (backtracking) quando o processo levar a uma situação não factível (dead end).

Alguns softwares comerciais utilizam estratégias CBS. O sistema ILOG (2009) considera apenas as restrições por recursos unitários compartilhados, ou seja, recursos que não podem ser utilizados por mais de uma operação ao mesmo tempo (por exemplo, processadores). $\mathrm{O}$ sistema Claire (1999) foi desenvolvido com extensões que consideram os recursos compartilhados cumulativos, ou seja, recursos que podem ser utilizados por várias operações ao mesmo tempo (por exemplo, mão de obra, água).

A partir de 2004, começaram a ser apresentados resultados de trabalhos acadêmicos sobre heurísticas de programação do tipo APS que utilizavam as "janelas de tempo" em conjunto com a propagação de restrições (PESSOA, 2004; MONTESCO, 2004; RODRIGUES et al., 2004; PESSOA et al., 2011; PESSOA et al., 2014). Estes trabalhos possibilitaram que os sistemas APS tratassem problemas com forte restrição em relação à data de entrega dos produtos. Foi comprovado também que mesmo com a utilização das "janelas de tempo", em conjunto com a propagação de restrições, as heurísticas propostas encontravam uma solução num tempo semelhante ao dos sistemas APS tradicionais, entretanto os APS tradicionais não conseguem tratar os problemas com forte restrição à data de entrega, eles apenas relaxam a restrição, e destacam os itens que não conseguirão cumprir com o prazo de entrega.

\subsubsection{Sistemas de PCPs em EVs}

De acordo com Richards et al. (1997) e Xia e Li (2008), os sistemas de planejamento e controle da produção utilizados em empresas convencionais podem não satisfazer os requisitos de um ambiente de EV. Conforme Ding, Gao e Luo (2009), o planejamento e controle da produção é importante para a sobrevivência das EVs. Desta forma, têm sido propostos alguns trabalhos sobre sistemas de planejamento da produção já direcionados para EVs, dentre eles (RICHARDS et al., 1997; IP; YUNG; WANG, 2004; XIA; LI, 2008; HSU; HSU, 2008; DING; GAO; LUO, 2009).

Em Richards et al. (1997) foi proposto um sistema para diminuir o intervalo existente entre os sistemas da camada transacional mais alta (ERP) com os das camadas mais baixas (MES). O sistema fez parte do projeto X-CITTIC da União Européia, tendo como objetivo principal o desenvolvimento de um sistema de informação que suportasse o planejamento e controle da 
produção em EVs. A arquitetura considerada para a EV adotava o conceito de orientação a objetos e uma aplicação distribuída via Object Request Brokers (ORBs) utilizando o CORBA (Common Object Request Broker Architecture) conectada diretamente ou por meio de um Data Base Management System (DBMS).

Em Ip, Yung e Wang (2004) foi pesquisado o problema de seleção de parceiros em EV. Os autores provaram que o problema de seleção de parceiros é um problema de planejamento da produção do tipo de "programação mais cedo x mais tarde", ou seja, é um problema de otimização de programação da produção e custo de produção. Em Ip, Yung e Wang (2004) foi utilizado também o custo de penalidade quando uma tarefa é entregue depois do prazo. Foi proposto um algoritmo do tipo "Branch and Bound" para reduzir o espaço da solução na escolha de parceiros. No algoritmo do tipo "Branch and Bound" o conjunto de soluções candidatas forma uma arvore com vários nós (ramos) candidatos, estes nós representam subconjuntos do conjunto de soluções. O algoritmo somente explora novos nós depois de verificar a relação dos limites superior e inferior estimado sobre a solução ideal, se o nó não produzir uma solução melhor do que a encontrada até o momento o nó é descartado e não são analisados seus sub nós, desta forma, o algoritmo segue analisando outros nós.

Em Xia e Li (2008) foi proposto um sistema para planejamento da produção para EV composto por duas camadas: a camada empresarial e camada de produção. A camada empresarial negocia as interações entre as empresas que compõem a EV e elabora um planejamento inicial da produção. A camada de produção elabora e executa o sequenciamento das atividades produtivas. O trabalho apresenta apenas o modelo do sistema, isto é, não relata como seria a sua aplicação prática.

Em Hsu e Hsu (2008) foi proposto um procedimento para desenvolver um sistema de planejamento da produção para EVs. O procedimento inclui uma análise top-down do modelo do processo de planejamento e uma implementação bottom-up, que utiliza conceitos e técnicas de Inteligência Artificial para implementação do sistema. Na parte de análise, a rede de Petri Predicado/Transição (MURATA; ZHANG, 1988) é utilizada para modelar o processo de planejamento de recursos do sistema produtivo. Desta forma, o planejamento de recursos pode ser considerado como o processo de atribuir $T_{i}$ tarefas para $R_{j}$ recursos. Esta análise utiliza técnicas de simulação de cenários. Com base no modelo resultante é feita a implementação em dois estágios. O primeiro é da construção da estrutura de dados, e o segundo, do desenvolvimento do mecanismo de planejamento baseado em conhecimento. Em Hsu e Hsu (2008) a estrutura de dados é representada como um fato em "cláusula de Horn" relacionada com as regras da rede de Petri Predicado/Transição para a posterior implementação em Visual Prolog.

Em Ding, Gao e Luo (2009) foi proposto um modelo de duas camadas de controle para o planejamento da produção em EVs, baseado numa estratégia de decomposição sub ótima. 
Neste, foi apresentado um modelo matemático para o problema de planejamento da produção e foi proposto um algoritmo para encontrar a solução ótima do problema, ou seja, um planejamento utilizando o menor custo que atenda a data de entrega do produto. Na camada superior, a empresa coordenadora se encarrega de criar um planejamento ótimo, selecionando os parceiros que produzam as tarefas com o menor custo possível dentro dos prazos estipulados. Na camada inferior, as empresas parceiras são responsáveis por fazer o planejamento interno da produção.

Entre os trabalhos apresentados e outros pesquisados nas bases do Scopus e do Web of Science, não foram encontrados trabalhos relacionados à arquitetura de EV que possibilite a integração do planejamento global da EV de acordo com as diferentes capacidades das empresas parceiras com os sistemas de programação das empresas parceiras, possibilitando desta forma que cada empresa parceira tenha a liberdade de escolha nos método de programação local.

\subsection{PROPOSTAS DE EVS UTILIZANDO WEB SERVICE}

Conforme Hsu e Hsu (2008) o conceito de web service (WS) está crescendo em popularidade e os desenvolvedores de sistemas empresariais estão criando novas aplicações utilizando este conceito. Desta forma, os WSs representam mais um passo para permitir a colaboração de entidades via web, superando os problemas de interoperabilidade que possam ocorrer (HERRERA; RAMOS; LASTRA, 2011). O WS é um conjunto de protocolos e padrões utilizados para troca de informações entre aplicativos de sistemas de informação (CALIZ et al., 2011). Desta forma, tais aplicativos escritos em linguagens diferentes e sendo executadas em plataformas diferentes podem se comunicar pela internet usando WS como se fossem sistemas executados num único computador (CALIZ et al., 2011). A seguir serão apresentados alguns trabalhos que utilizaram WS para sistemas de EVs.

Em Hsu e Hsu (2008) foi proposto um sistema em WS considerando o conceito de Web 3.0, que permite o controle sobre as interações das informações nas EVs. As informações são representadas em Resource Description Framework (RDF). A ideia é que o sistema possibilite que as EVs se reconfigurem automaticamente de acordo com os serviços disponíveis nas empresas participantes.

Em Qiushi et al. (2010) foi proposto um modelo integrado de sistema de informação para EV baseado em WS. O modelo é composto de três partes: "WS Broker", que é o centro de coordenação de informação, um tipo de UDDI (Universal Description Discovery and Integration) que prepara as normas do WS para os parceiros da EV; "WS Provider" da empresa virtual, que cria um registro UDDI privado num serviço de aplicativo da empresa parceira; e "WS 
Requester" da empresa virtual, que requisita dinamicamente o "WS Provider" de acordo com a descrição do serviço. Todos estes serviços foram adaptados para o ciclo de vida dos processos das EVs.

Em Caliz et al. (2011) foi proposto um sistema onde os processos de negócios podem ser compostos por WS. A composição consiste em agregar diversos serviços com o intuito de resolver uma determinada requisição. Esta composição é feita de forma automática, utilizando métodos de inteligência artificial.

Os trabalhos apresentados demonstraram a aplicabilidade dos WS para a integração de sistemas de informação em EV, entretanto, é importante que sejam seguidas as normas de integração existentes. Nenhum dos trabalhos estudados considera, por exemplo, a norma ANSI/ISA-95 para integração. Isso é um ponto fundamental a ser revisto, já que a utilização da norma facilita a implementação de sistemas de PCP por empresas reais.

\subsection{MODELOS E TERMINOLOGIAS PARA AS INTERFACES DE SISTEMAS DE MANU- FATURA}

De acordo com Dobrev, Gocheva e Batchkova (2008), a norma ANSI/ISA-95 ou simplesmente ISA95 é baseada num conjunto de normas internacionais, e estabelece modelos e terminologias para definir as interfaces entre os sistemas de negócios de uma empresa e seus sistemas de controle de manufatura. Os modelos e terminologias definidos neste padrão servem para: a) enfatizar as boas práticas de integração dos sistemas de controle com sistemas corporativos durante o ciclo de vida dos sistemas; b) podem ser usados para melhorar as capacidades de integração existentes de sistemas de controle de manufatura com os sistemas corporativos, e c) podem ser aplicadas independentemente do grau de automação. A ISA95 foi desenvolvida para as indústrias de manufatura para ser aplicada em todos os setores industriais e em todos os tipos de processos produtivos, como fabricação em lotes, processos contínuos ou processos repetitivos (GUERRERO; VASQUEZ; TEODORESCU, 2009).

A ISA95 foi concebida para fornecer os seguintes benefícios:

- Permitir que as empresas identifiquem melhor suas necessidades;

- Reduzir os esforços do ciclo de vida de engenharia;

- Reduzir os custos de automatizar os processos de manufatura;

- Habilitar os fornecedores para desenvolver e oferecer ferramentas adequadas para a implementação da integração de sistemas de controle para sistemas corporativos; 
- Reduzir os tempos que as empresas levam para alcançar níveis de produção plena de novos produtos;

- Otimizar as cadeias de fornecimento.

Os modelos são baseados no Modelo de Referência Purdue para Manufatura Integrada por Computador (Computer Integrated Manufacturing - CIM) (WILLIAMS, 1994), no Modelo Funcional Internacional da Manufacturing Enterprise Solutions Association Manufacturing Enterprise Solutions Association (MESA) (INTERNATIONAL, 1997) e no modelo de hierarquia de equipamento da norma IEC 61512-1 (ANSI/ISA- 88,01-1995) (ANSI, 1995). Atualmente, cinco partes da norma estão disponíveis: (1) ANSI/ISA-95.00.01-2010, Enterprise-Control System Integration, Part 1: Models and Terminology, (2) ANSI/ISA-95.00.02-2010, Part 2: Object Model Attributes, (3) ANSI/ISA-95.00.03-2013, Part 3: Activity Models of Manufacturing Operations Management, (4) ANSI/ISA-95.00.04-2012, Part 4: Object and Attributes of Manufacturing Operations Management Integration e (5) ANSI/ISA-95.00.05-2013, Part 5: Business-to-Manufacturing Transactions. A Parte 6 (ISA Draft 95.00.06, Part 6: Manufacturing Operations Management Transactions) ainda está em elaboração.

A ISA95 partes 1 e 2 focam nas interfaces de produção-para-negócios com base em quatro modelos: (1) modelo de hierarquia funcional, (2) modelo de hierarquia de equipamentos, (3) modelo funcional de fluxo de dados e (4) modelo de objetos. O modelo de hierarquia funcional fornece uma estrutura para as atividades de uma empresa de manufatura. A ISA95 identifica e estabelece um modelo de atividades e fluxos de dados das informações, denominado de diagrama de hierarquia funcional (Figura 12, adaptado de (ANSI, 2005)).

Figura 12 - Diagrama de hierarquia funcional.

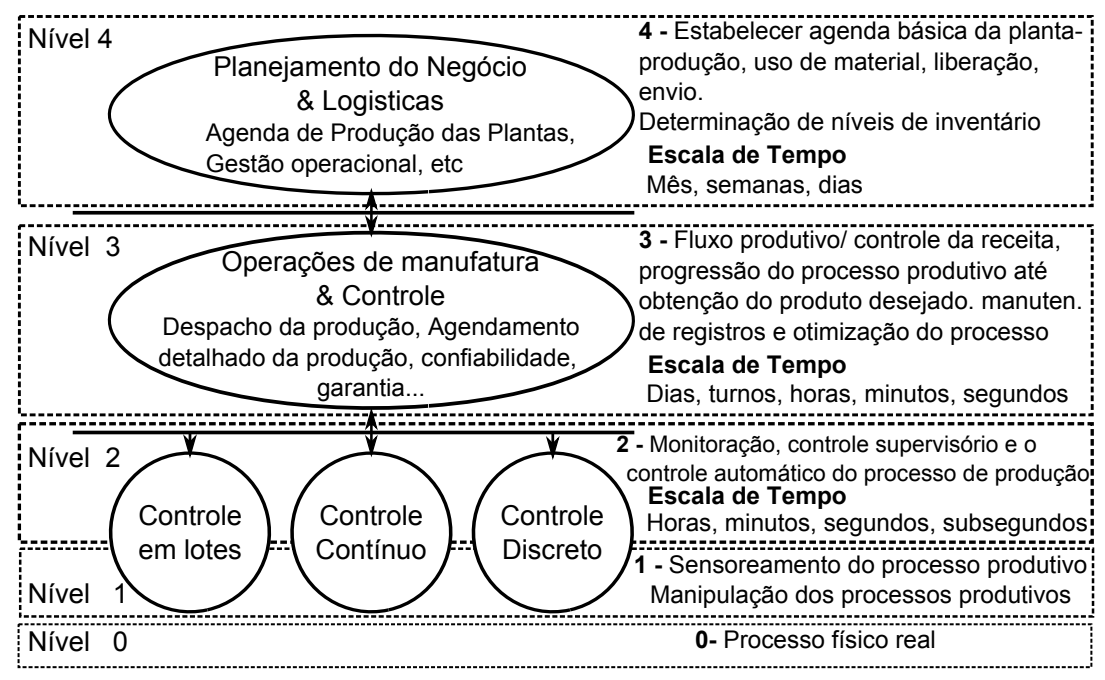

Fonte: (ANSI, 2005)

Basicamente, o diagrama de hierarquia funcional (Figura 12) identifica os seguintes níveis 
(NAKAMOTO, 2008):

- Nível 0: Corresponde às funções relacionadas com o processo físico real;

- Nível 1: Corresponde às funções relacionadas com as atividades envolvidas na coleta de sinais e manipulação dos processos físicos, operando tipicamente dentro da escala de tempo em segundos ou menos;

- Nível 2: Corresponde às funções relacionadas com as atividades de monitoração e controle local dos processos físicos, operando dentro da escala de tempo da ordem de minutos, segundos ou suas divisões. O nível 2 tipicamente trata de um equipamento dentro de um centro de trabalho, conforme a hierarquia proposta pela ISA95;

- Nível 3: Corresponde às funções relacionadas com as atividades que realizam a progressão dos processos para gerar os produtos finais. Inclui as atividades de manutenção de registros e coordenação dos processos. O nível 3 opera tipicamente dentro da escala de tempo de dias, turnos, horas, minutos e segundos, sobre áreas de centros de trabalho;

- Nível 4: Corresponde às funções relacionadas com as atividades do negócio necessárias para manter o sistema de manufatura. Entre as atividades relacionadas com a manufatura estão os estabelecimentos do planejamento da produção, determinação de níveis de inventário e garantia de que os materiais são liberados em tempo e no lugar certo para produção. O nível 4 opera tipicamente dentro da escala de tempo de mês, semanas e dias;

Cada nível envolve funções especializadas e com tempos de resposta característicos. A ISA95 partes 1 e 2 descrevem os modelos de objetos e atributos de objetos das informações que são compartilhadas entre os níveis 3 e 4 (Figura 12). Seus modelos de objeto são representados usando a notação UML (Unified Modeling Language). A parte 3 define os modelos de atividades do gerenciamento das operações de manufatura que possibilitam que o sistema da empresa controle o sistema de integração. O escopo da ISA95 parte 3 é limitado: a) ao modelo das atividades associadas ao gerenciamento de operações de manufatura, funções do nível 3 (Figura 12), e b) à identificação de alguns dos dados trocados entre as atividades de nível 3 (Figura 12). A parte 4 da ISA95 define as interfaces entre as atividades de negócios das empresas e as atividades de controle do gerenciamento das operações de manufatura, a parte 4 se limita na definição dos modelos de objetos e atributos declarados na parte 3 da norma. O foco da ISA95 parte 5 é a interface entre os sistemas de empresa/negócio e os sistemas de manufatura. Esta parte define a troca de conteúdos entre interfaces por meio da definição de transações. As transações podem ser utilizadas em relação aos objetos que são trocados entre os níveis 4 e 3 (Figura 12). 
O modelo de hierarquia de equipamento define a terminologia típica de equipamento e estrutura, onde as atividades de negócio da empresa e as relacionadas à manufatura são executadas. O modelo de hierarquia de equipamento pode ser utilizado para estruturar especificações e para padronizar interfaces de utilização. A Figura 13, adaptada de ANSI (2005), apresenta o modelo de hierarquia de equipamento.

Figura 13 - Modelo de hierarquia de equipamento.

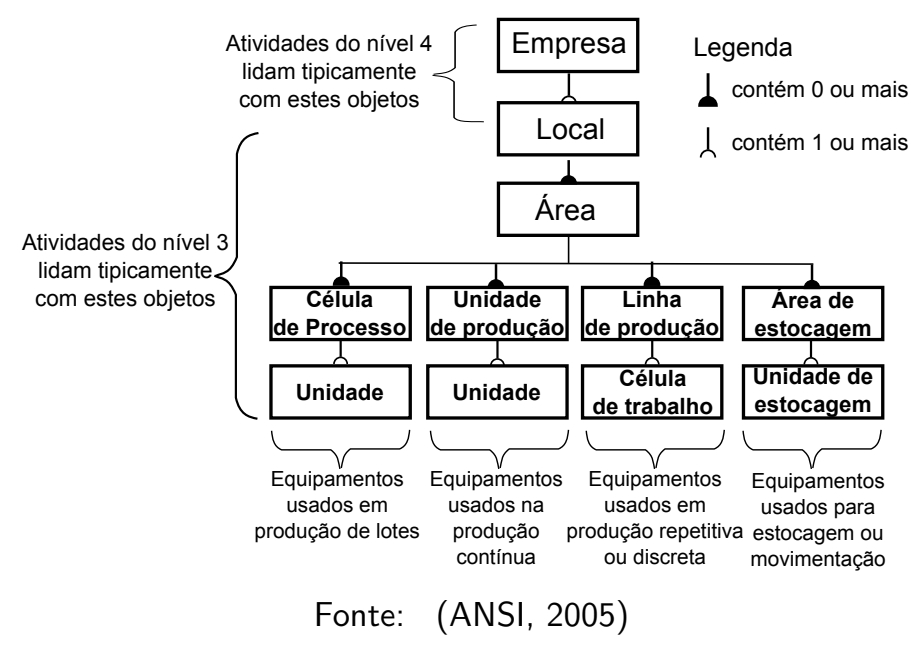

A seguir, uma breve descrição sobre cada item do modelo de hierarquia de equipamento:

- Unidade de Produção e Unidade é o menor grupo de equipamentos sequenciados pelos níveis de hierarquia funcional 4 ou 3 (Figura 12) para processo de produção contínua;

- Linha de Produção e Célula de Trabalho é o menor grupo de equipamentos sequenciados pelos níveis de hierarquia funcional 4 ou 3 (Figura 12) para processo de produção discreta;

- Célula de Processo e Unidade é o menor grupo de equipamentos sequenciados pelos níveis de hierarquia funcional 4 ou 3 (Figura 12) para processo de produção em lote;

- Área é um agrupamento físico, geográfico, ou lógico de: células de processo, unidades de produção, linhas de produção ou área de estocagem (todos determinados pelo local). A maioria das funções do nível de hierarquia funcional 3 (Figura 12) ocorrem na área;

- Local (Site) é um agrupamento físico, geográfico, ou lógico de: áreas, células de processo, unidades de produção, linhas de produção ou área de estocagem (todos determinados pelo local). Uma "planta de produção" pode ser um exemplo de local. O local geralmente é tratado pelo nível de hierarquia funcional 4 (Figura 12) relacionada ao gerenciamento e otimização local da produção. O local é utilizado frequentemente para o 
planejamento global e a programação da produção. O planejamento do local e a programação da produção podem envolver células, linhas de produção ou unidades dentro das áreas;

- Empresa é uma coleção de um ou mais locais e pode conter locais e áreas. A empresa é responsável por determinar quais produtos serão fabricados, em qual local, e geralmente como serão fabricados. A empresa normalmente é tratada pelo nível de hierarquia funcional 4 (Figura 12), entretanto, o planejamento da empresa e a programação da produção podem envolver as áreas ou células, linhas de produção ou unidades dentro das áreas.

O modelo funcional de fluxo de dados descreve as funções gerais dentro de uma empresa. O seu foco é na integração entre os sistemas de negócios e seus sistemas de controle de manufatura (Figura 14). Nesta figura foi utilizada a notação Yourdon dos diagramas de fluxo de dados (DEMARCO, 1979). A ideia é estabelecer uma terminologia comum para as funções envolvidas em trocas de informações. As funções são representadas por elipses. Uma função é um grupo de tarefas que são classificadas como tendo um objetivo em comum, onde o número entre parênteses representa o número da função. O retângulo representa uma entidade externa. Uma linha sólida com uma seta representa um agrupamento de dados definidos no modelo de integração entre empresa-controle que fluem entre as funções, armazenamentos de dados, ou entidades externas. Uma linha tracejada com uma seta representa um agrupamento de dados que não são pertinentes ao modelo de integração entre empresa-controle e que fluem entre as funções, armazenamentos de dados, ou entidades externas. Este fluxo é representado para ilustrar o contexto das funções.

A ISA95 definiu que as funções gerais da empresa são relacionadas às atividades realizadas na empresa. Um dos focos da ISA95 é referente às atividades dos sistemas de controle de manufatura. Nesses sistemas são tratadas as atividades de gestão de operação de fabricação, ou seja, atividades que estão relacionadas à coordenação de: pessoal, equipamentos, materiais e energia, e inventário de matérias-primas e/ou peças de produtos. Estas atividades foram divididas em quatro categorias: (1) gerenciamento de operações de produção; (2) gerenciamento de operações de manutenção; (3) gerenciamento de operações de qualidade, e (4) gerenciamento de operações de inventário. A Figura 14 representa o modelo funcional de fluxo de dados com a subdivisão das quatro categorias do gerenciamento de operações da manufatura. O gerenciamento de operações da manufatura são as atividades do nível 3 (Figura 12) de uma fábrica que são relacionadas à coordenação de: pessoas, equipamentos e material referentes à transformação de matéria-prima e/ou partes em produtos finais. 
Figura 14 - Modelo funcional de fluxo de dados.

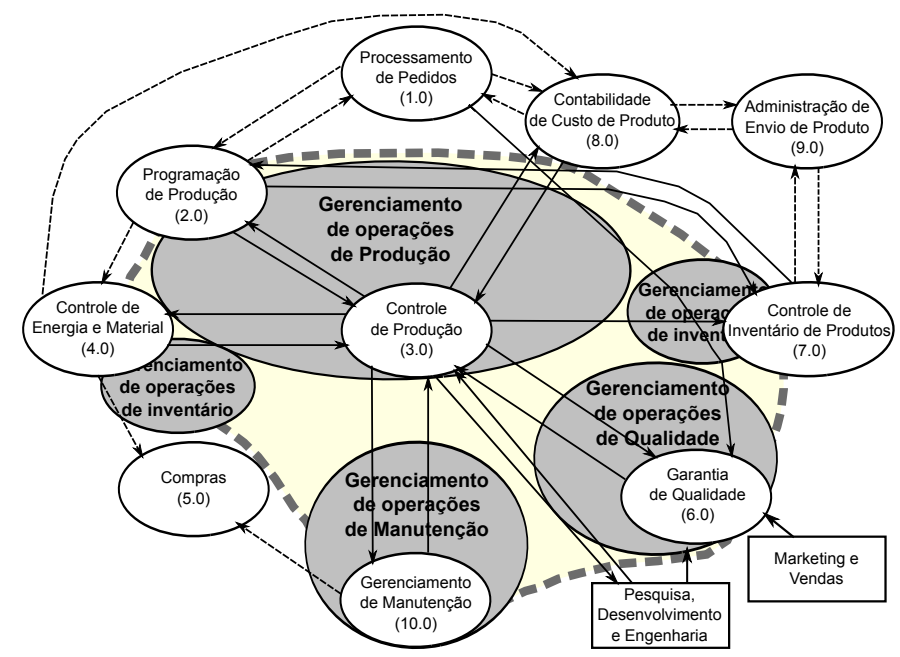

Fonte: (ANSI, 2005)

O modelo de objetos apresenta as informações que são compartilhadas entre a empresa e o sistema de controle de manufatura. É utilizado a notação UML em sua representação. Como exemplo, a Figura 15 apresenta o modelo de objeto referente à capacidade da produção.

Figura 15 - Modelo de objetos referente à capacidade da produção.

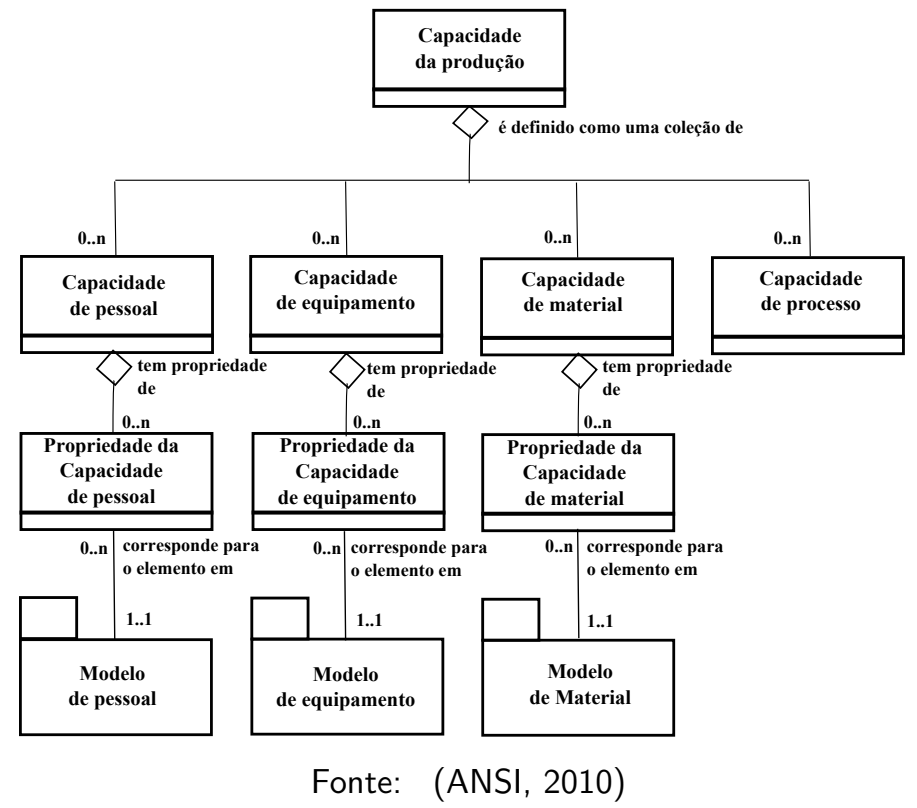

\subsubsection{Trabalhos correlatos sobre a ISA95}

Foram identificados alguns trabalhos acadêmicos relacionados com a ISA95, entretanto em pesquisas na base de dados Scopus e do Web of Science, não foi encontrado nenhum trabalho que utilizou a ISA95 num contexto de EV.

Em Amaral-Filho (2005), a partir da ISA95, foram estabelecidos procedimentos para a de- 
finição do escopo funcional do sistema de controle de sistemas produtivos integrado à gestão da organização. Estes procedimentos estabelecem os domínios semânticos dos subsistemas necessários para o desempenho das funções. Parte-se da coleta dos requisitos de cada subsistema produtivo, gerados por uma versão modificada do caso de uso da UML, e convertidos para modelos em Enhanced Mark Flow Graph (E-MFG) com comunicadores (MATSUSAKI, 2004).

No trabalho de Nakamoto (2008) foi proposto um sistema de controle modular para Sistemas Produtivos Flexíveis (SPFs). O sistema atende os requisitos de fluxo de informações envolvendo hierarquia e colaboração simultânea entre os módulos de controle de SPF, respeitando a diversidade semântica. Nakamoto adequou a sua proposta de acordo com a ISA95, pois a mesma estabelece uma divisão conceitual das funções de controle dos SPFs. O sistema proposto, além de respeitar a ISA95, foi concebido para atender as necessidades de flexibilidade requerida.

No trabalho de Ugarte, Artiba e Pellerin (2009) foi destacada a importância da ISA95 na identificação da necessidade de integração de diferentes partes de um sistema de Manufacturing Execution System (MES) com os sistemas de outras áreas da empresa. A norma ISA95 formalizou estes tipos de integração.

No trabalho de Guerrero, Vasquez e Teodorescu (2009) os níveis da hierarquia funcional da ISA95 foram adaptados para serem utilizados na integração de sistemas de distribuição de energia e sistemas de estocagem de energia. Nesse trabalho utilizou-se apenas as ideias dos níveis (Figura 12), os quais foram adaptados para a sua necessidade, criando-se três níveis de controle: nível 3 (controle terciário), nível 2 (controle secundário), nível 1 (controle primário), e o nível 0 (malhas de controle interno). Após esta adaptação os autores propuseram as regras de controle e de integração dos níveis.

Em Zhang et al. (2011) foi utilizada a ISA95 em conjunto com a business-to-manufacturing markup language (B2MML) para estabelecer o modelo de informação e os esquemas para uma plataforma de gerenciamento de work in progress (WIP) em ambientes de manufatura. Esta plataforma é baseada em objetos inteligentes, como identificação por rádio frequência/dispositivos de detecção automatizados e tecnologias de web service.

Do ponto de vista de teoria de sistemas, as EVs podem ser tratadas como sistemas dinâmicos a eventos discretos (SDED). Nos sistemas SDED a evolução dos estados ocorre de forma assíncrona com base na ocorrência de eventos que causam uma transição abrupta de estados. Desta forma, os valores das variáveis são modificados instantaneamente de acordo com a ocorrência de eventos e permanecem constantes entre as ocorrências dos mesmos (MIYAGI, 1996: CARDOSO; VALETTE, 1997; CASSANDRAS; LAFORTUNE, 2007). O tratamento das EVs como SDED possibilita a utilização da RdP para a modelagem do sistema de manufatura. 


\subsection{REDE DE PETRI}

A Rede de Petri (RdP) é uma técnica de modelagem gráfica e matemática desenvolvida por Carl Adam Petri em sua tese de doutorado "Kommunikation mit Automaten" pela Universidade de Darmstadt, na antiga Alemanha Ocidental em 1962 (BRAUER; REISIG, 2006). Desde então ela tem sido utilizada para a modelagem e análise de sistemas concorrentes, assíncronos, distribuídos e paralelos (MURATA, 1989; CARDOSO; VALETTE, 1997; JUNQUEIRA, 2006). A RdP também tem sido usada na modelagem e análise de diferentes tipos de aplicações tais como: protocolos distribuídos (KANESHIRO et al., 2008), aplicações industriais (ZURAWSKI; ZHOU, 1994), tratamento de falhas (MORALES; MELO; MIYAGI, 2007), fluxo de processos (KIEPUSZEWSKI; HOFSTED; AALST, 2003), controle supervisório (MELO; MORALES; MIYAGI, 2008; LEE; ZHOU; HSU, 2005), entre outras. A RdP é de compreensão relativamente fácil e simples devido à sua representação gráfica, se comparada a outras técnicas.

A RdP é um grafo composto de "lugares" representados por círculos, "transições" representadas por barras, "arcos orientados" interligando os componentes anteriores e "marcas" que são utilizadas para definir o estado de uma RdP. A RdP é considerada como grafo direcionado e bipartido (Figura 16), pois existe a restrição de que os "arcos" só interligam elementos de natureza diferente (PETERSON, 1981; MURATA, 1989; SRINIVASAN; VENKATASUBRAMANIAI, 1998).

Figura 16 - Representação de uma Rede de Petri.

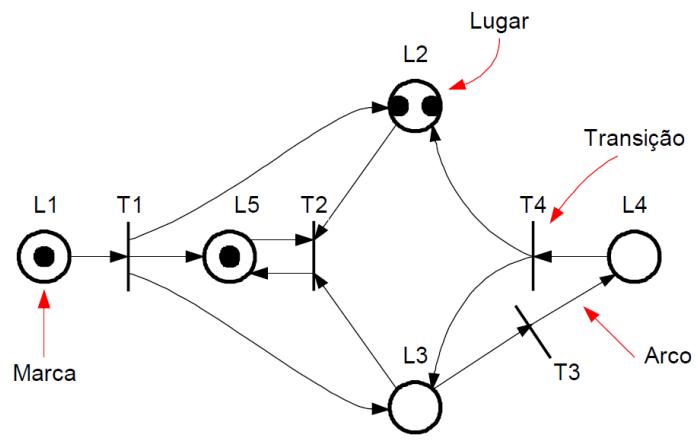

Fonte: (PETERSON, 1981)

A RdP, como uma ferramenta gráfica e matemática, provê um ambiente uniforme para modelagem, análise formal e projeto de sistemas a eventos discretos (SEDs) (ADAM; ATLURI; HUANG, 1998; ZURAWSKI; ZHOU, 1994). Ela é muito efetiva como técnica de descrição e especificação de processos (MORALES; MELO; MIYAGI, 2007; YOO; JEONG; CHO, 2010; HAMADI; BENATALLAH, 2003), podendo prover um meio de comunicação entre os usuários dos projetos, como por exemplo, entre o engenheiro de requisitos e o cliente. 
A RdP é uma representação que pode ser usada tanto no nível conceitual quanto no nível funcional, em que o sistema ou processo podem ser analisados e validados antes de prosseguir com o projeto detalhado e a implementação (ADAM; ATLURI; HUANG, 1998). A RdP pode ser usada para modelar propriedades de sistemas como sincronização de processos, eventos assíncronos, operações concorrentes, conflitos ou compartilhamento de recursos, etc (ADAM; ATLURI; HUANG, 1998; ZURAWSKI; ZHOU, 1994). Possui a vantagem de um mesmo modelo poder ser usado para análise das propriedades comportamentais e para avaliação de desempenho, assim como desenvolvimento sistemático de simuladores e controladores (ZURAWSKI; ZHOU, 1994).

Matematicamente, a RdP pode ser descrita como um conjunto de equações algébricas lineares. Desta forma, pode ser usada para a verificação formal de relações de precedência entre eventos, operações concorrentes, sincronização de processos, inexistência de deadlock, atividades repetitivas e exclusão mútua de recursos compartilhados (MELO, 2011; ZURAWSKI; ZHOU, 1994).

\subsubsection{Formalização}

RdP condição-evento

A RdP proposta inicialmente é chamada de rede de Petri condição-evento ( $C / E$ net) e, matematicamente, é descrita como uma 4-tupla

$P N_{C E}=\left(P, T, F_{C E}, M_{C E}\right)$

em que:

$P$ é o conjunto de elementos passivos chamados de "lugares",

$T$ é o conjunto de elementos ativos chamados de "transições",

$F_{C E}$ é o conjunto de relacionamentos entre os elementos passivos e os elementos ativos chamados de "arcos orientados" e

$M_{C E}$ é um vetor de números binários em que cada elemento $m_{i}$ indica o número de "marcas" no "lugar" $p_{i}$, isto é $m_{i}=M_{C E}\left(p_{i}\right)$ e, $\forall p \in P, M_{C E}(p) \in(0,1)$.

Ainda,

$P$ e $T$ são conjuntos finitos, não nulos $(P \cup T \neq \varnothing)$ e disjuntos $(P \cap T=\varnothing)$,

$F_{C E} \subseteq(P \times T) \cup(T \times P) \mathrm{e}$

os estados do sistema ou processo e sua evolução são representados pela distribuição das "marcas" nos "lugares" da rede. A dinâmica da RdP depende de seus elementos ativos, isto é, das "transições", e de como as "marcas" estão distribuídas entre os elementos passivos, os "lugares" da rede. Pode-se assim adotar a ideia de que as "marcas" fluem pela rede direcionadas 
pelos "arcos orientados", isto é, fluem de um "lugar" para uma "transição" ou de uma "transição" para um "lugar".

Para que uma "marca" flua de um "lugar" $p \in P$ para uma "transição" $t \in T$ por um "arco orientado" $f \in F_{C E}$, esse "lugar" deve possuir uma "marca", ou seja, $M_{C E}(p)=1$. Esse "lugar"

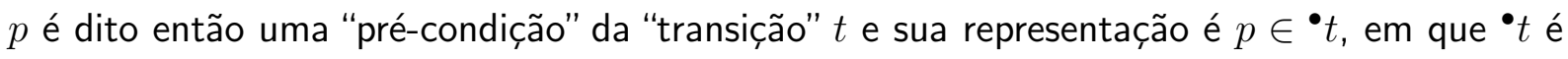
o conjunto de "pré-condições" da "transição" $t$.

Para que uma "marca" flua de uma "transição" $t \in T$ para um "lugar" $p \in P$ por um "arco orientado" $f \in F_{C E}$, esse "lugar" não deve possuir "marcas", ou seja, $M_{C E}(p)=0$. Esse "lugar" $p$ é dito então uma "pós-condição" da "transição" $t$ e sua representação é $p \in t^{\bullet}$, em que $t^{\bullet}$ é o conjunto de "pós-condições" da "transição" $t$.

Quando uma "transição" possui todas as suas "pré-condições" e "pós-condições" atendidas essa "transição" é dita "habilitada" para o "disparo". Uma "transição" "habilitada" para o "disparo" pode realizar o fluxo de "marcas" e, caso esse ocorra (num certo instante denominado passo), todo "lugar" $p_{i}$ tal que $p_{i} \in{ }^{\bullet} t$ tem sua "marcação" alterada entre o passo $k$ e o passo $k+1$ da seguinte maneira $M_{C E_{k+1}}\left(p_{i}\right)=0$, e todo "lugar" $p_{j}$ tal que $p_{j} \in t^{\bullet}$ tem sua "marcação" alterada entre o passo $k$ e o passo $k+1$ da seguinte maneira $M_{C E_{k+1}}\left(p_{j}\right)=1$.

RdP lugar-transição

A RdP lugar-transição é matematicamente descrita como uma 5-tupla

$P N=(P, T, F, M, C)$

em que:

$P$ é o conjunto de elementos passivos chamados de "lugares",

$T$ é o conjunto de elementos ativos chamados de "transições",

$F$ é o conjunto de relacionamentos entre os elementos passivos e os elementos ativos chamados de "arcos orientados" e,

$M$ é um vetor de recursos chamado de "marcação", ou seja, um vetor de números naturais em que cada elemento $m_{i}$ indica o número de "marcas" no "lugar" $p_{i}$, isto é, $m_{i}=M\left(p_{i}\right)$ e, $\forall p \in P, M(p) \in \mathbb{N}$.

$C$ é um vetor de "marcações" que define a quantidade máxima de "marcas" que cada "lugar" pode possuir, chamado de "capacidade", ou seja, $M\left(p_{i}\right) \leq C\left(p_{i}\right), \forall p_{i} \in P$, e ainda,

$P$ e $T$ são conjuntos finitos, não nulos $(P \cup T \neq \varnothing)$ e disjuntos $(P \cap T=\varnothing)$, $F \subseteq(P \times T) \cup(T \times P)$.

Para que uma "transição" "dispare", ela deve estar em uma condição de "habilitada" para o "disparo", ou seja, todas as suas "pré-condições" e "pós-condições atendidas". Uma "transição" "habilitada" para o "disparo" é uma "transição" $t \in T$ em que $\forall p \in \bullet t \mid M(p)>0$ (possui as 
"pré-condições" atendidas) e $\forall p \in t^{\bullet} \mid M(p)<M(p)$ (possui as "pós-condições atendidas").

\subsubsection{Características dos SEDs}

O comportamento dinâmico de SEDs pode ser entendido pela evolução de seus processos que possuem características específicas. Estes processos por sua vez são compostos por um conjunto de atividades. Algumas das características mais importantes dos processos em SEDs são:

\section{Sequência}

A sequência é a característica mais frequente em processos e indica uma ordem de realização das atividades envolvidas, isto é, qual processo ou conjunto de atividades deve ser concluído para que outro seja iniciado.

Em RdP, atividades são representadas por "transições". Assim, a relação de sequência de duas atividades $t_{1}$ e $t_{2}$, pode ser representada adicionando-se um "lugar" $p_{1}$ e "arcos orientados" de modo que $p_{1} \in t_{2}$ e $p_{1} \in t_{1}^{\bullet}$. Assim, para que a "transição" $t_{2}$ seja "habilitada", é necessário que a "transição" $t_{1}$ tenha em algum momento anterior sido "disparada". A Figura 17 mostra duas atividades numa relação de sequência.

Figura 17 - Representação em RdP de dois processos em sequência.

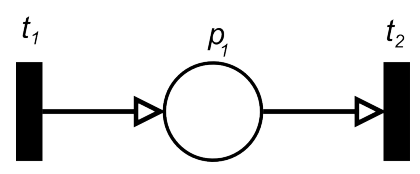

Paralelismo

O paralelismo é uma característica de processos que podem ser executados ao mesmo tempo sem que haja interferência da execução de um em outro, mas ambas com a mesma origem, isto é, uma única condição ("estado") inicial.

Em RdP, o paralelismo de duas atividades pode ser modelado por duas "transições" $t_{2}$ e $t_{3}$ e dois "lugares" $p_{1}$ e $p_{2}$ e "arcos orientados" de modo que $p_{1} \in t^{\bullet}, p_{2} \in t_{3}$. Para representar a mesma condição inicial, adiciona-se mais uma "transição" $t_{1}$ e "arcos orientados" para que, $p_{1} \in t_{1}^{\bullet}$ e $p_{2} \in t_{1}^{\bullet}$. Assim, quando ocorre o "disparo" da "transição" $t_{1}$, tanto a "transição" $t_{2}$ quanto a "transição" $t_{3}$ ficam "habilitadas", mas o "disparo" de um independe da outra. A Figura 18 mostra um paralelismo de duas atividades. 
Figura 18 - Representação do paralelismo em RdP de duas atividades com a mesma condição inicial.

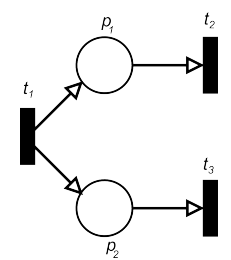

\section{Sincronização}

A sincronização é uma característica de sistemas em que um processo depende da execução de outros processos. Em geral, a sincronização é feita entre atividades em paralelo, mas também pode ocorrer entre duas atividades com origens totalmente independentes.

Em RdP, a sincronização de duas atividades pode ser modelada por três "transições" $t_{1}, t_{2}$ e $t_{3}$ e dois "lugares" $p_{1}$ e $p_{2}$ e "arcos orientados" de modo que $p_{1} \in t^{\bullet}, p_{2} \in \bullet t_{3}, p_{1} \in t_{1}^{\bullet}$ e $p_{2} \in t_{2}^{\bullet}$. Assim, é necessário que tanto a "transição" $t_{1}$ como a "transição" $t_{2}$ sejam anteriormente "disparadas" para que a "transição" $t_{3}$ seja "habilitada". A Figura 19 mostra uma sincronização de duas atividades.

Figura 19 - Representação em RdP da sincronização de duas atividades.

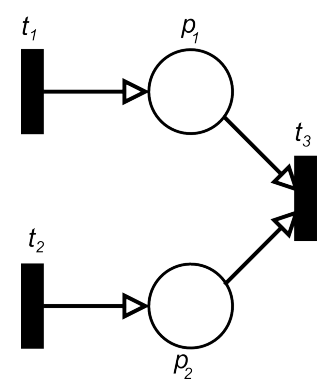

\section{Conflito}

O conflito é uma característica de processo associada à escolha. Quando os processos estão em conflito, significa que apenas um deles pode ser executado e a execução de um desses processos inibe a execução dos outros processos que estavam em conflito.

Em RdP, o conflito de duas atividades pode ser modelada por três "transições" $t_{1}, t_{2}$ e $t_{3}$ e um "lugar" $p_{1}$ em que $p_{1} \in t_{2}, p_{1} \in t_{3}$ e $p_{1} \in t_{1}^{\bullet}$. Assim, após o "disparo" da "transição" $t_{1}$, tanto a "transição" $t_{2}$ quanto a "transição" $t_{3}$ ficam "habilitadas", mas apenas uma delas poderá ser "disparada". A Figura 20 ilustra este caso. 
Figura 20 - Representação em RdP do conflito entre duas atividades.

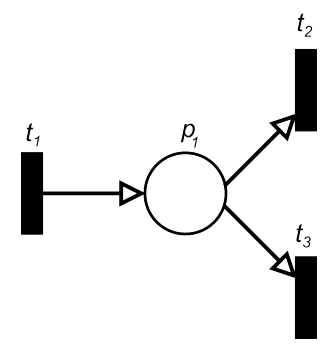

Compartilhamento de recursos

O compartilhamento de recursos é uma característica de processos com origens diferentes que dependem de um mesmo recurso para serem executados. Um recurso pode ser um equipamento usado em diferentes processos em um sistema produtivo, uma informação na memória de um sistema operacional, uma linha de transmissão em um sistema de comunicação, uma máquina ou ferramenta usada em sistemas de manufatura, entre outros das diferentes áreas de SEDs.

Em RdP, o compartilhamento de recursos de duas atividades pode ser modelado por quatro "transições" $t_{1}, t_{2}, t_{3}$ e $t_{4}$ e três "lugares" $p_{1}, p_{2}$ e $p_{3}$ em que $p_{1} \in t_{1}, p_{1} \in \bullet t_{2}, p_{2} \in t_{3}$, $p_{3} \in t_{4}, p_{2} \in t_{1}^{\bullet}, p_{3} \in t_{2}^{\bullet}, p_{1} \in t_{3}^{\bullet}$ e $p_{1} \in t_{4}^{\bullet}$ e $M\left(p_{1}\right)=1$. Assim, tanto a sequência $t_{1}, t_{3}$ quanto a sequência $t_{2}, t_{4}$ dependem de um recurso presente em $p_{1}$, mas por ser um recurso único, apenas uma das sequências pode ocorrer de cada vez, mas após essa sequência ocorrer, o recurso volta a ficar disponível. A Figura 21 mostra um compartilhamento de recurso de duas atividades.

Figura 21 - Representação em RdP do compartilhamento de recursos entre duas atividades.

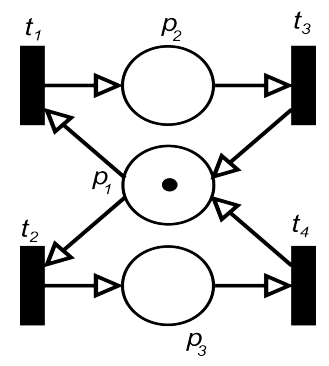

A representação de sistemas complexos (grande número de elementos e/ou interações entre estes elementos) através de RdP pode gerar um grafo cuja dimensões podem ser de difícil manipulação, entendimento e análise. Como consequência, muitos usuários de RdP desenvolveram extensões para suprir suas necessidades, incluindo atributos, relações de tempo e eventos estocásticos, porém mantendo a simplicidade conceitual do grafo (JENSEN, 1981; JENSEN; KRISTENSEN; WELLS, 2007; GUSTAVSON; TOERN, 1995; MOORE; CHIANG, 2000). 


\subsubsection{Metodologia PFS/RdP (Production Flow Schema/Rede de Petri)}

Entre as abordagens derivadas da rede de Petri, destaca-se o PFS/RdP (Production Flow Schema/Rede de Petri), apresentado em Miyagi (1996) para sistematizar a modelagem de SEDs segundo uma abordagem hierárquica, com base em refinamentos sucessivos para construir o modelo detalhado de forma progressiva e estruturada onde as propriedades do sistema modelado ficam asseguradas por construção. Inicialmente, o modelo conceitual do sistema (representando um alto nível de abstração do sistema sem detalhamento de sua dinâmica) é desenvolvido com PFS. Nesta etapa o propósito é modelar as principais características das funções que são consideradas no sistema. A ênfase está na identificação dos componentes ativos e passivos do sistema, assim como do fluxo de itens (material e/ou informação) entre elementos. O PFS é uma classe de rede canal - agente (REISIG, 1992) devidamente interpretada e constitui uma técnica para desenvolver uma descrição de um sistema a partir de uma visão conceitual, ou seja, em um alto nível de abstração sem o detalhamento do seu comportamento dinâmico. O PFS caracteriza um sistema a partir de seus elementos ativos e o fluxo de materiais e informações dentro de um processo produtivo. Um componente ativo realiza uma atividade, e um componente passivo é um distribuidor de itens. De acordo com a metodologia, os elementos do PFS são detalhados gradativamente segundo uma abordagem hierárquica. Este detalhamento pode gerar sub-grafos:

- Totalmente em PFS;

- Com alguns elementos em PFS e outros em RdP;

- Totalmente em RdP.

Para a modelagem detalhada do comportamento dinâmico do sistema, o modelo em PFS é convertido progressivamente em um modelo em RdP que descreve o funcionamento das diversas partes do sistema (até o nível desejado) (MIYAGI, 1996). Originalmente o PFS/RdP, como técnica para modelar SEDs, foi proposto para aplicação em sistemas de manufatura, e neste campo tem sido usada para tratar sua modelagem e análise com sucesso (RIASCOS; MIYAGI, 2001; MELO, 2011).

Esta abordagem baseia-se no princípio de que um sistema é composto por elementos ativos que realizam transformações sobre itens (materiais ou informações) e elementos passivos que realizam o armazenamento e a distribuição destes, existindo, portanto, uma inter-relação entre estes elementos para a descrição efetiva dos fluxos presentes no sistema. O PFS utiliza a técnica de refinamentos sucessivos por meio de uma abordagem top-down, de maneira que seja possível inserir, progressivamente, no modelo, o detalhamento na descrição dos processos 
do sistema. O objetivo é representar o fluxo de operações tendo como referência a evolução dinâmica de um determinado processo. Deve-se salientar que o PFS, distintamente da RdP, não possui o conceito de "marcação", pois é um modelo conceitual do sistema com o foco na descrição estrutural dos fluxos de itens e informações/dados no sistema. O PFS é composto pelos seguintes elementos (Figura 22):

- "Atividade": representa um componente ativo do sistema capaz de realizar transformações, isto é, ações. Graficamente, corresponde a um macro-elemento delimitado por colchetes e com inscrições em linguagem formal para especificá-lo. Cada "atividade" pode ser refinada em "sub-atividades" com as suas respectivas interações;

- "Distribuidor": representa um componente passivo, não realiza transformação, mas é capaz de armazenar e distribuir os itens. Graficamente é indicado por uma circunferência.

- "Arco orientado": representa as relações entre as "atividades" e "distribuidores". Os "arcos" indicam uma relação lógica, entre os componentes. Graficamente corresponde a uma seta.

Figura 22 - Exemplo de PFS com identificação de seus elementos construtivos.

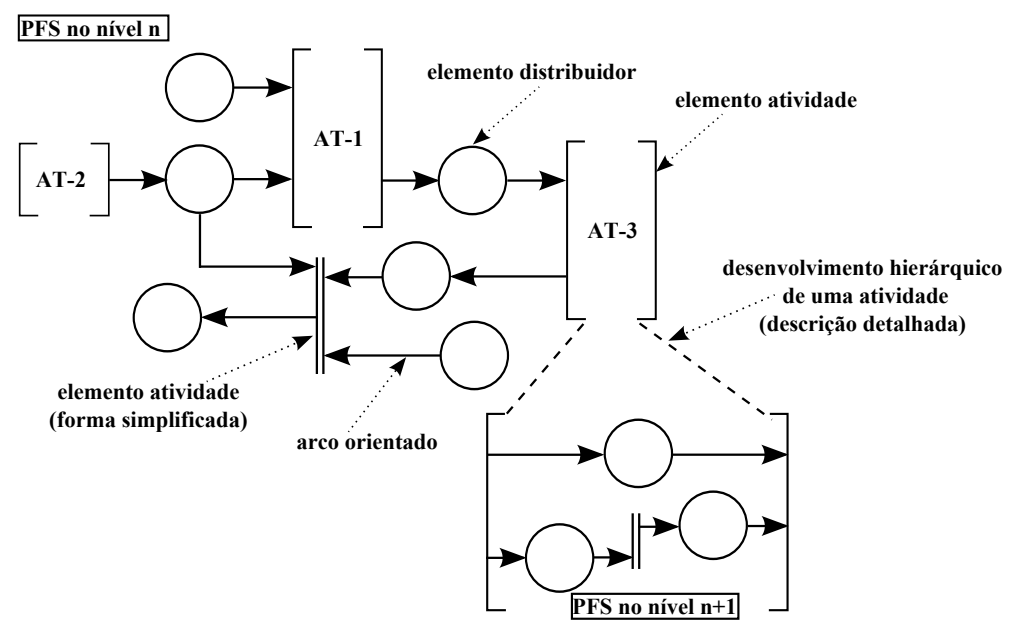

Fonte: (HASEGAWA et al., 1999)

Pela Figura 22 é possível perceber que a atividade $A T-3$ do PFS no nível $n$ foi refinada para uma descrição mais detalhada gerada pelo PFS no nível $n+1$. Uma atividade pode ser expandida em duas transições e um lugar em RdP (Figura 23). Caso seja necessário indicar o início e fim de uma atividade, é possível distinguir a transição de entrada e a transição de saída e seus respectivos pesos $(n$ e $m$ ). 
Figura 23 - Elemento Atividade do PFS e um possível detalhamento em RdP.

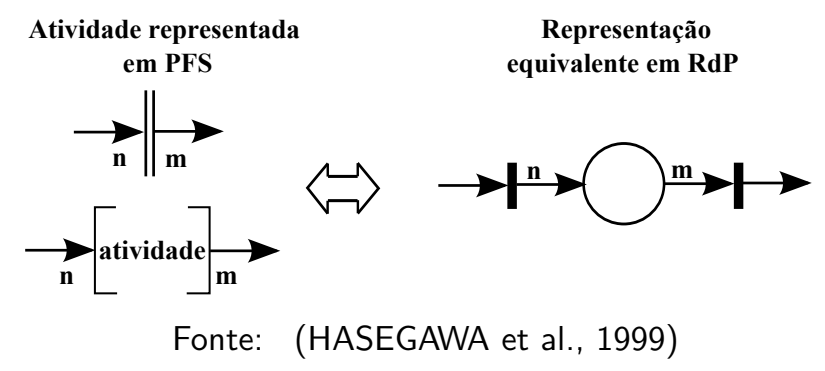

O elemento distribuidor também pode ser expandido conforme Figura 24.

Figura 24 - Elemento Distribuidor do PFS e um possível detalhamento em RdP.

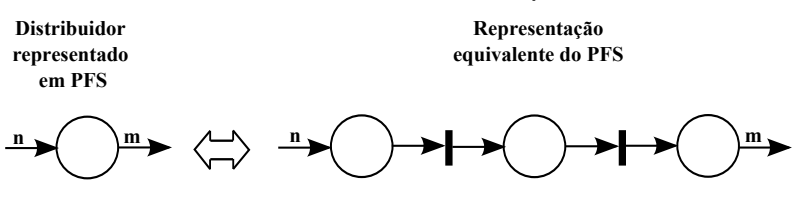

Fonte: (HASEGAWA et al., 1999)

A seguir é apresentado um exemplo da utilização do PFS e sua conversão em RdP retirado de (JUNQUEIRA, 2006). É exemplificado um sistema de movimentação de materiais composto por quatro estações de trabalho produtoras ou consumidoras de peças (Figura 25). A Estação A fornece peças para a Estação B e a Estação C fornece peças para a Estação D. Para a movimentação das peças, o sistema conta com um trilho por onde circula um transportador, o qual transporta uma peça por vez. Existem fluxos secundários de informação entre as paradas e as estações e, entre as paradas e o transportador.

Figura 25 - Representação do sistema de movimentação de materiais.

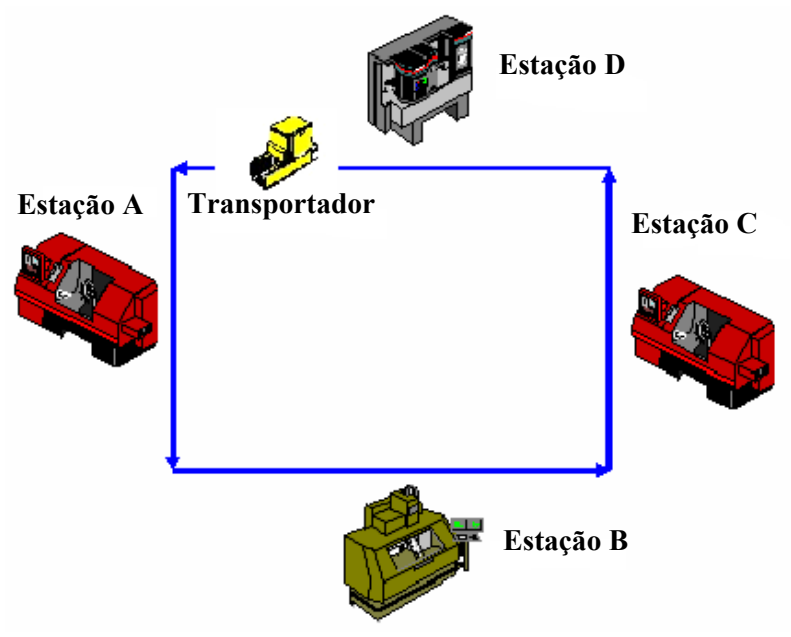

Fonte: (JUNQUEIRA, 2006)

Por simplificação, não fazem parte do exemplo a alimentação das Estações $\mathbf{A}$ e $\mathbf{C}$ e nem a remoção de peças em $\mathbf{B}$ e $\mathbf{D}$. Considera-se que nenhuma delas utiliza o transportador para 
esta finalidade (alimentação ou remoção). Cada estação possui um tempo de processamento correspondente à operação desempenhada nas peças. $\mathbf{A}$ e $\mathbf{C}$ só liberam (e $\mathbf{B}$ e $\mathbf{D}$ só aceitam) a peça assim que tiverem terminado seu processamento.

Desconsidera-se no modelo o (s) mecanismo (s) responsável (eis) por transferir as peças do transportador para as estações e vice-versa. Considera-se que o tempo necessário que tal operação seja uma característica ao transportador, ou seja, um tempo que este obrigatoriamente deve permanecer parado até que a operação de transferência seja concluída.

Com base na representação do sistema apresentada na Figura 25, utiliza-se o PFS para modelar a estrutura funcional geral do sistema. A Figura 26 apresenta o sistema da Figura 25 modelado em PFS. Neste modelo, pode-se distinguir as atividades: (1) o [transporte entre entre duas estações]; (2) [a parada na estação] (para que a peça seja carregada ou descarregada); (3) o [transportador]; e (4) [estação]. Além disso, apresentam-se os fluxos secundários de informação entre as paradas e as estações (em azul) e, entre as paradas e o transportador (em vermelho).

Figura 26 - Representação em PFS do sistema da Fig. 25 indicando o deslocamento do transportador no trilho, deslocando-se de forma circular pelas estações.

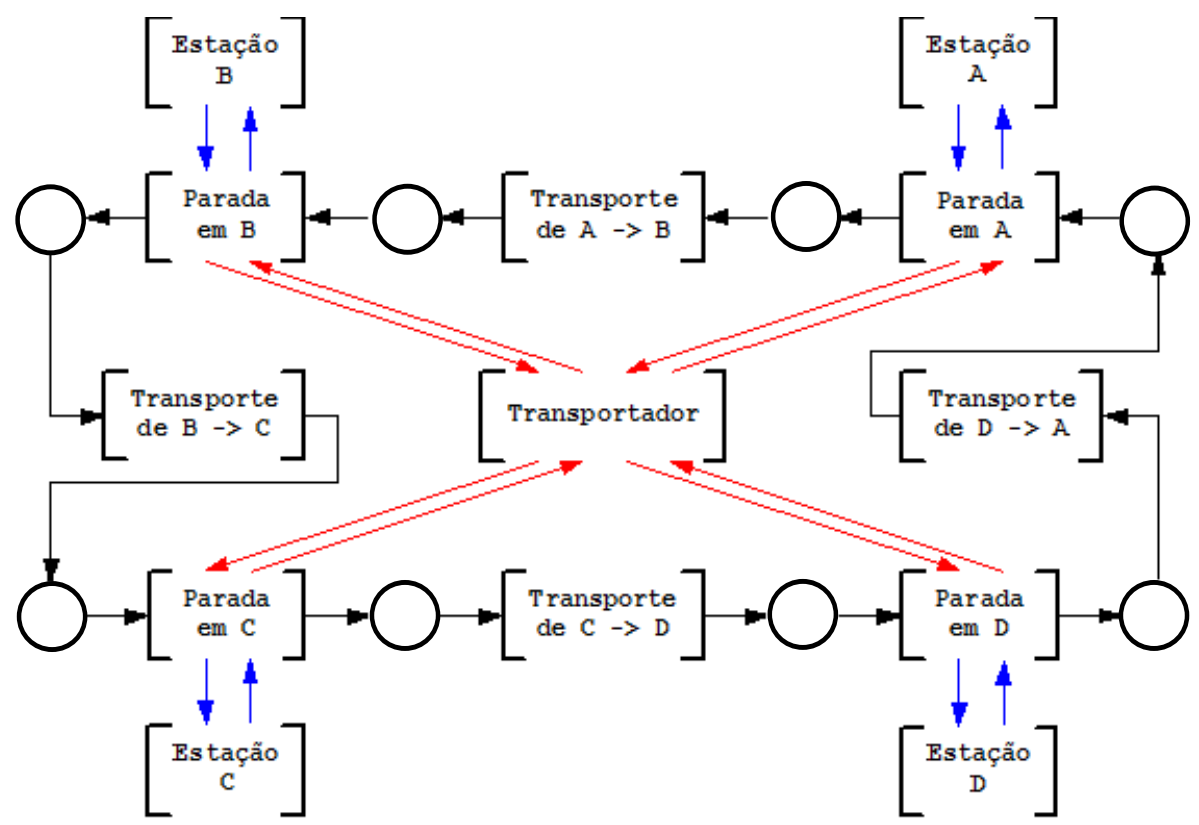

Fonte: (JUNQUEIRA, 2006)

Na Figura 27, o "lugar" L1 indica a "pré-condição" para realizar o trajeto entre a Parada X e a Parada Y. A "transição" T1 indica o tempo necessário para se sair de $\mathrm{X}$ e se chegar a $\mathrm{Y}$ e o "lugar" L2 indica a "pós-condição" desta operação. 
Figura 27 - Modelo em RdP do transporte entre duas estações.

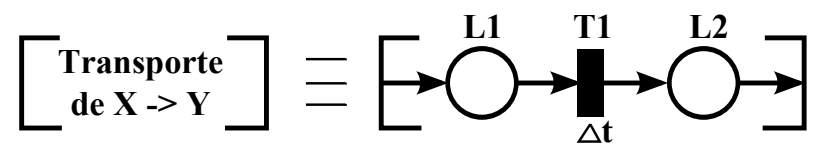

Fonte: (JUNQUEIRA, 2006)

No modelo da [Parada em Z] (Figura 28), o "lugar" L1 representa a chegada do transportador à estação. A "transição" T1 indica o início da operação de (des) carregamento da peça, enquanto T2 indica o final desta operação. O "lugar" L2 indica a manutenção do estado de (des) carregamento e L3 o final da operação de (des) carregamento.

Figura 28 - Modelo em RdP da [Parada em Z].

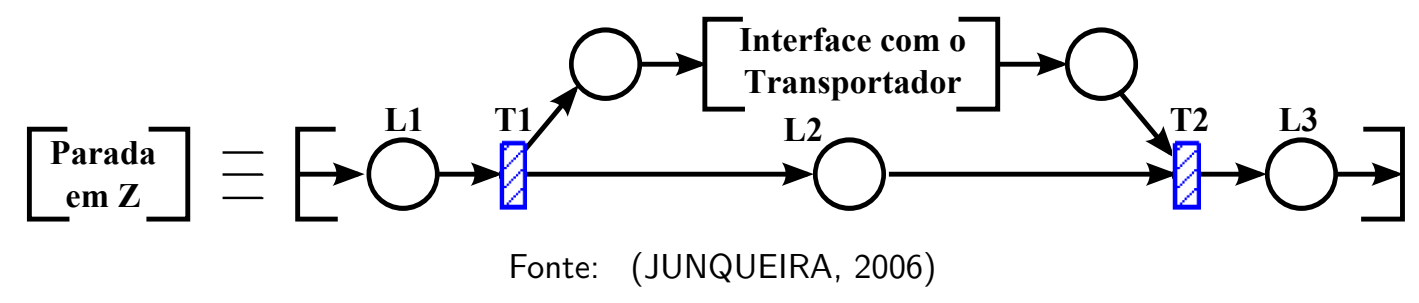

A Figura 29 detalha a atividade [Interface com o transportador]. Nela L1 indica o estado inicial de (des) carregamento, L2 a manutenção da operação de (des) carregamento e L3 o estado final da operação de (des) carregamento. A "transição" T1 representa o início do (des) carregamento e T2 é a finalização desta operação.

Figura 29 - Modelo em RdP da Interface com o Transportador.

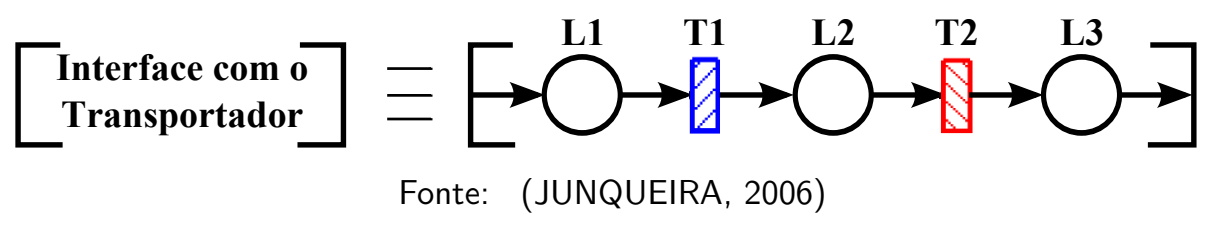

As Figuras 30 e 31 ilustram respectivamente os modelos em RdP da estação e do transportador. Na Figura 30, as "transições" T1 e T2 representam as interfaces com o modelo da [Parada em Z], que são o início e o fim do (des) carregamento, respectivamente, enquanto T3 representa o tempo envolvido na operação da [Estação]. O "lugar" L1 representa o estado de espera da estação enquanto aguarda o (des) carregamento da peça. L3 e L2, respectivamente, o estado durante a operação e o estado ao final desta. 
Figura 30 - Modelo em RdP da Estação.

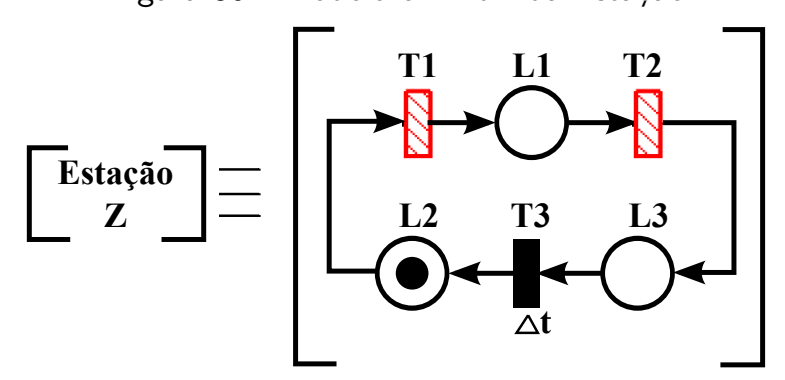

Fonte: (JUNQUEIRA, 2006)

Na Figura 31, o "lugar" L1 modela o estado quando o transportador está em movimento, enquanto L2 é o estado inicial da operação de (des) carregamento e L3 o estado de término da operação. T1 é a "transição" de interface que representa a parada do transportador e o início da operação de (des) carregamento. T3 representa o tempo de (des) carregamento e T2 é a interface associada à [Interface com o transportador] que representa a finalização da operação.

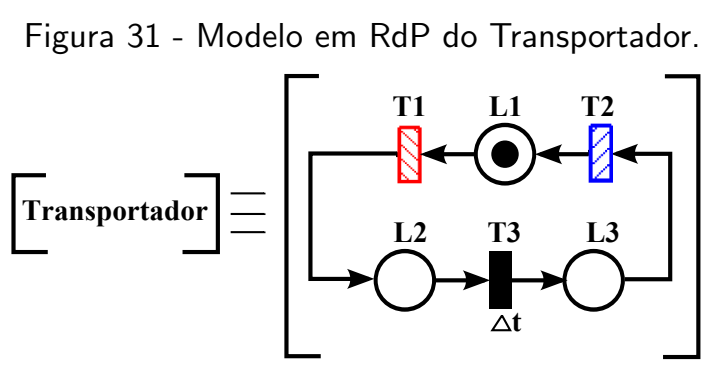

Fonte: (JUNQUEIRA, 2006)

O PFS tem sido utilizado com sucesso para a modelagem e análise de sistemas de manufatura e pode ser explorado para a descrição dos processos envolvidos na EV, isto é, o PFS pode ser usado para a modelagem das principais características da EV, em especial para a especificação e operação dos sistemas de PCP.

\subsection{SÍNTESE DO CAPÍTULO}

Neste capítulo apresentou-se a bibliografia relacionada ao escopo do trabalho que é referente a Sistemas de Planejamento e Controle da Produção e Redes Colaborativas, especificamente a rede do tipo Empresa Virtual. Foram apresentadas as ferramentas que contribuíram para o desenvolvimento da arquitetura proposta, tais como: as gerações das "janelas de tempo", a utilização da propagação de restrições, as heurísticas do tipo APS, e a norma de integração de sistemas de informação ANSI-ISA95. Apresentou-se também os conceitos básicos da Rede de Petri e de PFS que são utilizados para a análise e o controle do processo produtivo. No capítulo a seguir é apresentada a arquitetura proposta. 


\section{ARQUITETURA PROPOSTA}

Neste capítulo é apresentada a proposta de "arquitetura de sistema de planejamento e controle da produção no contexto de Empresa Virtual". Esta arquitetura é concebida para ser aplicada nas seguintes classes de EVs descritas em (CAMARINHA-MATOS; AFSARMANESH, 1999), ou seja:

- EV com duração de aliança a longo prazo;

- EV de topologia variável ou de estrutura fixa;

- EV de participação de aliança única ou de aliança múltipla;

- EV com coordenação de estrutura tipo estrela, aliança democrática ou federação;

- EV de visibilidade de único nível ou multi-nível.

O escopo desta arquitetura está na fase de "operação" do ciclo de vida da EV, ou seja, a fase em que EV já está estabelecida com: 1) seus parceiros iniciais definidos; 2) o que cada parceiro irá produzir, 3) e onde o seu processo de negócio é realizado normalmente a fim de alcançar o seu objetivo comum. São tratadas as seguintes funcionalidades:

- Compartilhamento de informações;

- Gerenciamento de pedidos e processamento de pedidos incompletos;

- Planejamento dinâmico e distribuído, sequenciamento da produção;

- Gerenciamento de tarefas distribuídas;

- Elevado nível de coordenação de tarefas.

Para atender as principais características de uma EV que são a autonomia e a colaboração das Empresas Parceiras (EPs), na arquitetura de sistema de PCP proposta, são utilizados os conceitos de janelas de tempo em conjunto com a propagação de restrições (PESSOA et al., 2012; PESSOA et al., 2013; PESSOA et al., 2014). Estes conceitos foram descritos nas subseções 2.3.3 e 2.3.4 e estão exemplificados no Apêndice A. 


\subsection{ADEQUAÇÃO DA ARQUITETURA PROPOSTA COM A ANSI/ISA-95}

Esta proposta abrange os níveis 3 e 4 da ISA95, conforme o diagrama de hierarquia funcional (Figura 13). Como o conceito de EV é posterior à norma ISA95, uma revisão da reinterpretação no modelo de hierarquia de equipamento da norma foi realizada (Figura 32a). Na reinterpretação considerada é introduzido um elemento "EV", e o elemento "Empresa" do modelo original é modificado para "Empresa Parceira" (EP) (Figura 32b). O fato da EV ser uma associação temporária entre empresas, implica que uma EV deve conter pelo menos dois parceiros (podem ser EVs ou EPs).

Figura 32 - Abstração em relação ao Modelo de hierarquia de equipamento.

(a) Modelo de hierarquia de equipamento (ISA95).

(b) Modelo de hierarquia proposto.
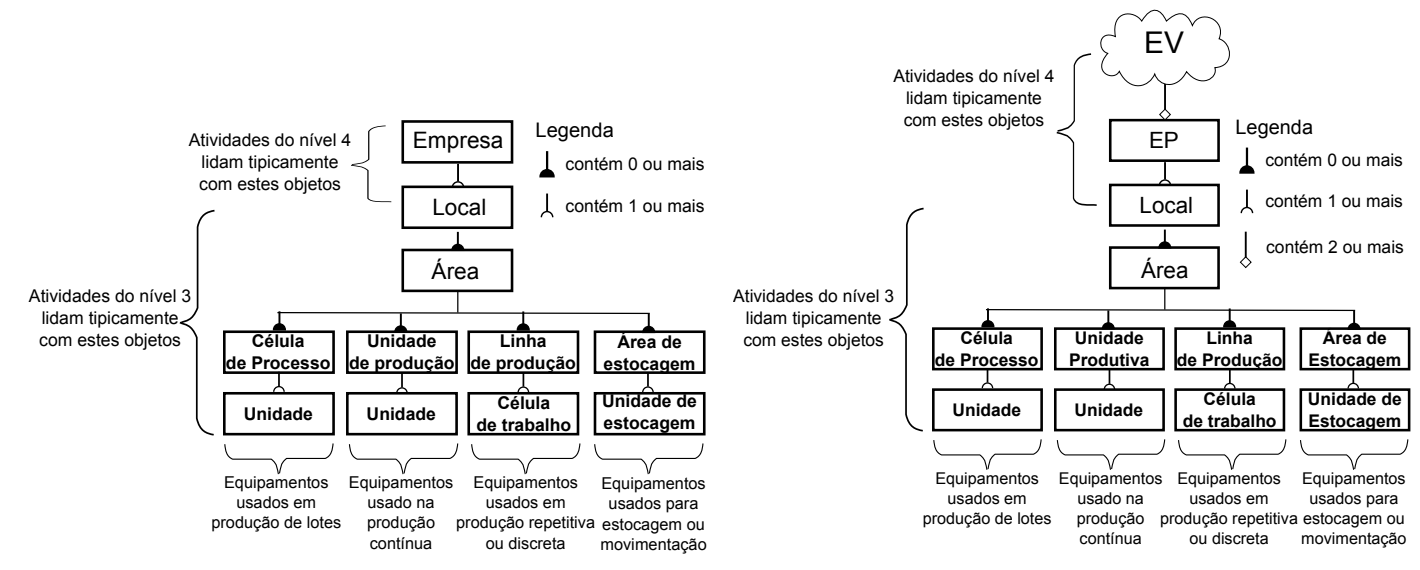

Em relação ao modelo funcional "empresa-controle" (Figura 33a), a nova arquitetura se restringe às categorias de "gerenciamento de operações da produção", e "gerenciamento de operações de inventário" (Figura 33b).

O foco deste trabalho é o PCP, desta forma, as funções utilizadas neste são (o número entre parênteses representa o número da função de acordo com a ISA95 e a Figura 33b):

- "Processamento de Pedidos" (1.0); que inclui as seguintes funções:

a) "Processamento de pedidos" do cliente, "aceitação e confirmação";

- "Programação de Produção" (2.0); onde as informações geradas ou modificadas pelas funções da programação de produção incluem:

1. A "programação da produção" propriamente dita;

2. A "produção executada" versus a "produção planejada";

3. A "capacidade de produção" e a "disponibilidade de recursos"; 
4. O estado atual da "ordem de produção".

As funções da "Programação da Produção" (2.0) interfaceiam com as funções do "Controle de Produção" (3.0) por meio do "sequenciamento de produção", "atualização da produção", e "capacidade de produção". O "sequenciamento" detalhado de uma área é definido como uma função de controle.

- "Controle de produção" (3.0); que inclui as funções:

a) "Controle" da transformação de matéria-prima em produto final de acordo com a "Programação de Produção" (2.0) e as normas de produção;

b) Avaliação de "restrições de capacidade".

As principais funções do "Controle de Produção" (3.0) incluem o "controle operacional", e o "planejamento das operações". O "controle operacional" é a coleção de funções que gerenciam toda a produção de um "Local" ou "Área". As funções incluem:

1. Controle de transformação de matérias primas em produtos finais de acordo com a programação e as especificações de produção;

2. Relatórios sobre produção, processos e recursos;

3. Balancear e otimizar a produção do "Local" ou "Área".

Estas funções podem gerar ou modificar as seguintes informações usadas em outras funções de controle: (a) status dos pedidos de produção; (b) desempenho da produção; e (c) status dos recursos. Não existe interface direta entre as funções de processamento de pedidos (1.0) e as funções de controle de produção (3.0).

O "planejamento das operações" inclui as seguintes funções:

a) A criação de um "plano de produção" de curto prazo com base na "programação de produção";

b) Verificação da "programação" em vista da "disponibilidade de matéria-prima" e "capacidade de armazenamento do produto";

c) Verificação da "programação" em vista da "disponibilidade de equipamento";

d) Modificação do "plano de produção horária" de acordo "disponibilidade de equipamento".

Estas funções podem gerar ou modificar as seguintes informações em outras funções de controle: (a) necessidades de material para atender o "plano de produção"; (b) "plano 
de produção" do "Local" ou "Área" para o "controle de operações", e (c) a capacidade disponível dos recursos de produção.

- "Controle de inventário de produtos" (7.0); que inclui as seguintes funções:

a) Gestão de inventário de produtos acabados;

b) Geração de envio de produtos finais de acordo com o cronograma de entrega;

c) Relatórios de estoques para a programação da produção.

Estas funções podem gerar ou modificar as seguintes informações em outras funções de controle: (a) estoque de produtos acabados; (b) balanços dos estoques, e (c) confirmação de envio.

Figura 33 - Funções consideradas na arquitetura proposta em relação ao Modelo funcional empresa-controle da ISA95.

(a) Modelo funcional empresa-controle da ISA95. (b) Funções consideradas pela arquitetura proposta.
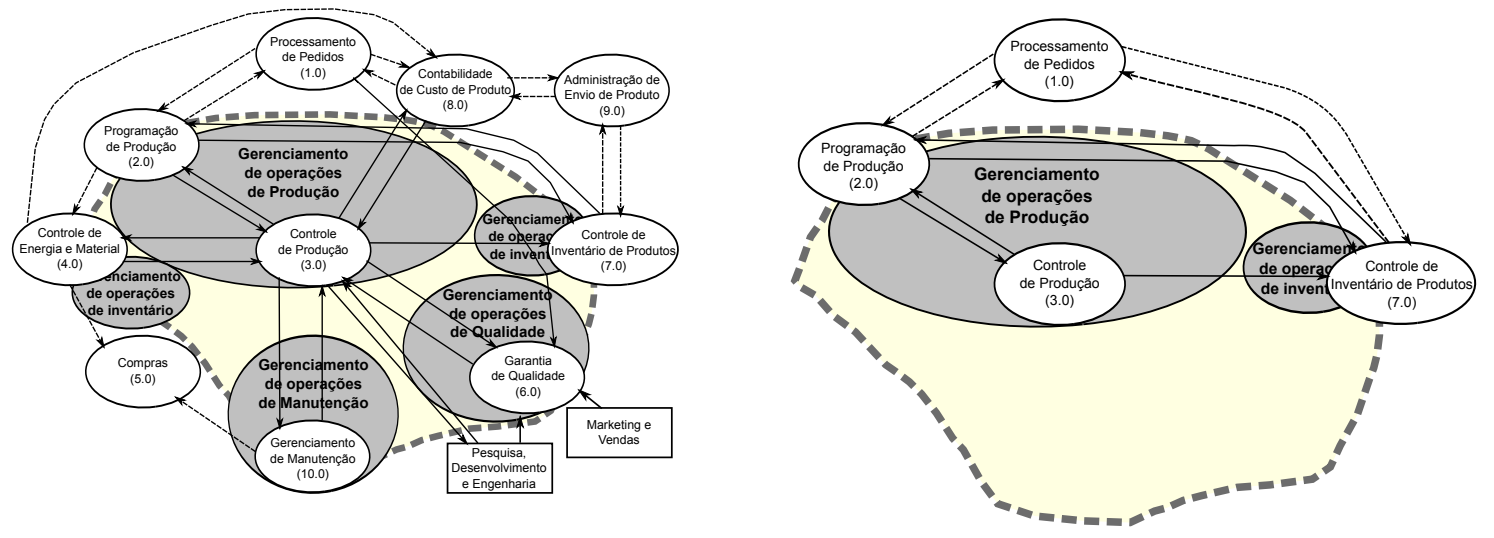

\subsection{MODELAGEM DA EV E GERAÇÃO DE SUAS JANELAS DE TEMPO}

Nesta seção é apresentada a metodologia de modelagem usando um exemplo de EV. Explicase como o PFS é gerado assim como o, seu respectivo refinamento em RdP e a geração das janelas de tempo para a EV. Neste exemplo, tem-se duas empresas $E A$ e $E B$, a empresa $E A$ produz uma peça (de manutenção) para certos equipamentos que é um cilindro com rasgo de chaveta, a $E B$ produz a chaveta para este cilindro. As Figuras 34 e 35 apresentam uma simplificação do chão de fábrica destas empresas, o cilindro é estocado em $S 12$ na $E A$ e a chaveta é estocada em $S 22$ na $E B$. As Tabelas 1 e 2 apresentam as relações entre as operações necessárias para realizar as tarefas e os recursos necessários. A lista de materiais e a lista de recursos das empresas, respectivamente, itens 3.1 .4 e 3.1 .5 da norma ANSI-ISA 95 
parte 1 são levantados. A lista de materiais apresenta as partes ou materiais que são utilizados na produção do item, e a lista de recursos apresenta os recursos que produzem o item.

Figura 34 - Simplificação do chão de fábrica e da produção de $E A$.

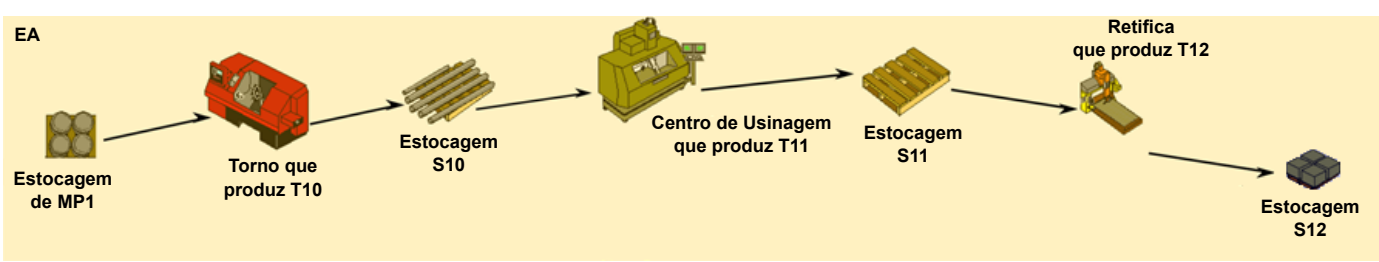

Tabela 1 - Relação das tarefas com o processo de produção e os recursos de $E A$.

\begin{tabular}{|c|c|c|}
\hline Tarefa & Processo de produção & Recurso necessário \\
\hline \multirow{2}{*}{ T10 } & Tornear diâmetro maior & \multirow{2}{*}{ Torno 1} \\
& \multicolumn{2}{|c|}{ Facear } \\
\cline { 2 - 2 } & Tornear diâmetro menor & \multicolumn{1}{|c|}{} \\
\cline { 2 - 2 } & Furar & \\
\hline & Fazer rasgo chaveta & Centro de Usinagem 2 \\
\hline T11 & Retificar diâmetro maior & Retifica 3 \\
\hline
\end{tabular}

Figura 35 - Simplificação do chão de fábrica e da produção de $E B$.

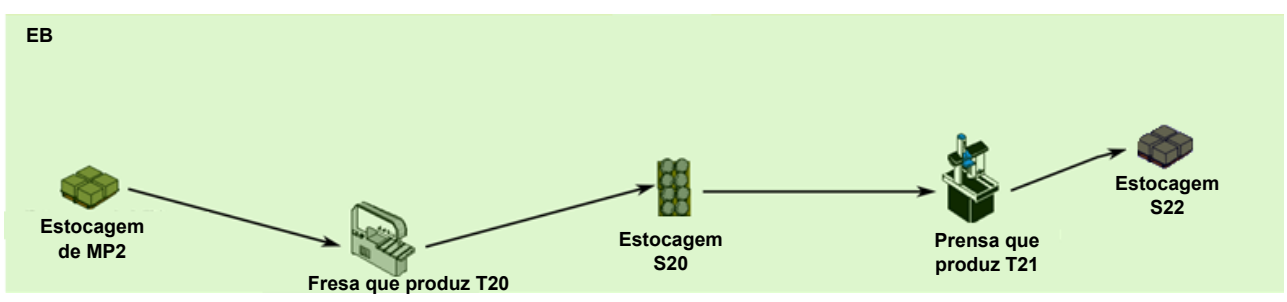

Tabela 2 - Relação das tarefas com o processo de produção e o recurso de $E B$.

\begin{tabular}{|c|c|c|}
\hline Tarefa & Processo de produção & Recurso necessário \\
\hline T20 & Fazer chaveta & Fresa 5 \\
\hline T21 & Prensar chaveta & Prensa 4 \\
\hline
\end{tabular}

Assume-se que as empresas $E A$ e $E B$ consideram que se seus dois produtos fossem vendidos em conjunto aumentariam o número de vendas e decidem com isso criar uma EV, a Figura 36 apresenta a simplificação do chão de fábrica da $E V$ onde, $E A$ é a $E P 1$ e $E B$ é a $E P 2$. Entretanto as empresas parceiras não desejam enviar informações sobre seus processos internos (chão de fábrica). Na arquitetura proposta não é necessário enviar informações sobre como as tarefas são produzidas e em que recurso especificamente são produzidas, as informações são enviadas codificadas e como uma especificação de fluxo, como exemplo, $x$ quantidades de $T 11$ são produzidas em $y$ unidades de tempo (u.t) por $R 2$, e desta forma nenhuma informação 
sobre os processos internos de cada EP é informado, pois não se sabe como $T 11$ de fato é realizada, isto é, nem como é produzida e nem que tipo de recurso é necessário.

Figura 36 - Simplificação do chão de fábrica e da produção das $E P s$ na $E V$.

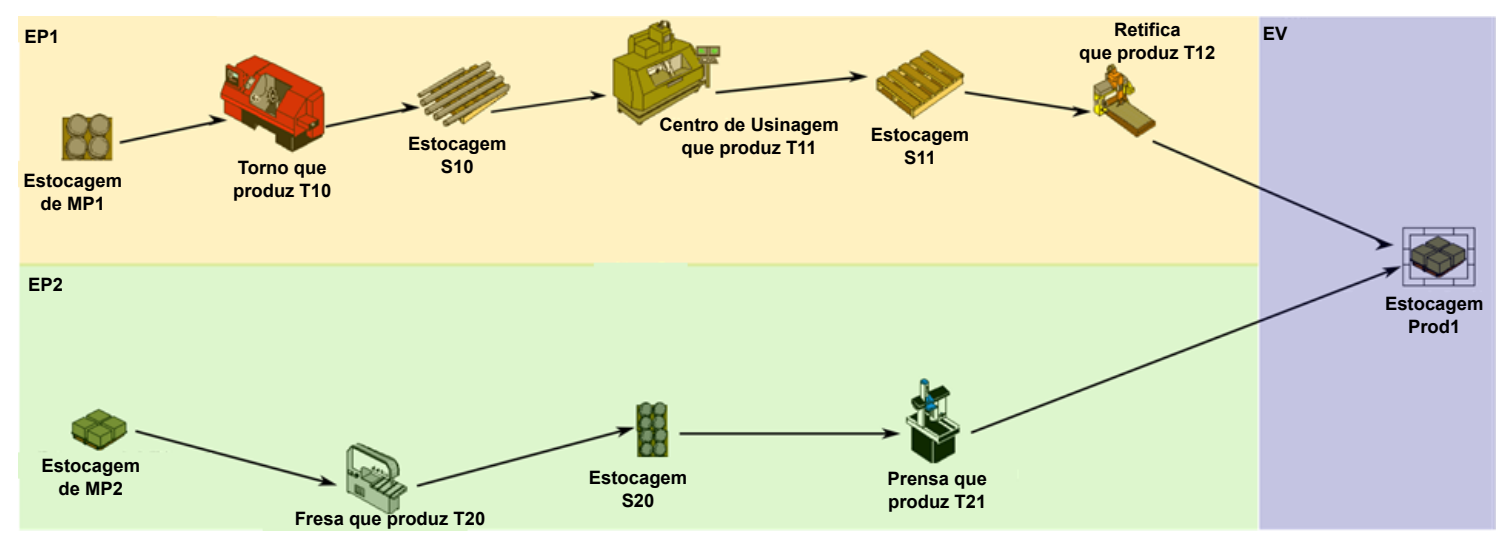

Neste primeiro momento as EPs somente enviam as informações em PFS dos produtos que são objetos da $E V$, ou seja, não enviaram nenhum outra informação de quantas tarefas são necessárias para produzir os produtos da EV. Para criar os PFS são seguidas as seguintes etapas:

1. Identificar os componentes que são passivos (elemento "distribuidor"), neste caso para a EP1 o $S 11$, para a EP2 o $S 20$ e para a $E V$ o Prod1.

2. Identificar os componentes que são ativos (elemento "atividade"), neste caso para a EP1 a $T 12$ e para a EP2 a $T 21$.

3. incluir no elemento "atividade" as informações referentes a tarefa, o código da tarefa, o tempo de processamento e a quantidade que a tarefa produz.

4. Identificar as relações lógicas (arco orientado) entre as "atividades" e "distribuidores".

Cada EP fornece o seu modelo em PFS para a outra EP no intuito de validar o PFS global da EV. Com esta troca é possível perceber qual foi o entendimento de cada EP em relação a EV. A Figura 37 apresenta o PFS consolidado do processo produtivo da EV relativo a Figura 36 que fornece o produto Prod1 para o mercado. A EV é formada por duas EPs, a EP1 que produz $T 12$ e pela $E P 2$ que produz $T 21$. O $\operatorname{Prod} 1$ que é o produto final é composto pelo que é produzido em $T 12$ e $T 21$.

Figura 37 - PFS do processo produtivo da EV referente à Fig. 36.

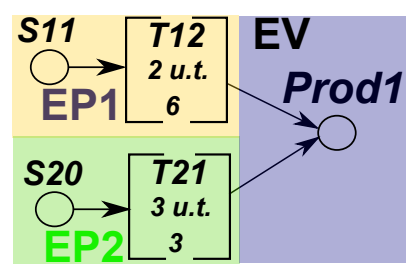


O PFS do processo produtivo da EV é validado pela equipe de Engenharia de Produção de cada EP. Com o PFS validado faz-se o refinamento do PFS. Após o refinamento das tarefas $T 12$ e $T 21$ da Figura 37, tem-se o PFS da Figura 38 em que $T 12$ foi refinado para apresentar em RdP o estado do recurso $R 3$ da $E P 1$ e $R 4$ da EP2.

Figura 38 - Primeiro Refinamento do PFS.

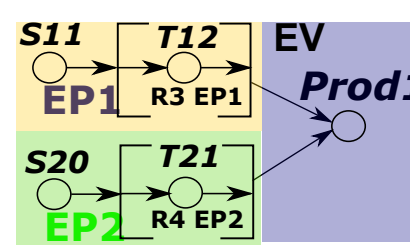

Como os recursos podem ser compartilhados é importante identificar e caracterizar o status do recurso (ocupado ou disponível). Neste caso a atividade T12 é dividida em T12I (entrada) e $T 12 O$ (saída) e são caracterizados os estados ocupado e disponível. Para identificar estes estados são utilizados dois "lugares" (início e fim), o início garante que somente quando existe uma "marca" do "lugar" disponível a tarefa $T 12$ esta habilitada para iniciar. Isto permite que a "transição" dispare e o "lugar" ocupado seja marcado indicando assim o novo status do "lugar" $R 3$ da $E P 1$. Com a RdP gerada é possível simular o modelo para analisar o comportamento da rede. Neste exemplo foi utilizado o software HPSIM ${ }^{2}$ para a simulação de situações e para validar o modelo resultante.

Figura 39 - RdP referente ao PFS da Figura 37.

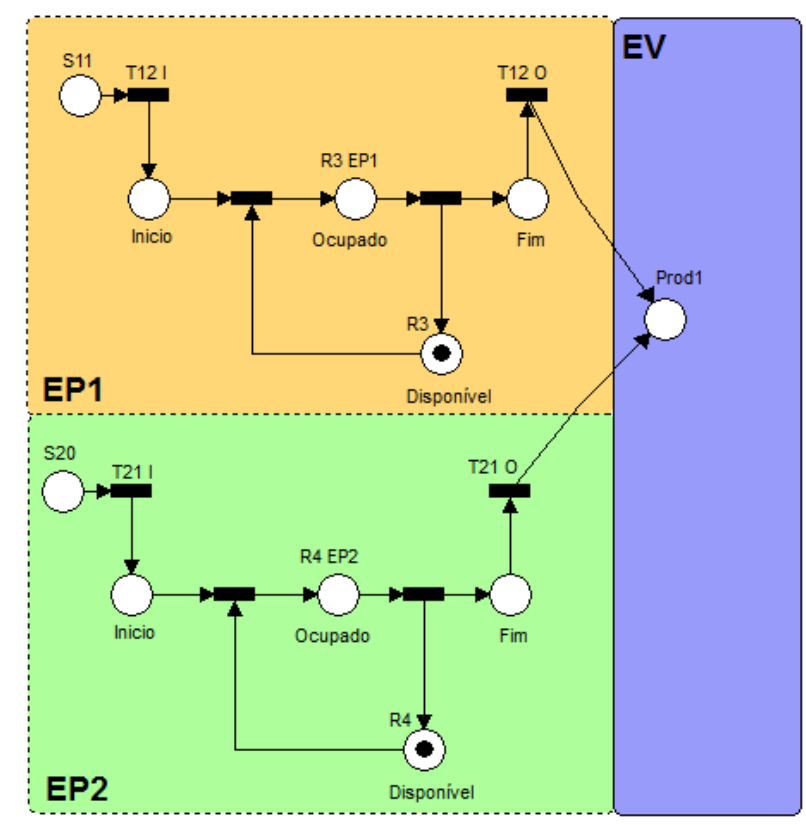

Além de enviarem os respectivos PFS a EP1 informa para o sistema da EV que a disponibilidade para produzir $T 12$ é a partir de 2 unidade de tempo (u.t.), e a $E P 2$ informa que a

\footnotetext{
${ }^{2} \mathrm{HPSim}$ é um software livre para uso acadêmico que permite modelar e simular RdP; ele foi desenvolvido por Henryk Anschuetz e pode ser encontrado em http://www.winpesim.de/
} 
disponibilidade para atender $T 21$ é a partir de 10 u.t. Após a análise e validação do modelo em RdP, as informações sobre o fluxo do processo e sobre os recursos podem ser inseridos no "Serviço de Dados". Estas informações são utilizadas pelo "Serviço de planejamento Virtual" para gerar as "janelas de tempo". Os "serviços" (web services) são descritos na seção 3.3 . Nesta proposta, as "janelas globais" são "janelas de tempo" da EV, ou seja, são "janelas de tempo" que são geradas utilizando as informações do fluxo do processo produtivo inserido na EV. As "janelas de tempo" que são separadas e enviadas para suas respectivas EPs são nomeadas como "janelas locais". Neste caso somente são geradas duas "janelas globais" (Figura 40), e a EP1 recebe apenas a "janela local" relacionada a $T 12$ (Figura 41) e a EP2 recebe a "janela local" da T21 (Figura 42) não importando quais são as etapas de produção anteriores a estas etapas.

No caso da Figura 43, ela representa o PFS da mesma EV da Figura 36, e a Figura 44 apresenta a sua respectiva RdP. Nestas figuras, as EPs enviam as informações relacionadas ao fluxo de todo o processo produtivo para que sejam geradas as "janelas de tempo" de todas as tarefas relacionadas com a EV ("janelas globais"). Pode-se observar que mesmo com as EPs enviando todas as informações relacionadas ao fluxo do processo produtivo, nenhuma informação interna dos processos de fabricação foi enviada, nem mesmo o tipo de máquina usado para executar a tarefa. Somente são enviados dados relacionados ao tempo de produção, à quantidade que se produz neste tempo, se existem ou não limites de estocagem e dados sobre a disponibilidade dos equipamentos e de matérias primas. Neste caso o sistema de PCP gera janelas locais para todas as tarefas das EPs.

Figura 40 - "Janelas globais" de uma EV que recebe informações somente do produto a ser entregue pela EV.

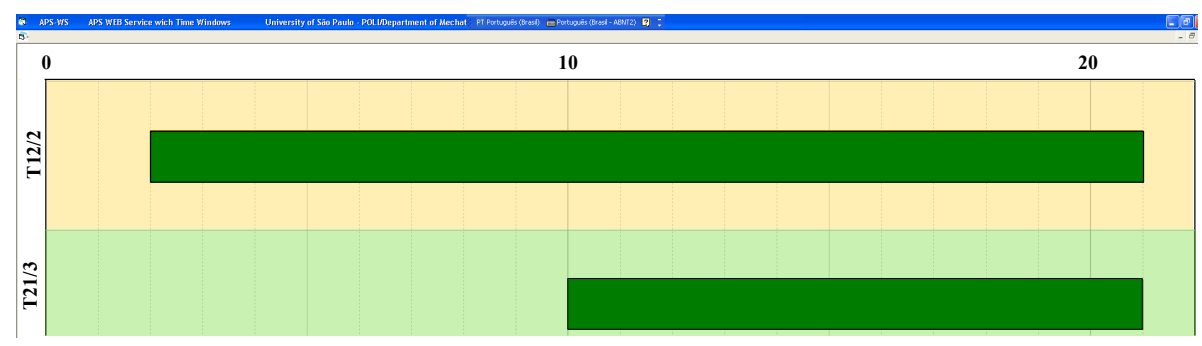

Figura 41 - "Janelas locais" de EP1 referentes ao fluxo codificado do processo da Figura 37.

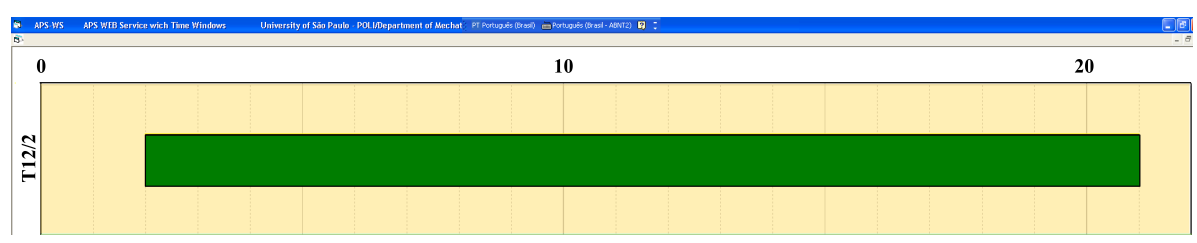


Figura 42 - "Janelas locais" de EP2 referentes ao fluxo codificado do processo da Figura 37.

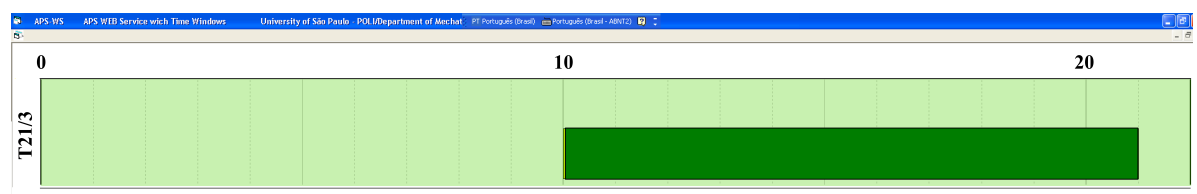

Figura 43 - PFS do processo produtivo de uma EV com informações do fluxo codificado do processo produtivo completo.

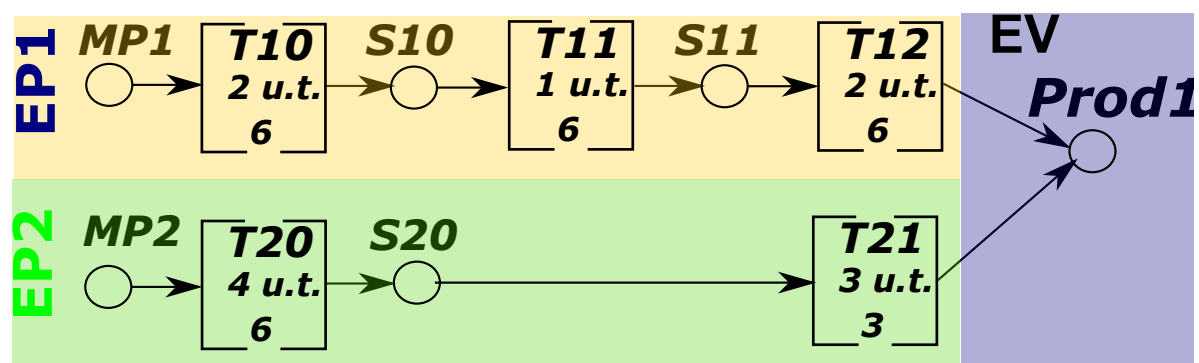

Figura 44 - RdP referente ao PFS do fluxo codificado do processo apresentado na Figura 43.

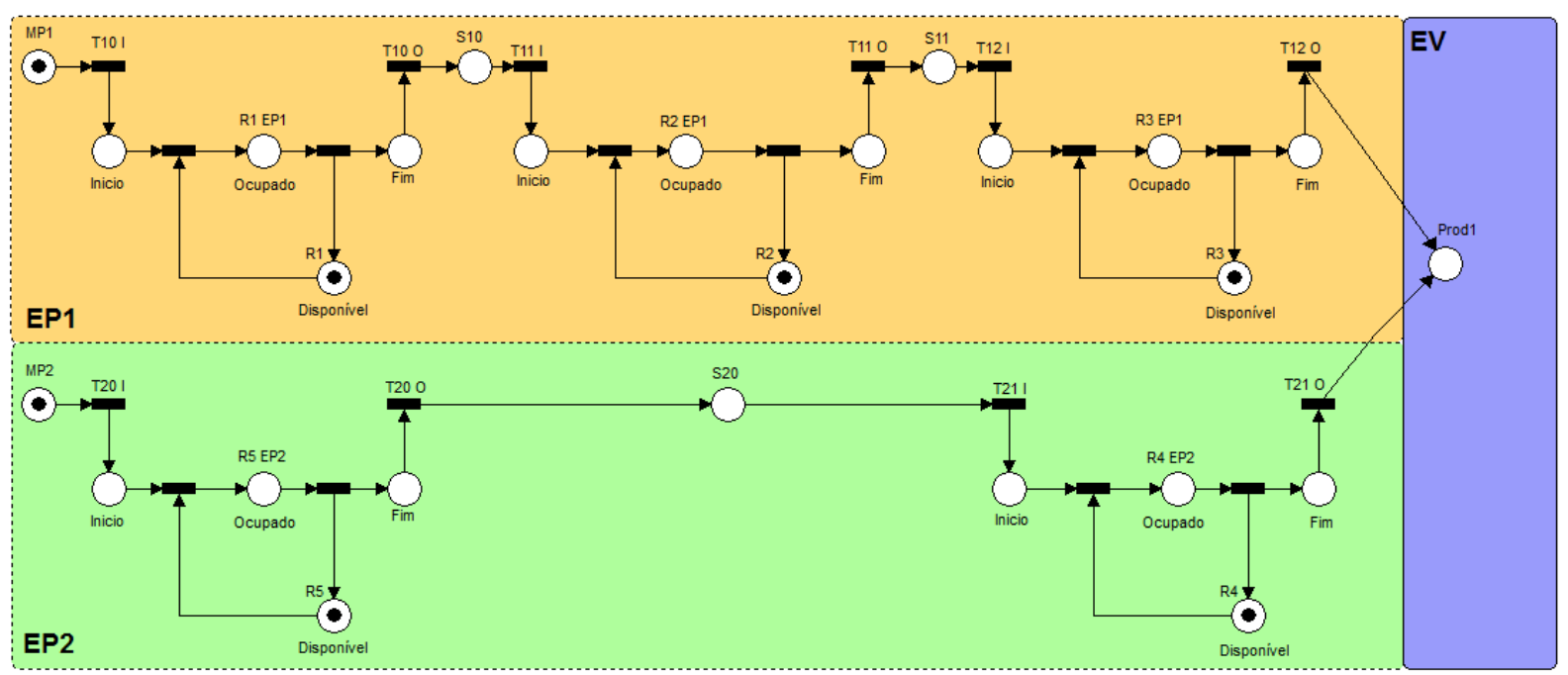

A Figura 45 representa as "janelas globais" referentes à Figura 43. As Figuras 46 e 47 representam respectivamente as "janelas locais" da EP1 e EP2 referentes à Figura 43. Figura 45 - "Janelas globais" referentes ao fluxo codificado do processo produtivo completo ilustrado na Figura 43 .

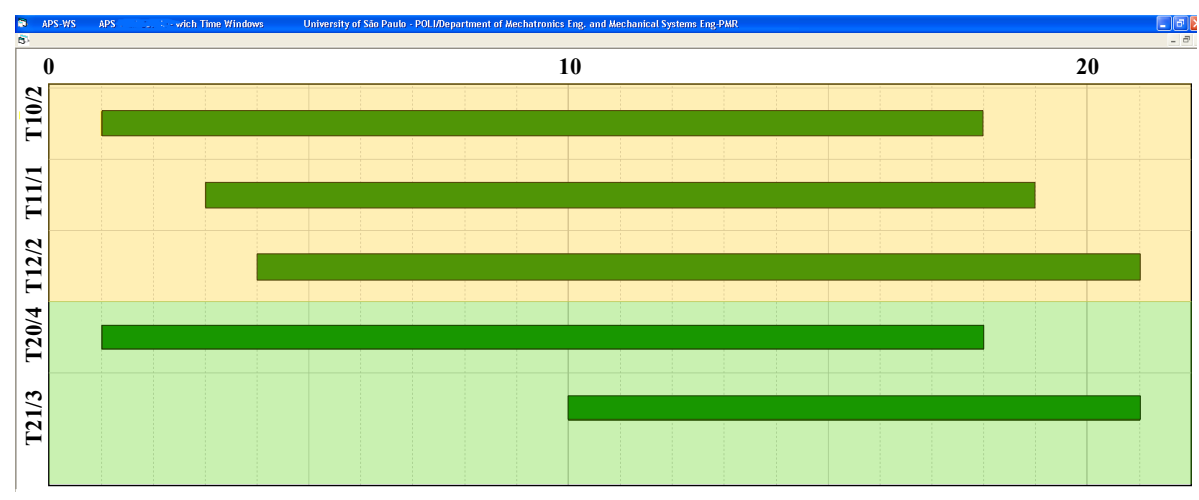


Figura 46 - "Janelas locais" da EP1 referentes ao fluxo codificado do processo produtivo completo ilustrado na Figura 43 .

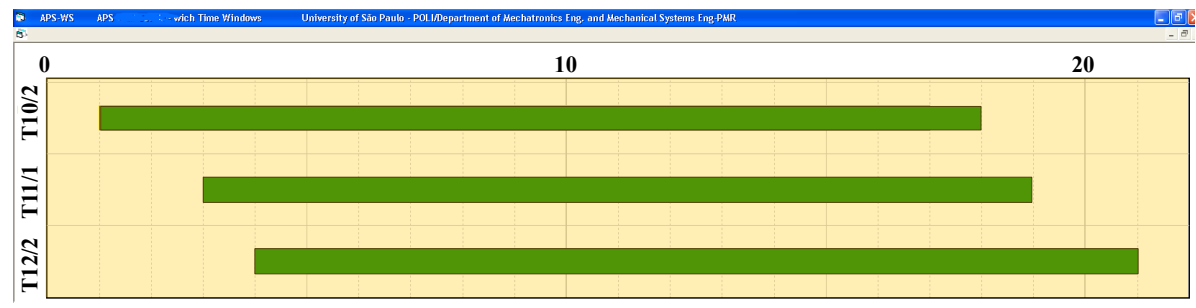

Figura 47 - "Janelas locais" da EP2 referentes ao fluxo codificado do processo produtivo completo ilustrado na Figura 43 .

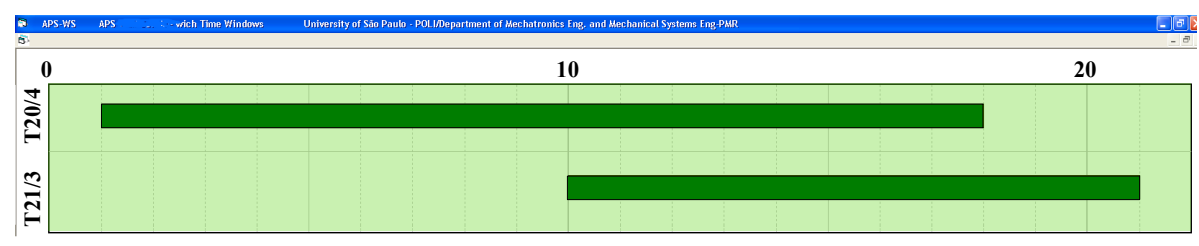

É importante observar que quando não é informado o fluxo codificado do processo produtivo completo, as "janelas locais" enviadas para as EPs podem não ser válidas, isto devido à falta de informação fornecida pelas EPs, pois o sistema proposto somente fornece as "janelas de tempo" referentes às tarefas nele informadas e não tem como propagar as restrições para o fluxo codificado do processo como um todo. Como exemplo, pode-se observar que pelas "janelas de tempo" na Figura 40, a tarefa $T 12$ poderia iniciar em $T=2$ u.t.. Entretanto, pela Figura 45, percebe-se que a tarefa $T 12$ somente poderia iniciar em $T=4$ u.t. Mesmo que o recurso que produziria $T 12$ estivesse disponível em $T=2$ u.t. não seria possível produzir antes devido às restrições de produção.

Podem existir casos em que uma EP consome um item que é produzido por outra EP, conforme apresentado pela Figura 48 e pelo PFS do fluxo codificado do processo produtivo ilustrado na Figura 49 e RdP na Figura 50. Nestes casos, quando é apresentado o fluxo codificado do processo produtivo completo para a EV, o sistema gera as "janelas globais" de forma integrada, possibilitando uma melhor colaboração entre as EPs. A informação da "janela local" referente à tarefa que é consumida por outra EP, permite que a empresa produtora faça a alocação da tarefa da melhor forma, seguindo os seus objetivos locais, entretanto, sem deixar de levar em consideração os objetivos globais da EV. Se neste caso as EPs somente enviassem as informações referentes às últimas tarefas que devem ser fornecidas para a EV, não seria possível perceber que existe a relação de consumidor e produtor entre as EPs e as "janelas" geradas não seriam integradas nestas tarefas. Com a RdP da Figura 50 é possível verificar se existe a sincronização entre os "lugares" $S 10$ e $S 20$. 
Figura 48 - Simplificação do chão de fábrica de uma EV em que suas EPs tenham relação de consumo.

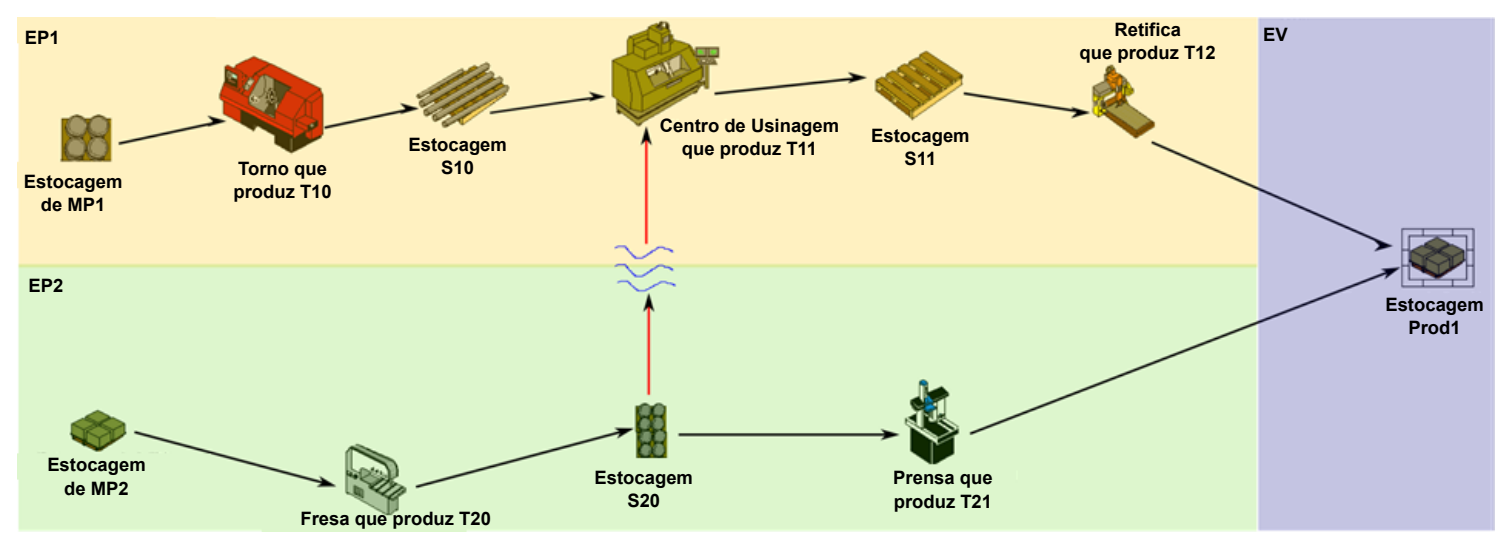

Figura 49 - PFS do fluxo codificado do processo produtivo de uma EV em que suas EPs tenham relação de consumo.

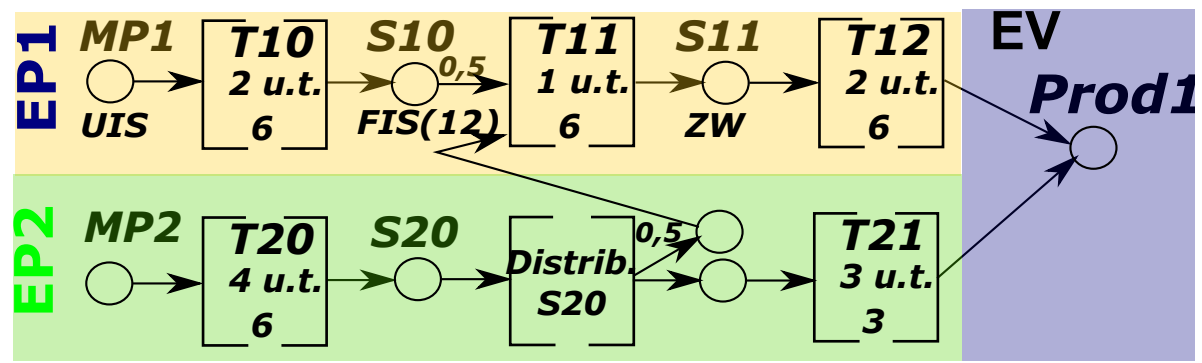

Figura 50 - RdP referente ao PFS da Figura 49 apresentando a sincronização necessária para a tarefa $T 11$.

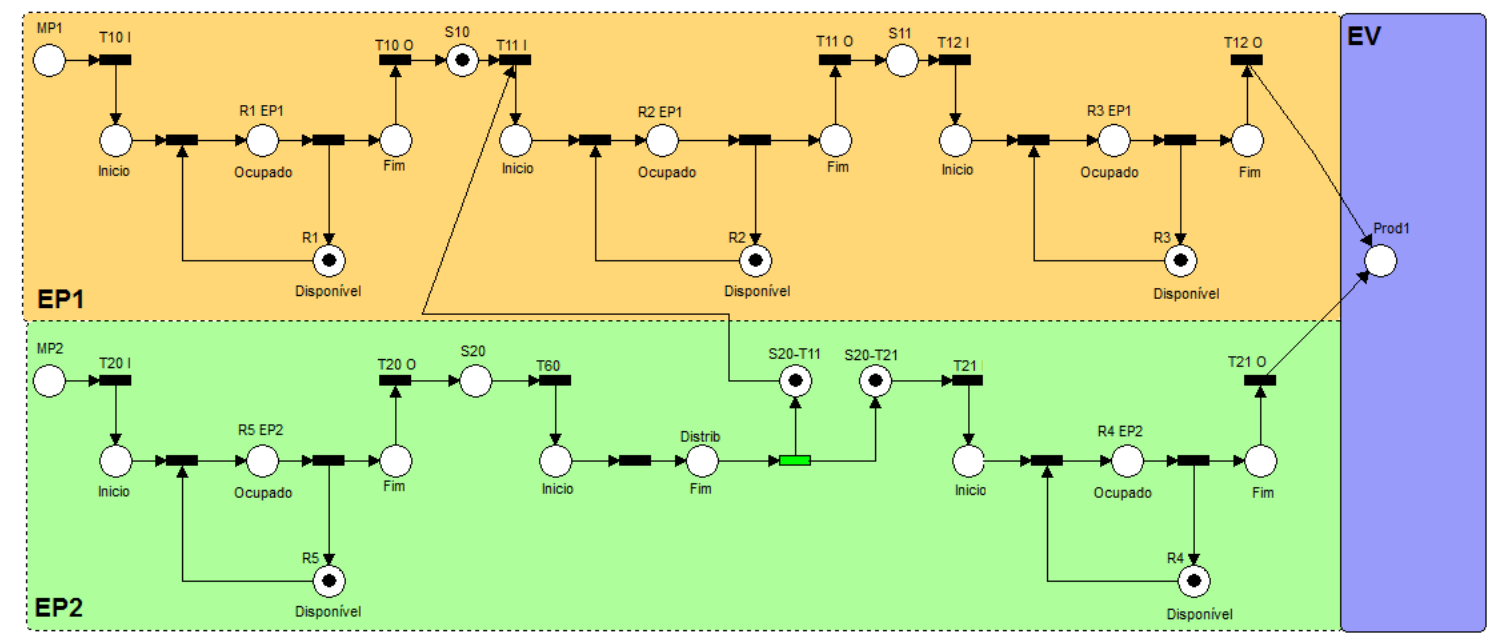

Na Figura 50 consegue-se perceber que a sincronização necessária para produção da tarefa $T 11$ está sendo atendida. Isto porque $T 11$ depende de $S 10$ e de $S 20$ para poder "disparar" e evoluir com a RdP. A Figura 51 representa as "janelas globais" referente à Figura 49. 
Figura 51 - "Janelas globais" referentes à Figura 49

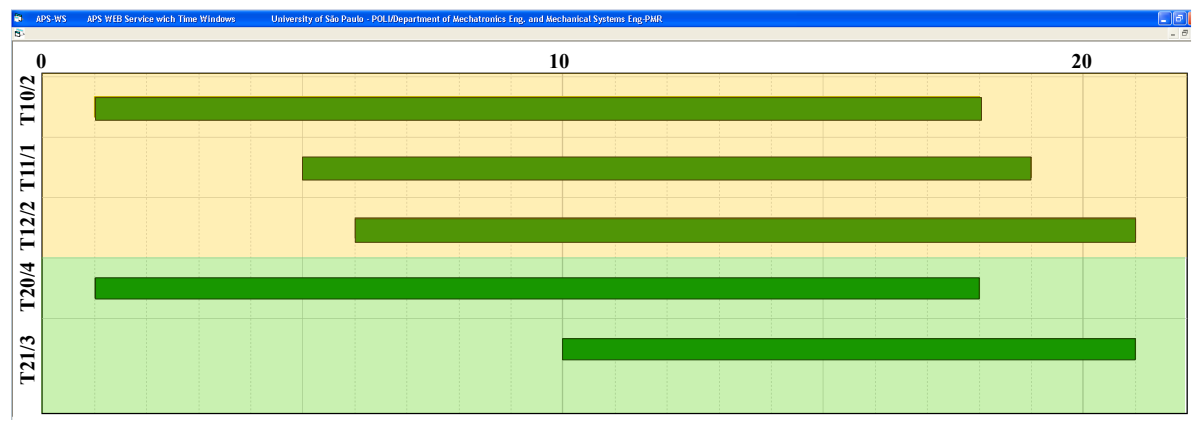

Como neste caso existe relação de consumo entre as empresas parceiras, isto é, a tarefa $T 11$ da EP1 depende de $S 20$, que é produzido pela tarefa $T 20$ da $E P 2$, o sistema de geração de "janelas de tempo" propaga as restrições e recorta o inicio da janela de $T 11$ de $T=3$ u.t. para $T=5$ u.t., pois $T 11$ somente pode começar depois de $S 20$.

A Figura 52 representa as "janelas locais" da EP1 referentes ao fluxo codificado do processo ilustrado pelo PFS da Figura 49.

Figura 52 - "Janelas locais" da EP1 referentes ao fluxo codificado do processo ilustrado pelo PFS da Figura 49.

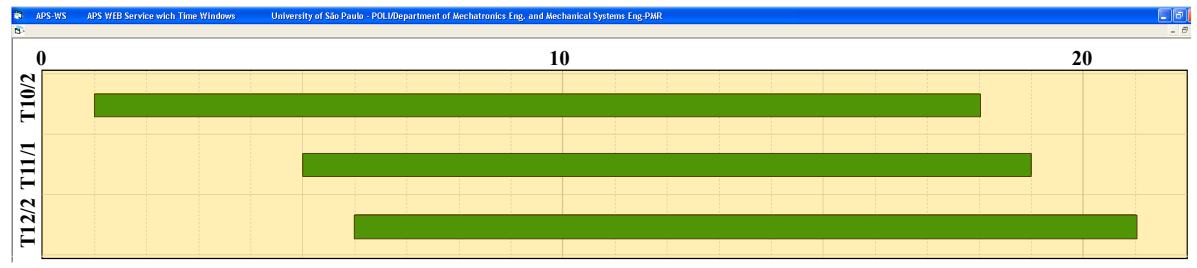

A Figura 53 representa as "janelas locais" da EP2 referente ao fluxo codificado do processo ilustrado pelo PFS da Figura 49.

Figura 53 - "Janelas locais" da EP2 referente ao fluxo codificado do processo ilustrado pelo PFS da Figura 49

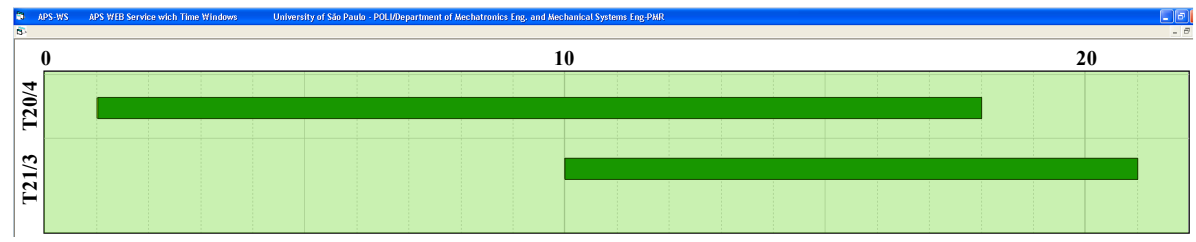

Como o escopo aqui é de EV, o fato de existir uma relação de consumo entre as EPs faz necessário que exista uma grande colaboração entre elas. Desta forma, a empresa EP1 não pode fazer as suas alocações de produção sem as informações da EP2. Como as EPs são parceiras, uma não pode prejudicar a outra, devendo, deste modo, colaborar para que todos tenham a produção mais eficiente possível. Para solucionar este problema, foram desenvolvidas três tipos diferentes de "janelas de tempo" ("globais" e "locais"):

• “Janelas de processamento", de cor verde, são “janelas de tempo" onde não existem relação 
de dependência de consumo entre EPs. Desta forma as EPs podem alocar as tarefas quando for mais conveniente para a EP.

- "Janelas imediatas", de cor vermelho, são "janelas de tempo" que impactam na alocação das tarefas de outras EPs, ou seja, são "janelas de tempo" de tarefas que produzem itens que são consumidos por outras EPs. Neste caso, assim que a EP recebe a informação que existem "janelas imediatas", a EP deve alocar imediatamente a tarefa e enviar as informações para a outra EP que depende desta informação para poder alocar as suas tarefas.

- "Janelas temporárias", de cor amarela, são "janelas de tempo" que dependem da alocação de uma ou mais tarefas de outra EP. Somente podem ser alocadas quando recebem as informações das "janelas imediatas".

A Figura 54 apresenta as "janelas globais" referentes ao fluxo codificado do processo produtivo representado pelo PFS da Figura 49, já identificando cada tipo de "janela de tempo" entre as EPs.

Figura 54 - Tipos de "Janelas globais" referente ao fluxo codificado do processo produtivo representado pelo PFS da Figura 49.

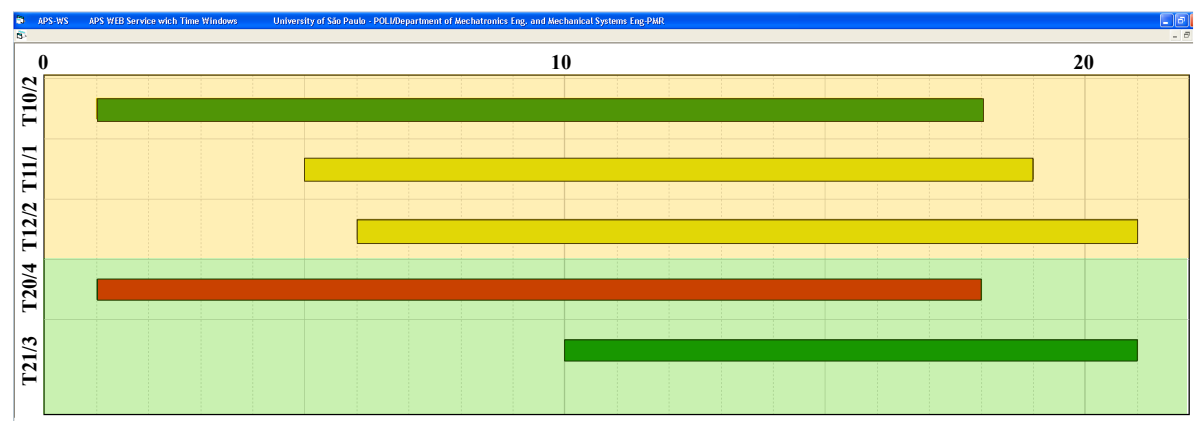

Neste caso, assim que a EP2 recebe as informações das "janelas locais" e verifica que tem uma "janela imediata" T20, a EP2 já envia esta informação para o seu PCP local sequenciar a tarefa. Por exemplo, se a EP2 decidir alocar a T20 no instante $T=14$ u.t. (Figura 55). As "janelas locais" são atualizadas e as informações propagadas são enviadas para a EP1 e para a $E V$ atualizarem as suas "janelas de tempo".

Figura 55 - "Janelas" atualizadas da EP2 depois da alocação de T20 e das propagações de restrições.

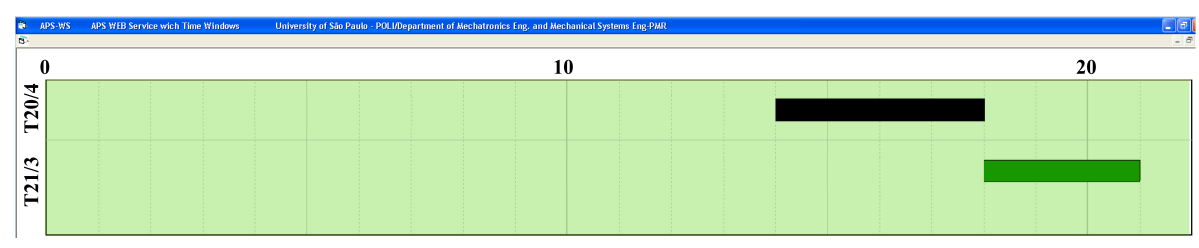

Como na Figura 55, $T 20$ foi alocada em $T=14$ u.t. e a sua duração de produção é de 4u.t, ou seja, sua alocação é de $T=14$ u.t. a $T=18$ u.t. e a sua "janela local" fica com a cor 
preta, isto é, alocada. Esta alocação é propagada para $T 21$ e o início de sua "janela local" é recortado para $T=18$ u.t.

A Figura 56 apresenta as "janelas locais" da EP1 depois da atualização da EP2 com a T20 alocada no instante $T=14$ u.t.. Como já não existem mais "janelas temporárias", elas são atualizadas para "janelas de processamento" indicada em cor verde.

Figura 56 - "Janelas atualizadas" da EP1 depois das propagações de restrições.

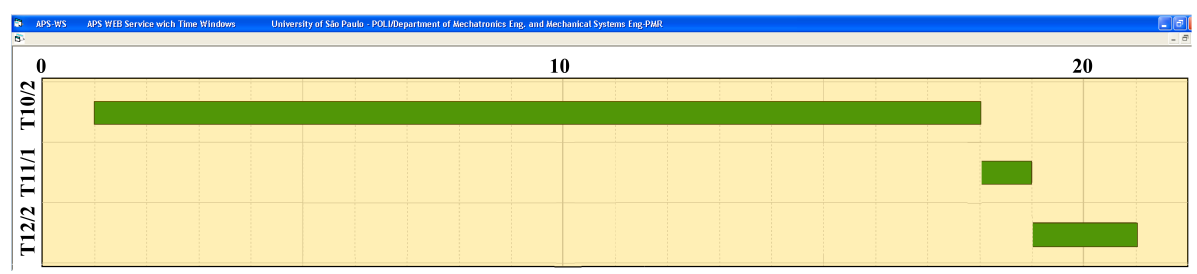

Com a alocação de $T 20$ no instante $T=14$ u.t. a propagação de restrições recortou o início da "janela local" de $T 11$ para $T=18$ u.t. e o início de $T 12$ para $T=19 u$.t. Este tipo de relação de consumo entre EPs pode não ser frequente entre as EVs. Entretanto, a proposta já está preparada para tratar esta questão, acreditando que com o futuro aumento de competitividade, este tipo de relação será cada vez mais frequente.

\subsection{ARQUITETURA DE SISTEMA DE PLANEJAMENTO E CONTROLE DA PRODUÇÃO NO CONTEXTO DE EV}

A arquitetura proposta de sistema de planejamento e controle da produção no contexto de EV é composta de duas camadas: a camada "Coordenadora da EV" e a camada "Empresa Parceira". A camada "Coordenadora da EV" recebe as informações de disponibilidades das empresas parceiras, recebe os pedidos dos consumidores, gera o planejamento global da EV, separa e envia este planejamento localmente para cada EP, possibilitando que cada EP somente receba o planejamento referente aos itens que ela tem que produzir. A camada "Empresa Parceira" envia as informações de disponibilidade da EP e recebe o planejamento local referente aos itens da EV, integrando estes itens no fluxo de pedidos da empresa parceira. A camada empresa parceira também troca informações diretamente entre as empresas parceiras.

A camada "Coordenadora da EV" é composta pelos seguintes módulos: "Serviço de Pedidos", "Serviço de Dados, "Serviço de Gerenciamento de Requisições" e "Serviço de Planejamento Virtual". A camada "Empresa Parceira" é composta do módulo "Serviço de Planejamento Local", relacionado com seus respectivos sistemas produtivos (SPs) que compõem as EPs da EV. Na arquitetura proposta é possível considerar o caso em que uma EP também pode ser uma EV. A Figura 57 apresenta a arquitetura proposta. O contorno tracejado apresenta o domínio da EV com suas respectivas EPs. O retângulo tracejado representa uma EP que é 
uma EV. Na camada externa da EV estão os consumidores.

Figura 57 - Arquitetura proposta.

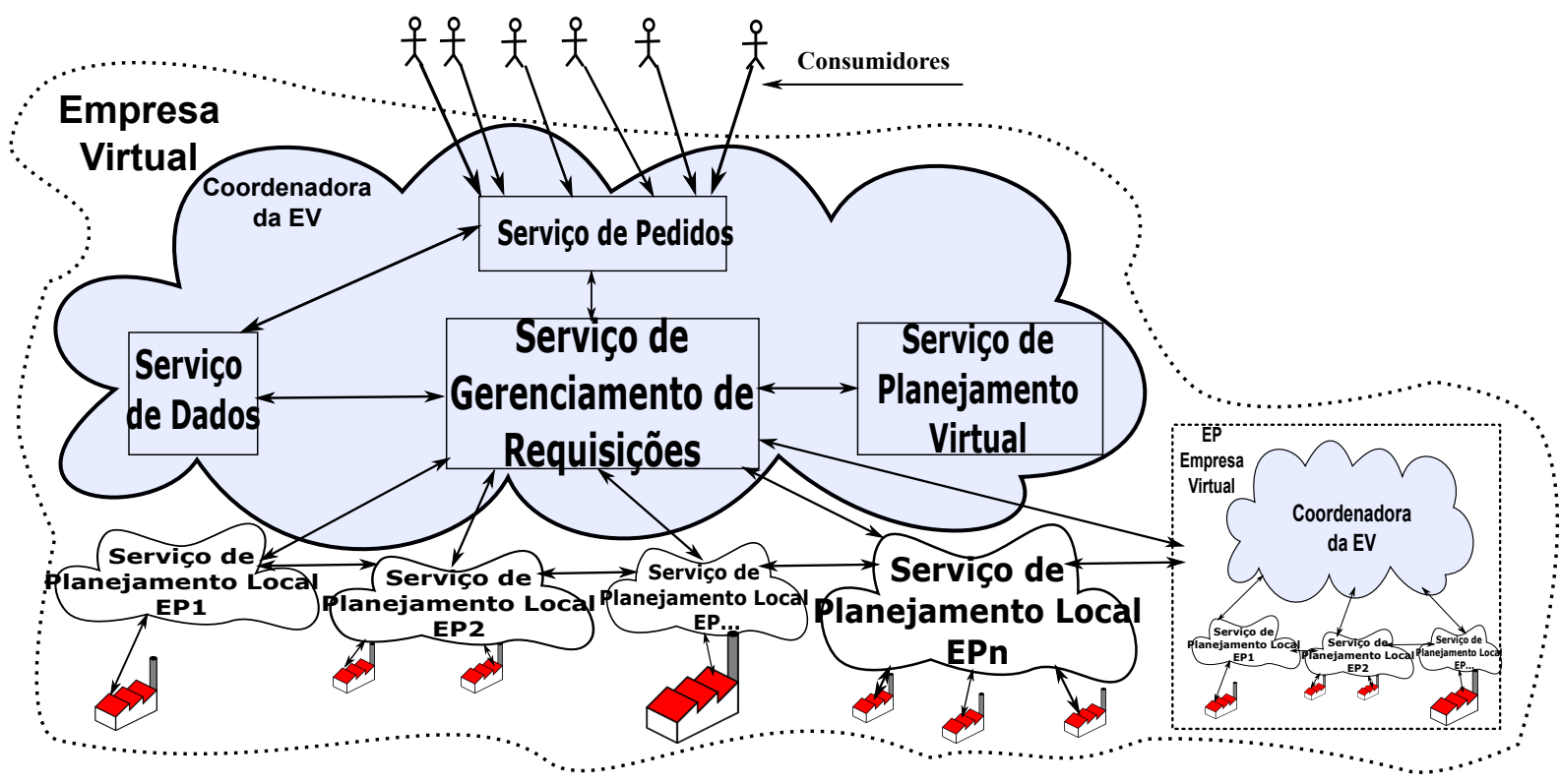

Nesta EV, os consumidores têm acesso ao "Serviço de Pedidos" via Internet, de modo que eles podem enviar solicitações para um repositório de pedidos de produtos por meio de dispositivos de comunicação (PDAs, netbooks, web sites, rede de dados 4G, etc) e também monitorar o estado dos serviços solicitados.

O "Serviço de Pedidos" tem interface com os consumidores, com o "Serviço de Dados" e com o "Serviço de Gerenciamento de Requisições". Na interface do "Serviço de Pedidos", os consumidores podem criar uma conta, enviar um pedido, consultar o status da solicitação dos pedidos, simular se um pedido pode ser entregue a tempo, e saber sobre a factibilidade de um pedido. Estas informações são trocadas com o "Serviço de Gerenciamento de Requisições" e com o "Serviço de Dados", conforme o diagrama de caso de uso da Figura 58. 
Figura 58 - Diagrama caso de uso do "Serviço de Pedidos".

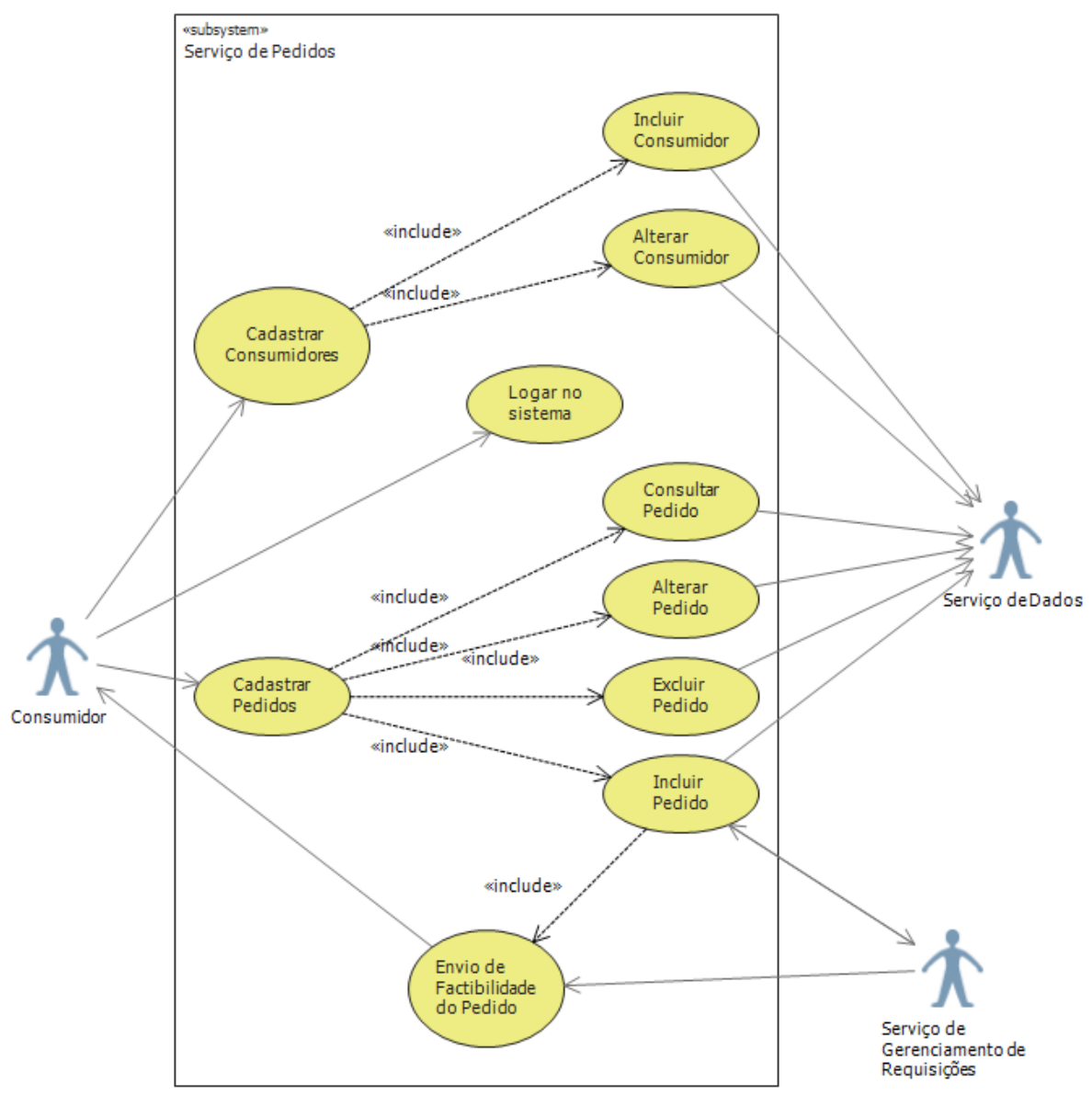

O "Serviço de Gerenciamento de Requisições" é o "orquestrador" (HERRERA; RAMOS; LASTRA, 2011). Ele gerencia as informações sobre as disponibilidades das EPs com o "Serviço de Planejamento Local" e informa o "Serviço de Pedidos" sobre a factibilidade do pedido. Ele faz interface com: "Serviço de Pedidos", "Serviço de Dados", "Serviço de Planejamento Virtual" e os respectivos "Serviço de Planejamento Local". A primeira etapa é o recebimento das informações sobre disponibilidades dos recursos e de materiais vindas de cada "Serviço de Planejamento Local" das EPs. Estas informações vão para o "Serviço de Dados". Na segunda etapa os consumidores solicitam um pedido no "Serviço de Pedidos". Esta informação é enviada para o "Serviço de Gerenciamento de Requisições". Neste momento, as informações de disponibilidades das EPs recebidas do "Serviço de Planejamento Local" e as informações sobre os pedidos recebidas do "Serviço de Pedidos" são solicitadas ao "Serviço de Dados" pois estas informações são necessárias para o cálculo das "janelas globais". As informações sobre as disponibilidades das EPs e sobre os pedidos são enviadas para o "Serviço de Planejamento Virtual" calcular as "janelas globais". Se o pedido for factível de ser cumprido no prazo estipulado pelo consumidor, o "Serviço de Planejamento Virtual' envia as informações das "janelas globais" geradas para o "Serviço de Gerenciamento de Requisições", confirmando que o pedido é factível. O "Serviço de Gerenciamento de Requisições" envia a mensagem de que a ordem é 
factível para o "Serviço de Pedidos", envia as informações das janelas globais para o "Serviço de Dados", e recebe do "Serviço de Dados" as informações referentes às "janelas locais", e envia as informações das "janelas locais" referentes a cada EP para os seus respectivos "Serviço de Planejamento Local". As "janelas globais" são as janelas referentes a todas as tarefas relacionadas à EV que as EPs devem realizar. As "janelas locais" são relacionadas apenas com as respectivas tarefas que cada EP produz. Se a ordem não for factível, o "Serviço de Planejamento Virtual" envia a mensagem de que a ordem não é factível para o "Serviço de Gerenciamento de Requisições" e também para o "Serviço de Pedidos", que é a interface com os consumidores. Esta arquitetura, representada na Figura 57, considera que todos os processos produtivos estão devidamente orquestrados para a integração e coordenação dos serviços. A Figura 59 representa o caso de uso do "Serviço de Gerenciamento de Requisições".

Figura 59 - Diagrama caso de uso do "Serviço de Gerenciamento de Requisições".

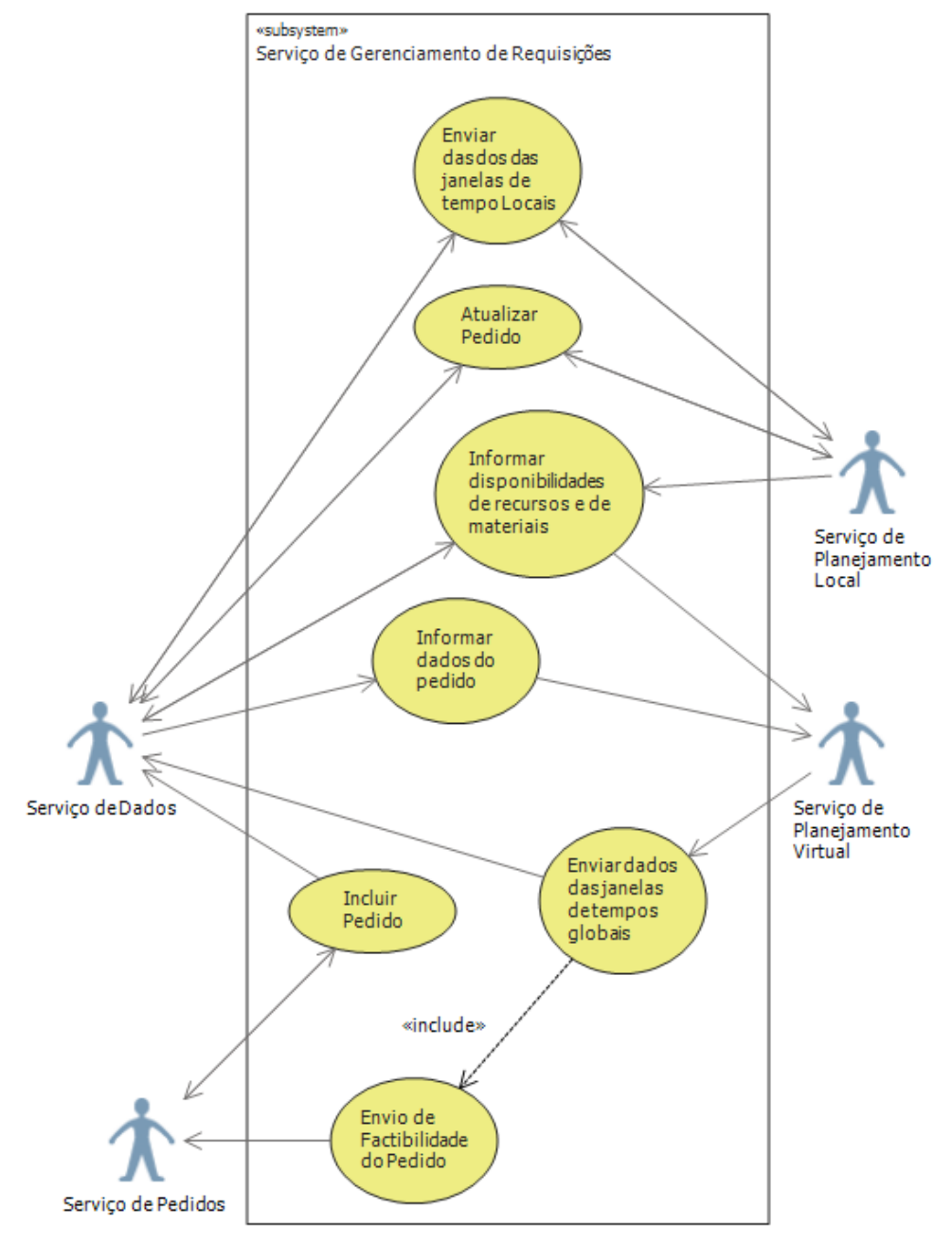

O "Serviço de Dados" é responsável por organizar as informações recebidas e enviadas ao "Serviço de Gerenciamento de Requisições" e ao "Serviço de Pedidos". Pelo "Serviço de Pedidos" são incluídos/alterados os dados sobre os consumidores e sobre os pedidos no "Serviço de Dados". Os dados sobre os pedidos são atualizados e enviados ao "Serviço de Gerenciamento de 
Requisições". O "Serviço de Gerenciamento de Requisições" informa sobre as disponibilidades de recursos e de materiais das EPs para o "Serviço de Dados". Quando o "Serviço de Planejamento Virtual" inicia o cálculo das janelas globais, o "Serviço de Gerenciamento de Requisições" requisita as informações sobre os pedidos e sobre as disponibilidades de recursos e de materiais das EPs simultaneamente para o "Serviço de Dados" e as envia para o "Serviço de Planejamento Virtual". O "Serviço de Gerenciamento de Requisições" também envia os dados das janelas globais ao "Serviço de Dados". Quando o "Serviço de Planejamento Local" requisita as janelas locais, o "Serviço de Gerenciamento de Requisições" requisita que o "Serviço de Dados" trate as informações recebidas sobre as janelas globais, separe as janelas globais em janelas locais por EP, e atualize o status do pedido. A Figura 60 representa o caso de uso do "Serviço de Dados".

Figura 60 - Diagrama caso de uso do "Serviço de Dados".

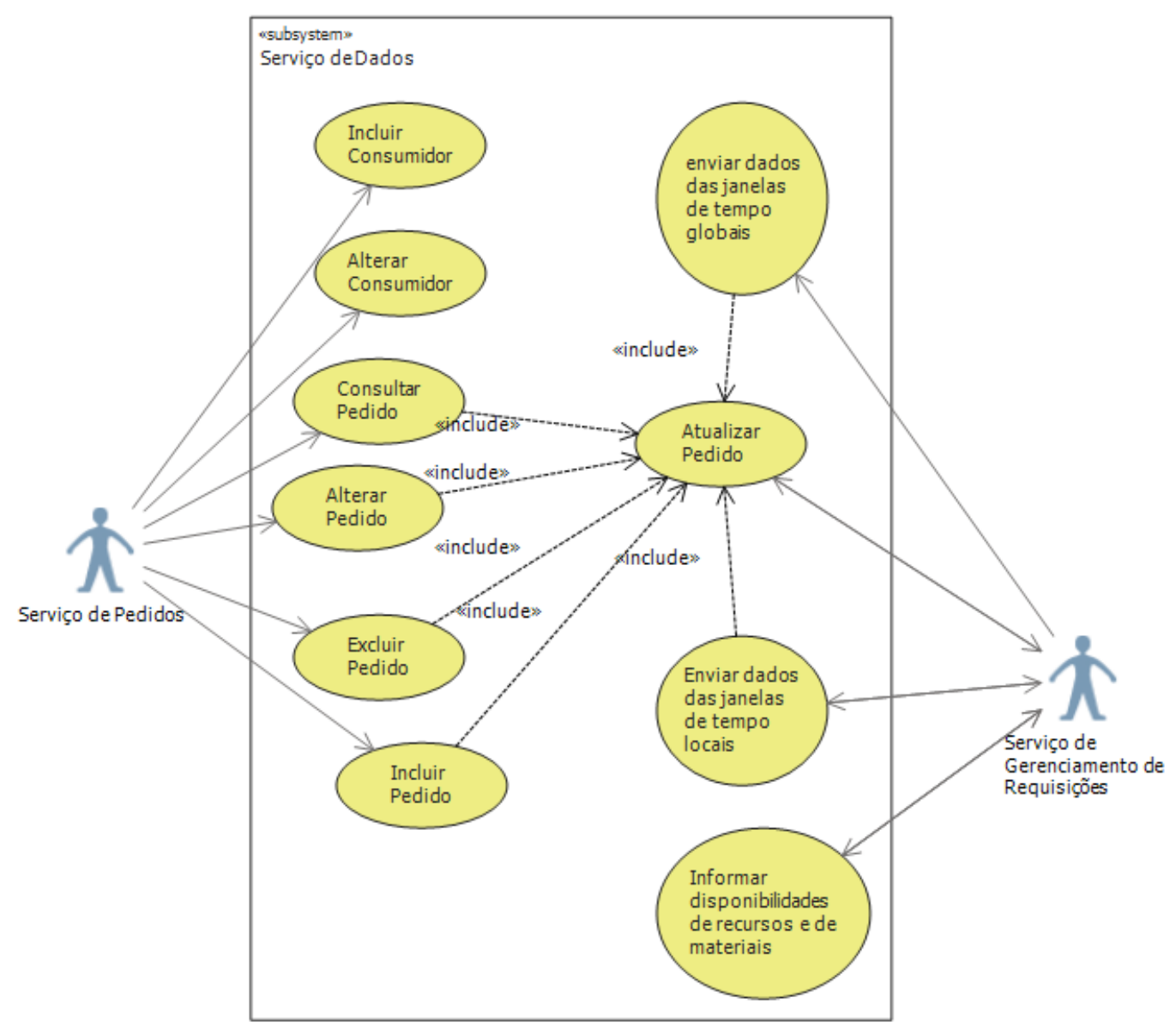

Parte das informações enviadas do "Serviço de Dados" para o "Serviço de Gerenciamento de Requisições" são usadas pelo "Serviço de Planejamento Virtual" para calcular as "janelas globais". As informações mais importantes são:

- Demandas de produtos, para obter um plano de produção factível: as modificações nos pedidos dos consumidores, as datas de vencimento e/ou as quantidades (recebidas do 
"Serviço de Pedidos");

- Plano de entrega de matérias-primas e estoques de cada EP: a disponibilidade de matériaprima pode ser restrita devido a contratos com fornecedores, os procedimentos de controle de qualidade, etc;

- Disponibilidade de recursos de cada EP: o período em que os recursos estão disponíveis.

O planejamento de capacidade de produção enfrenta o problema de envio de pedidos que não podem ser fabricados pelo setor de produção na data desejada pelos consumidores, devido ao planejamento utilizar, em geral, o conceito de "capacidade infinita", que não considera as restrições de produção. Nesta proposta estes problemas serão resolvidos com a abordagem de "janelas de tempo" associada ao conceito de "capacidade finita" e às restrições de produção na sua geração. Cada tarefa tem a sua própria "janela de tempo". Estas janelas de tempo serão geradas na fase do planejamento, considerando, globalmente, todos os pedidos da EV. As "janelas de tempo" serão geradas por heurísticas de "busca orientada por restrições" e enviadas aos sistemas produtivos locais. Com a utilização das janelas de tempo na arquitetura de sistema de planejamento e controle da produção (PCP) proposta, é assegurada a autonomia das EPs. Como um dos desafios da EV é a autonomia das EPs, na arquitetura proposta uma das informações mais importantes e necessárias para calcular as janelas de tempo é a disponibilidade das EPs. Isto assegura autonomia para a EP, pois é a EP que escolhe quando está disponível para atender a EV. Tradicionalmente os sistemas de PCP são sistemas hierárquicos, ou seja, a camada mais acima do sistema impõe o que a camada mais abaixo deve fazer, ou seja, os sistemas de PCP empurram para os Sistemas produtivos o que, quanto, quando e onde produzir as tarefas produtivas. No caso da EV, esta situação não pode existir, pois cada EP é um parceiro com sua autonomia, e não se pode alterar as prioridades da EP. É a EP que deve decidir qual é o melhor momento para produzir. A EV quebra o paradigma da hierarquia nos sistemas de PCP. Na arquitetura proposta, as janelas de tempo são geradas a partir da informações das disponibilidades das EPs.

As "janelas de tempo" fornecem informações sobre a viabilidade dos pedidos para os consumidores ou para as EPs logo após a geração dos pedidos, sem a necessidade de análise prévia do sistema de programação da produção. No contexto apresentado, é possível avaliar esta viabilidade na camada "Coordenadora da EV" sem ter que descer para a camada "Empresa Parceira". Outro fator importante é que o uso de "janelas de tempo" fornece um intervalo de tempo para a alocação das tarefas das EPs e não uma data exata para a entrega dos produtos. Isso permite que as EPs possam decidir alocar as tarefas relacionadas à EV no melhor momento entre as suas atividades que não estão relacionadas com os pedidos da EV. Desta forma, tem-se uma flexibilidade de alocação para as EPs, possibilitando que elas façam as suas 
alocações de pedidos seguindo os seus distintos objetivos de sequenciamento sem interferir no objetivo geral da EV. Isto possibilita que o objetivo global da EV interfira o mínimo possível no objetivo local da EP.

O "Serviço de Planejamento Virtual" é responsável por gerar as "janelas de tempo" ("janelas globais") usando a propagação de restrições. É neste serviço que ficam os algoritmos para calcular as janelas de tempo. São utilizadas as seguintes restrições: restrição de capacidade; restrição de precedência por receita; restrição por monotonicidade, e restrição de armazenagem. Se for possível gerar as "janelas globais", os pedidos são considerados factíveis de serem entregues na data desejada; caso contrário é impossível de serem entregues na data. Este serviço recebe e envia as informações para o "Serviço de Gerenciamento de Requisições". As informações recebidas (entradas para o sistema) são:

- Demandas de produtos com quantidades e datas de entrega;

- Plano de entrega de matérias-primas e estoques de cada EP;

- Disponibilidade de recursos de cada EP.

As informações enviadas são as "janelas globais" ou a mensagem de que não foi possível gerar as "janelas globais". O serviço será executado quantas vezes a EV quiser, ou seja, enquanto as EPs estão enviando/atualizando as suas disponibilidades e os consumidores estão inserindo os seus pedidos, estas informações estão sendo prontamente atualizadas pelo "Serviço de Dados". Quando a EV executar o "Serviço de Planejamento Virtual" as informações são requisitadas ao "Serviço de Dados" e são calculadas as "janelas globais". Entretanto, é possível ser disparado conforme o tempo que desejar, bastando verificar o tempo de resposta, pois isto vai depender de EV para EV. A Figura 61 representa o caso de uso do "Serviço de Planejamento Virtual". 
Figura 61 - Diagrama caso de uso do "Serviço de Planejamento Virtual".

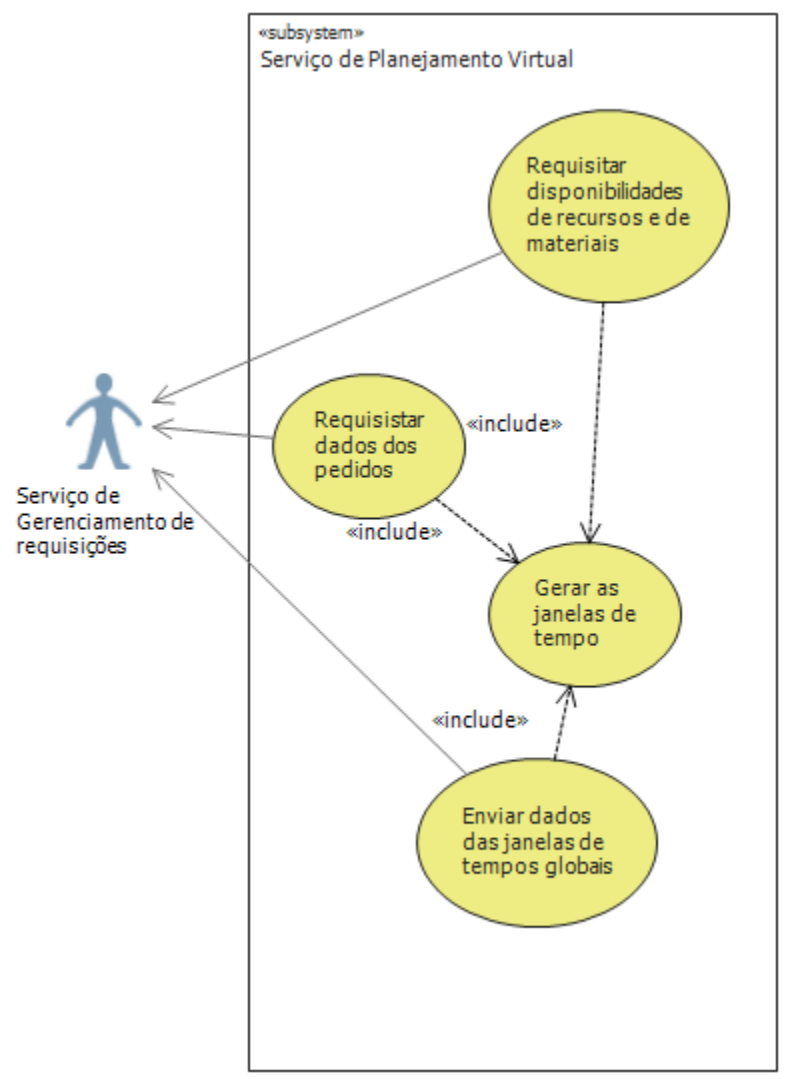

Cada "Serviço de Planejamento Local" é responsável pela troca de informações entre as EPs e entre cada EP com o "Serviço de Gerenciamento de Requisições". As informações recebidas das EPs e enviadas para o "Serviço de Gerenciamento de Requisições" são: a atribuição de recursos como, por exemplo, equipamentos, os respectivos estoques, o plano de entrega de matériasprimas, e a disponibilidade dos recursos das EPs. Com base nas informações do "Serviço de Gerenciamento de Requisições", cada "Serviço de Planejamento Local" decide quando vão enviar as "janelas locais" para os suas respectivas EPs. Podem existir casos em que o "Serviço de Planejamento Local" de uma $E P_{1}$ colabore diretamente com o "Serviço de Planejamento Local" de uma $E P_{2}$, conforme descrito na seção 3.2 (caso de relação de consumo entre EPs). Nestes casos são feitas as atualizações necessárias entre as EPs (atualizações das janelas locais, quando as janelas imediatas mudam para janelas de processamento e as outras propagações de restrições) e paralelamente estes dados são atualizados no "Serviço de Gerenciamento de Requisições". Os desenvolvimentos de sistemas para EVs geralmente utilizam o conceito de web service (WS) (HSU; HSU, 2008; QIUSHI et al., 2010; CALIZ et al., 2011). Este trabalho também utiliza o WS na sua elaboração. 
Figura 62 - Diagrama caso de uso do "Serviço de Planejamento Local".

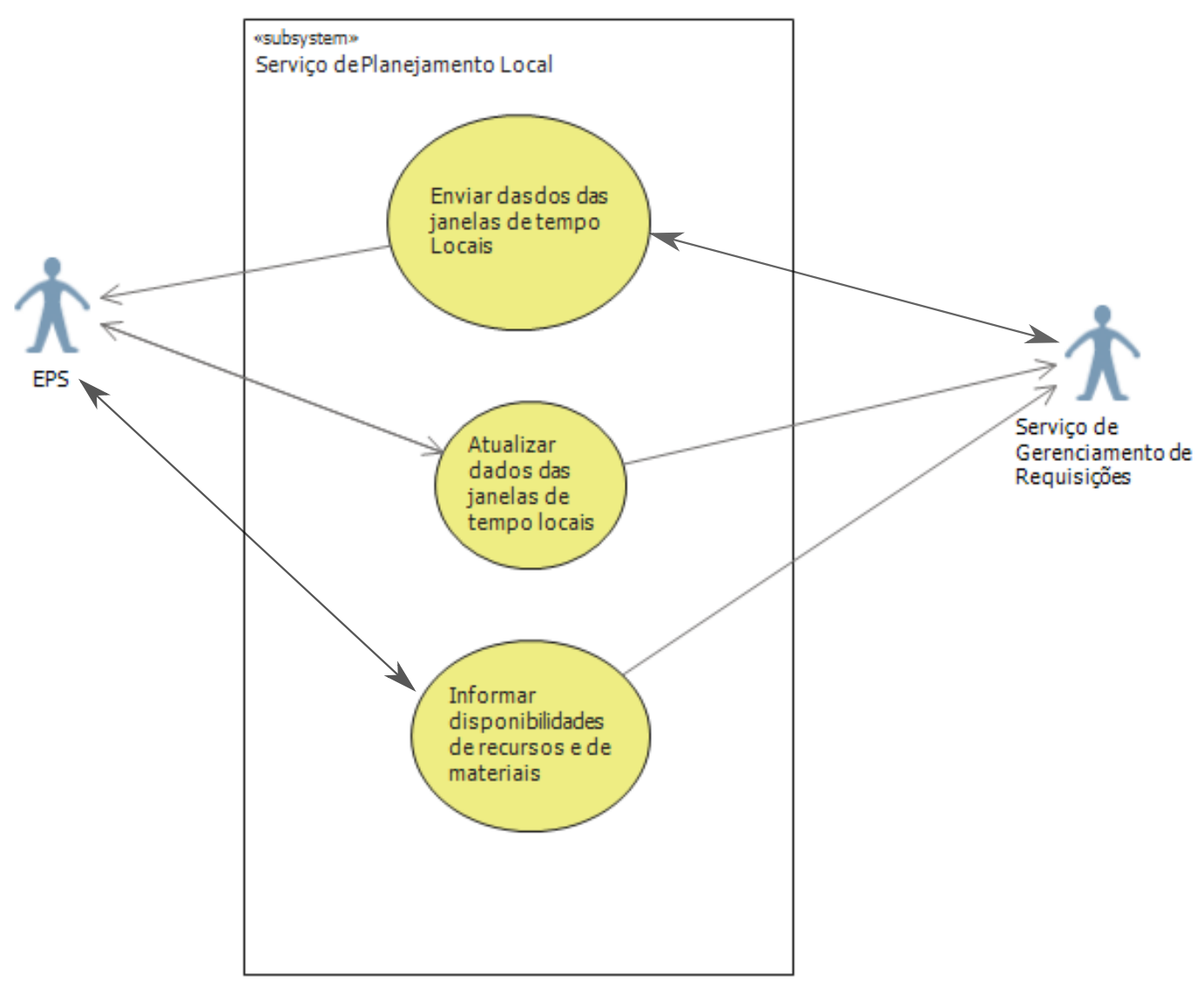

Com as informação recebidas no "Serviço de Planejamento Local", cada EP da EV deve gerar o seu planejamento local ou seja, conciliar os pedidos recebidos da EV com os pedidos recebidos de seus próprios consumidores. Estas informações serão utilizadas na fase de programação da produção local. De acordo com Maravelias e Sung (2009) a integração entre planejamento de capacidade e programação da produção é um problema difícil. Isto devido ao desafio de modelar as restrições dos recursos numa rede de processos, a dificuldade de comunicação (compartilhamento) de objetivos entre as áreas, e a diferença entre as respectivas escalas de tempo (MARAVELIAS; SUNG, 2009). Estes problemas são aqui resolvidos com a utilização das "janelas de tempo". Cada EP pode utilizar a heurística de programação da produção que desejar, desde que as heurísticas utilizem o conceito de "janela de tempo" para que mantenham compatíveis as informações entre EP e a EV. Este trabalho propõe o uso de heurísticas de programação da produção do tipo "Advanced Planning and Scheduling" (APS) (Apêndice B) utilizando "janelas de tempo" (subseções 2.3.3 e 2.3.4). A Figura 63 apresenta o fluxograma das etapas de funcionamento do sistema de PCP para EV . 
Figura 63 - Fluxograma das etapas de funcionamento do sistema de PCP para EV.

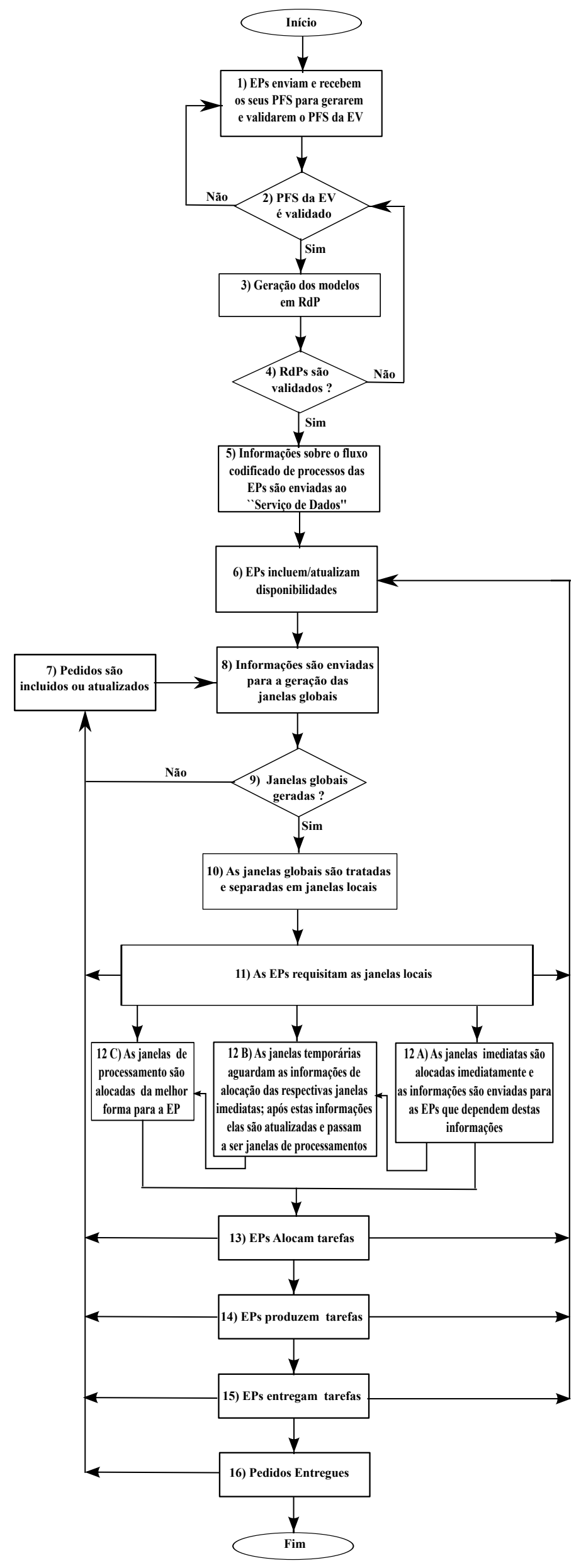


Comparando a arquitetura proposta com trabalhos encontrados na literatura sobre planejamento de produção em EVs, percebe-se que a característica de autonomia das EPs não é atendida por nenhum dos outros trabalhos, entretanto a característica de autonomia é atendida na arquitetura proposta, pois é a EP quem fornece a sua disponibilidade para a EV gerar as "janelas de tempo", assegurando assim plena autonomia para a EP decidir quando ela disponibiliza seus recursos para produzir os itens da EV. A Tabela 3 apresenta a comparação da arquitetura proposta em relação a contemplar as características da EV com trabalhos encontrados na literatura sobre planejamento de produção em EVs e se estes descrevem o método de modelagem adotado.

Tabela 3 - Características das EV contempladas por alguns trabalhos apresentados na literatura.

\begin{tabular}{|c|c|c|c|c|}
\hline \multirow[t]{2}{*}{ Autores } & \multicolumn{3}{|c|}{ Características da EV } & \multirow{2}{*}{$\begin{array}{l}\text { Método de } \\
\text { Modelagem }\end{array}$} \\
\hline & Distribuição & Colaboração & Autonomia & \\
\hline Richards et al. (1997) & $\operatorname{sim}$ & $\operatorname{sim}$ & não & não \\
\hline Goulart (2000) & $\operatorname{sim}$ & sim & não & $\operatorname{sim}$ \\
\hline Ip, Yung e Wang (2004) & $\operatorname{sim}$ & $\operatorname{sim}$ & não & não \\
\hline Xia e Li (2008) & $\operatorname{sim}$ & $\operatorname{sim}$ & não & não \\
\hline Hsu e Hsu (2008) & $\operatorname{sim}$ & $\operatorname{sim}$ & não & $\operatorname{sim}$ \\
\hline Ding, Gao e Luo (2009) & $\operatorname{sim}$ & $\operatorname{sim}$ & não & $\operatorname{sim}$ \\
\hline Arquitetura aqui proposta & $\operatorname{sim}$ & sim & $\operatorname{sim}$ & $\operatorname{sim}$ \\
\hline
\end{tabular}

\subsection{PROCEDIMENTOS DE IMPLEMENTAÇÃO}

Nesta seção são apresentados os procedimentos de implementação da arquitetura proposta. Entende-se que uma forma eficaz de implementação é com a utilização de softwares ERPs. Desta forma, é possível utilizar parte das informações contidas no ERP para gerenciar as operações, o banco de dados e as informações. Como na proposta é utilizado o conceito de "janelas de tempo", o ideal é que as EPs também tenham sistemas que aceitem este conceito, o que facilita na gestão das informações. Se nem a EV e nem as EPs tiverem ERPs, elas podem utilizar algum programa gratuito que está disponibilizado na internet. Deve-se ter um ERP para a EV e um para cada EP. As matérias primas, produtos semi-acabados e produtos finais são armazenados nos módulos e tabelas de depósitos (warehouse) dos sistemas ERPs. Os web services podem ser instalados na internet (nas nuvens), ou podem ser instalados nas EPs que tenham infraestrutura de internet para suportar os web services, ou seja, devem ter conexão segura e estável com uma internet de alta velocidade.

Para criar a camada "Coordenadora da EV" é necessário: 
- Caso a EV tenha um software ERP, analisar se existem módulos que sejam compatíveis com a arquitetura proposta. Caso não existir criar um módulo EV.

- Criar as tabelas na EV para inserção dos dados referentes às EPs.

- Tabela para registrar os dados sobre as disponibilidades dos materiais, com dados sobre as entregas de novos materiais (data de entrega e quantidade);

- Tabela para o registro dos equipamentos de cada EP, recebendo o nome desse equipamento e de qual EP ele pertence;

- Tabela para receber as possíveis políticas de transferência de armazenagem (sem limitação ou ZW-zero wait);

- Tabela para receber os possíveis tipos de restrições de armazenagem (FIS - Finite Intermediate Storage, UIS - Unlimited Intermediate Storage, e NIS - No Intermediate Storage);

- Tabela para registro dos depósitos utilizados, fazendo referência à sua política de transferência e ao tipo de restrição de armazenagem;

- Tabela para receber os valores máximos a serem armazenados no depósito, no caso de FIS;

- Tabela para registro dos períodos de disponibilidade de cada equipamento (recursos);

- Tabela para registro da habilitação dos produtos nos equipamentos;

- Tabela para registro dos pedidos de materiais, que deve conter: a quantidade e tempo da demanda e a quantidade e o tempo no estoque, além da data de entrega e da "janela de tempo";

- Tabela para a listagem dos fluxos codificados dos processos das empresas parceiras (tarefas) necessárias para se produzir os itens;

- Tabela para declaração dos fatores de consumo e geração de materiais relacionados a cada tarefa;

- Tabela para registrar os dados das "janelas de tempo", com o tipo de "janela de tempo", e os intervalos das respectivas "janelas de tempo".

- Criação do "Serviço de Pedidos" com interface de acesso para os consumidores via web, pode ser criado utilizando o Visual Studio 2013 ou outro software que possibilite a criação de web service;

- Criação do "Serviço de Gerenciamento de Requisições"; 
- Criação do "Serviço de Planejamento Virtual".

Para criar a camada "Empresa Parceira" é necessário:

- Caso as EPs também tenham um software ERP, analisar se existem módulos compatíveis com a arquitetura proposta;

- Criar as tabelas nas EPs para inserção dos dados referentes à EV. Caso já existam tabelas no ERP analisado que possam somente ser feitas as inclusões de mais atributos, incluí-los. As tabelas a serem criadas são:

- Tabela para registrar os dados sobre as disponibilidades dos recursos;

- Tabela para registrar os dados sobre as disponibilidades dos materiais;

- Tabela para receber as possíveis políticas de transferência de estocagens (sem limitação ou ZW-zero wait);

- Tabela para receber os possíveis tipos de restrição de um depósito (FIS - Finite Intermediate Storage, UIS - Unlimited Intermediate Storage, e NIS - No Intermediate Storage);

- Tabela para registro dos depósitos utilizados, fazendo referência à sua política de transferência e ao tipo de restrição do depósito;

- Tabela para receber os valores máximos a serem estocados no depósito, no caso de FIS;

- Tabela para registro dos períodos de disponibilidade de cada equipamento (recursos);

- Tabela para registro da habilitação dos produtos nos equipamentos;

- Tabela para registro dos pedidos de materiais, que deve conter: a quantidade e tempo da demanda e a quantidade e o tempo no estoque, além da data de entrega e da "janela de tempo";

- Tabela para listagem dos fluxos codificados dos processos da EP (tarefas) necessários para se produzir os itens;

- Tabela para declaração dos fatores de consumo e geração de materiais relacionados a cada tarefa;

- Tabela para registrar os dados das "janelas de tempo", como o "tipo de janela de tempo", e os "intervalos das respectivas janelas". 
- Criação do "Serviço de Planejamento Local";

A Figura 64 apresenta o fluxograma das etapas necessárias para a implementação da arquitetura proposta de sistema de PCP para EV.

Figura 64 - Fluxograma das etapas necessárias para a implementação da arquitetura proposta de sistema de PCP para EV.

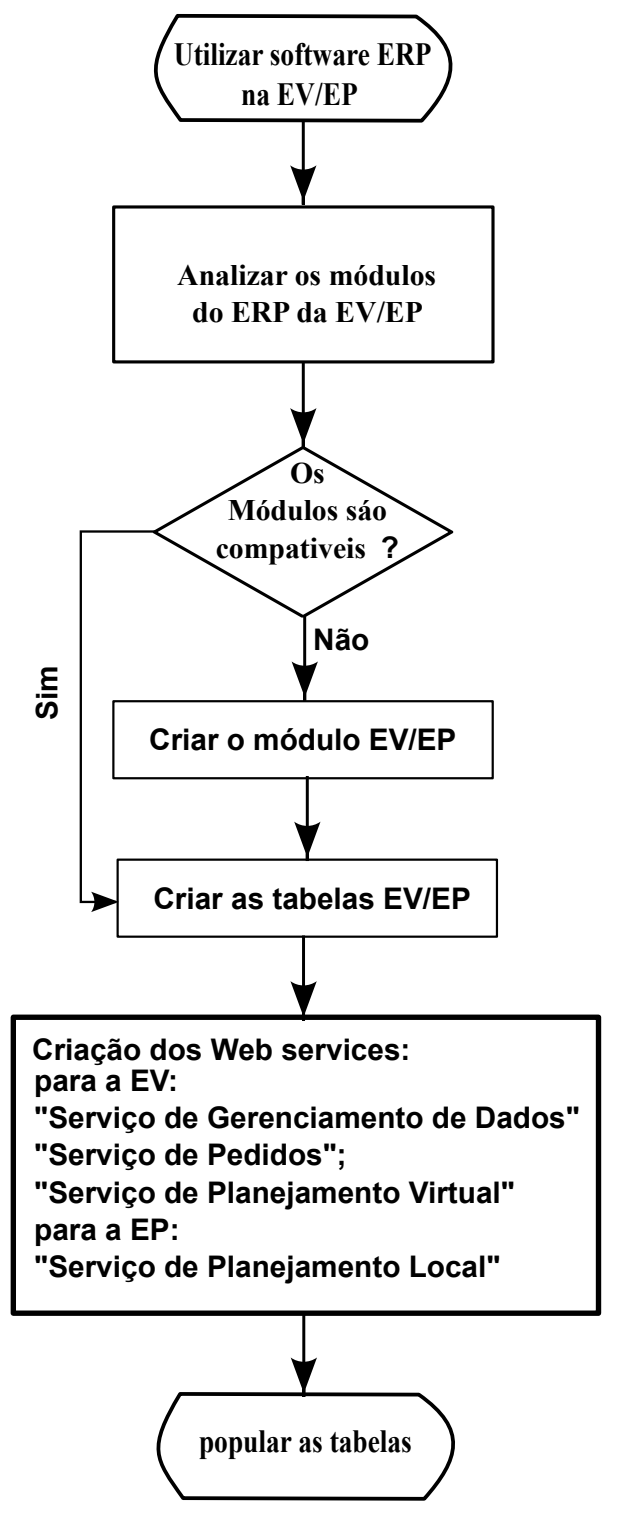

No capítulo a seguir será apresentado um exemplo de aplicação da arquitetura proposta e no apêndice $C$ é apresentada uma implementação protótipo da arquitetura proposta. 


\section{EXEMPLO DE APLICAÇÃO}

Este capítulo apresenta um exemplo de utilização do sistema de PCP para EV baseado na arquitetura proposta para um problema acadêmico apresentado por Papageorgiou e Pantelides (1996), o qual foi adaptado a uma condição de EV e seus sistemas de produção dispersos em Pessoa et al. (2012). Este problema foi escolhido pois é um problema relativamente complexo e que possibilita a apresentação da relação de consumo entre EPs, deixando, desta forma, mais claro o entendimento sobre esta relação de consumo e a sua implicação nas gerações das janelas locais das EPs. O exemplo (Figura 65) representa uma EV composta de três EPs e seus sistemas produtivos (SPs): EP1, EP2, e EP3. A EP1 é composta pelos recursos: $P 1$, $P 4$ e $P 7$, a $E P 2$ é composta dos recursos: $P 2, P 3$ e $P 5$, e a $E P 3$ é composta pelos recursos: P6 e P8. Esta EV produz quatro produtos: Pro1, Pro2, Pro3 e Pro4. As EPs estão dispersas e operam por lotes. Neste exemplo, trata-se de tarefas de tamanhos diferentes, operações sucessivas, e limitação de recursos compartilhados. A EP2 é cliente e fornecedor de EP1. Há consumidores. EP1 fornece os produtos finais Pro1, Pro2, e Pro3, e a EP3 fornece o produto final Pro4. Cada um dos quatro consumidores solicita um pedido para a EV. Este exemplo demonstra como a arquitetura proposta gera as "janelas globais" e envia para cada empresa parceira as suas respectivas "janelas locais". Após cada EP receber as suas "janelas locais", elas analisam quando será melhor fazer a alocação das tarefas, e cada EP pode aplicar uma heurística de programação da produção diferente, isto pressupondo de que cada empresa parceira pode ter um objetivo de programação diferente. Assume-se que as EPs já informaram a disponibilidade de seus recursos para a "Coordenadora da EV" via "Serviço de Planejamento Local" (Tabela 4).

Figura 65 - EV e seus respectivos parceiros.

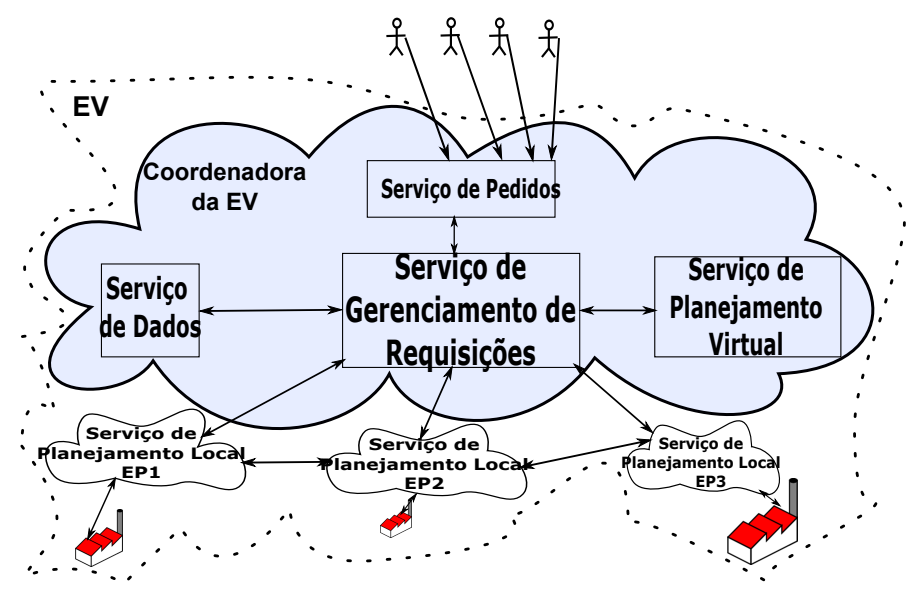

A Tabela 4 apresenta as informações sobre a disponibilidade de recursos em unidades de tempo (u.t.) utilizadas para gerar as respectivas "janelas globais" da EV. 
Tabela 4 - Atribuição e disponibilidade das EPs.

\begin{tabular}{|c|c|c|c|}
\hline $\begin{array}{c}\text { Empresa } \\
\text { Parceira (EP) }\end{array}$ & Recurso & Tarefas & $\begin{array}{c}\text { Disponibilidade } \\
\text { do Recurso em u.t. }\end{array}$ \\
\hline \hline \multirow{3}{*}{ EP1 } & $P 1$ & T10, T21, T51 & 20 \\
\cline { 2 - 4 } & $P 4$ & T23, T30 & 20 \\
\cline { 2 - 4 } & $P 7$ & T11, T22, T41 & 20 \\
\hline \multirow{3}{*}{ EP2 } & $P 2$ & $T 32$ & 20 \\
\cline { 2 - 4 } & $P 3$ & T31 & 20 \\
\cline { 2 - 4 } & $P 5$ & $T 20, T 40, T 50$ & 20 \\
\hline \multirow{2}{*}{ EP3 } & $P 6$ & $T 61, T 70, T 72$ & 20 \\
\cline { 2 - 4 } & $P 8$ & $T 60, T 62, T 71$ & 20 \\
\hline
\end{tabular}

A Tabela 5 apresenta, respectivamente: os produtos requeridos, o consumidor que efetuou o pedido, a quantidade e a data de entrega de cada pedido em unidades de tempo (u.t.) a partir do pedido.

Tabela 5 - Pedidos e suas respectivas data de entrega.

\begin{tabular}{|c|c|c|c|}
\hline Produtos & Consumidores & Quantidade & Data de entrega \\
\hline Pro1 & Consumidor 3 & 70 & 64 \\
\hline Pro2 & Consumidor 4 & 50 & 88 \\
\hline Pro3 & Consumidor 1 & 50 & 86 \\
\hline Pro4 & Consumidor 2 & 50 & 67 \\
\hline
\end{tabular}

Depois que os consumidores inserem os pedidos no "Serviço de Pedidos", o "Serviço de Gerenciamento de Requisições" é solicitado, e envia as informações para o "Serviço de Planejamento Virtual" calcular as "janelas globais" para todas as tarefas produtivas. Se o serviço conseguir gerar as "janelas globais", ele se comunica com o "Serviço de Gerenciamento de Requisições" para enviar as informações aos respectivos "Serviço de Planejamento Local" e envia uma mensagem para o "Serviço de Pedidos" informando que o pedido é factível. Caso contrário, o consumidor é informado da impossibilidade de atender o pedido para a data especificada. A Figura 66 mostra as tarefas, o tempo de produção (em unidades de tempo = u.t.), as quantidades de produção, isto é, o tamanho do lote, e os fluxos codificados dos processos produtivos em PFS onde as cores são para indicar que são EPs diferentes. A Figura 67 apresenta a RdP do PFS da Figura 66 modelado no software HPSIM. 
Figura 66 - Representação em PFS do fluxo codificado do processo produtivo completo referente à Figura 65 e Tabela 5 .

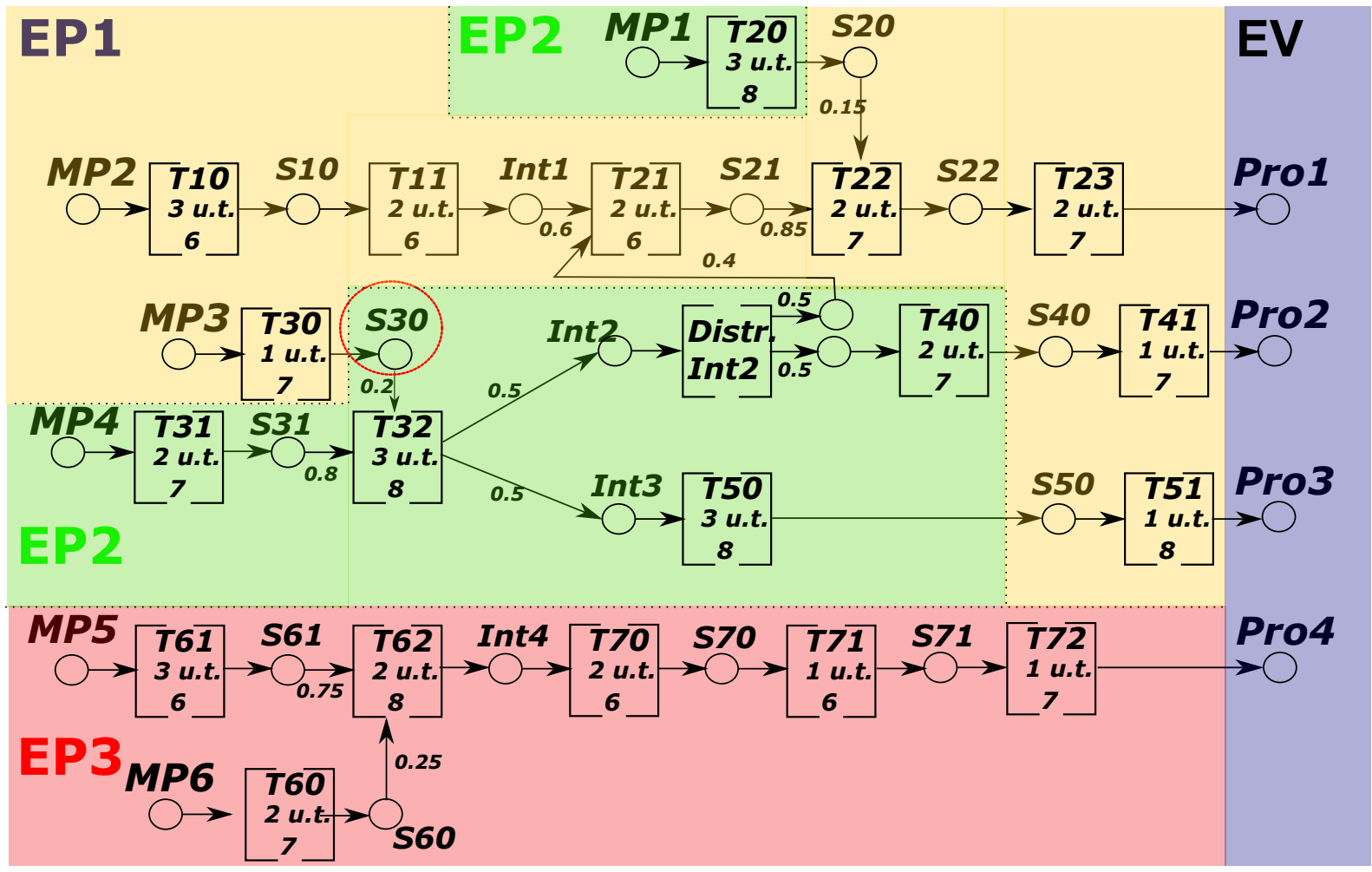

Figura 67 - Representação da RdP da Figura 66 .

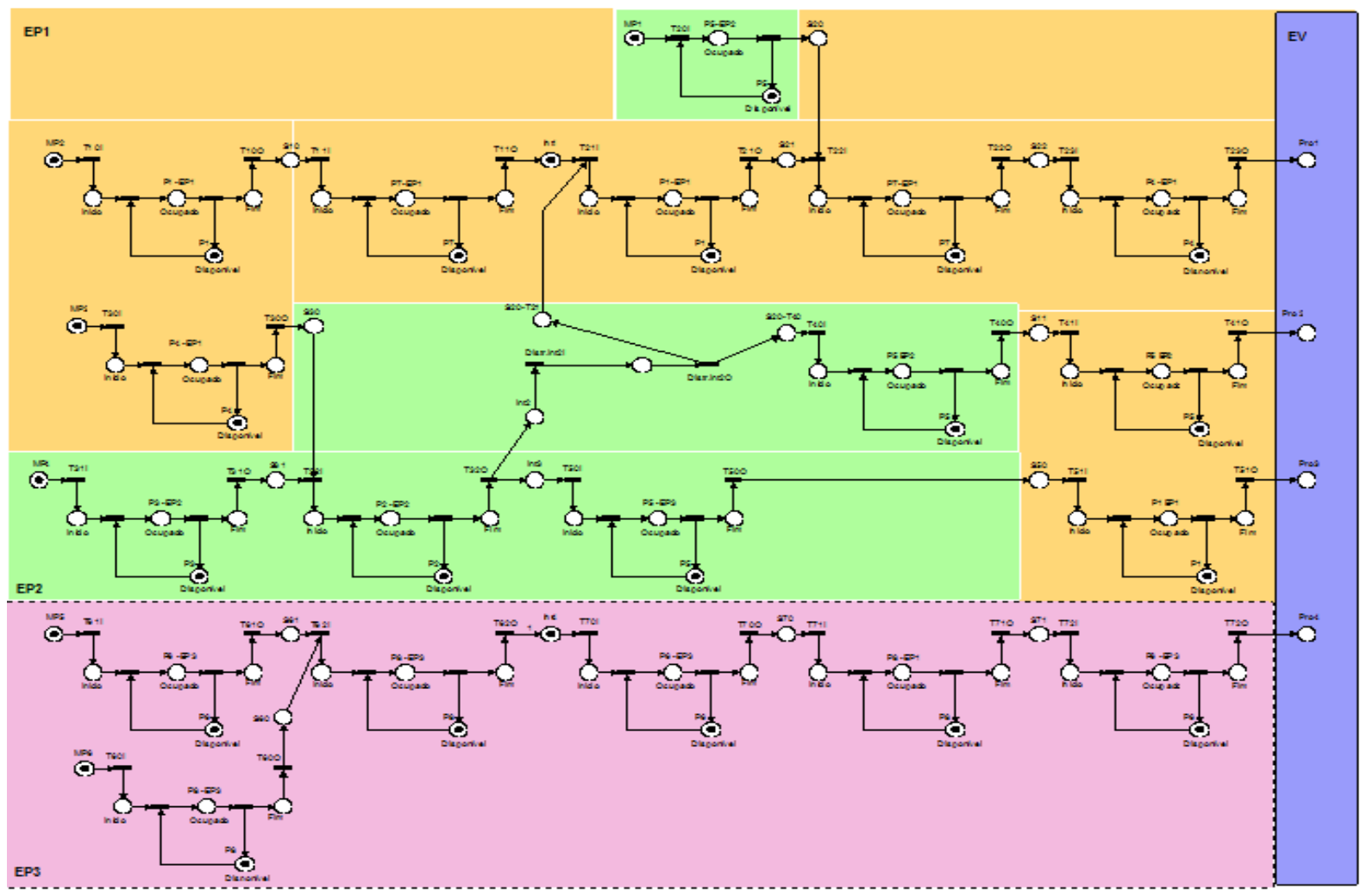


Neste exemplo, as EPs informam todo o fluxo codificado do processo produtivo relacionado à $\mathrm{EV}$, conforme apresentado nas Figuras 66 e 67. Isto é importante, pois somente desta forma o sistema de PCP baseado na arquitetura proposta pode gerar as "janelas globais", considerando todas as restrições de produção. Caso contrário, se somente fossem informadas as tarefas que tenham relação final com a EV, o PFS e a RdP somente teriam 4 tarefas e não seria possível saber se existe alguma relação de dependência entre as elas, Figuras 68a, e 68b.

Figura 68 - Representação em PFS e RdP do fluxo codificado do processo produtivo simplificado (quando a EV recebe informações somente dos produtos que serão entregues) referente à Figura 65
(a) Representação em PFS.
(b) Representação em RdP.

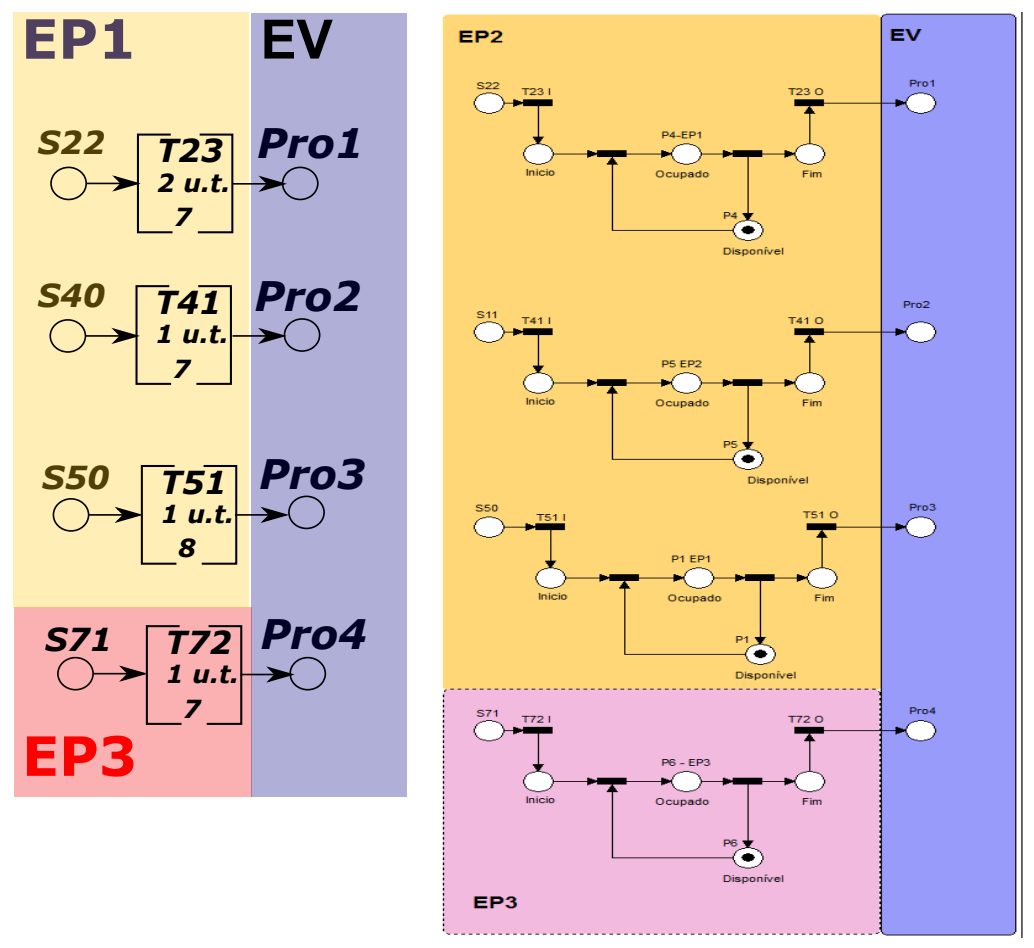

Pelas Figuras 66 e67, é possível perceber que se a EP1 atrasar o produto a ser depositado em $S 30$, ela não estará prejudicando apenas a empresa $E P 2$, ela também estará prejudicando a si mesma, pois, o atraso em $S 30$ para a $E P 2$ pode implicar no atraso em $\operatorname{Int} 2, S 40$, e $S 50$ para a própria EP1. Isto pode resultar no atraso das entregas dos produtos finais Pro1, Pro2, e Pro3. Pelas Figuras 68a e 68b, percebe-se que a apresentação com o fluxo codificado do processo produtivo simplificado não é adequado pois não possibilita ver o planejamento geral, o que pode impactar no fato da EP1 não perceber a importância da entrega na data certa em $S 30$.

As Figuras 69 a 72 apresentam as respectivas "janelas de tempo" da EV e das EP1, EP2, e EP3 geradas pelo Serviço de Planejamento Virtual. A linha horizontal representa o tempo do horizonte de programação. A parte vertical representa: a tarefa; o tempo de processamento em u.t. (ex. T10/3, tarefa T10 com tempo de processamento de 3 u.t.), as cores na 
primeira coluna da parte vertical representam as tarefas que compartilham o mesmo recurso (ex. T10/3, T21/2 e T51, são amarelas, estas tarefas compartilham o mesmo recurso). A quantidade de "janelas de tempo" de cada tarefa é relacionada com a quantidade necessária de lotes das tarefas. As tarefas T50-04, T50-05 e T50-06 da figura 71 possuem intervalos que obrigatoriamente serão utilizados pelas tarefas T40-05, T40-06 e T40-07, por exemplo, o intervalo da "janela de tempo" da tarefa $T 40-05$ é de $T=67$ à 70 e o $T p=2$, desta forma, o instante $T=68$ será obrigatoriamente utilizado pela tarefa, e a propagação de restrições recortou este instante da janela T50-04, impossibilitando uma futura alocação infactível, pois o recurso tem capacidade finita. 
Figura 69 - "Janelas globais" geradas para a EV pelo "Serviço de Planejamento Virtual".

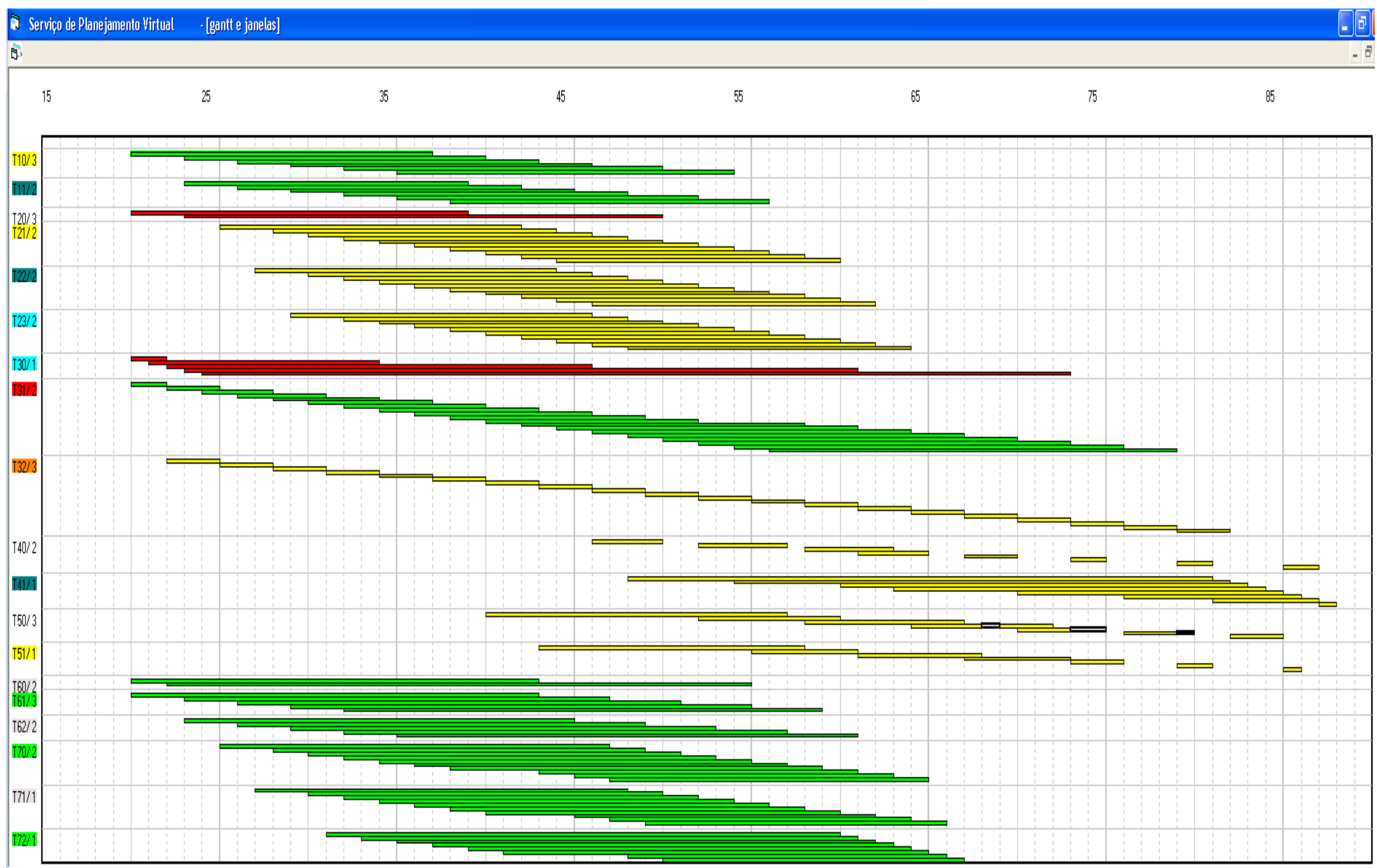


Figura 70 - "Janelas locais" geradas para a EP1 pelo Serviço de Planejamento Virtual.

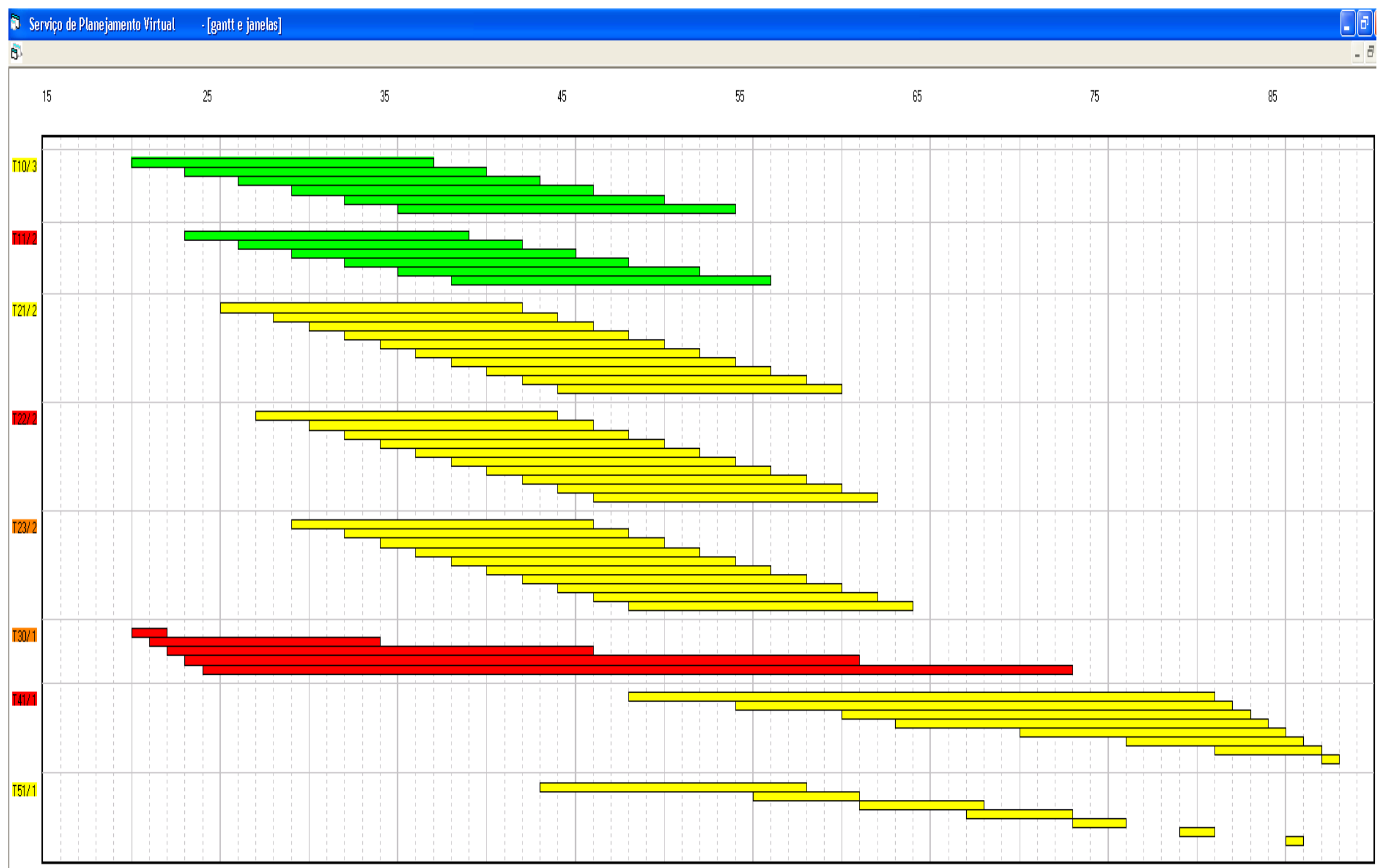


Figura 71 - "Janelas locais" geradas para a EP2 pelo Serviço de Planejamento Virtual.

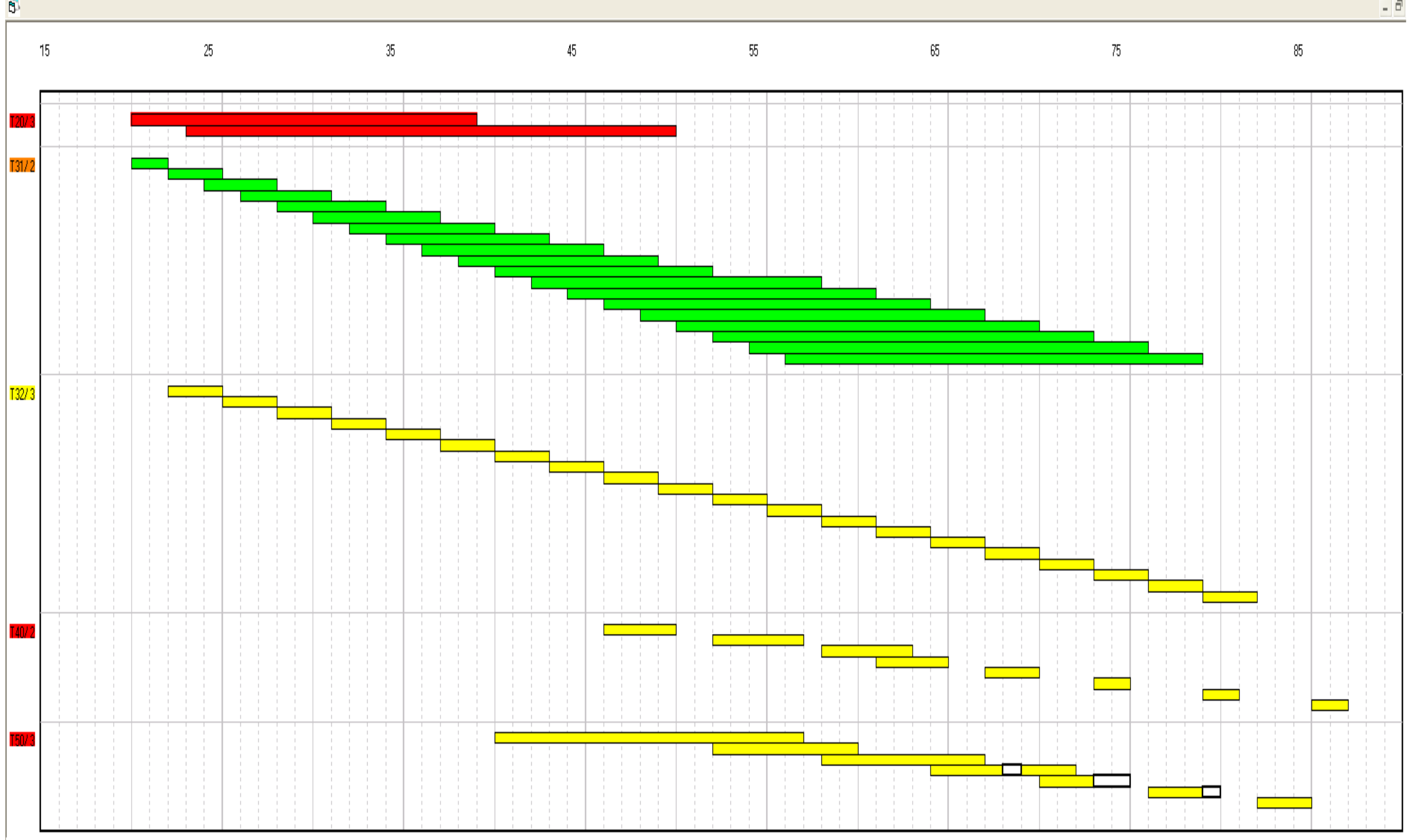


Figura 72 - "Janelas locais" geradas para a EP3 pelo Serviço de Planejamento Virtual.

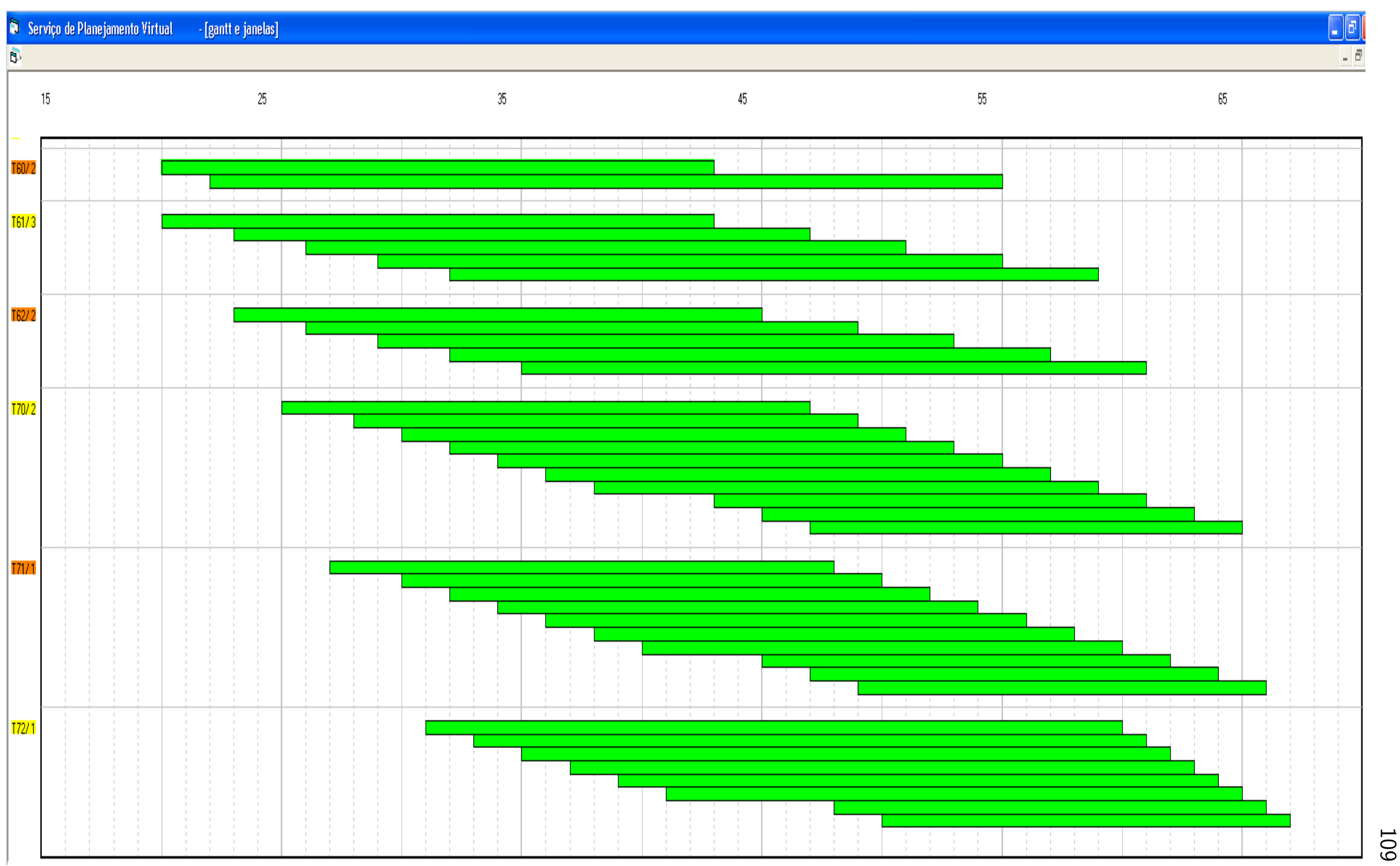


Com as "janelas globais" geradas para a EV, ou seja, o planejamento global, envia-se as respectivas "janelas locais" para cada EP. Neste exemplo, é possível gerar as "janelas globais". Desta forma, os pedidos são factíveis de serem entregues na data desejada.

Neste exemplo é possível observar quatro vantagens da proposta: (1) autonomia para as EPs, já que para gerar as "janelas de tempo" a primeira informação a ser inserida é a disponibilidade das EPs, desta forma, é a EP quem decide quando está disponível para produzir para a EV; (2) é possível verificar a factibilidade de um pedido sem a necessidade de descer a informação até a função de programação da produção de cada EP; (3) é possível gerar um planejamento global para a EV e dividir esse planejamento para cada EP, ou seja, garante-se uma integração e isomorfismo entre as informações; e (4) cada EP recebe a informação de um intervalo de tempo que pode ser utilizado para otimizar a sua alocação das tarefas produtivas, ou seja, cada EP pode alocar os recursos para outros pedidos não relacionados com a $E V$, utilizando seus critérios locais de otimização. Na Figura 71 é possível notar essa vantagem. Por exemplo, a tarefa T50 deve produzir 7 lotes, e a primeira "janela local" gerada estabeleceu um intervalo de 40 a 57 para realizar o primeiro lote desta tarefa. Como é necessário apenas 3 u.t. para concluir esta tarefa, a EP2 pode usar seu recurso para outras tarefas. No entanto, o último lote tem a "janela local" de 82 a 85 . Portanto, esta tarefa deve ser realizada exatamente neste período.

Pelo exemplo de aplicação apresentado, é possível perceber que, apesar das EPs serem distribuídas, elas necessitam de uma intensa interação entre si, como é o caso da entrega do produto em S30. Se houver um atraso, a EV não consegue atender nenhum dos quatro pedidos. Isto possibilitou perceber que apesar de todas as tarefas terem as suas "janelas locais" geradas, enquanto $T 30$ não for programado na $E P 1$, as outras EPs não podem fazer a programação de todas as suas tarefas. Para solucionar este problema e permitir uma maior colaboração entre as EPs, aumentando a eficiência no sistema como um todo, o sistema de PCP para EV baseado na arquitetura proposta cria três tipos diferentes de "janelas de tempo": "janelas de processamento" (cor verde), "janelas temporárias" (cor amarela), e "janelas imediatas" (cor vermelha). Estes três tipos de "janelas de tempo" estão representadas nas Figuras 70, 71, e 72 . É importante observar que uma tarefa que consome produto, isto é, tarefa consumidora de uma tarefa de "janela temporária", também passa a ter a sua janela do tipo "temporária". Isto devido às tarefas terem relação de dependência, ou seja, uma somente pode ser produzida depois da outra, como no caso das "janelas globais" T21, T40, T50, T41, e T51, que dependem de T32, que é temporária, pois necessitam de itens em $S 30$, que é produzido por outra EP. As tarefas T22 e T23 também são temporárias, entretanto, elas dependem de T20 e T21.

Depois que as EPs recebem as suas "janelas locais", elas analisam as "janelas". Se houver alguma "janela imediata", a EP deve fazer uma alocação imediata, como nos casos da EP1 
com $T 30$ e da EP2 com o $T 20$. Neste exemplo, a $E P 1$ faz as suas alocações utilizando a heurística APS de alocação mais cedo, e a EP2 faz com a heurística APS de alocação mais tarde, apresentadas no (Apêndice B) e em Pessoa et al. (2014). A Figura 73 apresenta a alocação mais cedo das 5 tarefas de $T 30$ na EP1. Na parte de cima da Figura 73 estão as 5 tarefas T30 (T30-01, T30-02, T30-03, T30-04, e T30-05) alocadas no recurso P4 e representadas numa Carta de Gantt. As cores na primeira coluna da parte da Carta de Gantt representam os recursos (ex.: o recurso $P 1$ está representado em amarelo). Na primeira coluna da parte de baixo da figura estão as tarefas, e pela cor da tarefa é possível identificar em qual recurso a tarefa é processada e quais tarefas compartilham o mesmo recurso (ex. T10/3, T21/2 e T51 são amarelas e estas tarefas compartilham o recurso $P 1$ ). As "janelas de tempo" de T30 deixam de ser "janelas de tempo", pois as tarefas já foram alocadas, desta forma, os intervalos de alocação ficaram na cor preta e o restante dos intervalos na cor salmão. Assim que é feita a alocação, a EP1 envia as novas informações de suas janelas para o "Serviço de Planejamento Local" da $E P 2$, que depende destas informações, pois suas janelas são temporárias, e para o "Serviço de Gerenciamento de Requisições" atualizar os novos dados. A EP2 aloca a tarefa $T 20$ e também envia as novas informações para a EP1 e para a EV. A Figura 74 apresenta a alocação mais tarde de $T 20$ na $E P 2$.

Na Figura 74 é possível perceber a propagação das restrições quando as duas tarefas da T20 são alocadas. Percebe-se que o início da janela de T40 foi recortado, isto porque quando a segunda tarefa de $T 20$ é alocada, ela ocupa o recurso entre $T=45$ u.t. e $T=48$ u.t. Desta forma a primeira tarefa de $T 40$ não pode ocupar o mesmo período. A $E P 2$ recebe as informações da $E P 1$, atualiza as suas janelas e analisa as informações. A Figura 75 apresenta as "janelas locais" da primeira atualização da EP2. Pode-se observar que, após as atualizações, as janelas relativas às tarefas T32, T40 e T50 mudaram do tipo "janela temporária" para "janela imediata" e não "janela de processamento". Isto ocorre porque elas produzem itens que são consumidos pela EP1.

A Figura 76 apresenta as "janelas locais" da primeira atualização da $E P 1$. É possível perceber que apesar das janelas não terem mudado de tipo, a propagação de restrição atualizou todas as janelas, e as janelas das tarefas T22 e T23 foram recortadas. Por exemplo, o EST da primeira tarefa de $T 22$ mudou de $T=27$ u.t. para $T=39 u$.t., e o $E S T$ da primeira tarefa de $T 23$ mudou de $T=29$ u.t. para $T=41$ u.t.. Estas informações sobre estes recortes são importantes para as EPs, pois como elas não podem mais alocar nestes intervalos recortados, elas podem disponibilizar estes intervalos para alocar outras tarefas que não estejam relacionadas com a EV. A EP2 ainda tem "janelas imediatas" (T32, T40, e T50). Elas devem ser alocadas assim que a $E P 2$ receber informações sobre elas. A Figura 77 apresenta a alocação das "janelas imediatas" da EP2. 
Figura 73 - "Janelas locais" de EP1 após alocação de $T 30$.

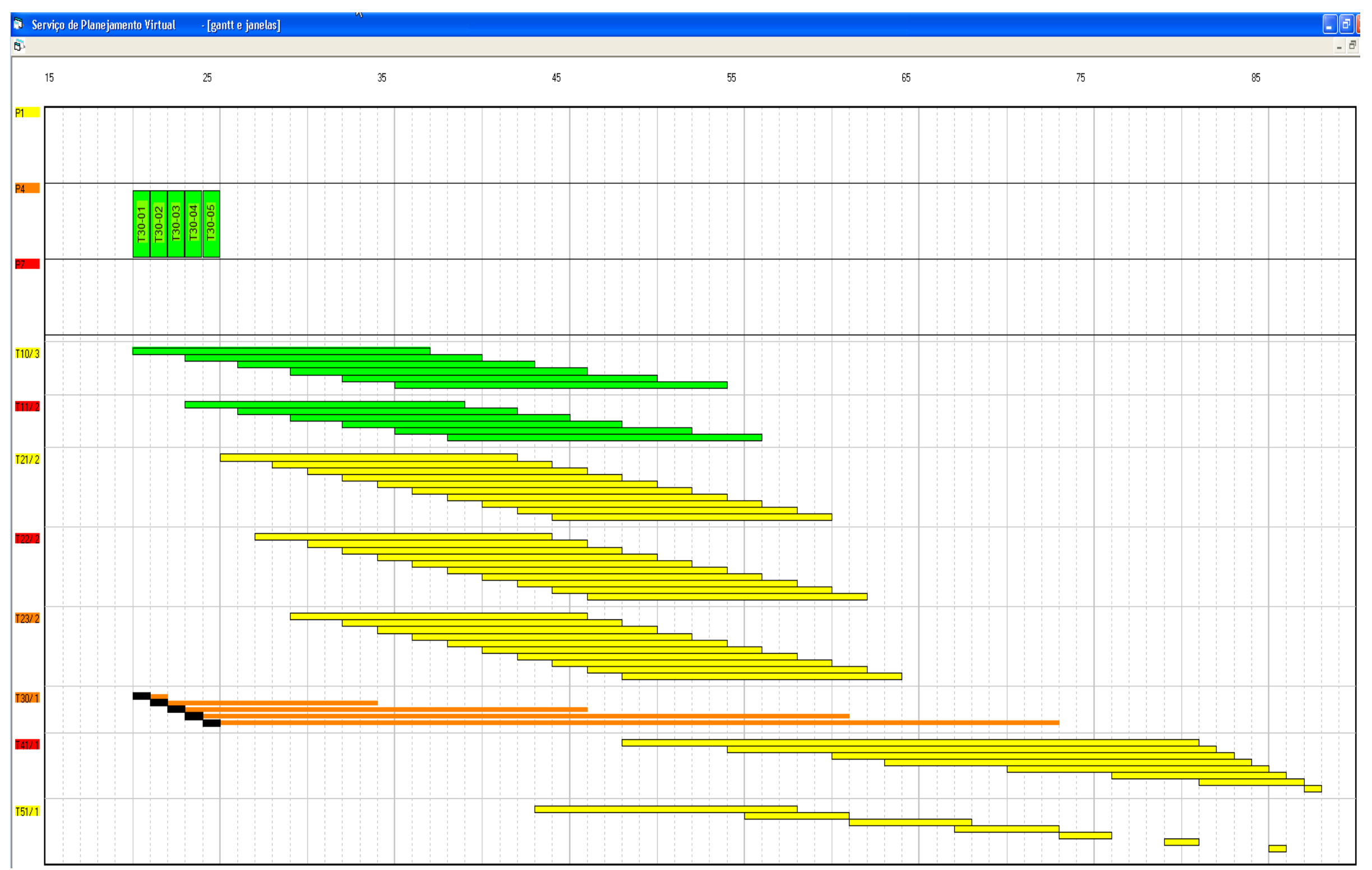


Figura 74 - "Janelas locais" de EP2 após alocação de $T 20$.

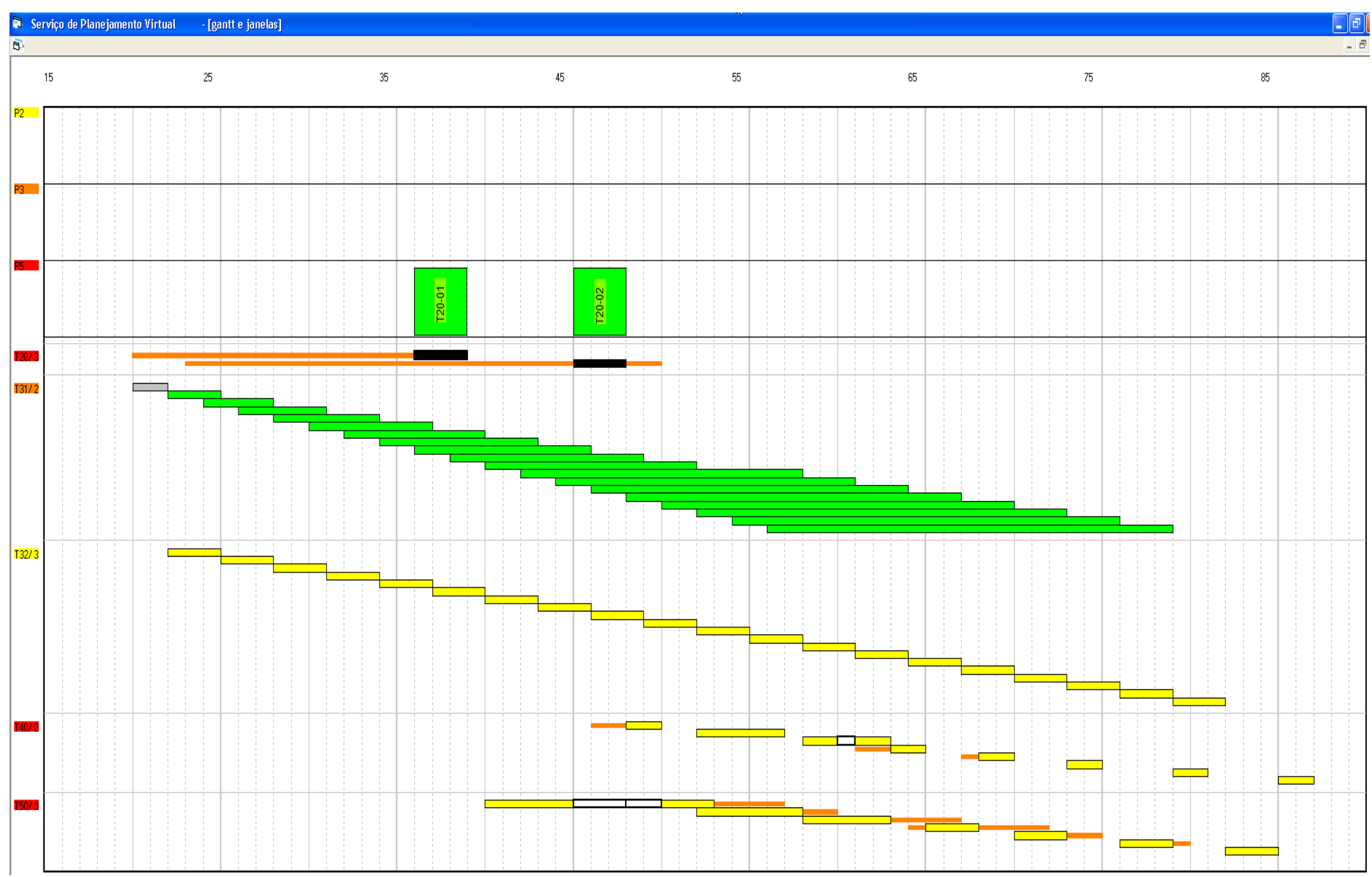


Figura 75 - "Janelas locais" de EP2 após a $1^{a}$ atualização das informações recebidas de $E P 1$.

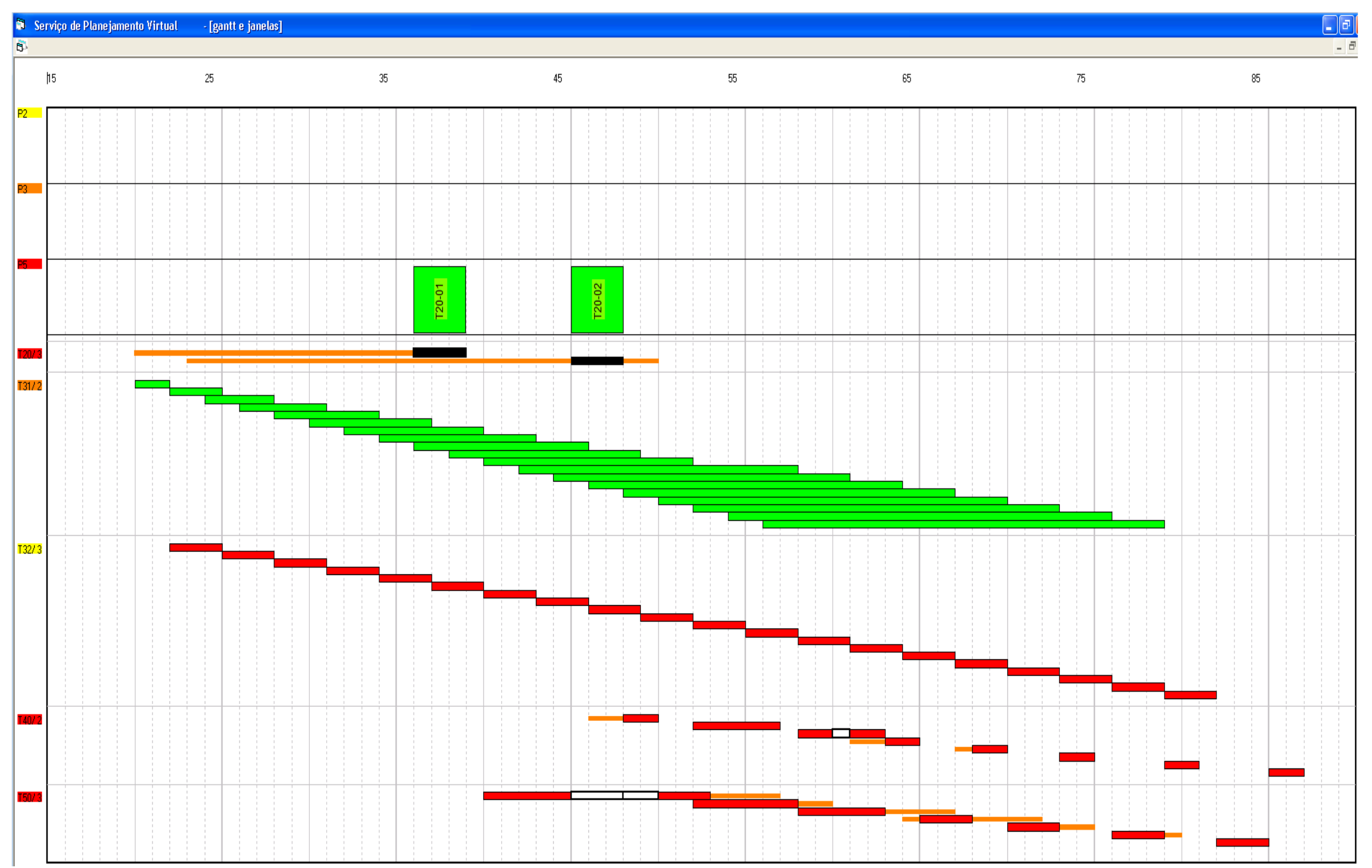


Figura 76 - "Janelas locais" de $E P 1$ após a $1^{a}$ atualização das informações recebidas de $E P 2$.

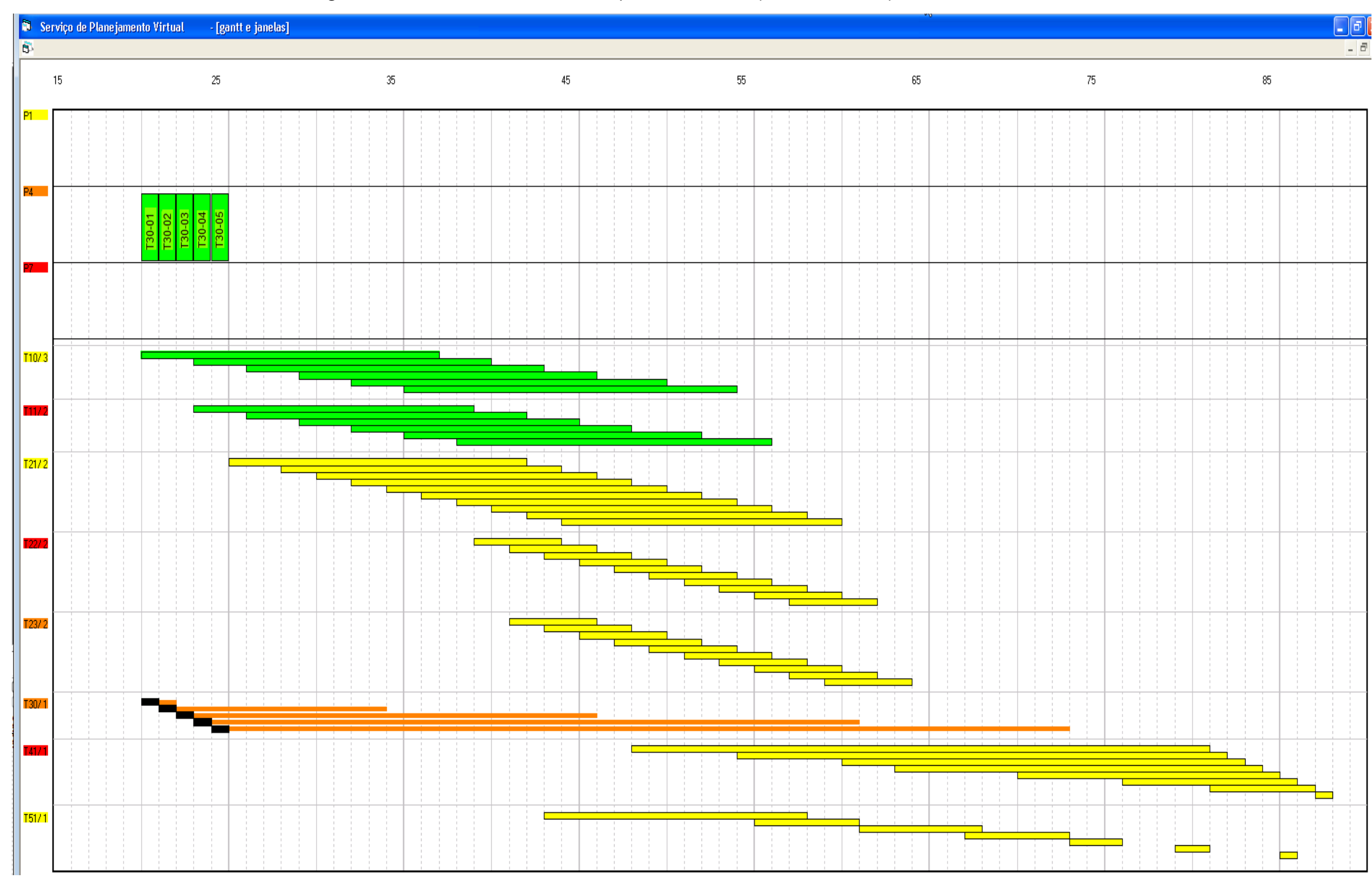


Figura 77 - "Janelas locais" de EP2 após alocação de $T 32$, T40, e $T 50$.

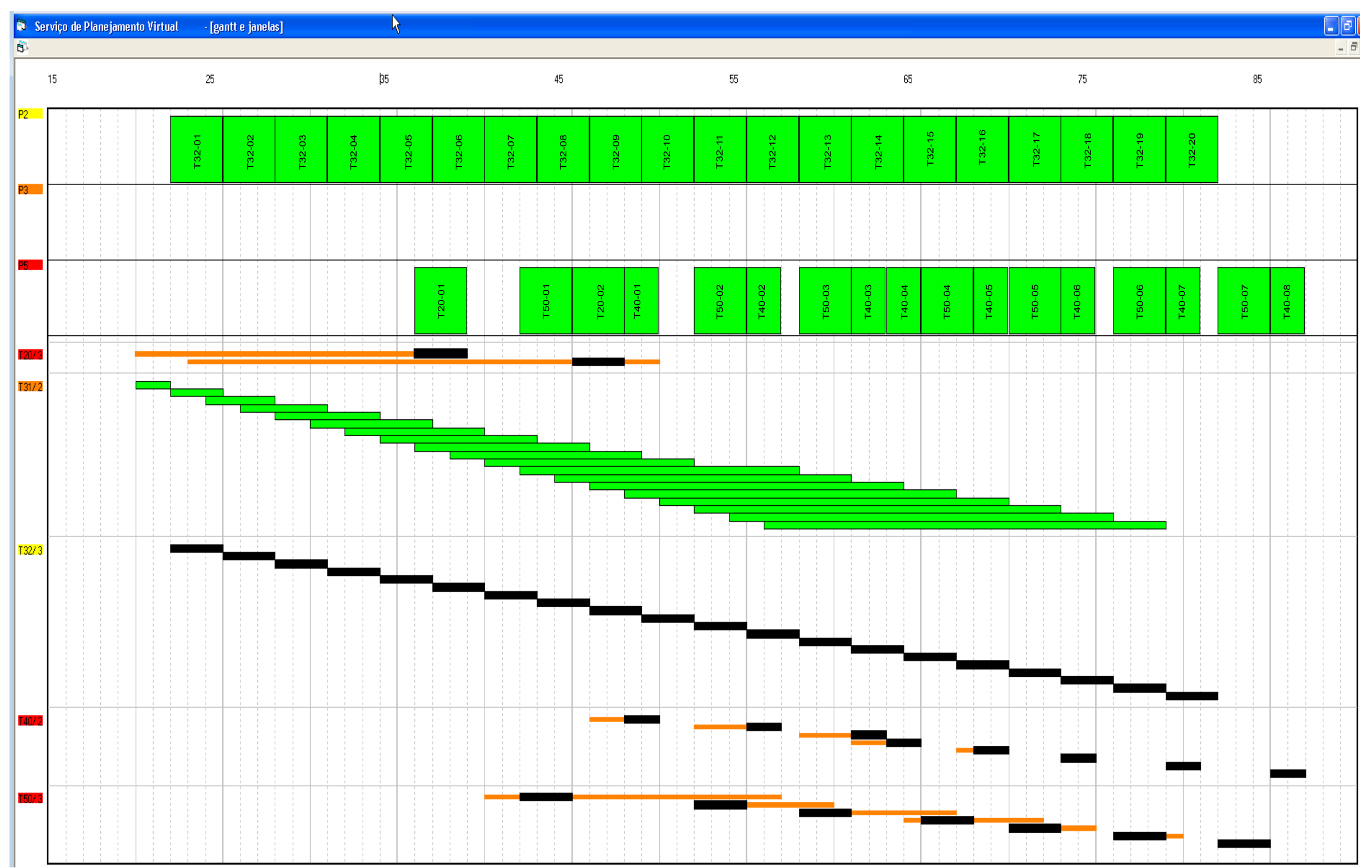


As informações das janelas atualizadas da EP2 são enviadas para o "Serviço de Planejamento Local" da EP1 e para o "Serviço de Gerenciamento de Requisições" da EV. A Figura 78 apresenta as janelas da EP1 após atualizações. Pela Figura 78 percebe-se que depois das atualizações das informações recebidas da $E P 2$, todas as janelas das tarefas de $E P 1$ ficaram do tipo "janelas de processamento". Desta forma, não existe mais nenhuma relação de dependência entre as EPs que impossibilitem as alocações das tarefas e nenhuma alocação propaga as janelas de outra EP. Cada EP pode escolher o melhor momento para alocar, desde que respeite as janelas fornecidas.

As Figuras de 79 a 81 apresentam as alocações finais de todas as tarefas das EPs. A EP1 teve como objetivo alocar todas as tarefas no instante mais cedo. Pela Figura 79 é possível perceber que a alocação foi no instante mais cedo. A $E P 2$ teve um objetivo inverso da $E P 1$, ou seja, a EP2 teve como objetivo alocar o mais tarde possível. Pela Figura 80 é possível perceber que a alocação foi no instante mais tarde. Entretanto, a EP3 trabalha com os dois objetivos, e desta forma, alocou as tarefas $T 71$ e $T 72$ mais tarde e as restantes mais cedo.

As heurísticas de alocação utilizadas são apenas alguns dos exemplos possíveis, pois para o sistema de PCP para EV baseado na arquitetura proposta é possível incluir outras heurísticas de alocação e, como está sendo utilizada a propagação de restrições, também é possível incluir diferentes regras de restrição, conforme a necessidade, desde que depois das propagações existam ainda intervalos para serem utilizados. O exemplo apresentado confirma que o sistema de PCP para EV baseado na proposta consegue atender as necessidades de autonomia e colaboração das EPs. Mostra que é viável e eficaz a utilização das "janelas de tempo" em conjunto com a "propagação de restrição" na arquitetura proposta. A arquitetura apresentada estabelece os elementos de um sistema de PCP que possibilita a geração do planejamento da EV de acordo com o seu objetivo global, interferindo o mínimo possível com o objetivo local das EPs. Neste exemplo a geração das "janelas globais" demorou menos de 1 minuto e as gerações das "janelas locais" demoraram menos de 30 segundos em cada EP. 
Figura 78 - "Janelas locais" de $E P 1$ após a $2^{a}$ atualização das informações recebidas de $E P 2$.

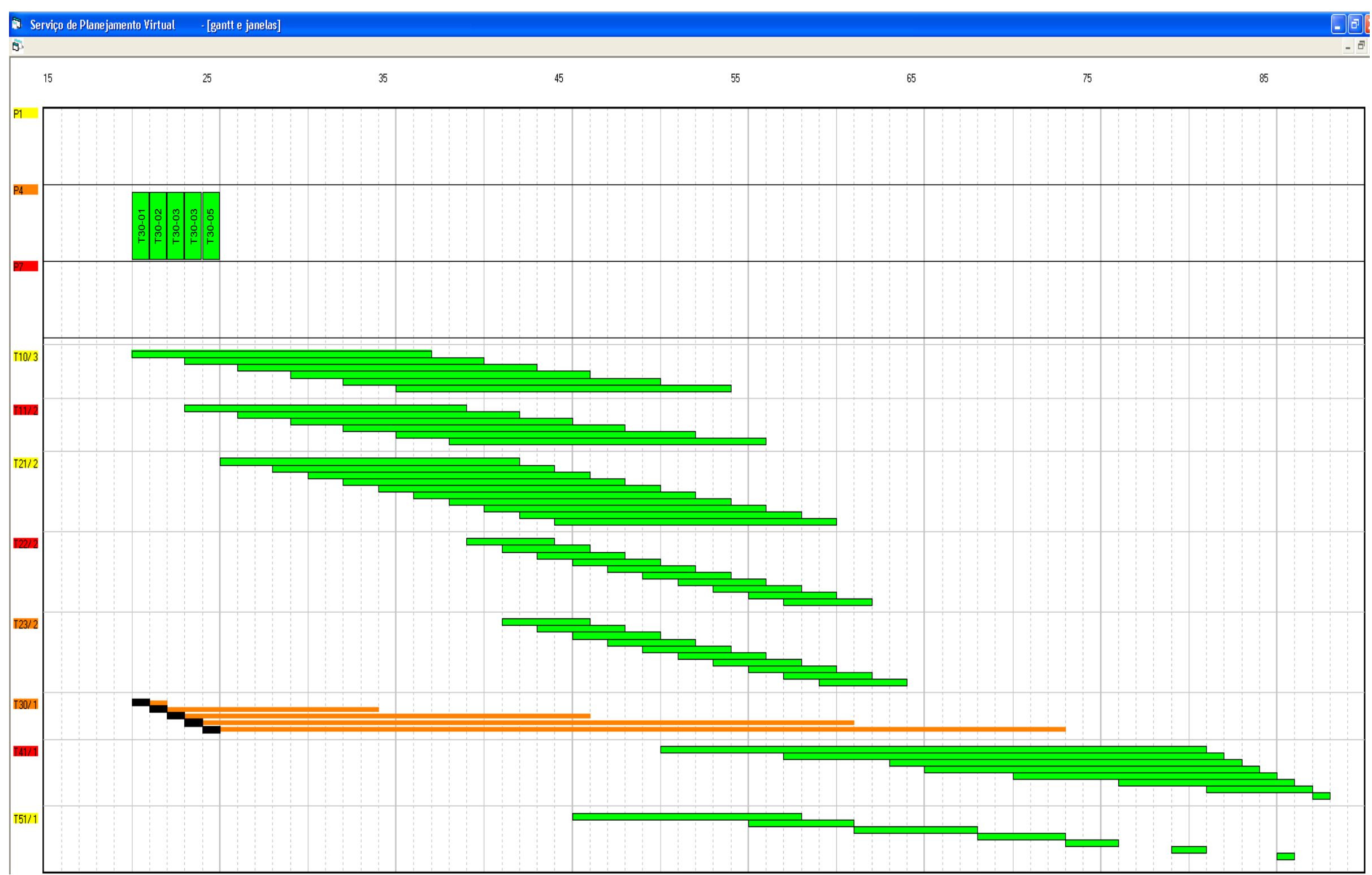


Figura 79 - "Janelas locais" e alocação final de EP1.

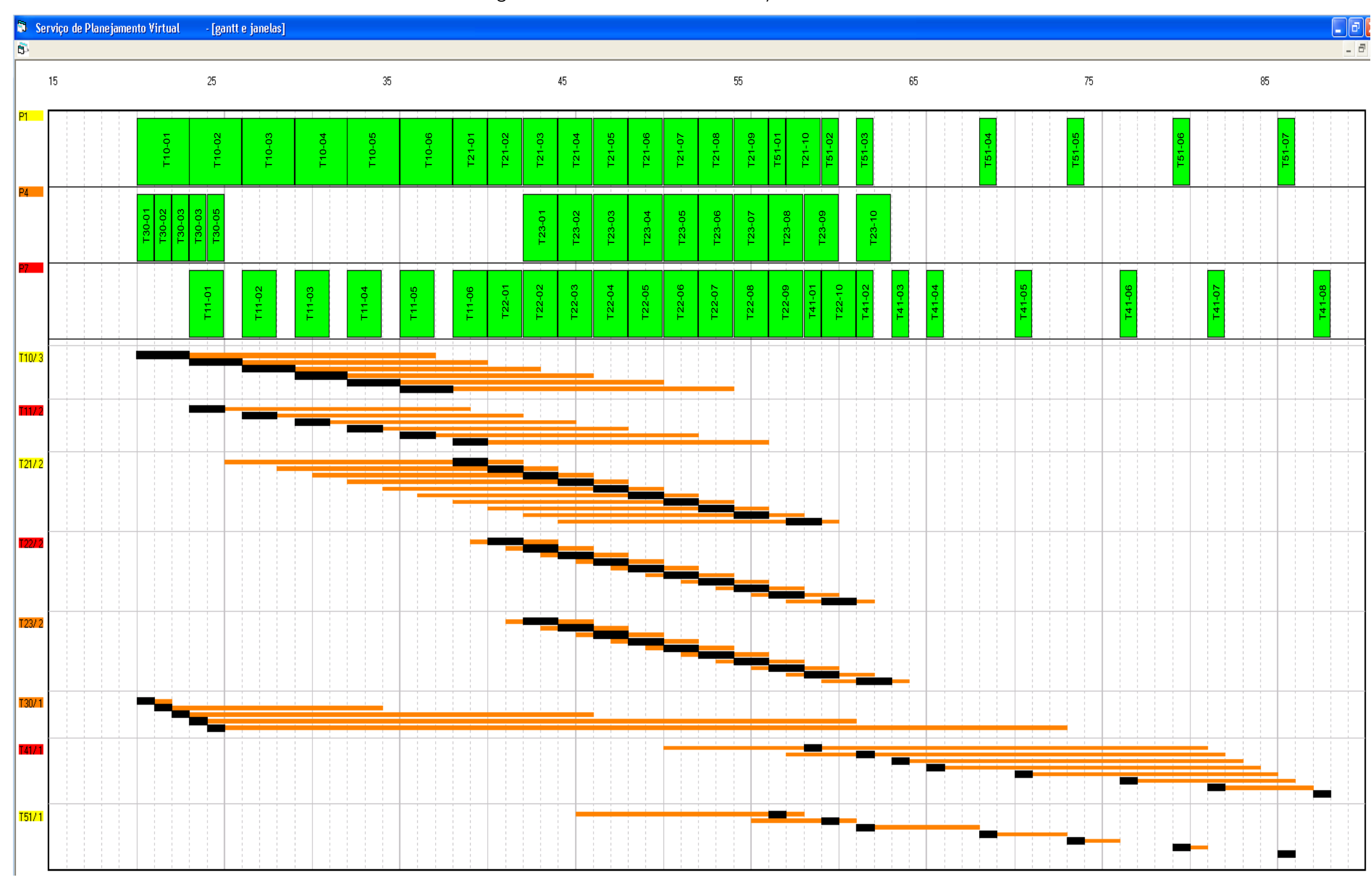


Figura 80 - "Janelas locais" e alocação final de EP2.

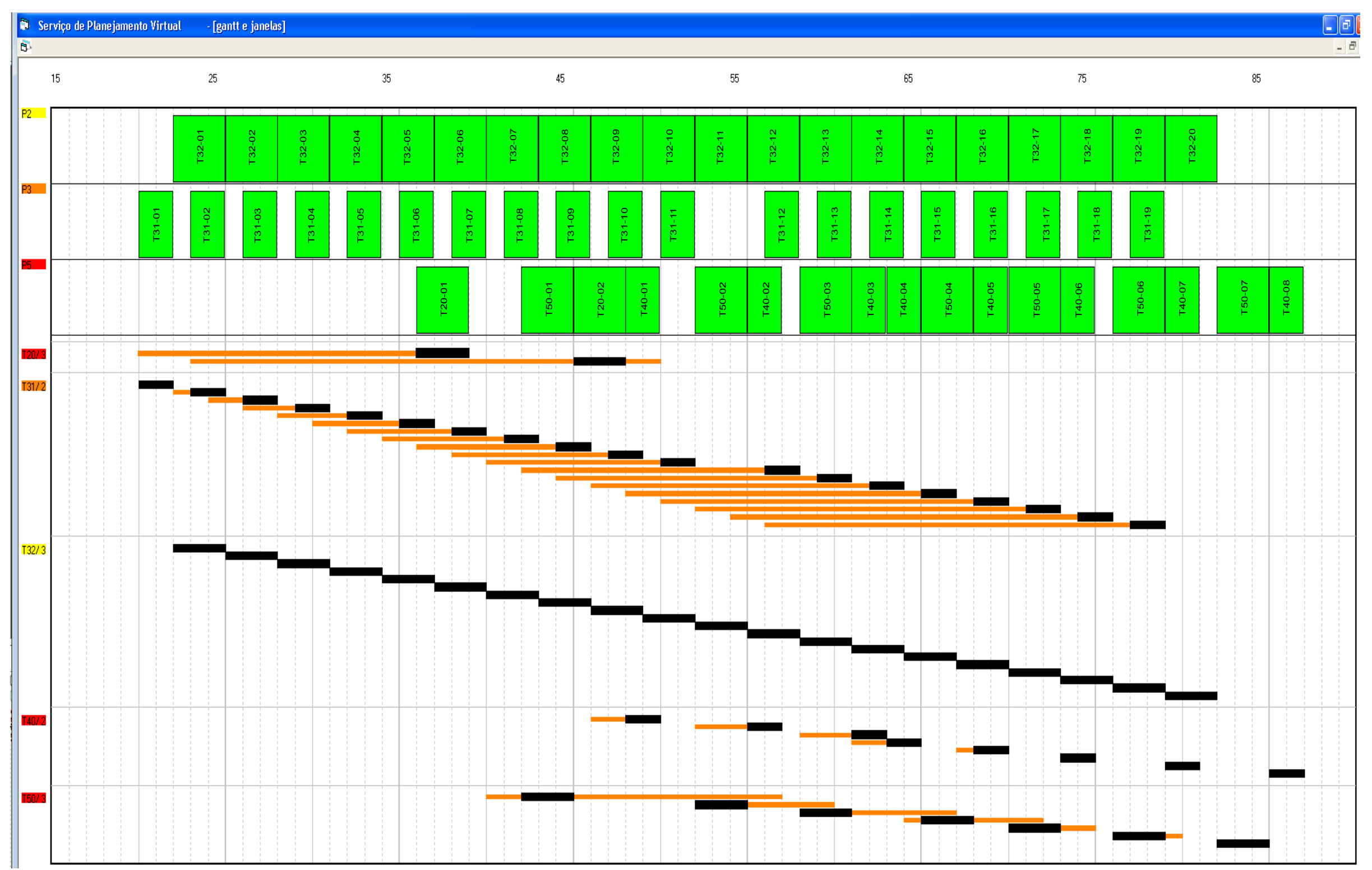


Figura 81 - "Janelas locais" e alocação final de EP3.

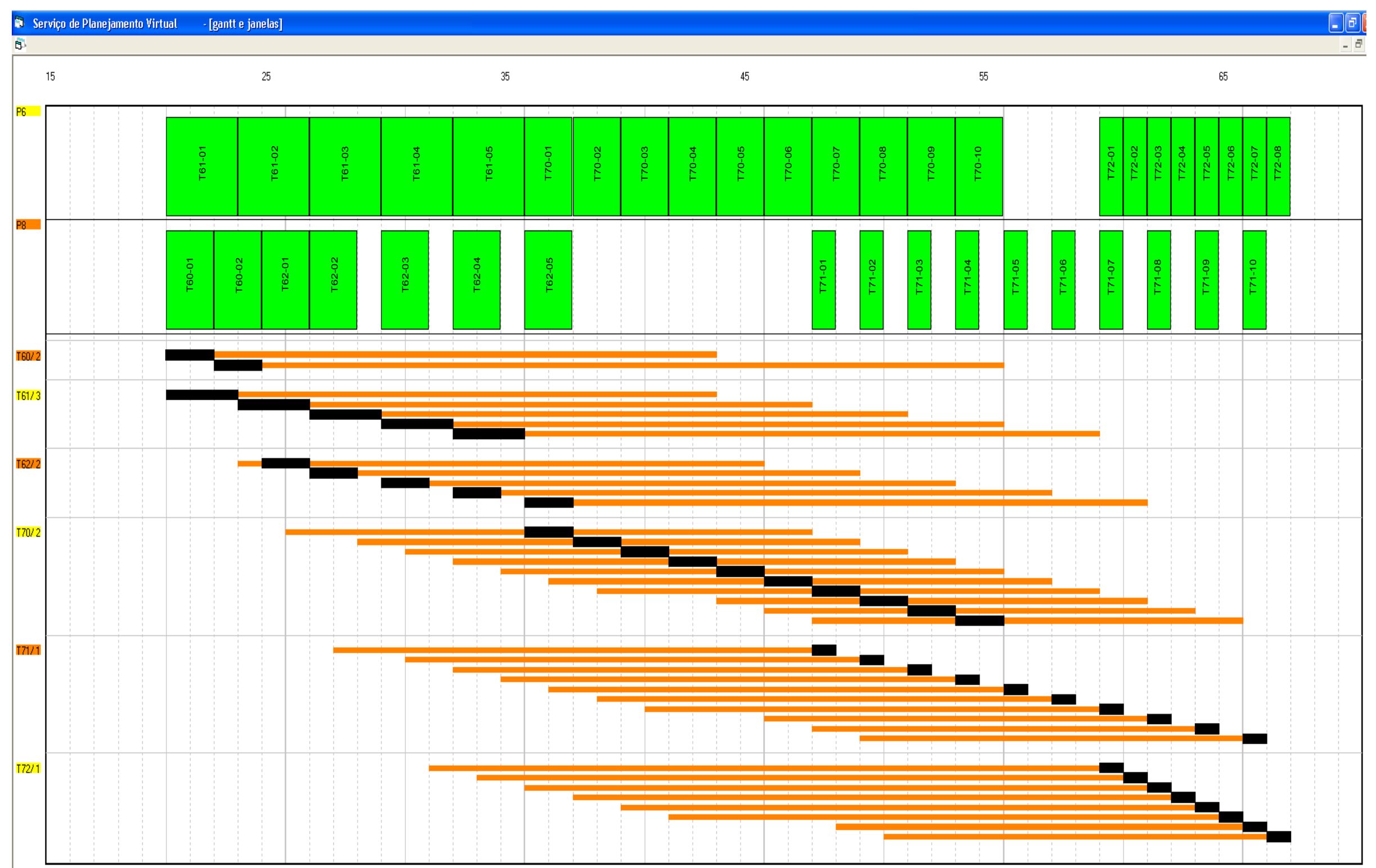




\section{CONCLUSÕES}

Foi proposta uma arquitetura de sistema de planejamento e controle da produção para EV utilizando-se o conceito de "janelas de tempo" e "propagação de restrições" para considerar as capacidades específicas de cada EP da EV e restrições operacionais para a programação de produção. A arquitetura proposta considera fundamental uma forte integração com sistemas de outras EPs.

A norma ANSI-ISA95 estabelece como deve ser a integração de sistemas industriais, estando de fato, presente em boa parte dos sistemas de gestão industrial e ERPs. Entretanto, a norma não contempla o contexto de EV. Assim, a norma foi analisada e devidamente reinterpretada para compatibilizar a arquitetura proposta. A ANSI-ISA95 se adequa ao conjunto da proposta em quase todo o seu contexto, sendo que foi necessário apenas considerar uma reinterpretação de elementos no modelo de hierarquia de equipamento.

$\mathrm{Na}$ arquitetura proposta, a utilização das "janelas de tempo" em conjunto com a propagação de restrições demonstrou ser efetiva, pois, como uma das características principais da EV é a autonomia das EPs, a arquitetura proposta assegura esta característica. Para a geração das "janelas de tempo" é necessário que a empresa parceira forneça a informação da disponibilidade dos seus processos, isto é, a EP pode deixar os processos disponíveis para a EV quando desejar, mas sem necessidade de disponibilizar informações internas da EP.

Foi possível verificar a factibilidade de um pedido sem a necessidade de refazer toda a função de programação da produção. A arquitetura proposta considera a geração de um planejamento global da EV e a divisão desse planejamento para cada empresa parceira (EP), ou seja, considera uma integração entre a EV e as EPs. Assim, a EP pode receber a informação de um intervalo de tempo e não de uma data exata para entrega do produto, o que pode ser utilizado para otimizar a programação de suas tarefas produtivas. Ou seja, cada EP pode alocar os recursos para outros pedidos não relacionados com a EV adotando critérios locais de otimização. Desta forma, a arquitetura possibilita o planejamento da EV de acordo com o seu objetivo global, interferindo o mínimo possível com o objetivo local das EPs.

O trabalho realizado envolveu a concepção de três tipos de "janelas de tempo" para a arquitetura assegurar uma maior colaboração entre as EPs, permitindo uma eficiência maior do sistema produtivo como um todo. Os diferentes tipos são: "janela de processamento", "janela temporária", e "janela imediata". Com estes três tipos de "janelas" foi possível criar uma forte colaboração entre as EPs e assegurar uma melhor eficiência na gestão dos recursos das EPs.

Com a integração dos web services e o gerenciamento das informações pelo "serviço de dados", a EV de tipo de estrutura fixa é atendida plenamente e a do tipo variável é atendida 
parcialmente. Isto porque não faz parte do escopo da arquitetura proposta contemplar funcionalidades específicas de pesquisa e seleção de parceiros. Como trabalho futuro é necessário testar e avaliar a proposta para este tipo de caso a fim de aprimorar a arquitetura. As informações trocadas entre EPs são codificadas de maneira que mesmo validando o fluxo do processo produtivo da EV com o PFS e RdP, nenhum dado relativo aos processos internos da EP seja trocado entre as empresas, atendendo, desta forma, os tipos de participação das EPs de aliança única e aliança múltipla. A estrutura hierárquica modificada da arquitetura proposta permite que os três tipos de coordenação sejam atendidos, ou seja: 1) a estrutura tipo estrela é atendida pois o gerenciamento das informações e dos web services pode ser feito pela empresa dominante; 2) os web services podem permitir que todos os parceiros cooperem numa base de igualdade, entretanto o parceiro (coordenador) administra as informações gerais; 3) cada web service pode ser instalado numa EP diferente, ou até mesmo na internet desde que todos os parceiros tenham os mesmos direitos de acesso (poder), permitindo desta forma atender o requisito de uma coordenação do tipo federação. A validação do modelo da EV em PFS confirma que um parceiro pode ter acesso às informações de outro parceiro (evidentemente por este disponibilizadas) não relacionado diretamente a ele permitindo assim, uma visibilidade multi-nível. A arquitetura proposta atende a EV de duração de aliança a longo prazo, pois os web services fornecem uma infraestrutura de apoio para a definição de processos de negócios e supervisão relacionadas aos pedidos e ao planejamento. Entretanto não foram consideradas as EVs de duração de negócio único, isto porque não faz parte do escopo da proposta. Pode ser avaliado em trabalhos futuros.

O desenvolvimento deste trabalho geraram os seguintes artigos: (PESSOA et al., 2010; PESSOA et al., 2011; PESSOA et al., 2012; PESSOA et al., 2013; PESSOA et al., 2014)

Como trabalhos futuros pode-se citar:

- A inclusão de infraestrutura de apoio à criação e dissolução de EVs e desenvolvimento de funcionalidades específicas de pesquisa e seleção de parceiros.

- A combinação com a Arquitetura com Orientação a Serviços para Sistemas Produtivos Teleoperados e Dispersos. Esta arquitetura foi desenvolvida em Web service e com ela é possível controlar e teleoperar Sistemas Produtivos Dispersos. Entretanto, os pedidos são introduzidos no sistema como uma fila, sem nenhum tratamento para verificação de factibilidade do mesmo. Ou seja, a arquitetura proposta por Melo (2011) não contempla um sistema de PCP como o apresentado neste trabalho. Com a combinação adequada do sistema de PCP para EV baseado na arquitetura proposta com a arquitetura de Sistemas Produtivos Teleoperados e Dispersos, pode-se melhorar a forma de controle da produção, pois os sistemas produtivos poderão enviar as informações do chão de fábrica de uma 
forma mais rápida e consistente.

- A adoção de um Sistema Dinâmico de Controle de alocação de Recursos que considera máquinas ferramentas multifuncionais (ASATO et al., 2013). O sistema proposto por Asato et al. (2013) realiza o reescheduling no nível de chão de fábrica, recebendo dados do sistema de PCP e utilizando as informações referentes às funcionalidades das máquinas multifuncionais. O reescheduling é feito de acordo com a informação do último scheduling e o status do conjunto de recursos disponíveis. A utilização do sistema de PCP para EV baseado na arquitetura proposta possibilita o envio dos intervalos das "janelas de tempo" em conjunto com as informações do último scheduling para o sistema proposto por Asato et al. (2013), o que possibilita, quando necessário, que o reescheduling seja feito nos intervalos das "janelas de tempo" garantindo assim que o reescheduling mantenha a data de entrega dos produtos. 


\section{Referências}

ADAM, N. R.; ATLURI, V.; HUANG, W.-K. Modeling and analysis of workflows using Petri nets. Journal of Intelligent Information System, Boston, Kluwer Academic Publisher, v. 10, n. 2, p. 131-158, mar 1998. DOI: 10.1023/A:1008656726700.

AMARAL-FILHO, G. C. Requisitos para Sistemas de Controle de Sistemas Produtivos Integrados à Gestão. 2005. Dissertação (Mestrado) - Escola Politécnica da Universidade de São Paulo, São Paulo, Brasil.

ANSI. ANSI/ISA-S88.01. Batch Control Part 1: Model and terminology. [S.I.], 1995.

ANSI. ANSI/ISA-95.00.03-2005. Enterprise-control system integration Part 3: Activity Models of Manufacturing Operations Management. [S.I.], 2005.

ANSI. ANSI/ISA-95.00.01-2010. Enterprise-control system integration, Part 1: Models and terminology. [S.I.], 2010.

APPLEGATE, L. M.; MCKENNEY, J. L.; MCFARLAN, F. W. Corporate Information System Management: Text and Cases. [S.I.]: Irwin Professional Pub, 1999.

ASATO, O. L. et al. Dynamic control of resource allocation considering multifunctional machine tools. 11th IFAC Workshop on Intelligent Manufacturing Systems. 2013.

BARBINI, F. M.; ATRI, A. D. How innovative are virtual enterprises? Proceedings of the Thirteenth European Conference on Information Systems, Proceedings of the Thirteenth European Conference on Information Systems, p. 1091-1102, 2005.

BASS, L.; CLEMENTS, P.; KAZMAN, R. Software Architecture in Practice: third edition. [S.I.]: Addison-Wesley Professional, 2012.

BECKETT, R. C. Utilizing and adaptation of the absorptive capacity concept in a virtual enterprise context. International Journal of Production Research, v. 46, n. 5, p. 12431252, 2008. DOI: 10.1080/00207540701224327.

BEL, G. et al. A knowledge-based approach to industrial job-shop scheduling, in Knowledge-Based Systems in Manufacturing. [S.I.]: Ed. A. Kusiak. Taylor and Francis, 1989.

BOSE, S. K.; BHATTACHARYA, S. A state task network model for scheduling operations in cascaded continuous processing units. Computers and Chemical Engineering, v. 33, n. 1, p. 287 - 295, 2009. DOI: DOI: 10.1016/j.compchemeng.2008.09.023. 
BRAUER, W.; REISIG, W. Carl adam petri and "petri nets". Informatik-Spektrum -, v. 29, n. 5, p. 369-374, 2006.

BROWNE, J.; ZHANG, J. Extended and virtual enterprises - similarities and differences. International Journal of Agile Management Systems, v. 1, n. 1, p. 30-36, 1999.

CALIZ, E. et al. Analyzing web service choreography specifications using colored petri nets. In: Service-Oriented Perspectives in Design Science Research. Service-Oriented Perspectives in Design Science Research. [S.I.]: Springer Berlin / Heidelberg, 2011. (Lecture Notes in Computer Science, v. 6629), p. 412-426.

CAMARINHA-MATOS, L.; AFSARMANESH, H. Collaborative networks. In: Knowledge Enterprise: Intelligent Strategies in Product Design, Manufacturing, and Management. Knowledge Enterprise: Intelligent Strategies in Product Design, Manufacturing, and Management. [S.I.]: Springer Boston, 2006. (IFIP International Federation for Information Processing, v. 207), p. 26-40.

CAMARINHA-MATOS, L. M.; AFSARMANESH, H. The virtual enterprise concept. Proceedings of the IFIP TC5 WG5.3 / PRODNET Working Conference on Infrastructures for Virtual Enterprises: Networking Industrial Enterprises. p. 3-14, 1999.

CAMARINHA-MATOS, L. M.; AFSARMANESH, H. Elements of a base ve infrastructure. Computers in Industry, v. 51, n. 2, p. $139-163,2003$.

CAMARINHA-MATOS, L. M. et al. Collaborative networked organizations - concepts and practice in manufacturing enterprises. Comput. Ind. Eng., Tarrytown, NY, USA, Pergamon Press, Inc., v. 57, p. 46-60, August 2009. 15 p. DOI: 10.1016/j.cie.2008.11.024.

CAMARINHA-MATOS, L. M. et al. Towards an architecture for virtual enterprises. Journal of Intelligent Manufacturing, Springer Netherlands, v. 9, p. 189-199, 1998.

CAMARINHA-MATOS, L. M.; PANTOJA-LIMA, C. Cooperation coordination in virtual enterprises. Journal of Intelligent Manufacturing, v. 12, p. 133-150, 2001.

CAO, Q.; HOFFMAN, J. J. Alignment of virtual enterprise, information technology, and performance: an empirical study. International Journal of Production Research, v. 49, n. 4, p. 1127-1149, 2011.

CARDOSO, J.; VALETTE, R. Redes de Petri. Florianópolis: Editora da UFSC, 1997.

CASEAU, Y.; LABURTHE, F. Improved clp scheduling with task intervals. International Conference on Logic Programming/Joint International Conference and Symposium on Logic Programming. p. 369-383, 1994. 
CASEAU, Y.; LABURTHE, F. Improving branch and bound for job-shop scheduling with constraint propagation. Proceedings of the Eighth Franco-Japanesse Conference. 1995.

CASSANDRAS, C. G.; LAFORTUNE, S. Introduction to Discrete Event Systems. Second. New York: [s.n.], 2007. 776 p.

CHEN, K.; JI, P.; WANG, Q. A case study for advanced planning and scheduling (aps). Journal of Systems Science and Systems Engineering, Systems Engineering Society of China, co-published with Springer-Verlag GmbH, v. 20, p. 460-474, 2011.

CLAIRE. Claire Schedule 1.0, reference Manual. Mountain View, EUA: Claire, 1999. Http:/www.ens.fr/ laburthe.

COTTYN, J. et al. A method to align a manufacturing execution system with lean objectives. International Journal of Production Research, v. 49, n. 14, p. 4397-4313, 2011.

CUNHA, M. M.; PUTNIK, G. D. Identification of the domain of opportunities for a market of resources for virtual enterprise integration. International Journal of Production Research, v. 44, n. 12, p. 2277-2298, 2006. DOI: 10.1080/00207540500409947.

DEMARCO, T. Structured Analysis and System Specification. Upper Saddle River, NJ, USA: Prentice Hall PTR, 1979.

DESANCTIS, G.; MONGE, P. Introduction to the special issue: communication processes for virtual organizations. Organization Science, Institute for Operations Research and the Management Sciences, v. 10, n. 6, p. 693-703, 1999.

DING, Y.; GAO, Y.; LUO, G. Virtual enterprise global production planning based on cost optimization with time constraints. International Conference on Management and Service Science, 2009. MASS'09. p. 1 -4, sept. 2009. DOI: 10.1109/ICMSS.2009.5303693.

DOBREV, M.; GOCHEVA, D.; BATCHKOVA, I. An ontological approach for planning and scheduling in primary steel production. Intelligent Systems, 2008. IS '08. 4th International IEEE Conference. v. 1, n. 4670433, p. 614-619, sept. 2008. DOI: 10.1109/IS.2008.4670433.

DSPACE@MIT. Site com banco de dados do MIT de Teses, artigos e informações. Disponível em: <http://dspace.mit.edu/>. Acesso 01/08/2014.

DURUGBO, C.; RIEDEL, J. C. Readiness assessment of collaborative networked organisations for integrated product and service delivery. International Journal of Production Research, v. 51, n. 2, p. 598-613, 2013. DOI: 10.1080/00207543.2012.658529. 
ESPOSITO, E.; EVANGELISTA, P. Investigating virtual enterprise models: literature review and empirical findings. International Journal of Production Economics, v. 148, n. 0, p. $145-157,2014$.

EThOS. Base de dados de teses das Universidades Britânicas. Disponível em: $<$ http://ethos.bl.uk/Home.do>. Acesso 01/08/2014.

FERREIRA, J. C. E.; ZATTAR, I. C. Vantagens de utilização de sistemas híbridos para o planejamento da produção. 3 COBEF, Congresso Brasileiro de Engenharia de Fabricação. 2005.

GIMENO, L.; RODRIGUES, M. T. Technical report. Planejamento e programação da produção: Abordagens de otimização para indústria de processos. Campinas-São Paulo: [s.n.], 2002.

GOULART, C. P. Proposta de um Modelo de Referência para Planejamento e Controle da Produção em Empresas Virtuais. 2000. Dissertação (Mestrado) - Escola de Engenharia de São Carlos da Universidade de São Paulo.

GUERRERO, J.; VASQUEZ, J.; TEODORESCU, R. Hierarchical control of droop-controlled dc and ac microgrids - a general approach towards standardization. Industrial Electronics, 2009. IECON '09. 35th Annual Conference of IEEE. p. $4305-4310$, nov. 2009. [DOI: 10.1109/IECON.2009.5414926.

GUO, H. et al. Correlation-aware web services composition and qos computation model in virtual enterprise. The International Journal of Advanced Manufacturing Technology, v. 51, p. 817-827, 2010.

GUSTAVSON, A.; TOERN, A. Extending simulation nets with sensor arcs. Conference proceedings for SIMS'95 Simulation Conference, Lyngby, Denmark. p. 80-84, 1995.

HADAYA, P.; PELLERIN, R. Determinants of advance planning and scheduling system adoption. 3rd International Conference on Software Engineering Advances, ICSEA 2008. p. 494-499, 2008.

HAMADI, R.; BENATALLAH, B. A Petri net-based model for web service composition. Proceedings of the 14th Australasian Database Conference (ADC'03). p. 191-200, feb 2003.

HARJUNKOSKI, I. et al. Scope for industrial applications of production scheduling models and solution methods. Computers \& Chemical Engineering, v. 62, n. 0, p. $161-193$, 2014. DOI: http://dx.doi.org/10.1016/j.compchemeng.2013.12.001. 
HASEGAWA, K. et al. On resource arc for petri net modelling of complex resource sharing system. Journal of Intelligent and Robotic Systems, Kluwer Academic Publishers, v. 26, n. 3-4, p. 423-437, 1999. DOI: 10.1023/A:1008122101686.

HERRERA, V.; RAMOS, A.; LASTRA, J. An agent-based system for orchestration support of web service-enabled devices in discrete manufacturing systems. Journal of Intelligent Manufacturing, Springer Netherlands, p. 1-22, 2011. 10.1007/s10845-011-0539-z.

HSIEH, F.-S.; LIN, J.-B. Virtual enterprises partner selection based on reverse auctions. The International Journal of Advanced Manufacturing Technology, Springer-Verlag, v. 62, n. 5-8, p. 847-859, 2012. DOI: 10.1007/s00170-011-3843-z.

HSU, H. P.; HSU, H. M. Systematic modeling and implementation of a resource planning system for virtual enterprise by predicate/transition net. Expert Syst. Appl., Tarrytown, NY, USA, Pergamon Press, Inc., v. 35, p. 1841-1857, November 2008. 17 p. DOI: 10.1016/j.eswa.2007.08.082.

HUANG, A. F. M.; LAN, C.-W.; YANG, S. J. H. An optimal qos-based web service selection scheme. Inf. Sci., v. 179, p. 3309-3322, September 2009. 14 p. DOI: 10.1016/j.ins.2009.05.018.

HUANG, D. X.; ZHU, S. X. What are virtual enterprises virtualize. Advanced Materials Research, v. 305, p. 134-139, 2011. DOI: 10.4028/www.scientific.net/AMR.305.134.

HUANG, M. et al. Research on the production scheduling optimization for virtual enterprises. Mathematical Problems in Engineering, p. 1-9, 2013.

HVOLBY, H.-H.; STEGER-JENSEN, K. Technical and industrial issues of advanced planning and scheduling (aps) systems. Computers in Industry, v. 61, n. 9, p. $845-851,2010$. DOI: $10.1016 /$ j.compind.2010.07.009.

ILOG, I.(Org.). IBM ILOG Scheduler V6,7 User's Manual. Mountain View, EUA: ILOG, 2009.

INTERNATIONAL, M. White paper-6. MES Explained: A High Level Visions. Pittsburgh, PA 15215: [s.n.], 1997.

IP, W.; YUNG, K.; WANG, D. A branch and bound algorithm for sub-contractor selection in agile manufacturing environment. International Journal of Production Economics, v. 87 , n. 2, p. 195 - 205, 2004. DOI: 10.1016/S0925-5273(03)00125-7.

JARDIM-GONCALVES, R.; GRILO, A.; POPPLEWELL, K. Novel strategies for global manufacturing systems interoperability. Journal of Intelligent Manufacturing, Springer US, p. 1-9, 2014. DOI: 10.1007/s10845-014-0948-x. 
JENSEN, K. Coloured petri nets and the invariant-method. Theoretical Computer Science, v. 14 , n. 3, p. 317 - 336, 1981. DOI: 10.1016/0304-3975(81)90049-9.

JENSEN, K. Coloured Petri Nets: Basic Concepts, Analysis Methods and Practical Use. Berlin: [s.n.], 1992.

JENSEN, K.; KRISTENSEN, L. M.; WELLS, L. Coloured petri nets and cpn tools for modelling and validation of concurrent systems. Int. J. Softw. Tools Technol. Transf., Berlin, Heidelberg, Springer-Verlag, v. 9, n. 3, p. 213-254, maio 2007. 42 p. DOI: 10.1007/s10009007-0038-x.

JUNQUEIRA, F. Modelagem e Simulação Distribuída de Sistemas Produtivos. 2006. Tese (Doutorado) — Escola Politécnica da Universidade de São Paulo.

KANESHIRO, P. J. et al. Modeling of collision resolution algorithm in Lonworks networks. Proceedings of ASME International Mechanical Engineering Congress and Exposition. v. 9, p. 743-749, nov 2008.

KENG, N. P.; YUN, D. Y. Y.; ROSSI, M. Interaction sensitive planning system for job shop scheduling. Expert systems and intelligent manufacturing, Elsevier, Amsterdam, Holanda, p. 57-59, 1988.

KIEPUSZEWSKI, B.; HOFSTED, A. ter; AALST, W. van der. Fundamentals of control flow in workflows. Acta Informatica, v. 39, n. 3, p. 143-209, march 2003. DOI: 10.1007/s00236002-0105-4.

KONDILI, E.; PANTELIDES, C. C.; SARGENT, R. W. H. A general algorithm for short-term scheduling of batch operations-i. milp formulation. Computers and Chemical Engineering, v. 17 , n. 2 , p. $211-227,1993$. DOI: DOI: 10.1016/0098-1354(93)80015-F.

LEE, J.-S.; ZHOU, M.-C.; HSU, P.-L. An application of Petri nets to supervisory control for human-computer interactive systems. IEEE Transactions on Industrial Electronics, v. 52, n. 5, p. 1220-1226, Oct. 2005. DOI: 10.1109/TIE.2005.855694.

LEE, Y. H.; JEONG, C. S.; MOON, C. Advanced planning and scheduling with outsourcing in manufacturing supply chain. Computers and Industrial Engineering, v. 43, n. 1-2, p. $351-374,2002$.

LI, G.; WEI, M. Everything-as-a-service platform for on-demand virtual enterprises. Information Systems Frontiers, Springer US, v. 16, n. 3, p. 435-452, 2014. DOI: 10.1007/s10796012-9351-3.

LIANG, F. et al. A hybrid control architecture and coordination mechanism in virtual manufacturing enterprise. International Journal of Production Research, v. 46, n. 13, p. 3641-3663, 2008. 
LIN et al. A reappraisal on advanced planning and scheduling systems. Industrial Management \& Data Systems, v. 107, n. 8, p. 1212-1226, 2007.

LIU, P.; RAAHEMI, B.; BENYOUCEF, M. Knowledge sharing in dynamic virtual enterprises: a socio-technological perspective. Knowledge-Based Systems, v. 24, n. 3, p. $427-443$, 2011. DOI: $10.1016 /$ j.knosys.2010.12.004.

LIU, W. et al. Aps, erp and mes systems integration for semiconductor backend assembly. Control, Automation, Robotics and Vision, 2002. ICARCV 2002. 7th International Conference on. v. 3, p. 1403-1408, dec. 2002. DOI: 10.1109/ICARCV.2002.1234978.

MARAVELIAS, C. T. Integration of production planning and scheduling. In: 10th International Symposium on Process Systems Engineering: Part A. 10th International Symposium on Process Systems Engineering: Part A. [S.I.: s.n.], 2009. (Computer Aided Chemical Engineering, v. 27), p. 117 - 118. DOI: DOI: 10.1016/S1570-7946(09)70240-8.

MARAVELIAS, C. T.; SUNG, C. Integration of production planning and scheduling: overview, challenges and opportunities. Computers \&amp; Chemical Engineering, v. 33, n. 12, p. 1919 - 1930, 2009. DOI: 10.1016/j.compchemeng.2009.06.007.

MARTINEZ, M. T. et al. Virtual enterprise - organisation, evolution and control. International Journal of Production Economics, v. 74, n. 1-3, p. 225-238, December 2001.

MATSUSAKI, C. T. M. Modelagem de Sistemas de Controle Distribuídos e Colaborativos de Sistemas Produtivos. 2004. Tese (Doutorado) - Escola Politécnica da Universidade de São Paulo, São Paulo, Brasil.

MELO, J. I.; MORALES, R. A. G.; MIYAGI, P. E. Supervisory system for hybrid productive systems based on Bayesian networks and OO-DPT nets. IEEE International Conference on Emerging Technologies and Factory Automation, ETFA. p. 1108-1111, Sept. 2008. DOI: $10.1109 /$ ETFA.2008.4638536.

MELO, J. I. G. ARQUITETURA COM ORIENTAÇÃO A SERVIÇOS PARA SISTEMAS PRODUTIVOS TELEOPERADOS E DISPERSOS. 2011. Tese (Doutorado) Escola Politécnica da Universidade de São Paulo.

MELO, J. I. G.; JUNQUEIRA, F.; MIYAGI, P. E. TOWARDS MODULAR AND COORDINATED MANUFACTURING SYSTEMS ORIENTED TO SERVICES. DYNA, scielo, v. 77, p. $201-210,092010$.

MELO, J. I. G. et al. A procedure for modeling and analysis of service-oriented and distributed productive systems. Automation Science and Engineering, 2008. CASE 2008. IEEE International Conference on. p. 941-946, Aug 2008. 
MELO, J. I. G. et al. A systematical approach to expose manufacturing system as a service. Industry Applications (INDUSCON), 2010 9th IEEE/IAS International Conference on. p. 1-6, Nov 2010.

MIYAGI, P. E. Controle Programável - Fundamentos do Controle de Sistemas a Eventos Discretos. São Paulo, Brasil: [s.n.], 1996. 194 p.

MONIZ, S.; BARBOSA-POVOA, A. P.; SOUSA, J. Pinho de. New general discrete-time scheduling model for multipurpose batch plants. Industrial \& Engineering Chemistry Research, v. 52, n. 48, p. 17206-17220, 2013. DOI: 10.1021/ie4021073.

MONTESCO, R. A. E. Heurísticas para sistemas APS utilizando janelas de processamento: propostas, implementação e exemplos. 2004. Dissertação (Mestrado) - Universidade Estadual de Campinas, UNICAMP, Campinas, SP, Brasil.

MOON, C.; KIM, J. S.; GEN, M. Advanced planning and scheduling based on precedence and resource constraints for e-plant chains. International Journal of Production Research, v. 42 , n. 15 , p. 2941-2955, 2004. DOI: $10.1080 / 00207540410001691956$.

MOORE, K.; CHIANG, J. Alpha/sim simulation software tutorial. Simulation Conference, 2000. Proceedings. Winter. v. 1, p. $259-267$ vol.1, 2000. DOI: 10.1109/WSC.2000.899727.

MORAleS, R. A. G.; MELO, J. I.; MIYAGI, P. E. Diagnosis and treatment of faults in productive systems based on Bayesian networks and Petri net. IEEE International Conference on Automation Science and Engineering, CASE. p. 357-362, Sept. 2007. DOI: 10.1109/COASE.2007.4341823.

MUNTANI, R. V.; MIYAGI, P. E.; PESSOA, M. A. O. Implementação do serviço de planejamento virtual de uma empresa virtual. 22 SIICUSP - Simpósio Internacional de Iniciação Científica e Tecnológica da USP. 2014.

MURATA, T. Petri nets: properties, analysis and applications. Proceedings of the IEEE, v. 77 , n. 4 , p. $541-580$, apr 1989. DOI: $10.1109 / 5.24143$.

MURATA, T.; ZHANG, D. A predicate-transition net model for parallel interpretation of logic programs. Software Engineering, IEEE Transactions on, v. 14, n. 4, p. $481-497$, apr 1988. DOI: $10.1109 / 32.4671$.

NAGEL, R.; DOVE, R. 21st Century Manufacturing Enterprise Strategy: An Industryled view. [S.I.: s.n.], 1991.

NAKAMOTO, F. Y. Projeto de Sistemas Modulares de Controle para Sistemas Produtivos. 2008. Tese (Doutorado) — Escola Politécnica da Universidade de São Paulo. 
OPENBRAVOERP. Site do ERP Openbravo. Disponível em: $<$ http://sourceforge.net/projects/openbravo/>. Acesso 20/06/2014.

PAPAGEORGIOU, L. G.; PANTELIDES, C. C. Optimal campaign planning/ scheduling of multipurpose batch/semicontinuous plants. 2. a mathematical decomposition approach. Industrial Engineering and Chemical Research, v. 35, p. 510-529, 1996.

PESSOA, M. A. et al. Time windows and constraint programming to deal with strong restriction in the due date of productive systems. Annual Reviews in Control, v. 38, n. 1, p. 134 - 146, 2014. DOI: http://dx.doi.org/10.1016/j.arcontrol.2014.03.013.

PESSOA, M. A. O. Heurísticas para sistemas APS utilizando janelas de processamento: Interesse, conceitos e abordagens. 2004. Dissertação (Mestrado) — Universidade Estadual de Campinas, UNICAMP, Campinas, SP, Brasil.

PESSOA, M. A. O. et al. Virtual enterprise planning system using time windows and capacity constraint concepts. IECON 2012 - 38th Annual Conference on IEEE Industrial Electronics Society. p. 2851-2856, Oct 2012. DOI: 10.1109/IECON.2012.6389443.

PESSOA, M. A. O. et al. Planning and scheduling for dispersed and collaborative productive system. In: Technological Innovation for Sustainability. Technological Innovation for Sustainability. [S.I.]: Springer Boston, 2011. (IFIP Advances in Information and Communication Technology, v. 349), p. 57-64.

PESSOA, M. A. O. et al. Heurística de planejamento utilizando janelas de tempo para sistemas produtivos teleoperados. Industry Applications (INDUSCON), 2010 9th IEEE/IAS International Conference on. Nov 2010.

PESSOA, M. A. O. et al. Advanced planning and scheduling systems based on time windows and constraint programming intelligent manufacturing systems. 11th IFAC Workshop on Intelligent Manufacturing Systems. 2013. DOI: http://dx.doi.org/10.3182/20130522-3BR-4036.00069.

PETERSON, J. L. Petri Net Theory and the Modeling of Systems. New Jersey: Prentice Hall Inc., 1981.

QIUSHI, C. et al. Service-based virtual enterprise information system integrated model. Management and Service Science (MASS), 2010 International Conference on. p. $1-4$, aug. 2010. DOI: 10.1109/ICMSS.2010.5576655.

REISIG, W. A Primer in Petri design. Berlin: Springer Berlin Heidelberg, 1992.

RIASCOS, L.; MIYAGI, P. Supervisor system for detection and treatment of failures in balanced automation systems using petri nets. Systems, Man, and Cybernetics, 
2001 IEEE International Conference on. v. 4, p. 2528-2533 vol.4, 2001. DOI: 10.1109/ICSMC.2001.972938.

RICHARDS, $H$. et al. Flow of orders through a virtual enterprise - their proactive planning and scheduling, and reactive control. Computing and Control Engineering Journal, IEE, v. 8 , n. 4, p. 173-179, 1997. DOI: 10.1049/cce:19970408.

RODRIGUES, L. C. A. Planejamento e programação da produção em plantas multipropósito operando em batelada: Proposta de uma estratégia de decomposição usando janelas de tempo. 2000. Tese (Tese de doutorado) — Faculdade de Engenharia Elétrica e de Computação, Universidade Estadual de Campinas, Campinas, São Paulo, Brasil.

RODRIGUES, L. C. A.; RIECHI, J. L. S. Capacity analysis tool to support sales decisions. 18th International Conference on Production Research. 2005.

RODRIGUES, L. C. A.; RIECHI, J. L. S. Enhancing supply chain decisions using constraint programming: a case study. Proceedings of the artificial intelligence 6th Mexican international conference on Advances in artificial intelligence. p. 1110-1121, 2007.

RODRIGUES, M. T. M. et al. Scheduling heuristics based on tasks time windows for aps systems. In: European Symposium on Computer-Aided Process Engineering-14, 37th European Symposium of the Working Party on Computer-Aided Process Engineering. European Symposium on Computer-Aided Process Engineering-14, 37th European Symposium of the Working Party on Computer-Aided Process Engineering. [S.I.]: Elsevier, 2004. (Computer Aided Chemical Engineering, v. 18), p. 979 - 984. DOI: DOI: $10.1016 / S 1570-7946(04) 80229-3$.

ROJAS, E. P. S. Proposta de Aplicação de Tecnologias Colaborativas na Gestão de Empresas Virtuais. 2010. Dissertação (Mestrado) - Universidade Estadual de Campinas UNICAMP.

ROJAS, E. P. S. et al. Business model development for virtual enterprises. In: Collaborative Networks in the Internet of Services. Collaborative Networks in the Internet of Services. [S.I.]: Springer Berlin Heidelberg, 2012. (IFIP Advances in Information and Communication Technology, v. 380), p. 624-634.

RONDEAU, P. J.; LITTERAL, L. A. The evolution of manufacturing planning and control systems: from reorder point to enterprise resource planning. Production and Inventory Management Journal, v. 34, n. 2, p. 1-7, 2001.

SADEH, N. Look-Ahead Techniques for Micro-Opportunistic Job Shop Scheduling. 1991. Tese (Doutorado) - School of Computer Science, Carnegie Mellon University, Pittsburg, Pennsylvania, USA. 
SASAKI, H. A. U.; MIYAGI, P. E.; PESSOA, M. A. O. Implementação do serviço de gerenciamento de pedidos de uma empresa virtual. $22^{\circ}$ SIICUSP - Simpósio Internacional de Iniciação Científica e Tecnológica da USP. 2014.

SCOPUS - ELSEVIER, disponível em <http://www.scopus.com/home.url>. Acesso $01 / 08 / 2014$.

SHAIK, M. A. et al. Production scheduling of a large-scale industrial continuous plant: shortterm and medium-term scheduling. Computers \& Chemical Engineering, v. 33, n. 3, p. 670 - 686, 2009. DOI: DOI: 10.1016/j.compchemeng.2008.08.013.

SIBiUSP. Sistema Integrado de Bibliotecas da USP. Disponível em: $<$ http://www.usp.br/sibi/>. Acesso 01/08/2014.

SMITH, S. F.; CHENG, C. C. Slack-based heuristics for constraint satisfaction scheduling. proc. Proceedings of 11th National Conf. on Artificial Intelligence. p. 139-144, 1993.

SRINIVASAN, R.; VENKATASUBRAMANIAI, V. Automating hazop analysis of batch chemical plant: part i. the knowledge representation framework. Computers Chem. Enginnering, v. 22, n. 9 , p. 1345-1355, 1998.

STEVENSON, M.; HENDRY, L. C.; KINGSMAN, B. G. A review of production planning and control: the applicability of key concepts to the make-to-order industry. International Journal of Production Research, v. 43, n. 5, p. 869-898, 2005. DOI: 10.1080/0020754042000298520.

UGARTE, B. S. de; ARTIBA, A.; PELLERIN, R. Manufacturing execution system - a literature review. Production Planning and Control, v. 20, n. 6, p. 525-539, 2009. DOI: $10.1080 / 09537280902938613$.

UNICAMP. BIBLIOTECA DIGITAL DA UNICAMP. Disponível em: $<$ http://www.bibliotecadigital.unicamp.br/>. Acesso 01/08/2014.

WALTERS, D. Performance planning and control in virtual business structures. Production Planning Control, v. 16, n. 2, p. 226-239, 2005.

WEB OF SCIENCE, disponível em: <http://apps.webofknowledge.com>. Acesso em $01 / 08 / 2014$.

WEBER, L. K. F.; MIYAGI, P. E.; PESSOA, M. A. O. Implementação do serviço de planejamento local das empresas parceiras de uma empresa virtual. $22-$ SIICUSP - Simpósio Internacional de Iniciação Científica e Tecnológica da USP. 2014. 
WIERS, V. C. S. The relationship between shop floor autonomy and aps implementation success: evidence from two cases. Production Planning \& Control, v. 20:7, p. 576-585, 2009.

WILLIAMS, T. J. The purdue enterprise reference architecture. Computers in Industry, Kluwer Academic Pub, v. 24, n. 2-3, p. 141-158, 1994.

WILSON, J. M. Gantt charts: a centenary appreciation. European Journal of Operational Research, v. 149, n. 2, p. 430 - 437, 2003. DOI: 10.1016/S0377-2217(02)00769-5.

XIA, W.; LI, G. Research on virtual enterprise production planning and control system. Natural Computation, 2008. ICNC '08. Fourth International Conference on. v. 6, p. 555 -559, oct. 2008. DOI: 10.1109/ICNC.2008.850.

XIAOYONG, L.; ZHI, L.; YONGHONG, C. Study on knowledge learning curve of virtual enterprise based on life cycle. Advanced Management Science (ICAMS), 2010 IEEE International Conference on. v. 2, p. 418 -421, july 2010.

YANG, S. et al. Research on web service-based virtual enterprise model architecture. Business Computing and Global Informatization (BCGIN), 2012 Second International Conference on. p. 724-727, Oct 2012. DOI: 10.1109/BCGIN.2012.194.

YOO, T.; JEONG, B.; CHO, H. A Petri nets based functional validation for services composition. Expert Systems with Applications, v. 37, p. 3768-3776, 2010. DOI: 10.1016/j.eswa.2009.11.046.

ZADEH, A. H.; AFSHARI, H.; KHORSHID-DOUST, R. R. Integration of process planning and production planning and control in cellular manufacturing. Production Planning and Control, v. 25, n. 10, p. 840-857, 2014. DOI: 10.1080/09537287.2013.767394.

ZHANG, Y. et al. Real-time work-in-progress management for smart object-enabled ubiquitous shop-floor environment. International Journal of Computer Integrated Manufacturing, v. 24, n. 5, p. 431-445, 2011. DOI: 10.1080/0951192X.2010.527374.

ZHOU, Q.; RISTIC, M.; BESANT, C. B. An information management architecture for production planning in a virtual enterprise. The International Journal of Advanced Manufacturing Technology, v. 16, p. 909-916, 2000.

ZURAWSKI, R.; ZHOU, M. Petri nets and industrial applications: a tutorial. IEEE Transactions on Industrial Eletronics, v. 41, n. 6, p. 567-583, dec 1994. 


\section{Apêndice A - Geração das Janelas de Tempo}

A seguir é exemplificada a determinação das janelas de tempo apresentada em (PESSOA et al., 2014). Considerando, por exemplo, o PFS da Figura A.1, onde constam as operações, tempos de processamento, tamanhos dos lotes, condições de armazenagem, as tabelas A.1, e A.2, apresentam, respectivamente: a habilitação dos lotes nos processadores e condições de armazenagem, e as demandas e datas de entrega dos produtos finais fornecidas pelo planejamento. As matérias primas e os equipamentos estarão disponibilizados a partir do instante $T=1$.

Figura A.1 - Representação PFS do exemplo considerado.

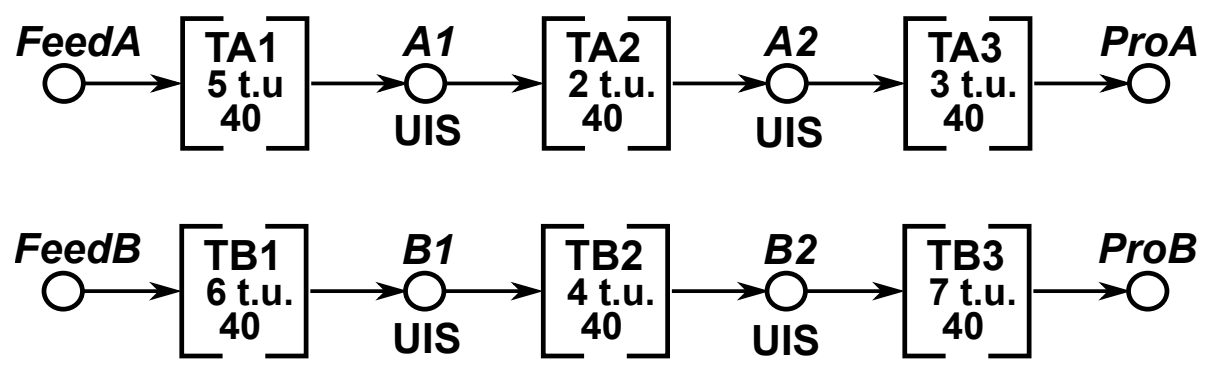

Tabela A.1 - habilitação dos lotes e condições de armazenagem.

\begin{tabular}{|c|c|c|}
\hline Equipamentos & Lotes & Armazenagem \\
\hline \hline P1 & TA1, TB1 & UIS \\
\hline P2 & TA2, TB2 & UIS \\
\hline P3 & TA3, TB3 & UIS \\
\hline
\end{tabular}

Tabela A.2 - Demanda de produtos finais e datas de entrega.

\begin{tabular}{|c|c|c|}
\hline Produtos & Demanda & Data de entrega \\
\hline \hline ProA & 40 & 21 \\
\hline ProB & 40 & 21 \\
\hline
\end{tabular}

Utilizando os dados da figura A.1 e das tabelas A.1 e A.2, as figuras de A.2 à A.5 ilustram a determinação das janelas iniciais de processamento do exemplo em questão para a produção do $\operatorname{ProdA}$. A figura A.2 apresenta o primeiro passo do procedimento de explosão de requisitos para trás. Como a última tarefa para produzir o $\operatorname{Prod} A$ é a $T A 3$, a tarefa tem que terminar no tempo $T=21$. O horizonte de planejamento (o tempo) está representado no eixo horizontal. As tarefas e seu tempo de processamento são representadas no eixo vertical.

A Figura A.3 apresenta o resultado do procedimento de explosão para trás de $T A 2$. Neste caso, $L f t_{T A 2}=L f t_{T A 3}-T p_{T A 3}=21-3=18$. 
Figura A.2 - Procedimento de explosão para trás de $T A 3$.

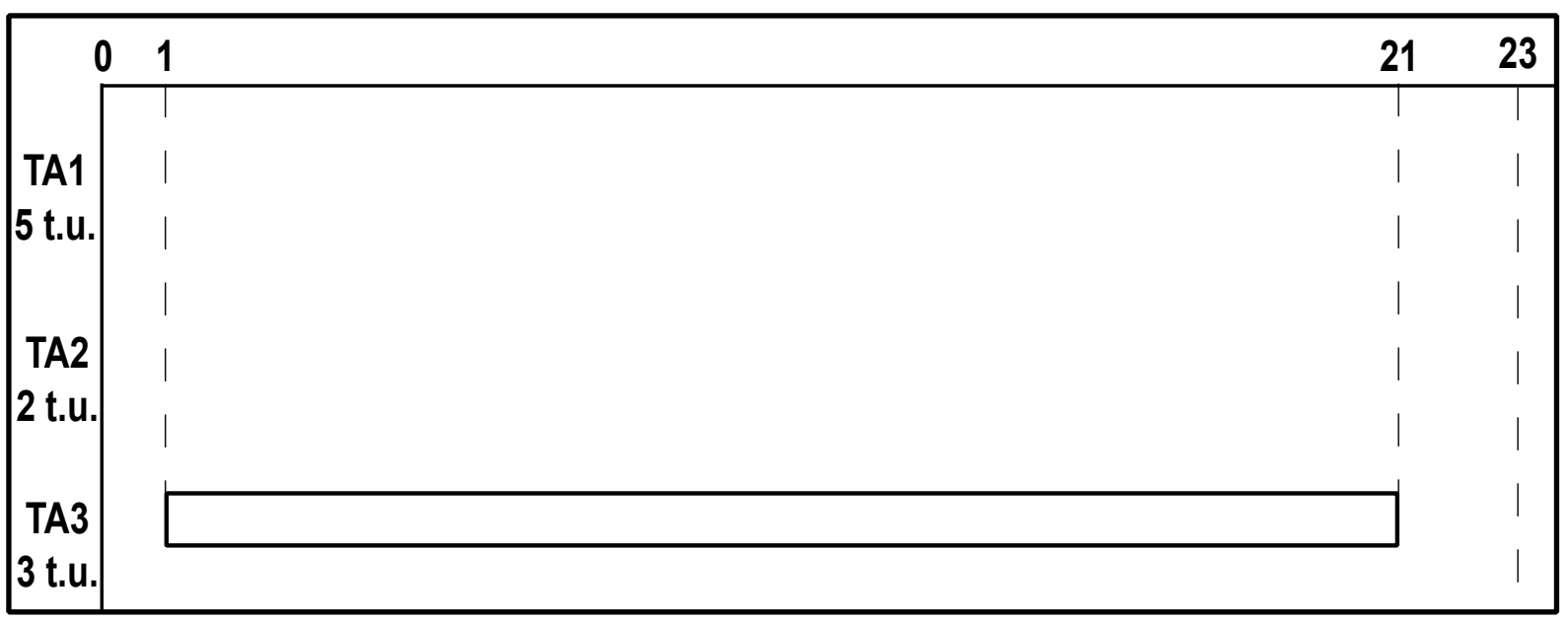

Figura A.3 - Procedimento de explosão para trás de $T A 2$.

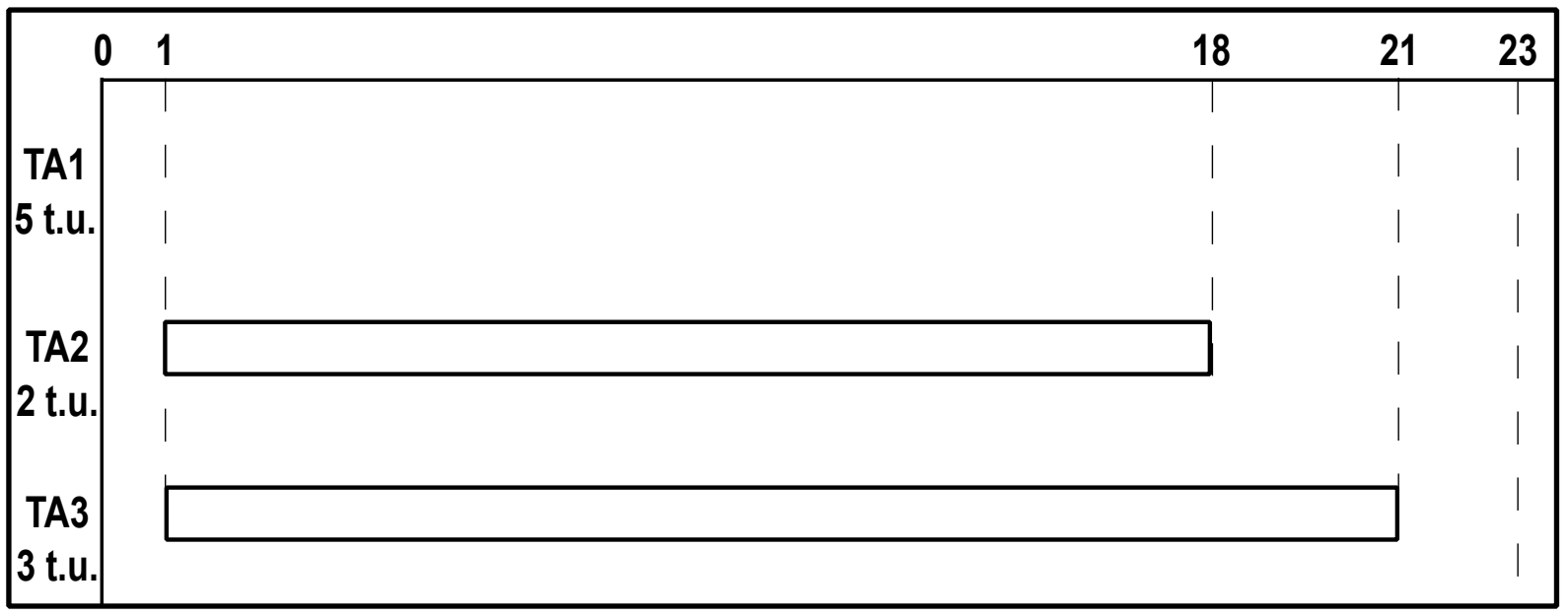

A Figura A.4 apresenta o resultado do procedimento de explosão para trás de $T A 1$. Neste caso, $L f t_{T A 1}=18-2=16$. 
Figura A.4 - Procedimento de explosão para trás de $T A 1$.

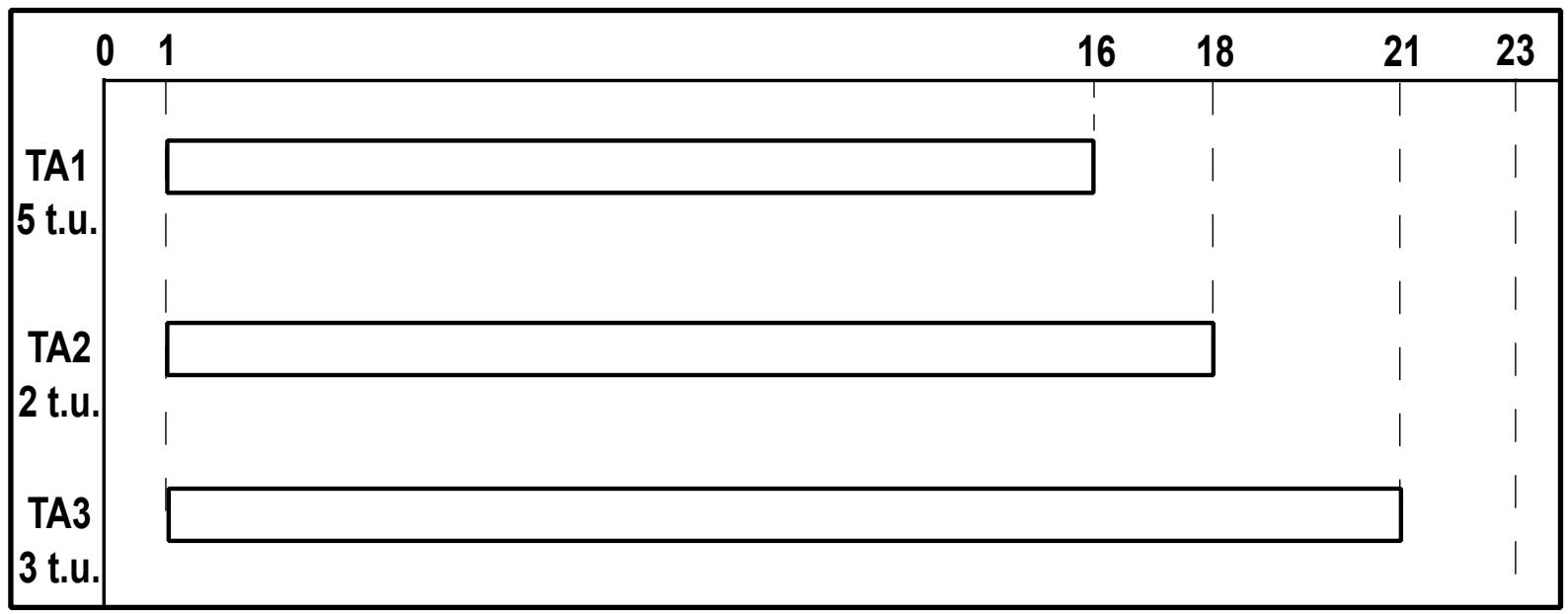

A Figura A.5 mostra o procedimento de explosão para frente das tarefas $T A 1, T A 2$ e $T A 3$. Neste caso, a $E s t_{T A 1}=1 ; E s t_{T A 2}=E s t_{T A 1}+5=6$; e $E s t_{T A 3}=E s t_{T A 2}+2=8$. Estas são as janelas de tempo iniciais para as tarefas do ProA.

Figura A.5 - Procedimento de explosão para frente das tarefas $T A 1, T A 2$ e $T A 3$.

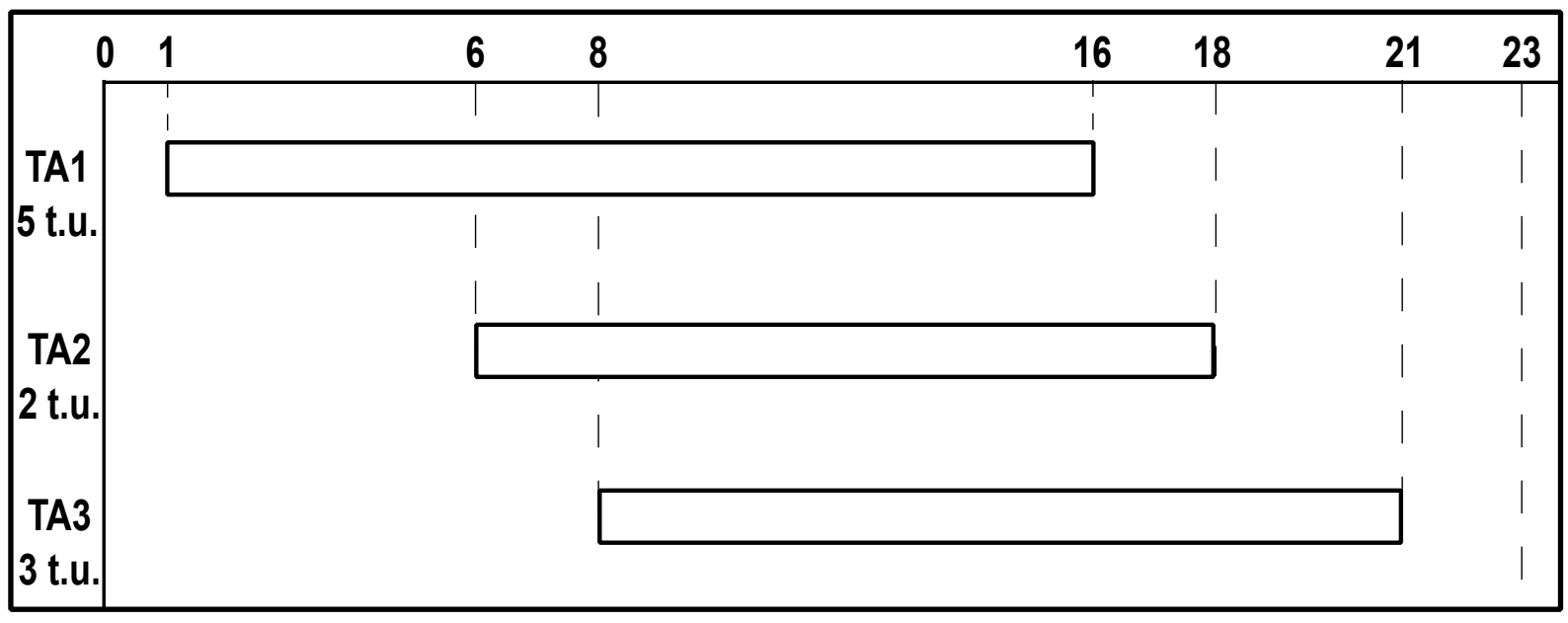

Depois dos procedimentos de explosão para frente e para trás das tarefas relacionadas com ProA aplicam-se os mesmos procedimentos para as tarefas de ProB. A Figura A.6 apresenta as janelas de tempo iniciais para as tarefas de $\operatorname{Pro} A$ e $\operatorname{ProB}$. Em seguida, utilizase a propagação de restrição. O resultado da propagação pode ter consequências em ambos os limites da janelas através do aumento do Est e / ou reduções do Lft. Essas modificações podem, por sua vez afetar as janelas de tempo de outras tarefas devido ao mecanismo de propagação de restrições. 
Figura A.6 - Janelas de tempo iniciais para as tarefas de $\operatorname{ProA}$ e $\operatorname{ProB}$.

\begin{tabular}{|c|c|c|c|c|c|c|c|c|c|c|c|}
\hline \multirow{3}{*}{\begin{tabular}{|l} 
TA1 \\
TA
\end{tabular}} & 1 & 6 & 7 & 8 & 10 & 11 & 14 & 16 & 18 & 21 & 23 \\
\hline & & $i$ & 1 & 1 & $\perp$ & $\perp$ & 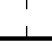 & & I & i & । \\
\hline & & & & & & & & & 1 & 1 & 1 \\
\hline \multirow[t]{3}{*}{5 t.u. } & 1 & & 1 & 1 & 1 & 1 & 1 & & 1 & 1 & 1 \\
\hline & 1 & . & 1 & 1 & I & 1 & 1 & & 1 & 1 & I \\
\hline & 1 & & $\perp$ & $\perp$ & $\perp$ & $\perp$ & $\perp$ & & & 1 & 1 \\
\hline \multirow{3}{*}{$\begin{array}{l}\text { TA2 } \\
2 \text { t.u. }\end{array}$} & 1 & & & & & & & & & 1 & 1 \\
\hline & 1 & & 1 & 1 & 1 & $T$ & $T$ & & & 1 & 1 \\
\hline & 1 & & 1 & 1 & 1 & 1 & 1 & & & 1 & 1 \\
\hline \multirow{3}{*}{$\begin{array}{l}\text { TA3 } \\
3 \text { t.u. }\end{array}$} & I & & 1 & & 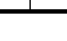 & $\perp$ & 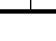 & & & 7 & 1 \\
\hline & 1 & & 1 & & 1 & 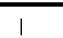 & 1 & & & I & 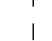 \\
\hline & 1 & & 1 & & 1 & 1 & 1 & & & 1 & 1 \\
\hline \multirow{4}{*}{$\begin{array}{l}\text { TB1 } \\
6 \text { t.u. }\end{array}$} & & & & & & I & I & & & 1 & 1 \\
\hline & & & & & & 1 & 1 & & & I & 1 \\
\hline & & & 1 & & & I & 1 & & & 1 & 1 \\
\hline & & & 1 & & & I & 1 & & & 1 & 1 \\
\hline \multirow{3}{*}{$\begin{array}{l}\text { TB2 } \\
4 \text { t.u. }\end{array}$} & & & & & & & & & & . & 1 \\
\hline & & & & & & $T$ & & & & 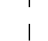 & 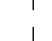 \\
\hline & & & & & & 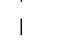 & & & & i & i \\
\hline TB3 & & & & & & & & & & & 1 \\
\hline 7 t.u. & & & & & & & & & & & i \\
\hline
\end{tabular}

A Figura A.7 mostra que $T A 1$ e $T B 1$ são produzidas no mesmo equipamento, caso em que é necessário verificar se existe alguma ordem obrigatória entre as tarefas. Há uma intersecção entre as duas janelas de tempo de 1 a 10, ou seja, a intersecção tem 9 u.t. e a soma dos tempos de processamento das tarefas é de $T p_{T A 1}+T p_{T B 1}=5+6=11$ u.t. Isso indica que não é possível a realização de ambas as tarefas entre a interseção das janelas de tempo. Neste caso, para realizar as duas tarefas, existe uma ordem obrigatória entre as tarefas.

A única maneira para estas duas tarefas serem entregues no prazo é alocando a tarefa $T B 1$ antes de $T A 1$. A Tarefa $T A 1$ teve o seu Est recortado para $T=7$ porque competia ao mesmo tempo com a tarefa $T B 1$ usando o equipamento $P 1$ (Fig. A.7). Desta forma, é possível verificar que as janelas de tempo iniciais foram recortadas.

Figura A.7 - $1^{a}$ etapa do mecanismo de propagação de restrições para as tarefas $T A 1$ and $T B 1$.

\begin{tabular}{|c|c|c|c|c|c|c|}
\hline 0 & 1 & 6 & 10 & 16 & 21 & 23 \\
\hline & I & I & & 1 & i & 1 \\
\hline TA1 & 1 & 1 & & & 1 & 1 \\
\hline 5 t.u. & 1 & 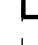 & & & 1 & 1 \\
\hline o c.u. & 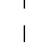 & 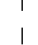 & & & 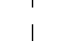 & 1 \\
\hline & 1 & I & & & 1 & 1 \\
\hline TB1 & 1 & & & & $\begin{array}{l}1 \\
1\end{array}$ & 1 \\
\hline 6 t.u. & & & & & 1 & 1 \\
\hline
\end{tabular}

A Figura A.8 apresenta as janelas de tempo finais geradas após o uso do mecanismo de 
propagação de restrições para todas as tarefas. Comparando as Figuras A.6 e A.8 é possível perceber que a propagação de restrições gerou vários recortes nas janelas de tempo iniciais, portanto, foram reduzidos os intervalos de alocação. No caso de tarefas $T A 3, T B 1, T B 2 \mathrm{e}$ $T B 3$ o tamanho das janelas de tempo são iguais ao tempo de processamento $(T p)$ das tarefas, portanto, não há nenhuma folga de alocação gerando intervalos de alocações obrigatórias.

Figura A.8 - Janelas de tempo finais após o mecanismo de propagação de restrições para todas as tarefas.

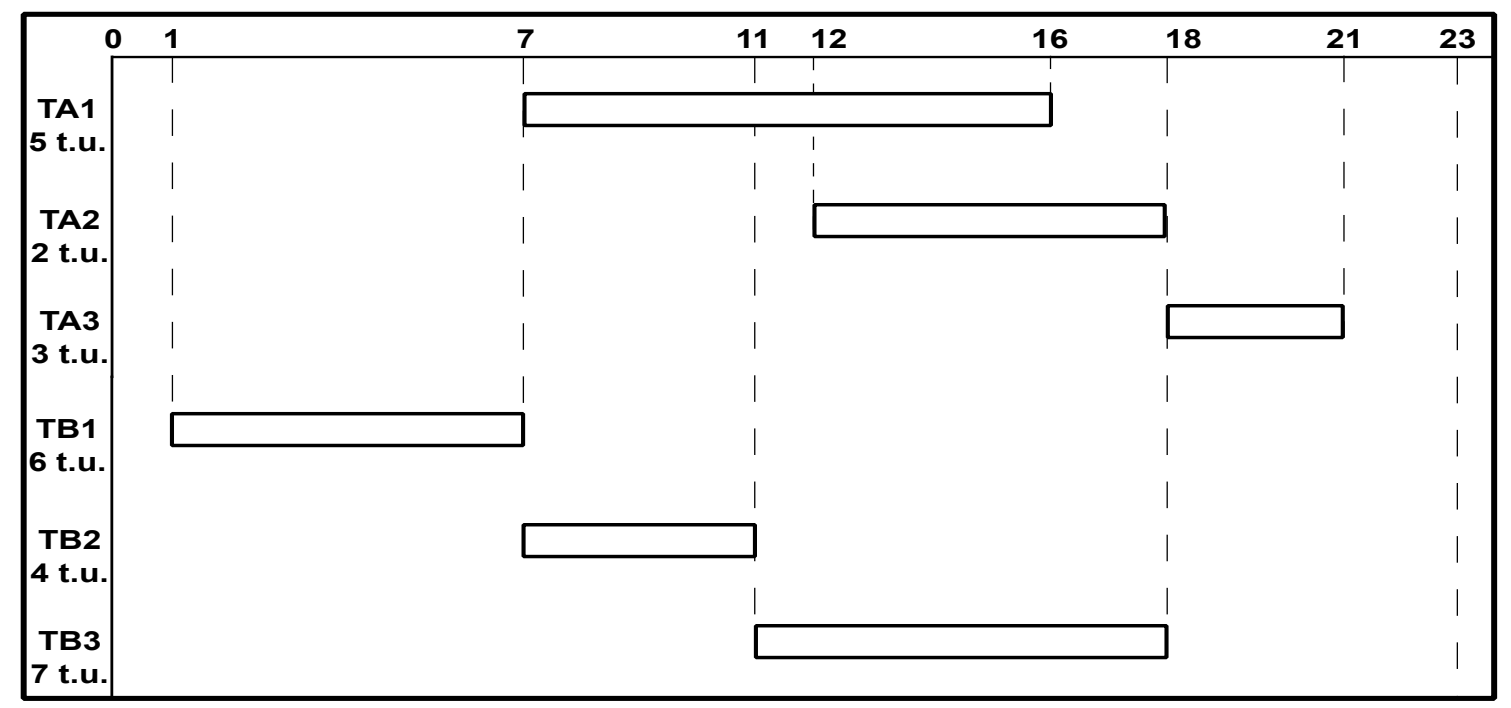




\section{Apêndice B - Heurísticas Utilizadas}

Neste trabalho serão utilizadas as janelas de tempo dos lotes em heurísticas de alocação aplicáveis a sistemas APS e exemplificadas em (PESSOA et al., 2014). A principal característica das heurísticas $A P S$, que é a rapidez de tempo de resposta do sistema, é mantida, pois é ela a responsável por permitir aos sistemas $A P S$ avaliar novos cenários de demanda em tempo hábil. Outra característica importante mantida é a possibilidade de considerar as diversas restrições existentes nos casos reais. Esta característica já é suportada naturalmente pelas "janelas de tempo" em conjunto com a propagação de restrições e que possibilita um resultado de programação confiável, mesmo em situações de restrições fortes sobre os recursos compartilhados pelas operações.

As heurísticas APS de alocação no instante de início mais cedo ou heurísticas APS de alocação no instante de início mais tarde foram inspiradas nas heurísticas normalmente encontradas nos sistemas $A P S$ comerciais.

\section{HEURÍSTICAS APS DE ALOCAÇÃO NO INSTANTE MAIS CEDO OU MAIS TARDE}

As heurísticas APS de alocação no instante mais cedo, é uma programação da produção no sentido crescente de tempo, começando do início do horizonte de planejamento avançando até o fim do horizonte de planejamento. A heurística escolhe a tarefa mais crítica dentro de um intervalo de sequenciamento mais próximo do início do horizonte de planejamento para alocar. Este intervalo parte do início do horizonte de planejamento avançando até o final do horizonte de planejamento. O intervalo é necessário, pois nada garante que a tarefa mais crítica seja a mais próxima do início do horizonte de planejamento. A escolha da tarefa é baseada na dificuldade esperada na alocação da tarefa (criticalidade).

As heurísticas APS de alocação no instante mais tarde, é uma programação da produção no sentido decrescente de tempo, começando do fim do horizonte de planejamento, retrocedendo até o início do horizonte de planejamento. A heurística escolhe a tarefa mais crítica dentro de um intervalo de sequenciamento mais próximo do fim horizonte de planejamento para alocar. Este intervalo parte do fim do horizonte de planejamento, retrocedendo até o início do horizonte de planejamento. O intervalo é necessário, pois nada garante que a tarefa mais crítica seja a mais próxima do fim do horizonte de planejamento. A escolha da tarefa também é baseada na criticalidade.

A criticalidade de cada lote da tarefa (KENG; YUN; ROSSI, 1988), é o quociente entre o tempo de processamento e a duração da sua janela. Assim por exemplo num procedimento de alocação no instante mais cedo, sendo inicialmente os lotes candidatos $T A 1 / 1$ e $T B 1 / 1$, 
com suas respectivas criticalidades $4 / 5$ e $3 / 9$, neste caso, o lote selecionado é o lote $T A 1 / 1$, que é o lote mais critico.

A heurística está representada no fluxograma da Figura B.1.

Figura B.1 - Fluxograma da heurística APS de alocação no instante de início mais cedo ou mais tarde.

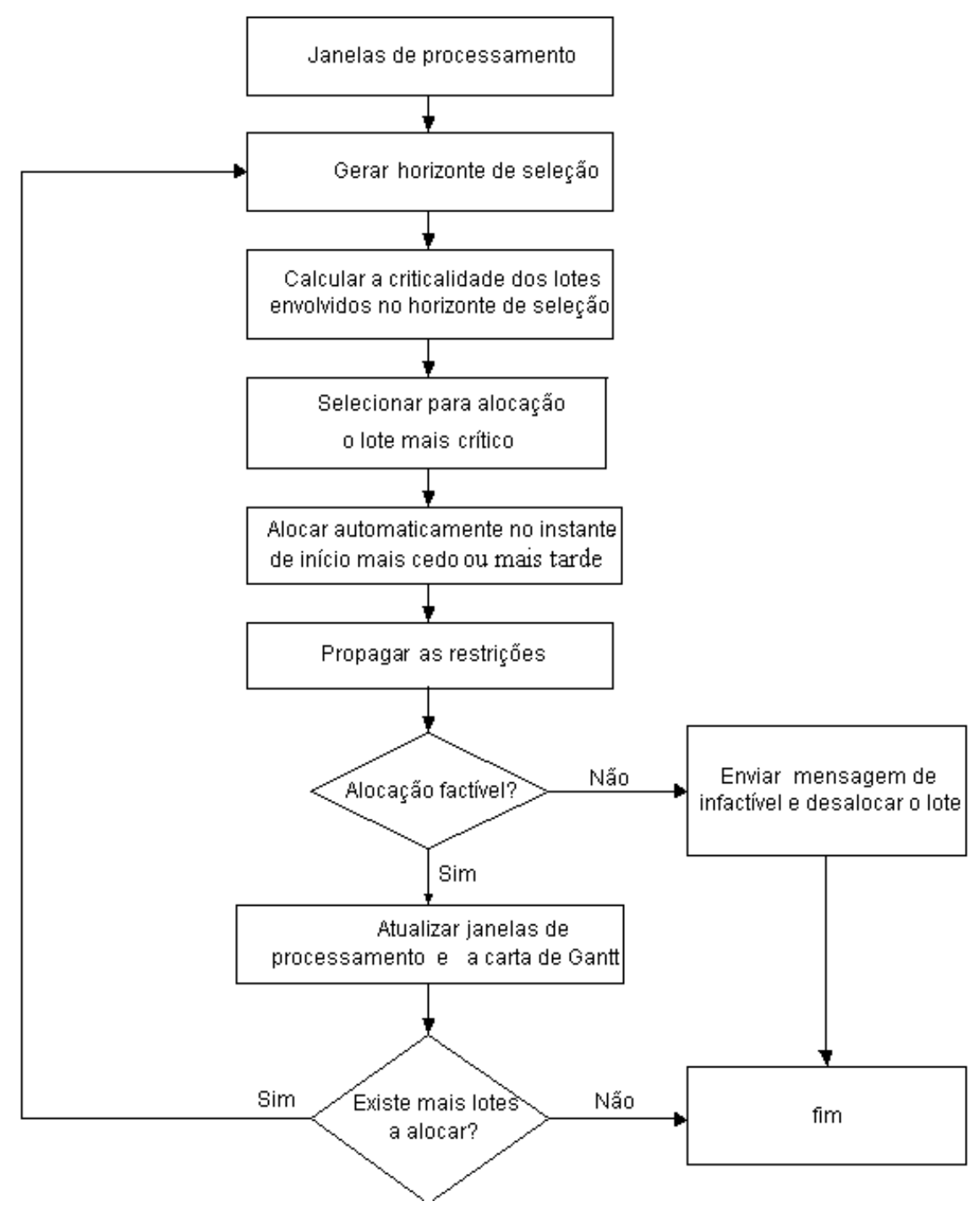

As heurísticas apresentadas neste apêndice se diferem das apresentadas na subseção 2.3.2, isto porque nas heurísticas da subseção é necessária uma ordem de prioridade fornecida pelo usuário e na heurística APS não existe esta necessidade.

A figura B.2] e as restrições de armazenagens da tabela B.1]ilustram o comentário anterior. Considerando que este exemplo tem uma ordem de produção do produto $\operatorname{Prod} A$ com duas demandas, e cada uma delas com 5 lotes de produto final, uma ordem de produção do produto ProdB com 18 lotes de produto final, e uma ordem do produto ProdC com 5 lotes de produto final. Considerando a segunda demanda de produção de $\operatorname{Prod} A$ e a ordem de produção de ProdC, as janelas dos lotes $T A 3 / 3,4$ e $T C 5 / 1,2,3,4,5$ com ambas operações ( $T A 3$ e $T C 5$ ) competindo pelo processador $P 7$ mostram que não será possível processar os dois conjuntos de 
lotes um após o outro (será necessário uma alternância entre os lotes de diferentes ordens de produção). Pois, existe o intervalo entre $T A 3\left(T A 3_{L T F(3)}=26 u\right.$.t e $T A 3_{E S T(4)}=36 u$.t. $)$ que deve ser alocado por tarefa de TC5, este intervalo foi gerado pela propagação de restrições. Esta alternância dificilmente pode ser conseguida através de um esquema de prioridades por ordens de produção conforme apresentado na seção 2.3.2. Na Figura B.2 no lado esquerdo está a curva de carregamento, quanto mais alta esta a curva, mais alto é o carregamento, ou seja, mais tarefas necessitam de serem produzidas num mesmo intervalo.

Tabela B.1 - Condições de armazenagem.

\begin{tabular}{|c|c|}
\hline Estados & Armazenagem \\
\hline \hline $\mathrm{A} 1, \mathrm{~B} 1, \mathrm{C} 1, \mathrm{C} 4$ & ZW \\
\hline $\mathrm{A} 3, \mathrm{~B} 2$ & $\mathrm{FIS}(50)$ \\
\hline $\mathrm{C} 2$ & $\mathrm{FIS}(100)$ \\
\hline $\mathrm{A} 2, \mathrm{C} 3$ & UIS \\
\hline
\end{tabular}

Figura B.2 - Janelas de processamento, e curvas de carregamento.

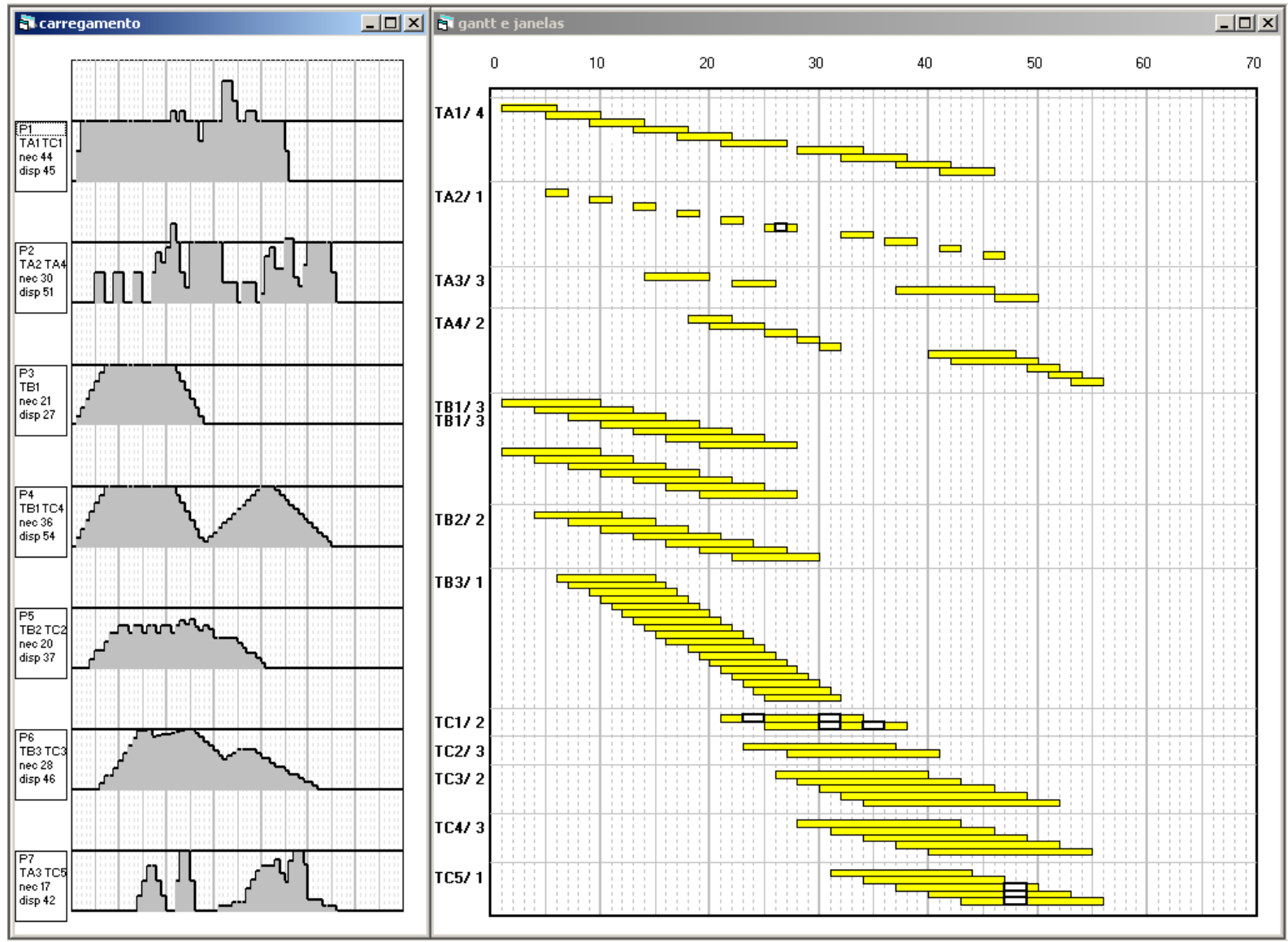

Foi devido a esta alternância obrigatória entre os lotes que apenas uma heurística conseguiu uma solução final onde todos os produtos finais cumprissem com a data de entrega. A heurística que obteve esta solução final foi a heurística APS de alocação no instante mais 
tarde. Como o objetivo final deste processo de ordenamento de prioridades é a seleção de um lote a ser alocado no procedimento sequencial, a melhor forma de priorizar esta seleção é utilizando um ordenamento de prioridades por lotes.

As janelas de processamento trazem duas vantagens importantes para o processo de escolha do lote a alocar:

- As janelas eliminam a necessidade de um mecanismo de relógio, pois o instante de tempo a partir do qual o lote pode ser alocado já está definido pelo Est da sua respectiva janela (analogamente o instante de tempo mais tarde, Lst). Convém notar que este instante de tempo independe da alocação anterior de lotes que precedam o lote em questão, isto porque as janelas já incorporam as condições de precedência entre lotes;

- A eliminação da responsabilidade do usuário ter que informar uma ordem de prioridade de operações, pois a escolha de um lote pode ser feita baseada na dificuldade esperada na alocação deste lote, que pode ser estimada pela criticalidade de cada lote (KENG; YUN; ROSSI, 1988), ou seja o quociente entre o tempo de processamento e a duração da sua janela. Assim por exemplo na figura anterior, num procedimento de alocação no instante mais cedo, inicialmente os lotes candidatos seriam $T A 1 / 1$ e $T B 1 / 1$, com suas respectivas criticalidades $4 / 5$ e $3 / 9$, neste caso, a heurística inicia o procedimento sequencial alocando o lote $T A 1 / 1$ que é o mais crítico automaticamente. Diferente da heurística de alocação por ordens de produção, que aloca começando pela primeira operação da primeira ordem até chegar na última operação da última ordem. Entretanto, esta ordem de prioridades é inserida por alguém e não calculada automaticamente.

Com a utilização das janelas de tempo, os instantes de início mais tarde também estão bem definidos e, como elas já incorporam as condições de precedência entre lotes, estas condições possibilitaram a criação da heurística de alocação no instante de início mais tarde. Esta é semelhante à heurística de alocação no instante de início mais cedo, entretanto, a escolha do lote a alocar é a partir dos due dates dos lotes, e a alocação é no instante de início mais tarde. 


\section{Apêndice C - Exemplo de implementação no Laboratório de Sistemas de Automação (LSA)}

Neste apêndice estão descritos os procedimentos de implementação da arquitetura proposta no laboratório de Sistemas de Automação (LSA) do Departamento de Engenharia Mecatrônica e de Sistemas Mecânicos (PMR) da Escola Politécnica da USP em três projetos de Iniciação Científica (WEBER; MIYAGI; PESSOA, 2014; SASAKI; MIYAGI; PESSOA, 2014; MUNTANI; MIYAGI; PESSOA, 2014).

Foi utilizado na implementação o ERP Openbravo (OPENBRAVOERP, 2014) com o banco de dados PostgreSQL. A Figura C.1 apresenta a janela de apresentação do Openbravo que é um software open-source e foi adaptado para uma integração entre as EPs e a EV. A implementação no LSA foi do exemplo acadêmico apresentado no capítulo 4. Foram implementados quatro ERPs em máquinas distintas, um deles relacionado com a EV e os outros com as EPs. A implementação foi realizada conforme os procedimentos apresentados na seção 3.4 .

Figura C.1 - Janela de apresentação do Openbravo.

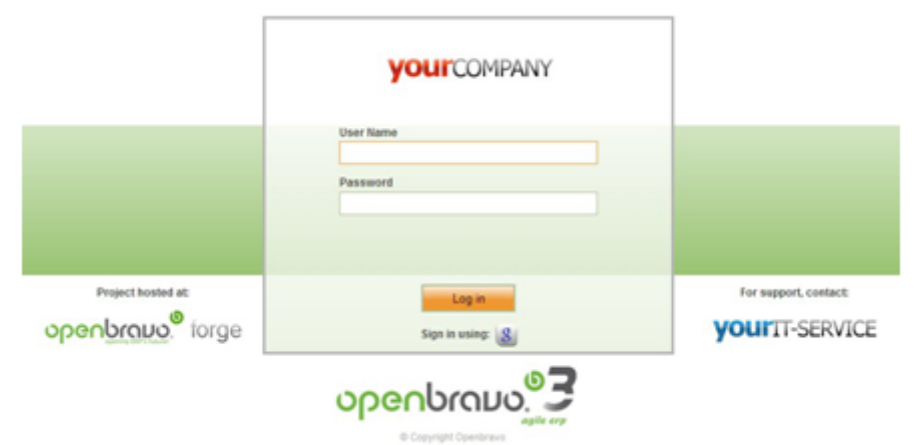

A seguir será apresentada uma descrição da implementação feita em Weber, Miyagi e Pessoa (2014). O passo inicial é o cadastramento de um Client, o client é o mais alto nível de organização no Openbravo e dentro dele são estabelecidas diversas organizations, que podem conter child organizations. Essa estrutura é que define quais os níveis de privacidade aos quais cada usuário terá acesso: um client tem acesso às informações de todas as suas organizations e as organizations têm acesso apenas às informações dela. No caso de uma EV, isso deve ser explorado para manter a autonomia entre as EPs que, apesar de terem uma forte união comercial, não disponibilizam suas informações internas às outras parceiras. A Figura C.2 apresenta o formulário de criação do client PMRLSA. 
Figura C.2 - Formulário de criação do client PMRLSA.

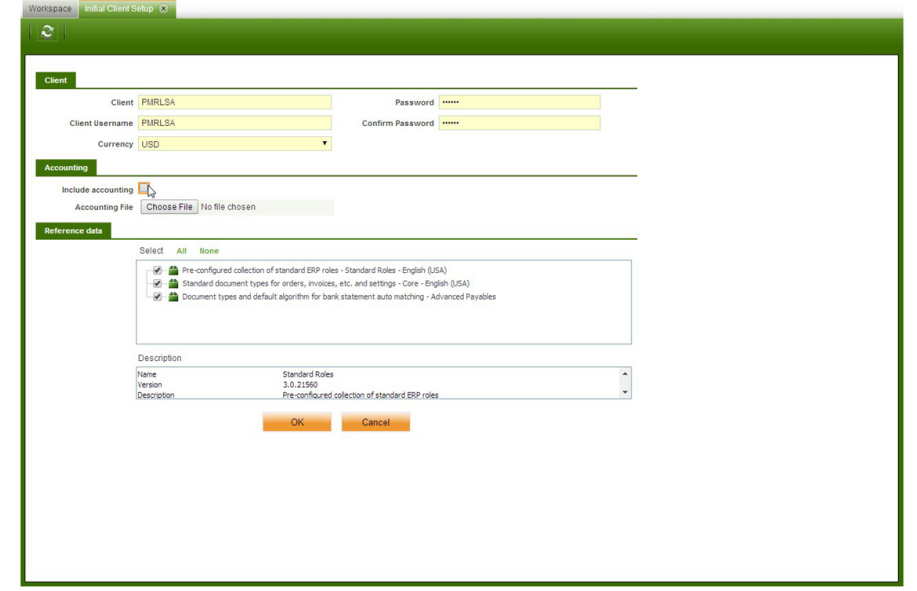

A personalização do Openbravo é efetuada com a criação de novos módulos, no qual as novas tabelas e janelas serão integradas. Para o desenvolvimento deste projeto, foi criado o módulo Empresa Virtual (Figura C.3), com pacote Java org.openbravo.pmrlsa. O prefixo escolhido para o módulo foi LSA, a sigla do Laboratório de Sistemas de Automação, no qual foi realizado o projeto. Para a personalização das EPs foi criado o módulo Empresa Parceira, com pacote Java org.openbravo.Isapmr. As declarações de pacote de dados e de dependência são análogos ao caso do módulo Empresa Virtual, com prefixo da base de dados determinado como PMR.

Figura C.3 - Módulo Empresa Virtual.

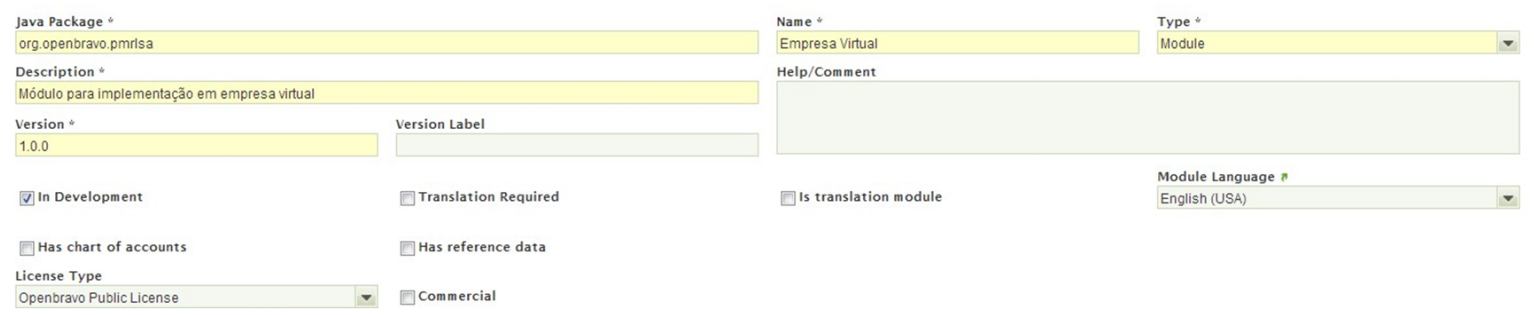

Para configurar o OpenBravo, adaptando suas funções para o uso na EV, é necessário que se crie tabelas para a inserção de dados pertinentes à operação da aliança entre empresas parceiras. Para o módulo Empresa Virtual foram criadas as tabelas listadas abaixo. É importante respeitar a ordem de criação dessas tabelas, pois as relações (chaves secundárias) entre elas faz com que a criação de uma determinada tabela necessite da pré-existência de outra tabela nela referenciada:

- Isa_product_av, é para armazenar os dados sobre as disponibilidades dos materiais, com dados sobre as entregas de novos materiais (data de entrega e quantidade) (Figura D.1); 
- Isa_equipamento, é para registrar dos equipamentos de cada empresa, recebendo o nome desse equipamento (Figura D.3);

- Isa_equipamento_av,é para registrar os períodos de disponibilidade de cada equipamento (Figura D.4).

- Isa_deposito, é para registrar os depósitos utilizados, fazendo referência a sua política de transferência e o tipo de restrição do depósito (Figura D.6);

- Isa_constype, é para receber os possíveis tipos de restrição de um depósito (FIS - Finite Intermediate Storage, UIS, Unlimited Intermediate Storage, e NIS, No Intermediate Storage) (Figura D.8.

- Isa_politran, é para receber as possíveis políticas de transferência (sem limitação ou ZW, zero wait (Figura D.10) ;

- Isa_restoque, é para receber os valores máximos a serem estocados em um certo depósito, no caso de FIS (Figura D.12);

- Isa_habilitacao, é para registrar a habilitação dos produtos nos equipamentos (Figura D.14);

- Isa_pedido, para registrar os pedidos de materiais junto com a quantidade e tempo da demanda e a quantidade e o tempo no estoque, além da data de entrega e da janela de tempo (Figura D.15);

- Isa_processo, é para listagem dos processos operados nas empresas parceiras, da matéria prima até que se chegue ao produto final (Figura D.16);

- Isa_gercontarefa, é para declaração dos fatores de consumo e geração de materiais relacionados a cada tarefa (Figura D.18);

- Isa_gerconprocesso, é para declaração dos fatores de consumo e geração de materiais relacionados a cada processo (Figura D.17);

Obs.: A tabela Isa_habilitacao e o módulo Empresa Parceira estão ainda sendo implementados, mas a estrutura geral e as funcionalidades consideradas podem ser analisadas de maneira análoga ao módulo Empresa Virtual.

As imagens das tabelas criadas no módulo Empresa Virtual do Openbravo serão apresentadas no Anexo D. As Figuras C.4 à C.7, apresentam as listas das novas janelas inseridas no OpenBravo, o novo índice gerado no menu Application, e a tabela de tarefas preenchida. 
Figura C.4 - Lista de novos ícones adicionados ao menu principal.

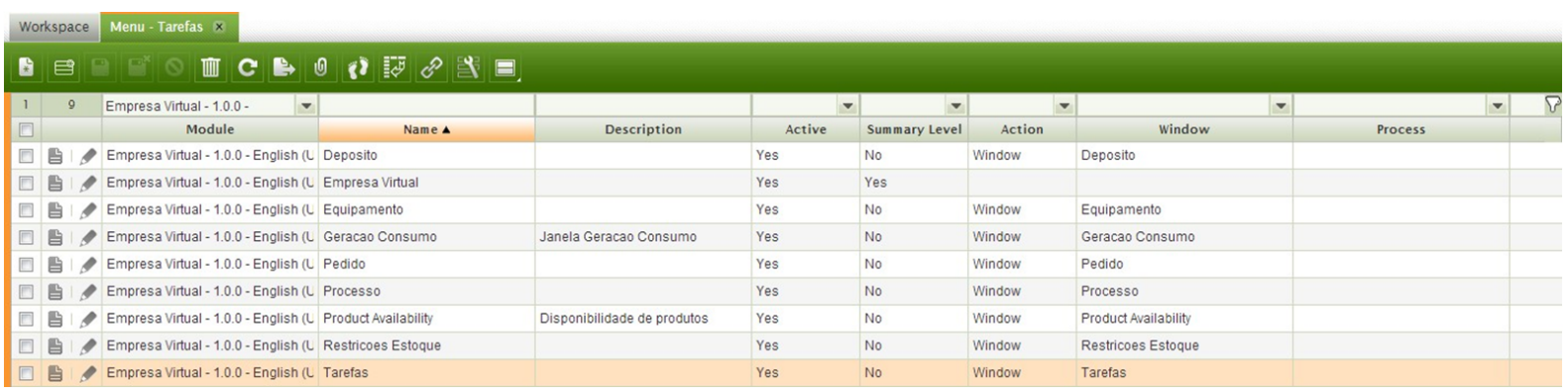

Figura C.5 - Lista das novas janelas implementadas na aplicação.

\begin{tabular}{|c|c|c|c|c|c|c|c|c|c|c|}
\hline \multicolumn{11}{|c|}{ 툴 } \\
\hline 1 & 8 & Empresa Virtual - 1.0 .0 - & & - & & & - & - & - & - \\
\hline$\square$ & & Module & Name $\boldsymbol{\Delta}$ & Window Type & Description & Help/Comment & Sales Transaction & n Thread Safe & Advanced feature & Active \\
\hline$\square$ & 罣 & Empresa Virtual - 1.0.0 - English (L & Deposito & Maintain & Depositos & & Yes & No & No & Yes \\
\hline 口 & 具 & Empresa Virtual - 1.0.0 - English (L) & Equipamento & Maintain & Janela de equipamentos & & Yes & No & No & Yes \\
\hline 四 & 署 & Empresa Virtual - 1.0.0 - English (L) & Geracao Consumo & Maintain & Relacoes de geracao e consumo de $f$ & & Yes & No & No & Yes \\
\hline 四 & 罣 & Empresa Virtual - 1.0.0 - English (L & Pedido & Maintain & Lista de pedidos & & Yes & No & No & Yes \\
\hline 回 & 署 & Empresa Virtual - 1.0.0 - English (L & Processo & Maintain & Lista de Processos & & Yes & No & No & Yes \\
\hline 回 & 罣 & Empresa Virtual - 1.0.0 - English (L & Product Availability & Maintain & Janela de inserção dos dados de dis! & Janela de disponibilidade de prodt & i Yes & No & No & Yes \\
\hline 四 & 署 & Empresa Virtual - 1.0.0 - English (L) & Restricoes Estoque & Maintain & Caracteristicas Restricao & & Yes & No & No & Yes \\
\hline 四 & 罣 & Empresa Virtual - 1.0.0 - English (L) & Tarefas & Maintain & Lista de tarefas & & Yes & No & No & Yes \\
\hline
\end{tabular}

Figura C.6 - Nova visualização do menu Application, com acesso às novas janelas.

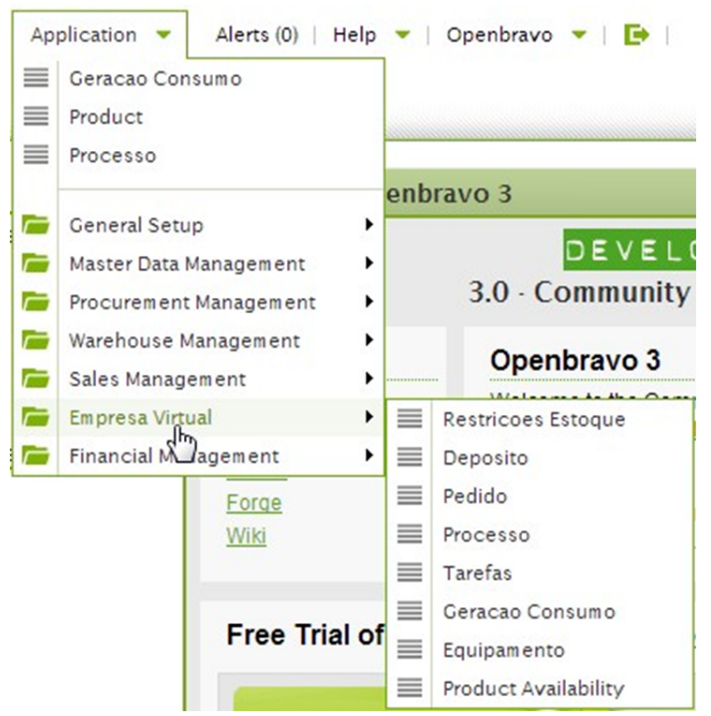

Figura C.7 - Tabela de tarefas preenchida.

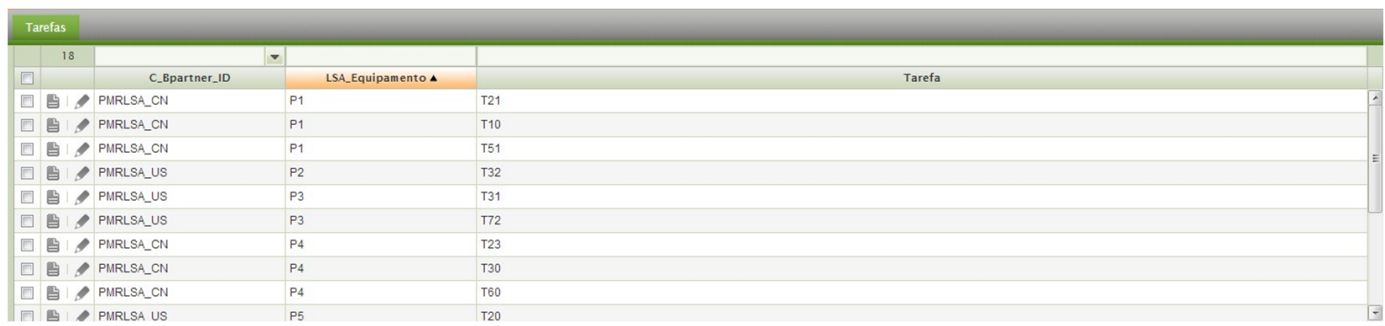


No projeto "Implementação do serviço de gerenciamento de pedidos de uma Empresa Virtual" (SASAKI; MIYAGI; PESSOA, 2014) houve a implementação do "Serviço de Pedidos" e do "Serviço de Gerenciamento de Requisições" e suas conexões com os outros serviços. A seguir será apresentada uma descrição da implementação feita. Foram criados os web services utilizando o Windows Communication Foundation (WCF) e o Internet Information Services (IIS) com o Visual Studio (VS). O IIS é um servidor web, disponível como ferramenta pelo Windows, que possibilita a hospedagem de serviços web, como o WCF. O WCF é um recurso, disponível no próprio VS, que fornece um modelo unificado de programação para a criação, de forma rápida e prática, de aplicativos mais versáteis com SOA, em que há troca de informações entre cliente e servidor. Foi desenvolvida uma interface de programação de aplicações (API) para o consumidor, responsável pela captação dos pedidos dos consumidores. A API faz a ponte entre o consumidor e o "Serviço de Gerenciamento de Requisições", englobando o "Serviço de Pedidos" e o "Serviço de Dados". A Figura C.8 apresenta as telas desenvolvidas no projeto.

Figura C.8 - Telas desenvolvidas.

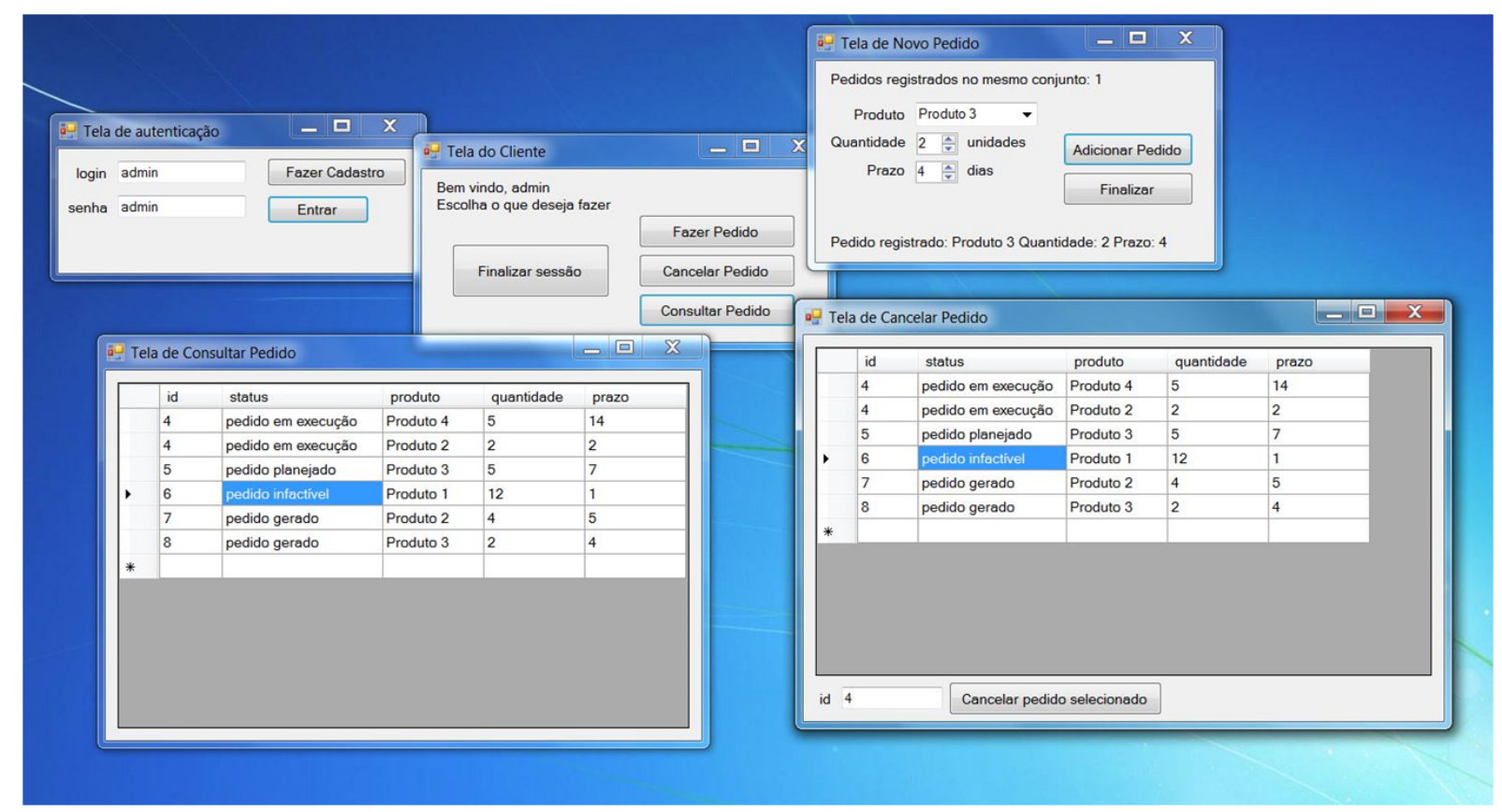

Foi elaborada também a tela de exibição dos pedidos (Figura C.9), nesta tela o consumidor pode visualizar os pedidos feitos por ele com seus respectivos status. Os status são alterados após o "Serviço de Planejamento Virtual" terminar a geração das "janelas globais", caso não seja possível atender o pedido no prazo estipulado, o status é alterado para "pedido infactível", senão, as janelas de tempo são geradas e o status, alterado para "pedido planejado".

Com os pedidos inseridos passa-se para a fase em que o "Serviço de Planejamento Virtual" 
irá gerar as "janelas globais" e enviará as informações para as EPs. O "Serviço de planejamento Virtual" não faz parte do escopo deste projeto, foi implementado em Muntani, Miyagi e Pessoa (2014). Após a geração das "janelas globais" no "Serviço de Planejamento Virtual", há a necessidade de passar as janelas para as EPs. As informações são enviadas para o "Serviço de Planejamento Local", onde irá analisar as janelas recebidas e dar sequência ao processo, conforme apresentado no capítulo 3 e exemplificado no capítulo 4 . A Figura C.10 apresenta a tela de visualização dos pedidos da EV com os dados referentes ao tipo de janela, os intervalos das janelas, e qual é a EP responsável pelas tarefas. Estes dados são separados por EPs e são enviados para cada EP apenas os dados referentes as suas tarefas.

Figura C.9 - Exemplo da tela de Exibição dos pedidos.

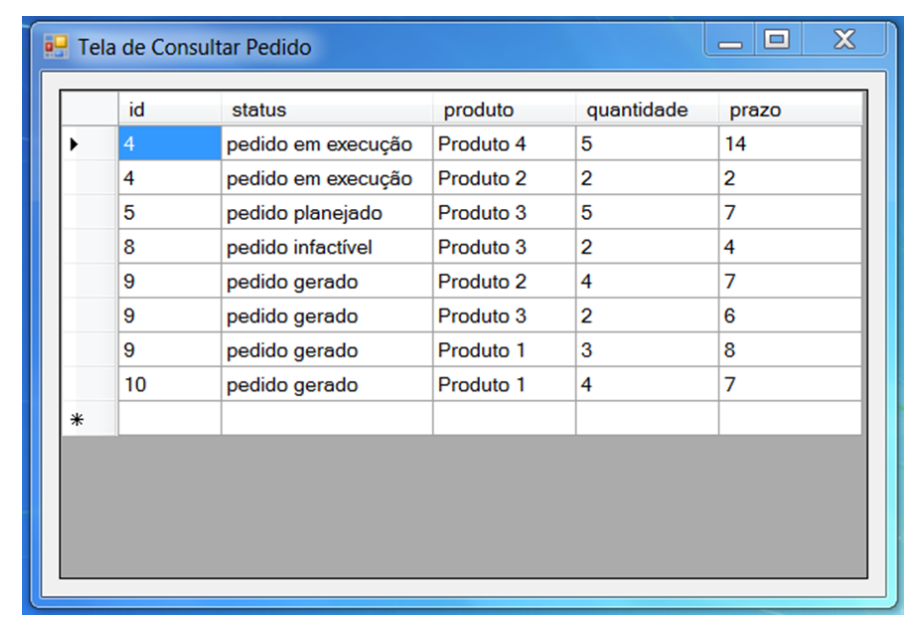

Figura C.10 - Exemplo da tela de Visualização dos pedidos.

\begin{tabular}{|c|c|c|c|c|c|c|c|c|c|}
\hline \multicolumn{7}{|c|}{ 므 Tela de visualização de pedidos EV } & 口 & 口 & $\mathfrak{x}$ \\
\hline & tarefa & janela & instante_inicio & instante_final & empresa_parceira & inicio_tarefa & \multicolumn{3}{|c|}{ fim_tarefa } \\
\hline \multirow[t]{6}{*}{ - } & $\mathrm{T} 10$ & em processamento & 1 & 5 & PRN1 & 0 & 0 & & \\
\hline & T11 & temporaria & 3 & 10 & PRN1 & 0 & 0 & & \\
\hline & T21 & temporaria & 7 & 16 & PRN1 & 0 & 0 & & \\
\hline & T22 & temporaria & 9 & 18 & PRN1 & 0 & 0 & & \\
\hline & T20 & em processamento & 1 & 17 & PRN2 & 0 & 0 & & \\
\hline & T23 & temporaria & 11 & 21 & PRN1 & 0 & 0 & & \\
\hline * & & & & & & & & & \\
\hline
\end{tabular}

A Figura C.11 apresenta uma pequena parte do código, a janela da direita é a interface IEmpresaVirtual.cs do WCF, onde são listadas apenas as operações que o serviço realizará. Já a janela da esquerda é a classe ServicoEV.svc.cs onde estão descritas as operações listadas na interface. 
Figura C.11 - Parte do código com a interface IEmpresaVirtual.cs e a classe ServicoEV.svc.cs.

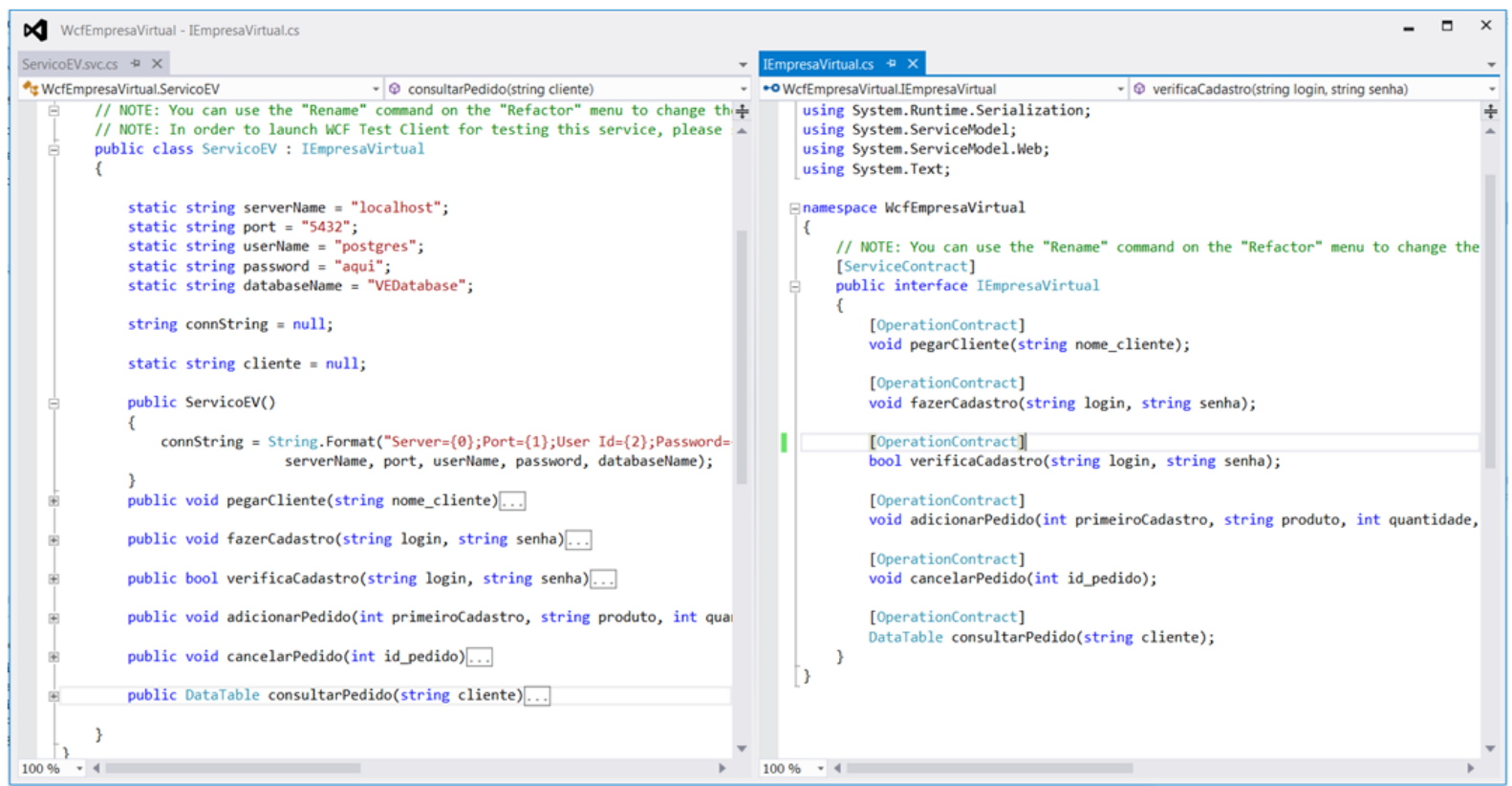

Na Figura C.12, destaca-se o uso da referência Npgsql.dll para a comunicação com o banco de dados PostgreSQL através de comandos começando com Npgsql. Qualquer comando que envolvesse o banco de dados, parte dele teve de ser escrito no script do PostgreSQL, como se verifica com o método NpgsqlConnectionou NpgsqlCommand, em que a string que entra no construtor é o código que vai no script.

Figura C.12 - Código do construtor e da operação fazerCadastro.

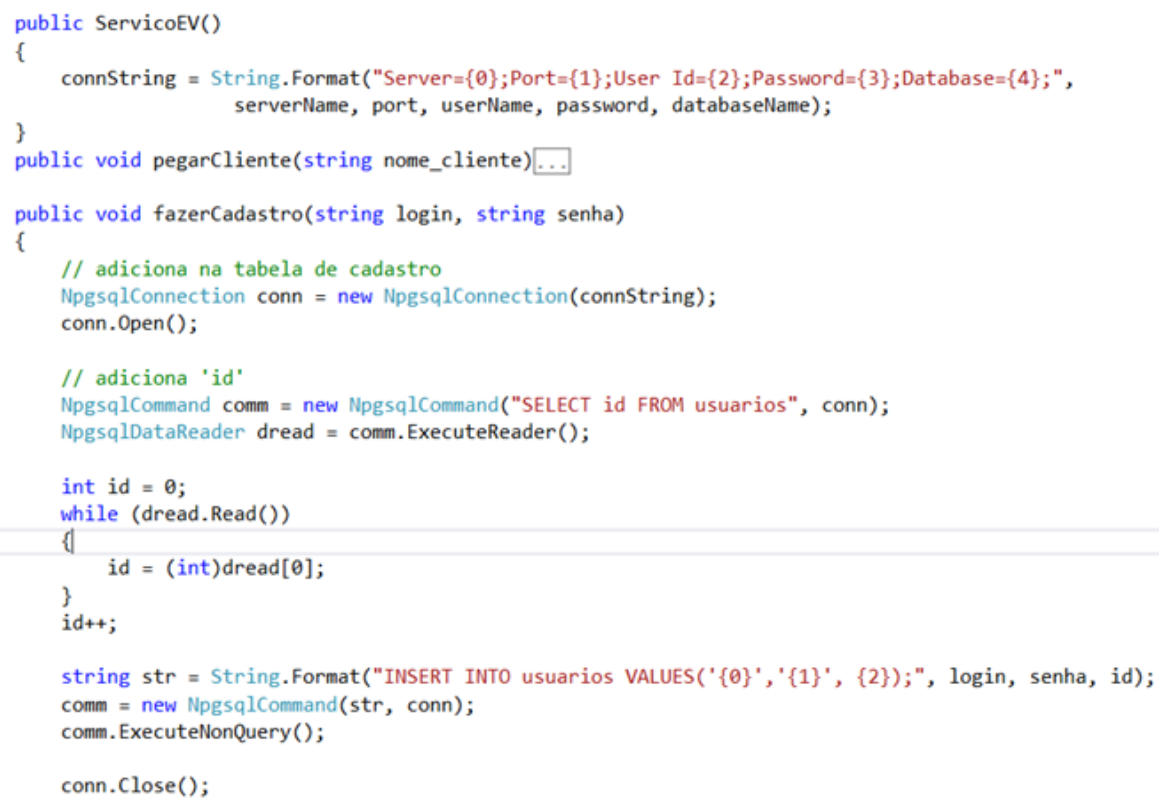


Em Muntani, Miyagi e Pessoa (2014) houve a implementação do "Serviço de Planejamento Virtual". A seguir será apresentada uma descrição da implementação feita no projeto. Foi implementado o Serviço de Planejamento Virtual conforme proposto no capítulo 3, num momento inicial foi utilizado um arquivo em txt com as informações necessárias para a geração das "janelas de tempo". Neste projeto, optou-se por utilizar vetores para os cálculos das janelas. A Tabela C.1 sintetiza as componentes do "Serviço de Planejamento Virtual" já com o nome adotado na implementação, o seu tipo (aplicação, classe ou WCF), além de sua função.

Tabela C.1 - Síntese sobre as componentes utilizadas no "Serviço de Planejamento Virtual".

\begin{tabular}{|c|c|c|}
\hline Componentes & Tipo & Função \\
\hline CarregaDados & Classe & $\begin{array}{l}\text { Carregar as informações presentes em um Text } \\
\text { File. }\end{array}$ \\
\hline Calcula Janelas & Classe & $\begin{array}{l}\text { Calcula as "janelas de tempo" de acordo com as } \\
\text { informações recebidas. }\end{array}$ \\
\hline RealizaHeuristica & Classe & $\begin{array}{l}\text { Realiza a heurística determinada sobre as "janelas } \\
\text { de tempo" calculadas. }\end{array}$ \\
\hline Alteralnformacao & Classe & $\begin{array}{l}\text { Altera as informações recebidas do "Serviço de Ge- } \\
\text { renciamento de Requisições" para permitir a rea- } \\
\text { lização dos métodos existentes nas outras classes } \\
\text { do "Serviço de Planejamento Virtual". }\end{array}$ \\
\hline FormPrincipal & Aplicação & $\begin{array}{l}\text { Permite a utilização de todos os métodos dispo- } \\
\text { níveis nas classes que possui, além de permitir a } \\
\text { representação gráfica das "janelas de tempo" e heu- } \\
\text { rísticas. }\end{array}$ \\
\hline PlanejamentoVirtual & $\begin{array}{l}\text { Windows } \\
\text { Commu- } \\
\text { nication } \\
\text { Foundation } \\
(\text { WCF })\end{array}$ & $\begin{array}{l}\text { Recebe as informações do "Serviço de Gerencia- } \\
\text { mento de Requisições" e permite a realização dos } \\
\text { métodos disponíveis nas classes que possui por esse } \\
\text { serviço. }\end{array}$ \\
\hline
\end{tabular}

O conjunto de classes e forms utilizados na aplicação estão representados na Figura C.13 
Figura C.13 - Classes e Form no programa final do "Serviço de Planejamento Virtual".

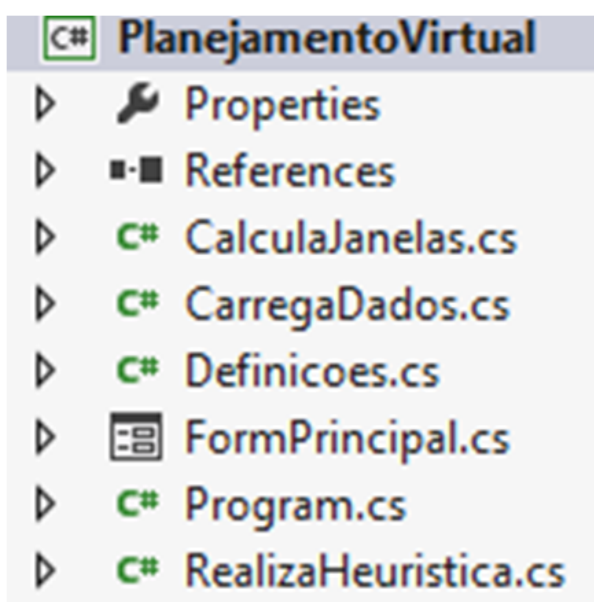

A seguir são apresentados trechos do código da fase de implementação do "Serviço de Planejamento Virtual".

O Form principal possui métodos para chamar outros métodos de outras classes. Ao apertar o botão destacado da Figura C.14, é chamado o método indicado. Esse método utiliza os métodos da classe que carrega as informações para salvá-las na aplicação principal e os métodos para cálculo das "janelas de tempo". Ele também informa qual o arquivo carregado, habilita a utilização dos outros botões do aplicativo e inicializa em uma ComboBox o nome das Empresas Parceiras. O método "CarregaTarefas" (Figura C.15) é o método "CarregaDados" (Figura C.16) servem para inserir as informações do Text File em vetores de vetores.

Figura C.14 - Botão que deve ser apertado para carregamento das informações e cálculo das "janelas de tempo".

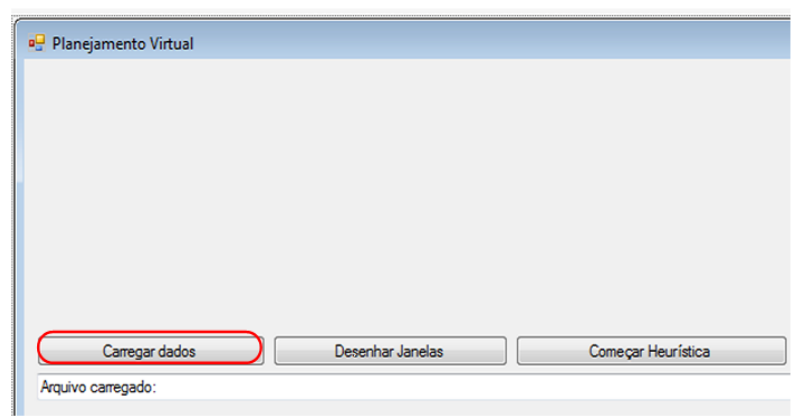


Figura C.15 - Parte do código do método CarregaTarefas.

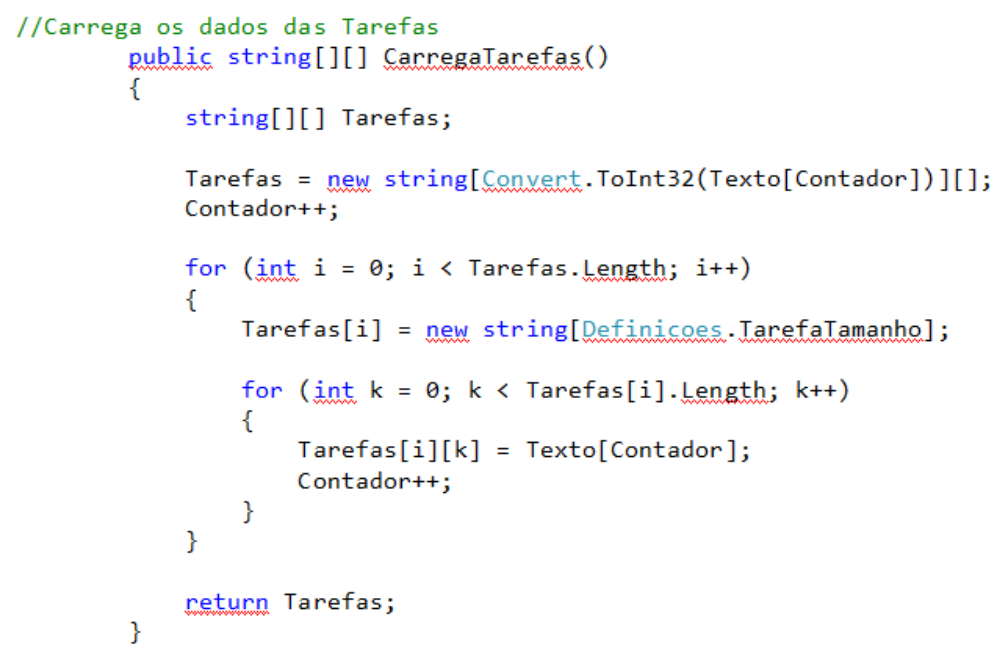

Figura C.16 - Parte do código do método CarregaDados.

private void CarregaDados Click (object sender, EventArgs e)

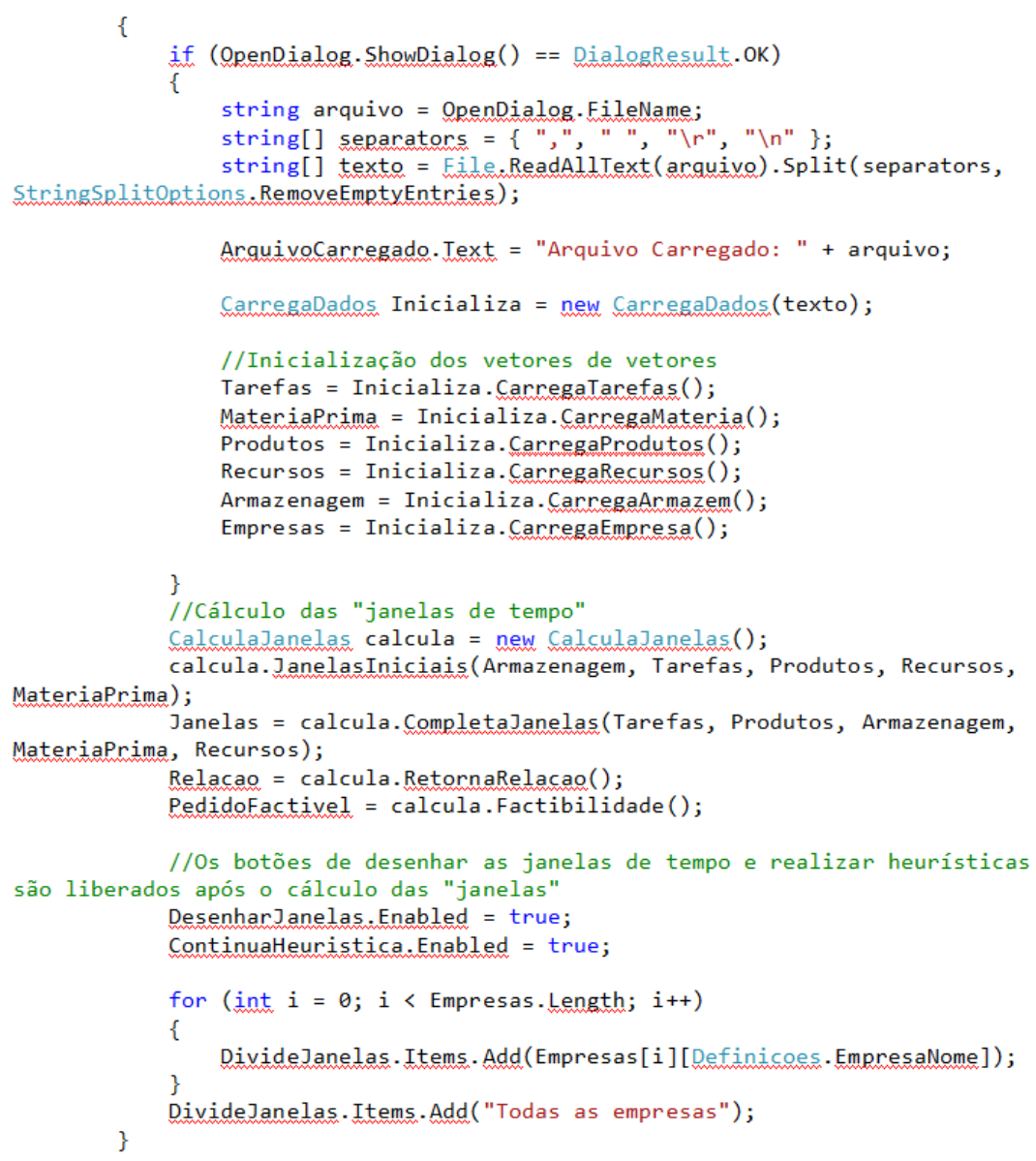

O método "RestricaoReceitaLotes" propaga as restrições de início mais cedo e final mais tarde (Figura C.17). Ele faz parte da classe "CalculaJanelas", que serve para o cálculo das 
janelas de tempo. Nesse método são utilizados outros métodos e informações dessa classe que não são mostrados no relatório.

Figura C.17 - Parte do código do método RestricaoReceitaLotes.

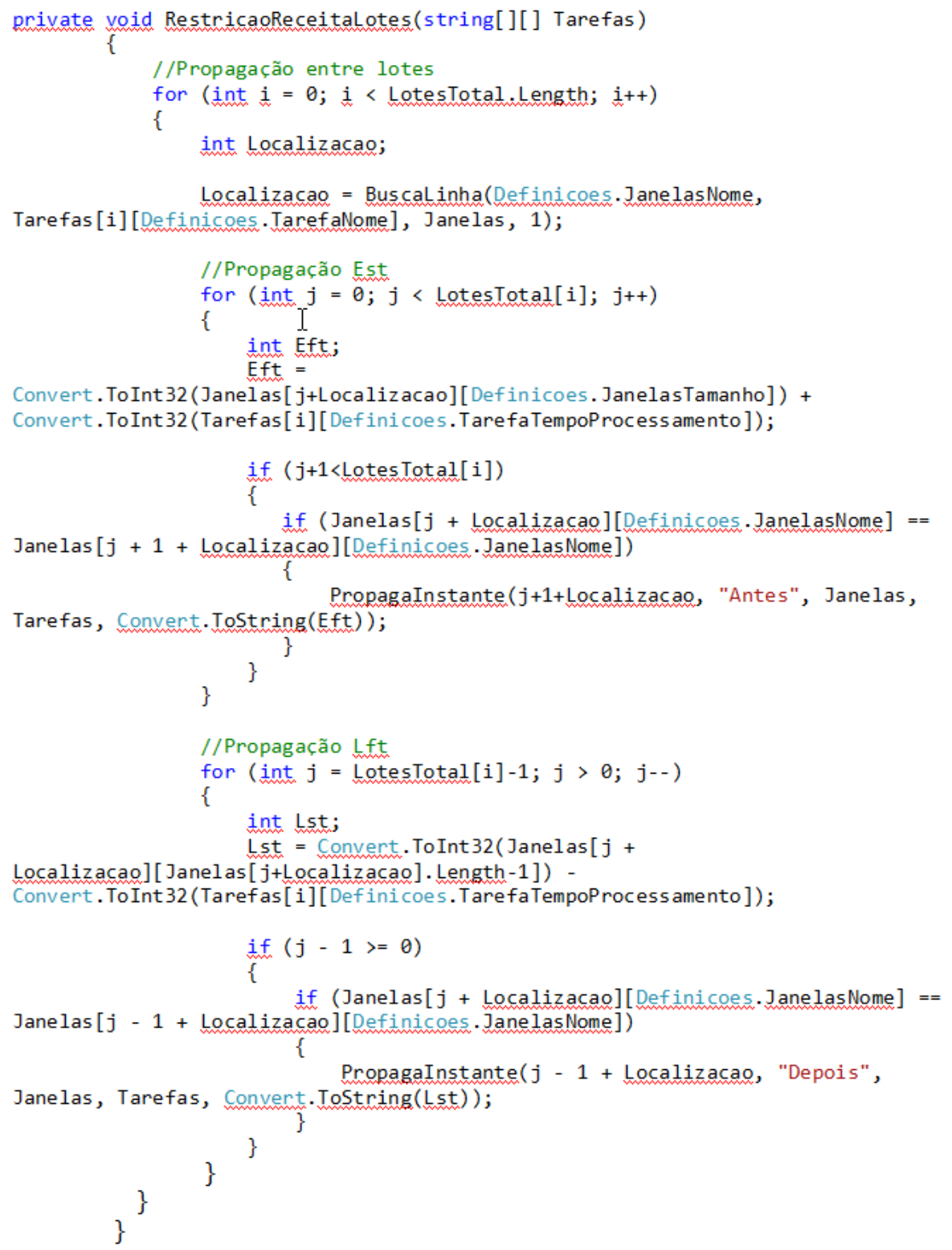

O método "Completa Janelas" é o método responsável pelo cálculo das "janelas de tempo", ele que propaga as restrições necessárias (Figura C.18). Ele repete a propagação das restrições até que as "janelas de tempo" não se variem mais, ou seja, todas as restrições tenham sido propagadas. É um método da classe "Calcula Janelas" e utiliza outros métodos dessa classe. 
Figura C.18 - Parte do código do método CompletaJanelas.

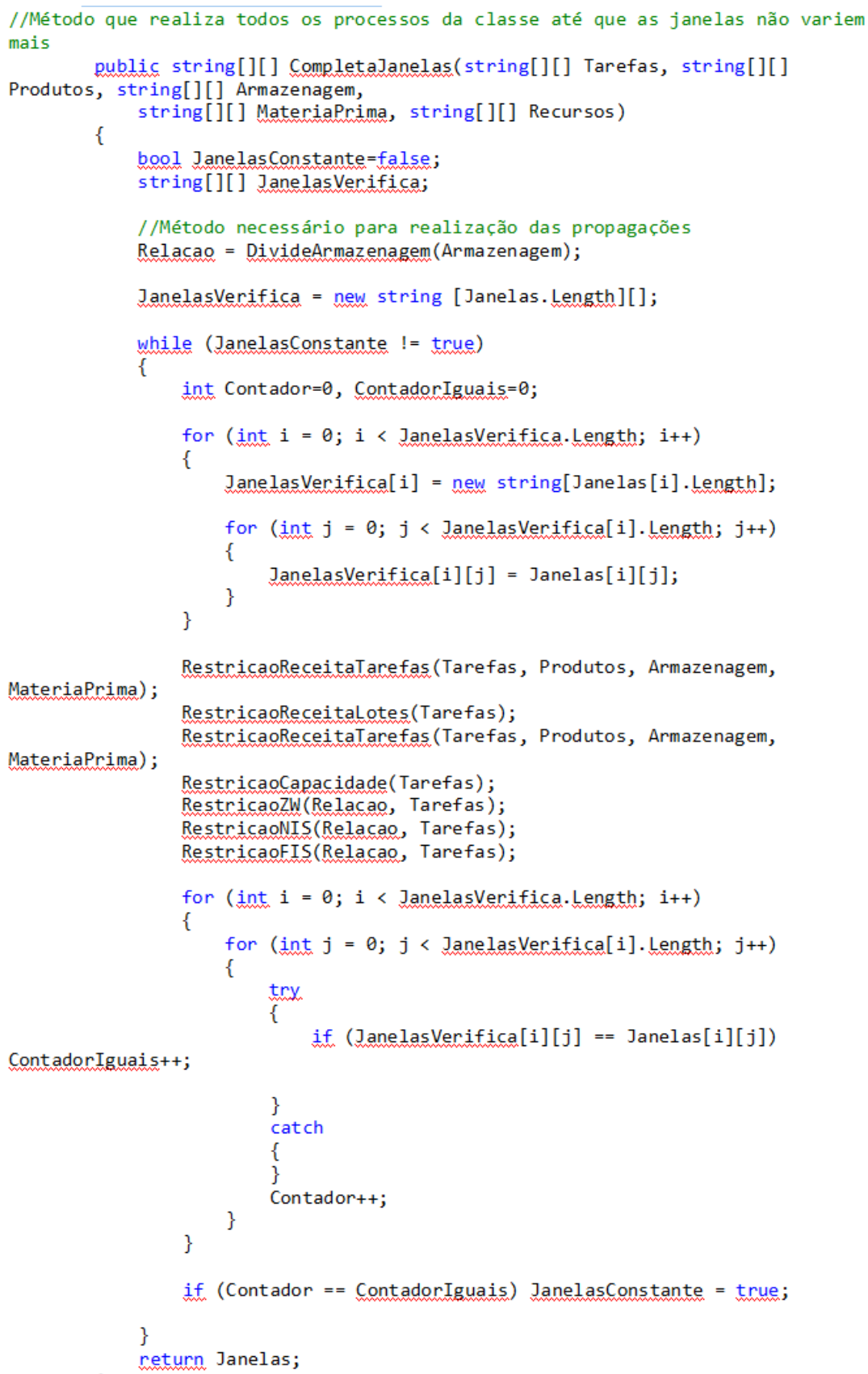

O método "CalculoCriticalidade" calcula o valor da criticalidade de todas as "janelas de tempo" (Figura C.19), faz parte da classe "RealizaHeuristica". 
Figura C.19 - Parte do código do método CalculoCriticalidade.

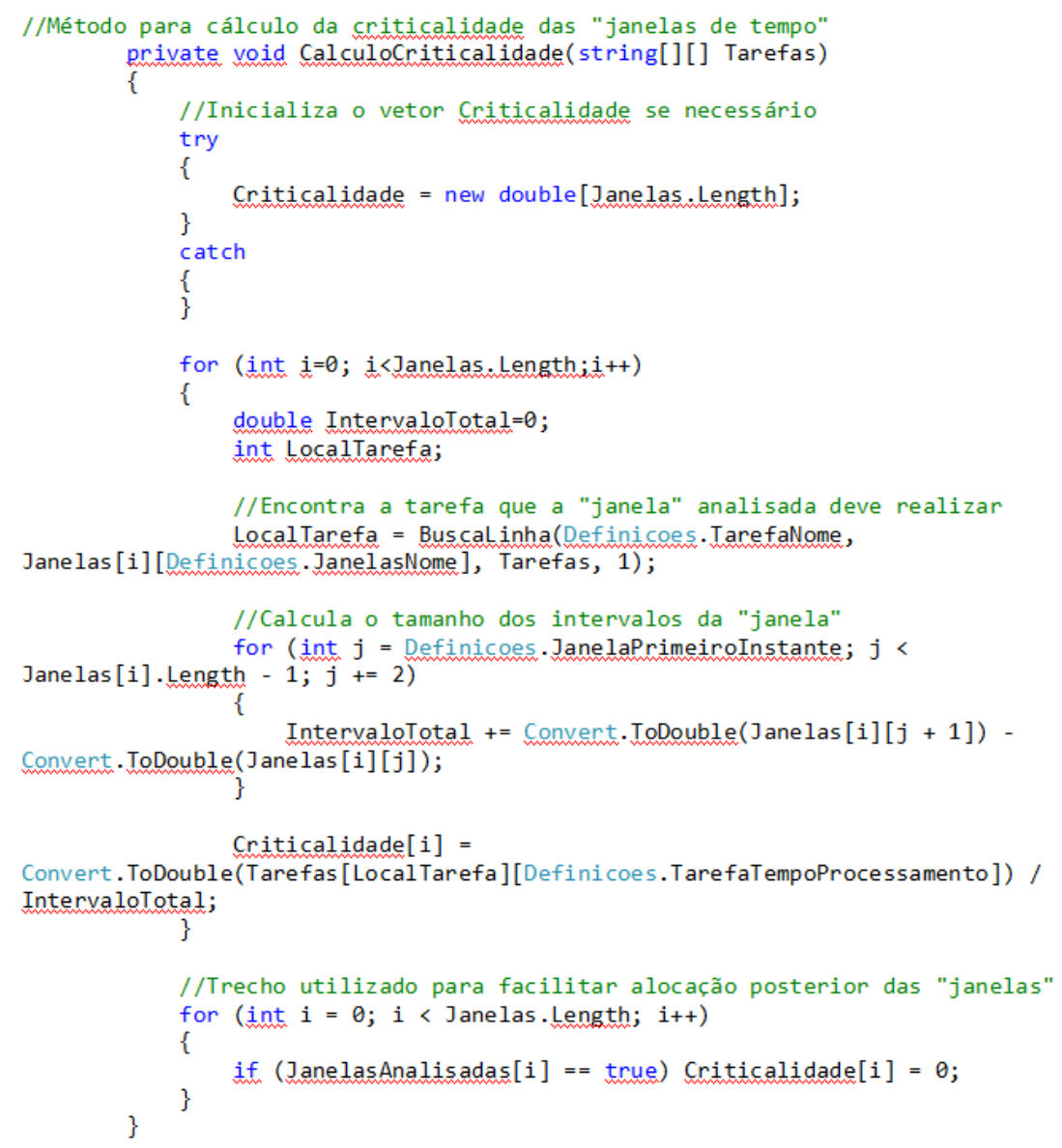

O método "ProcessoHeuristica" realiza as heurísticas APS determinadas pelas empresas (Figura C.20). Para isso, ele utiliza as informações como a criticalidade das "janelas de tempo" e se essa janela já foi alocada, ele é da classe "RealizaHeuristica".

Figura C.20 - Parte do código do método ProcessoHeuristica.

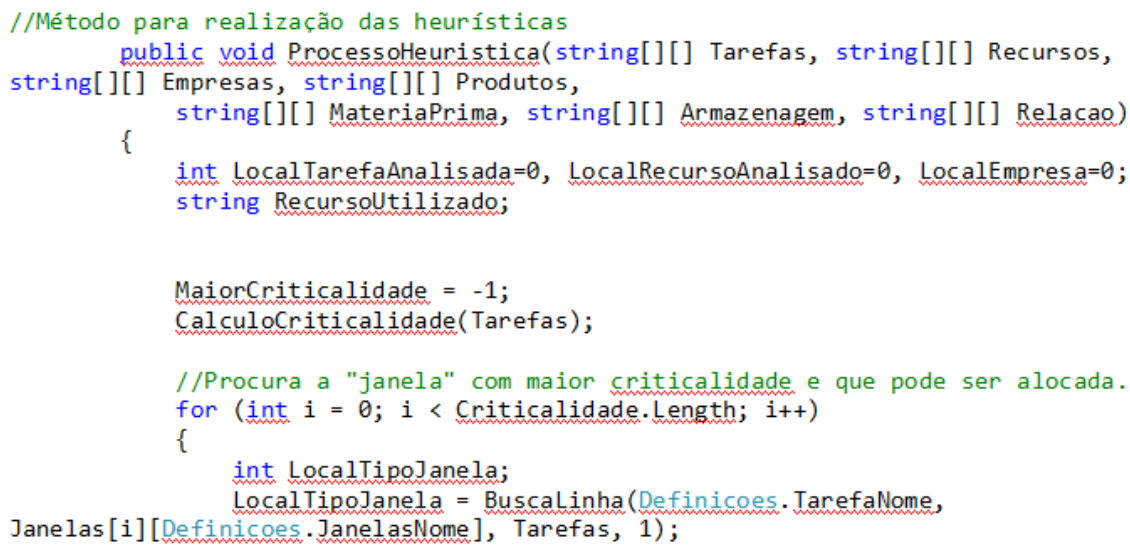


if (MaiorCriticalidade $==-1 \& \&$ (Tipo]anela[LocalTipo]anela] $==$ Definicoes. TipoProcessamento || Tipo]anela[LocalTipo] anela] == Definicoes. TipoImediata)

\&\& JanelasAnalisadas $[i]==$ false) MaiorCriticalidade $=i$;

if (MaiorCriticalidade!=-1 \&\& Criticalidade[i] > Criticalidade[MaiorCriticalidade] \&\&

(Tipo]anela [LocalTipo] anela $]==$ Definicoes. TipoProces samento || Tipo]anela[LocalTipo] anela] == Definicoes. TipoImediata) \&\& JanelasAnalisadas $[i]==$ false) MaiorCriticalidade $=i$; \}

//Encontra a empresa responsável pela tarefa escolhida

//Encontra-se a tarefa

LocalTarefaAnalisada = BuscaLinha(Definicoes. TarefaNome,

Janelas [MaiorCriticalidade] [Definicoes. JanelasNome], Tarefas, 1);

utiliza

//Encontra-se qual a empresa que possui o recurso que ela

Recursoltilizado $=$

Tarefas [Local TarefaAnali sada] [Definicoes.TarefaRecursoUtilizado];

LocalRecursoAnalisado = Buscalinha (Definicoes. RecursolNome, Recursoltilizado, Recursos, 1);

tarefa.

//Finalmente, é encontrado nome da empresa que realizará a

LocalEmpresa $=$ BuscaLinha (Definicoes. EmpresaNome,
ecursoAnalisado][Definicoes. RecursoEmpresa], Empresas, 1);

//Propaga a Heurística pré-determinada

"Cedo")

if (Empresas[LocalEmpresa] [Definicoes. EmpresaHeuristica] $==$

Janelas [MaiorCriticalidade] [Definicoes. JanelaSegundoInstante] =

Convert.ToString(Convert. ToInt 32(Janelas[MaiorCriticalidade][Definicoes.JanelaPr imeiroInstante]) +

Convert. ToInt 32 (Tarefas [ LocalTarefaAnalisada] [Definicoes. TarefaTempoProcessament o]));

Array.Resize(ref Janelas [MaiorCriticalidade],

Definicoes. JanelasUmIntervalo);

$$
\}
$$

"Tarde")

else if (Empresas[LocalEmpresa][Definicoes. EmpresaHeuristica] $==$

Janelas [MaiorCriticalidade][Definicoes. JanelaSegundoInstante] =

Janelas [MaiorCriticalidade] [Janelas[MaiorCriticalidade].Length - 1];

Janelas [MaiorCriticalidade] [Definicoes. JanelaPrimeiroInstante] $=$

Convert.ToString(Convert. ToInt 32(Janelas[MaiorCriticalidade][Definicoes.JanelaSe gundoInstante]) -

Convert. ToInt 32 (Tarefas [ LocalTarefaAnalisada][Definicoes. TarefaTempoProcessament o]));

Definicoes. JanelasumIntervalo)

Array.Resize(ref Janelas [MaiorCriticalidade],

\}

JanelasAnalisadas [MaiorCriticalidade] = true;

CalculaJanelas calcula = new CalculaJanelas();

calcula. Janelas $=$ this. Janelas;

Janelas = calcula.CompletaJanelas (Tarefas, Produtos,

Armazenagem, MateriaPrima, Recursos);

\}

Praticamente todas as etapas finais dos projetos foram cumpridas, sendo a parte que não foi concluída envolvia os testes de integração. 


\section{Apêndice D - Documentação das tabelas criadas na implementação no LSA}

Neste apêndice estão apresentadas os códigos em Structured Query Language (SQL) implementados usando o PostgreSQL além das janelas finais visível por meio do Openbravo referente à implementação no LSA.

A Tabela de disponibilidade de produtos armazena os dados sobre as disponibilidades dos materiais, com dados sobre as entregas de novos materiais (data de entrega e quantidade) (Figuras D.1 e D.2).

Figura D.1 - SQL da tabela Isa_product_av .

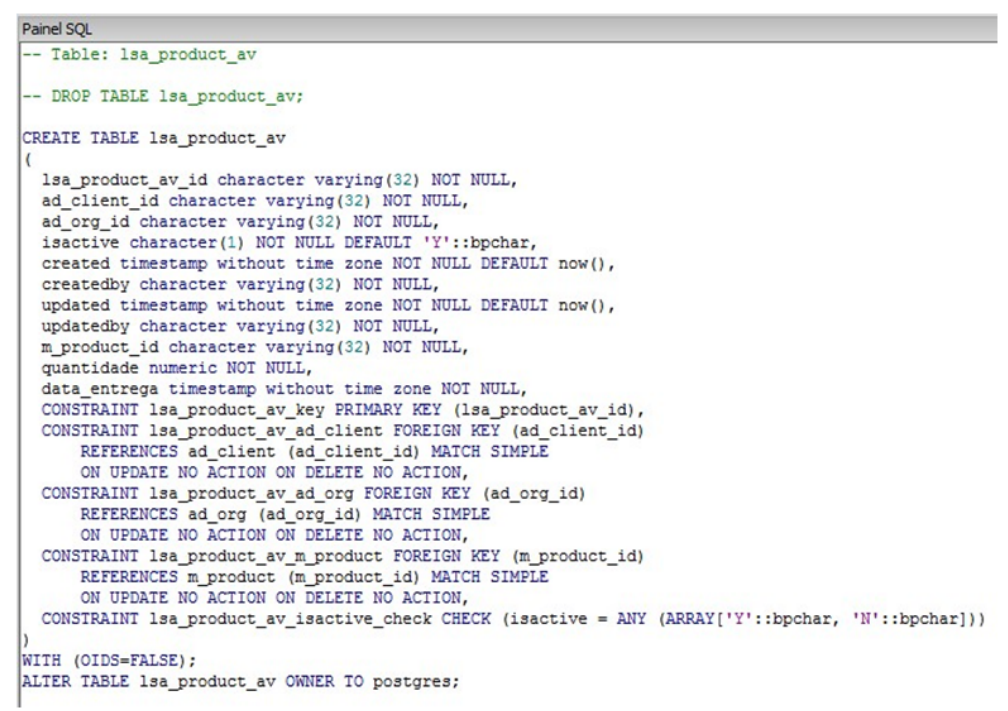

Figura D.2 - Janela da tabela de disponibilidade de produtos.

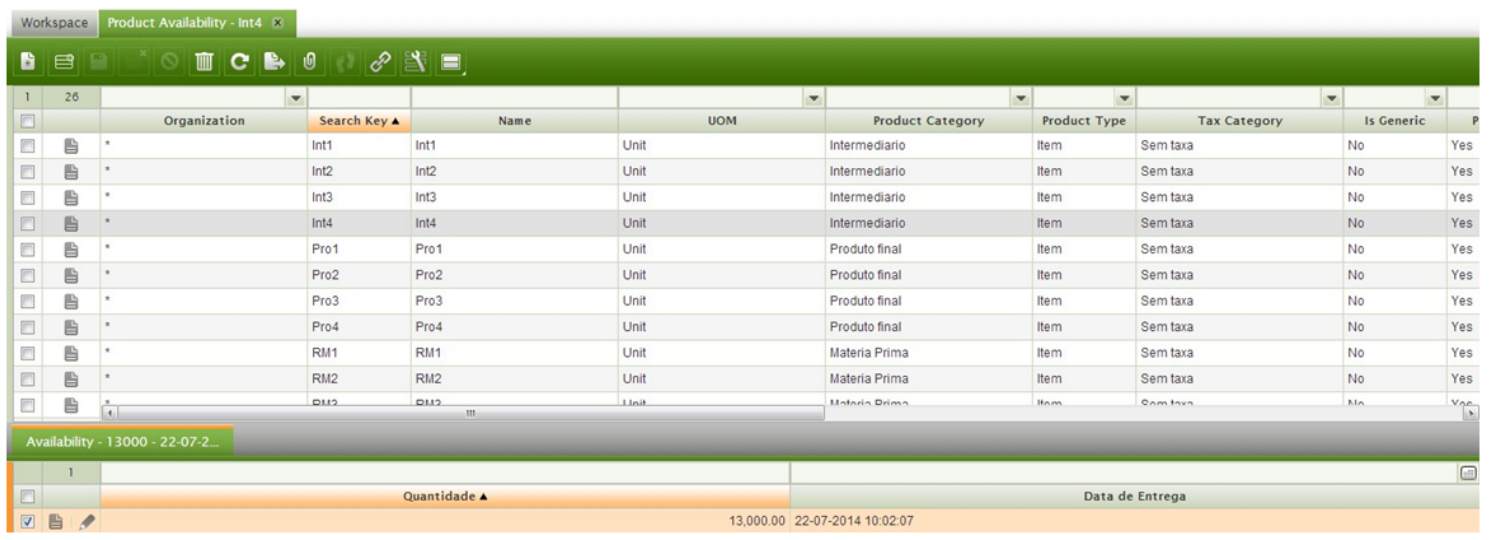

As tabelas de equipamentos e de disponibilidade de equipamentos contêm o registro dos equipamentos de cada empresa, recebendo o nome desse equipamento (Figuras D.3 a D.5); 
Figura D.3 - SQL da tabela Isa_equipamento .

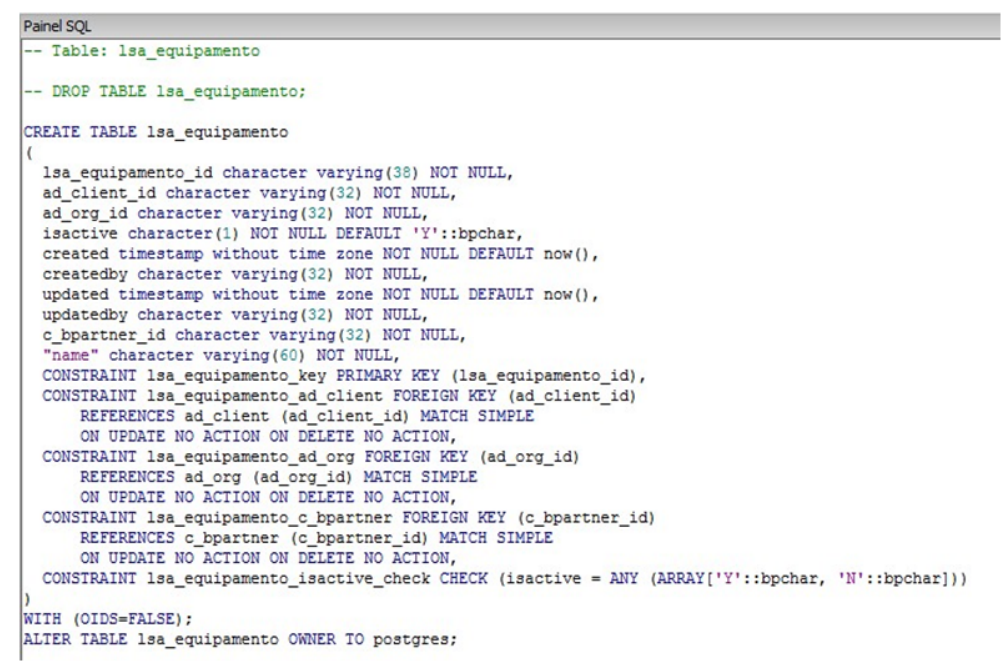

Figura D.4 - SQL da tabela Isa_equipamento_av .

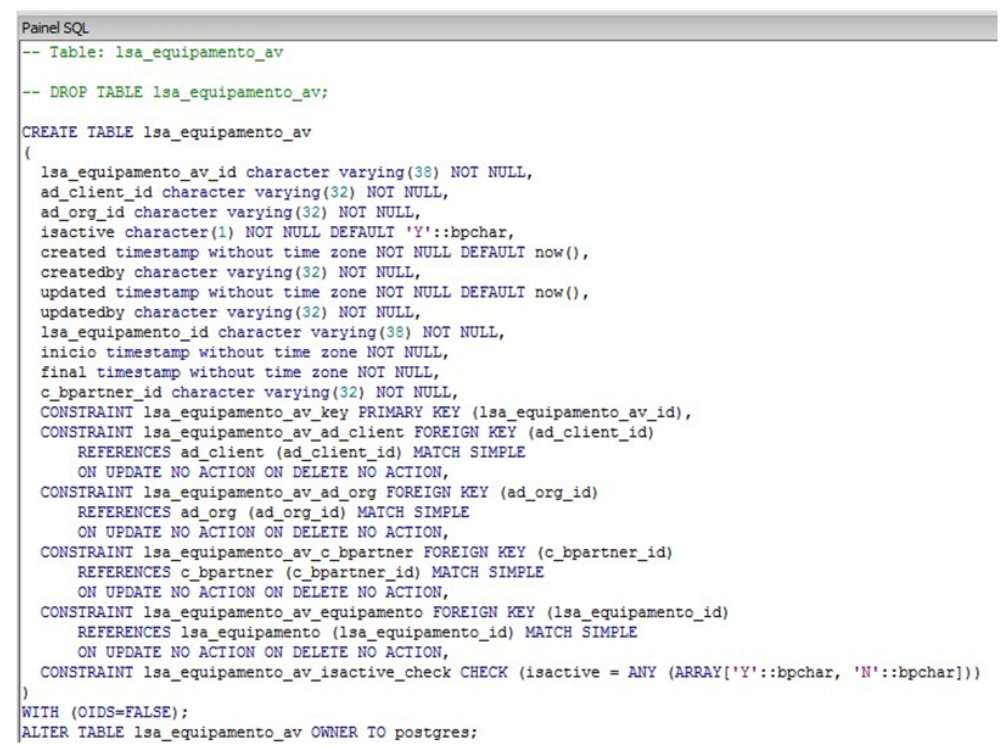

Figura D.5 - Janela da tabela equipamentos e de disponibilidade de equipamentos.

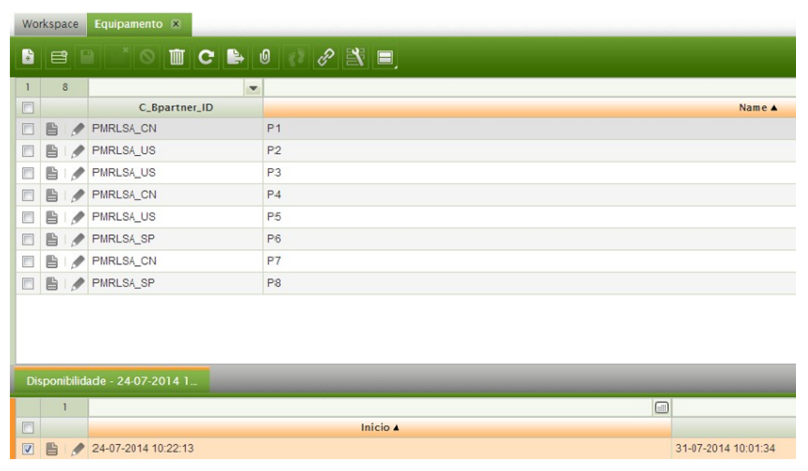

A tabela de restrições de armazenagem é para guardar os registro dos depósitos utilizados, fazendo referência a sua política de transferência e o tipo de restrição do depósito (Figuras D.6 e.7). 
Figura D.6 - SQL da tabela Isa_deposito .

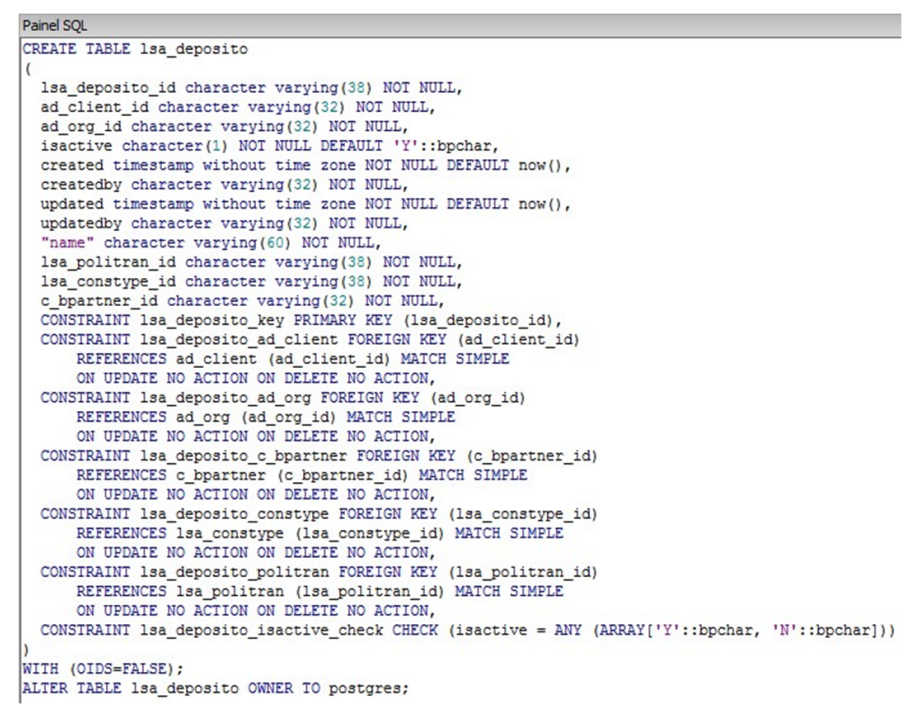

Figura D.7 - Janela para inclusão de depósitos.

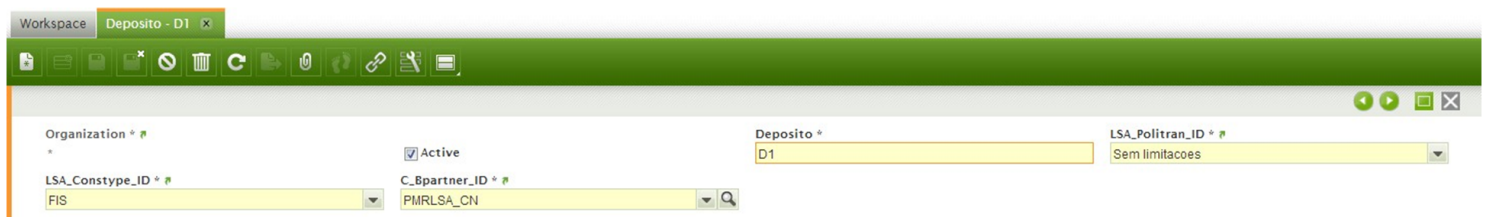

A tabela Isa_constype é para receber declaração dos possíveis tipos de restrição de um depósito (FIS - Finite Intermediate Storage, UIS, Unlimited Intermediate Storage, e NIS, No Intermediate Storage) (Figuras D.8 a D.9.).

Figura D.8 - SQL da tabela Isa_constype .

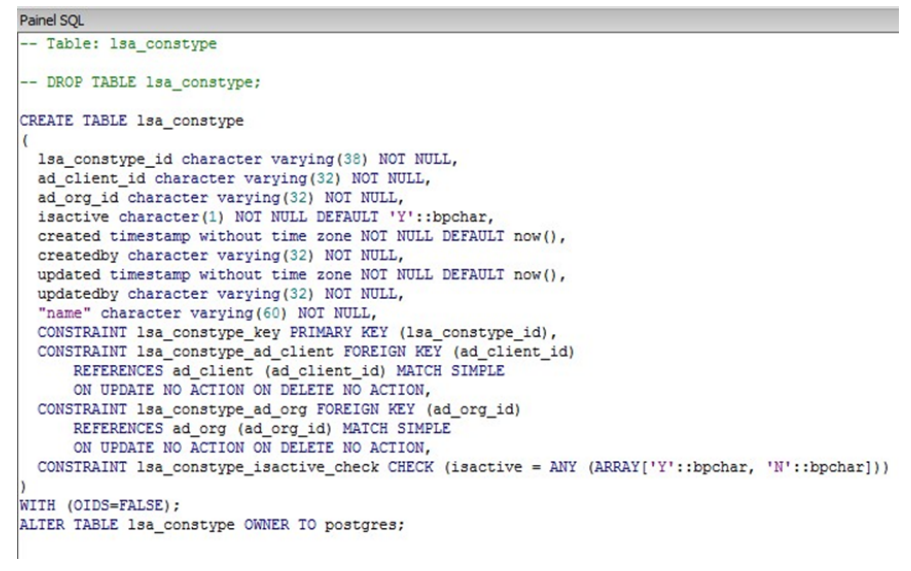

Figura D.9 - Janela para declaração dos tipos de restrição de armazenagem (FIS, NIS ou UIS).

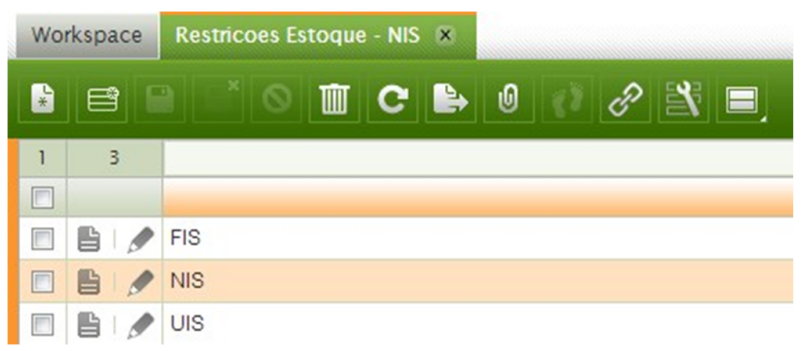


A tabela Isa_politran recebe as possíveis políticas de transferência (sem limitação ou ZW, zero wait (Figura D.10 e D.11).

Figura D.10 - SQL da tabela Isa_politran .

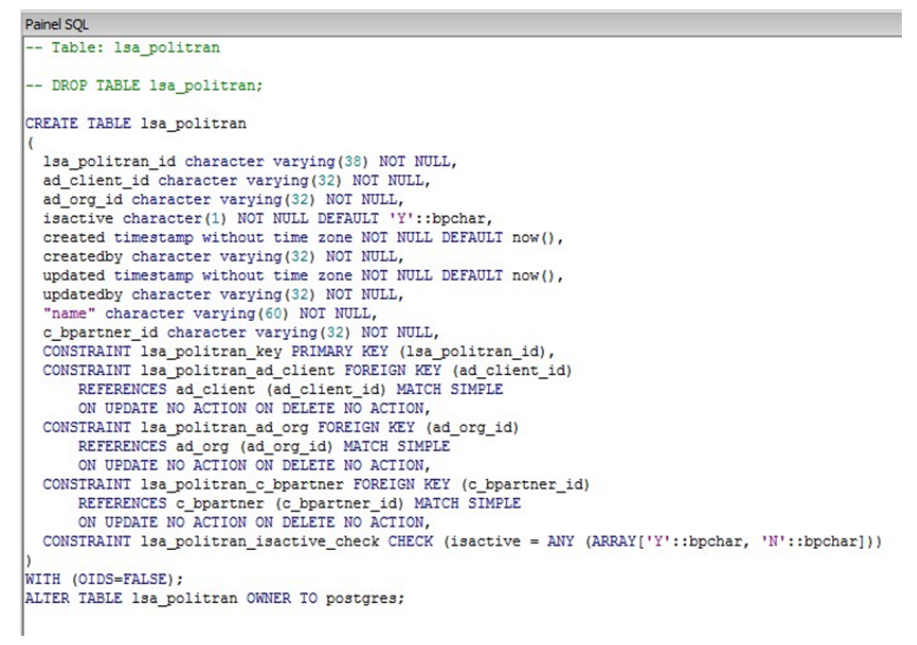

Figura D.11 - Janela para declaração dos tipos de política de transferência (sem limitações ou zero wait).

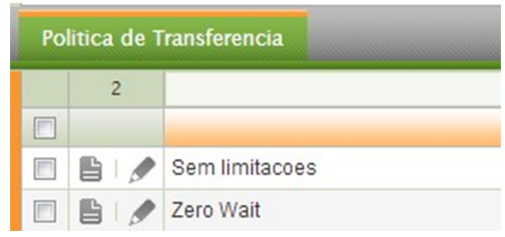

A tabela Isa_restoque recebe os valores máximos a serem estocados em um certo depósito, no caso de FIS (Figura D.12 e D.13).

Figura D.12 - SQL da tabela Isa_restoque .

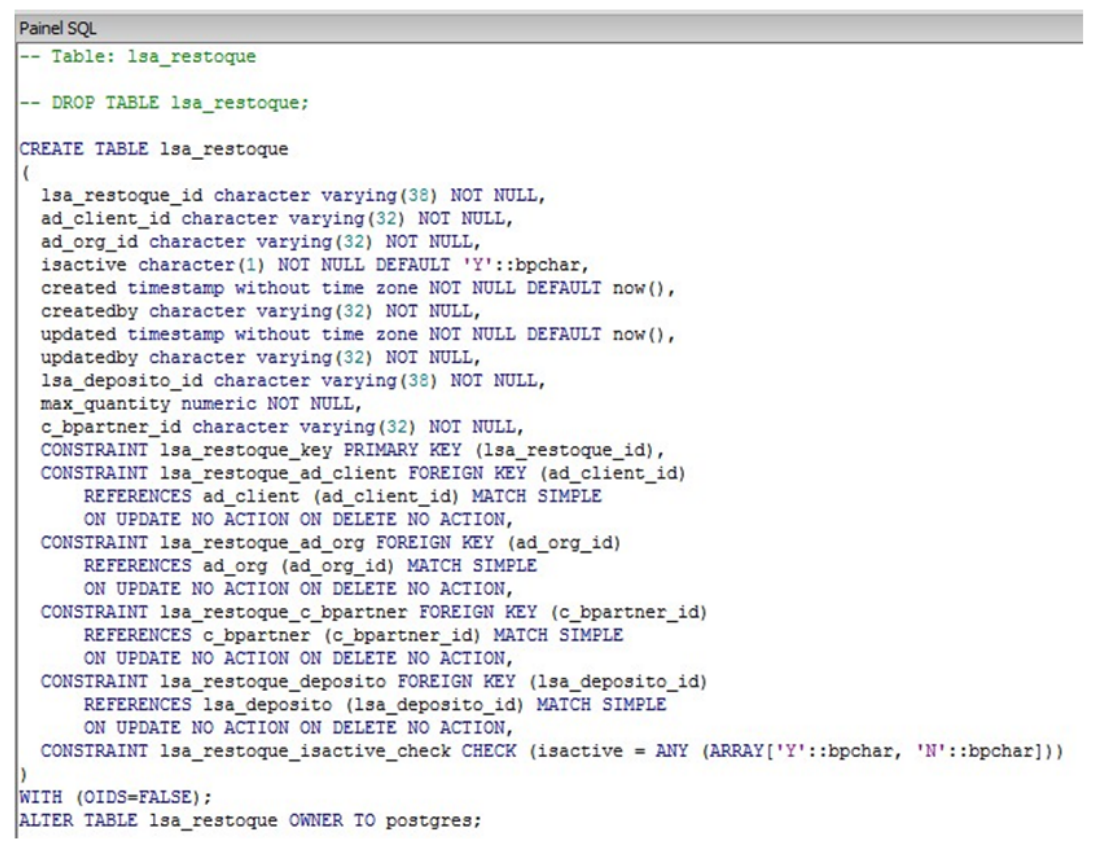


Figura D.13 - Janela de inclusão de registro de limite de armazenagem de depósito (no caso FIS).

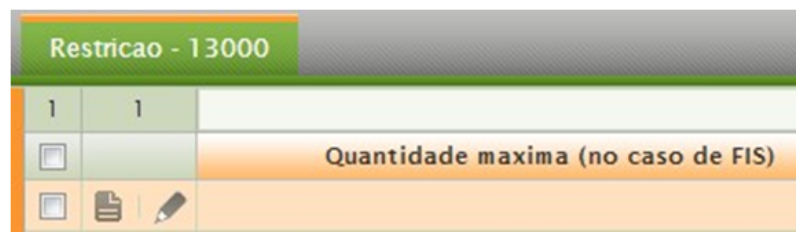

A tabela de habilitação de produtos nos recursos é para registrar a habilitação dos produtos nos equipamentos (Figura D.14);

Figura D.14 - SQL da tabela Isa_habilitacao.

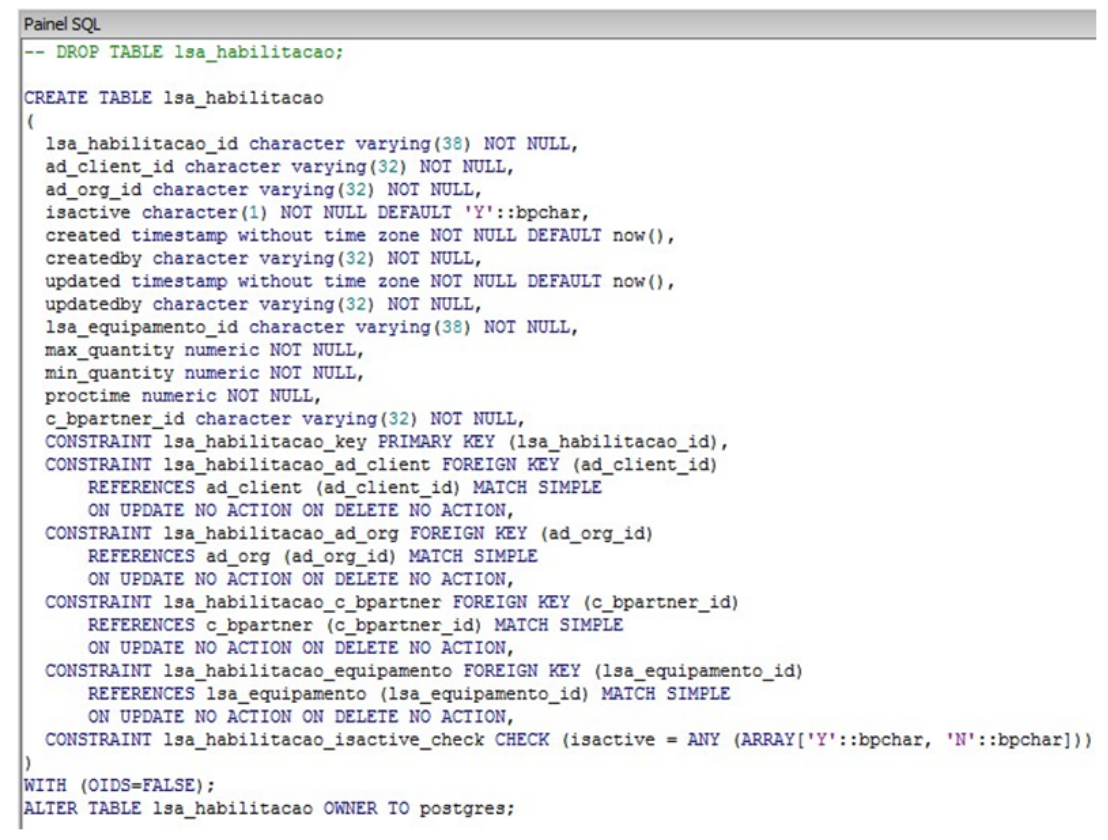

A tabela Isa_pedido, é para registrar os pedidos de materiais junto com a quantidade e tempo da demanda e a quantidade e o tempo no estoque, além da data de entrega e da janela de tempo (Figura D.15); 
Figura D.15 - SQL da tabela Isa_pedido .

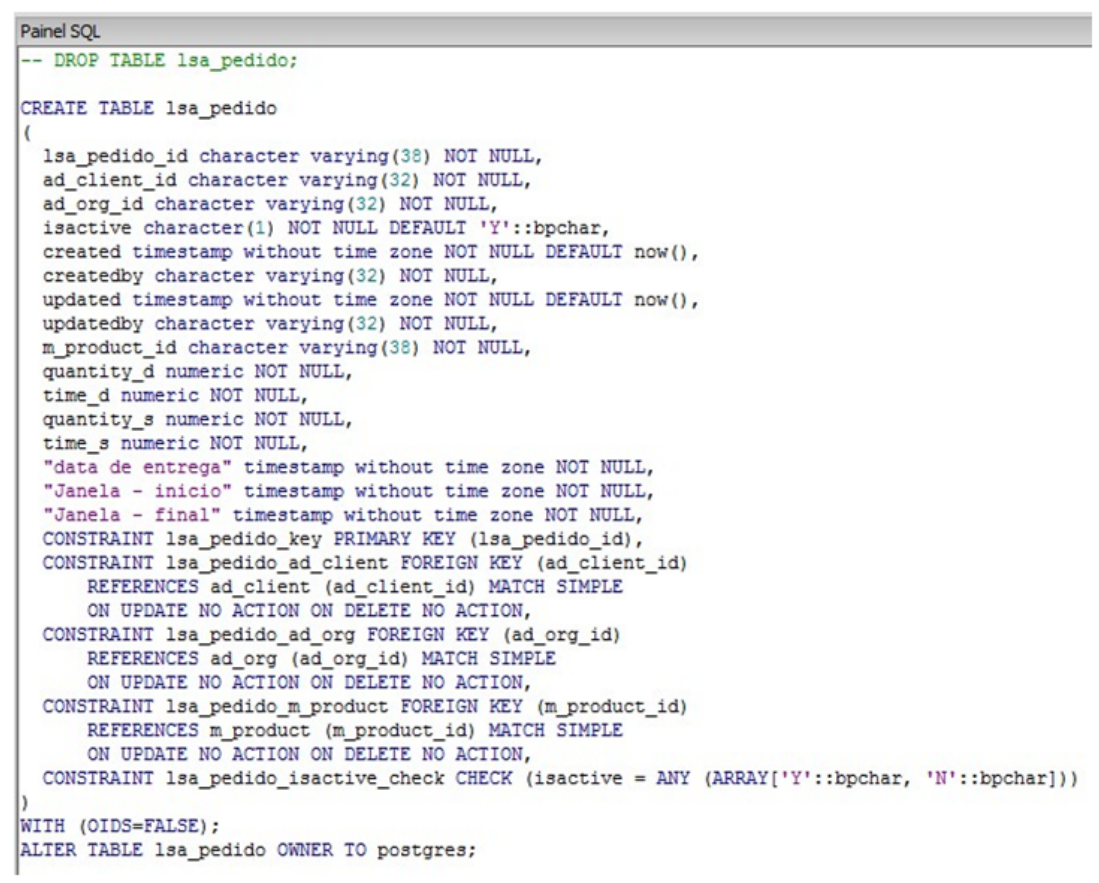

A Tabela de processos é para listagem dos processos operados nas empresas parceiras, da matéria prima até que se chegue ao produto final (Figura D.16);

Figura D.16 - SQL da tabela Isa_processo .

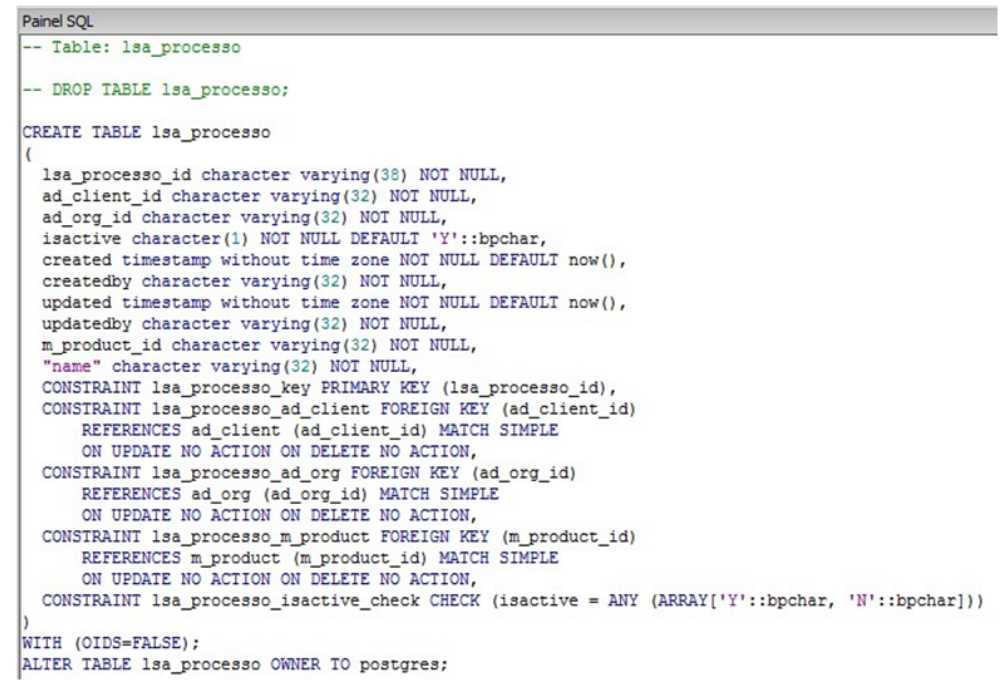

As Tabelas de fatores de geração e consumo são para a declaração dos fatores de consumo e geração de materiais relacionados a cada tarefa, é para declaração dos fatores de consumo e geração de materiais relacionados a cada processo (Figuras de D.17 a D.19); 
Figura D.17 - SQL da tabela Isa_gerconprocesso .

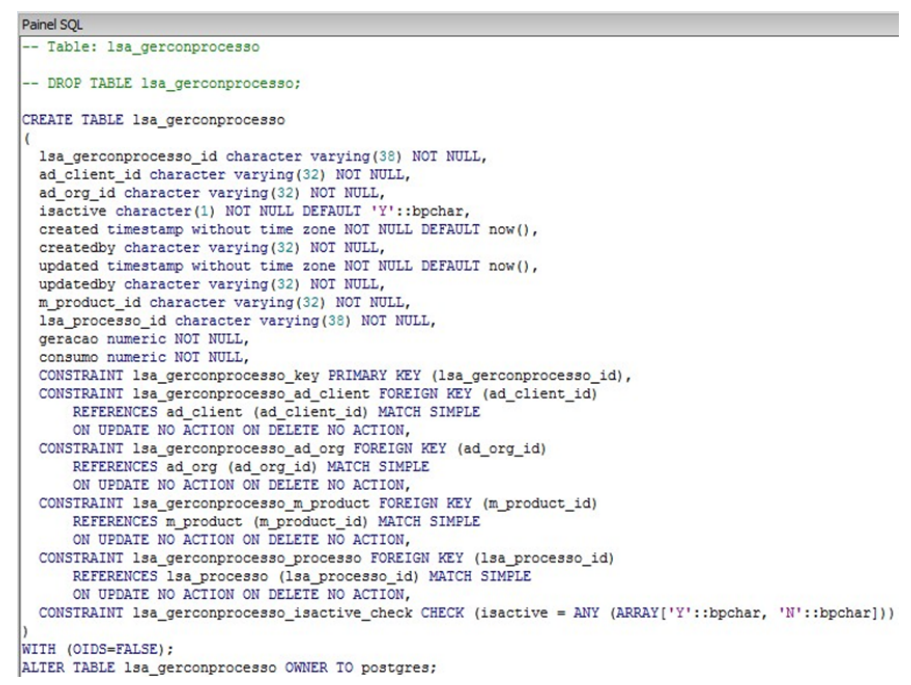

Figura D.18 - SQL da tabela Isa_gercontarefa .

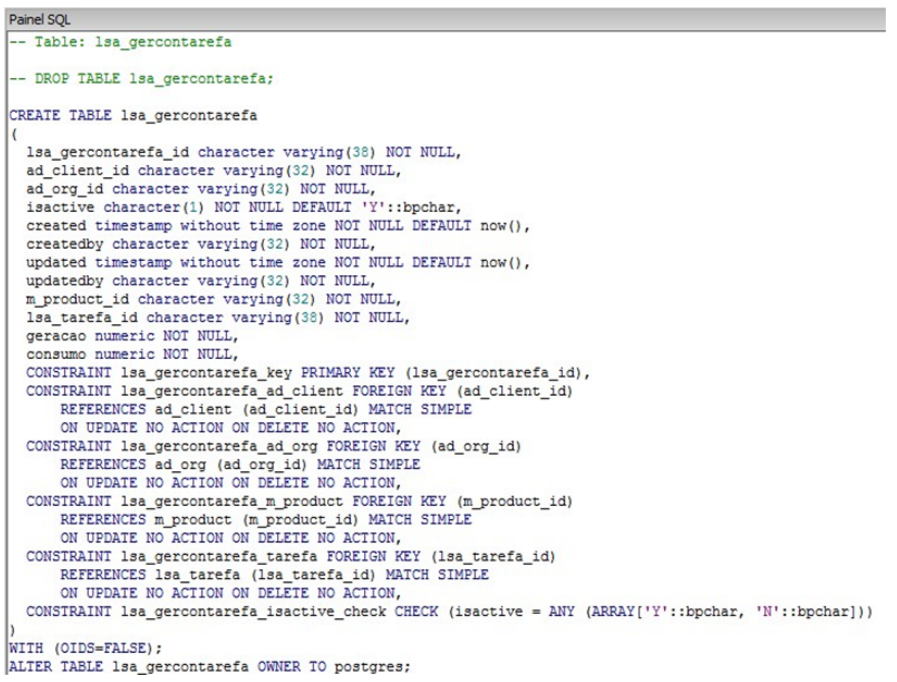

Figura D.19 - Janela para registro dos fatores de geração e consumo de tarefas e processos.

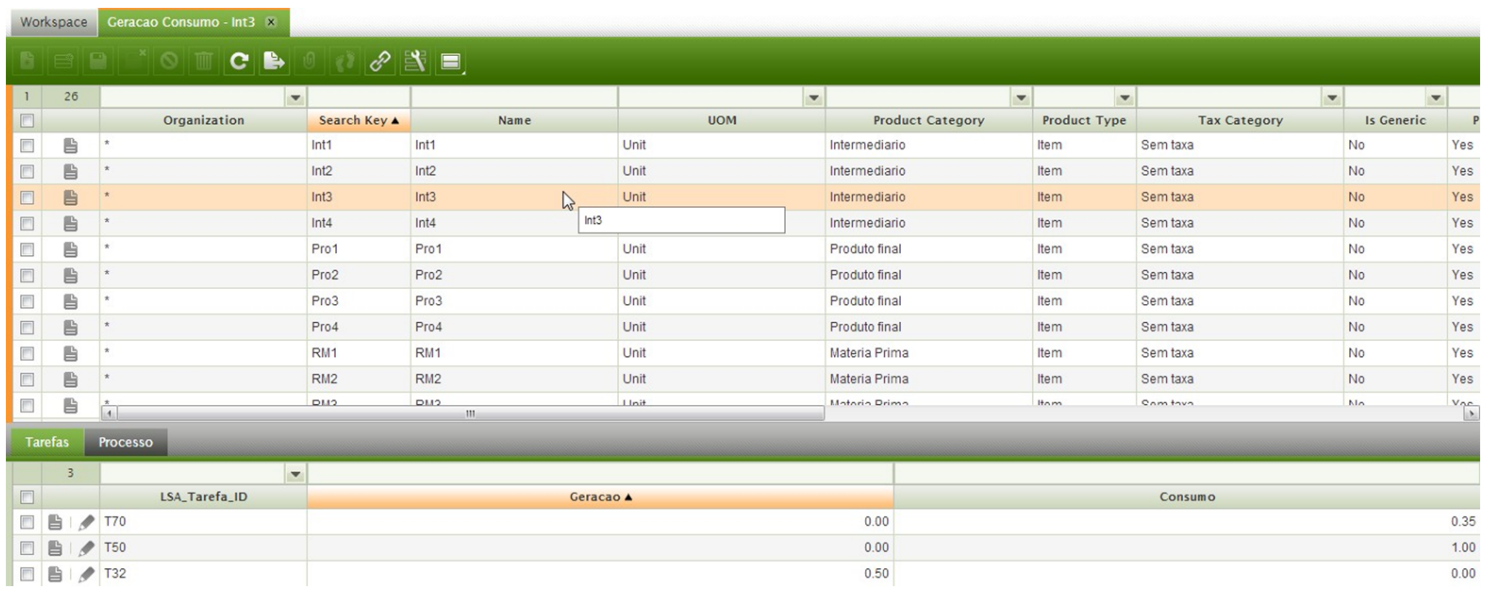




\section{Apêndice E - Conversão da rede estado tarefa em PFS}

Este trabalho engloba EVs com empresas parceiras de diversos tipos de produção, ou seja, produção contínua, produção de lotes, e produção discreta. Uma das formas utilizadas para modelar os fluxos destes diferentes tipos de processos em problemas de produção é com a rede STN (state-task network), entretanto, ela é uma rede estática e não possibilita a análise da dinâmica do processo. Desta forma neste projeto é analisada uma forma de representação gráfica que atenda as necessidades das EVs baseada na rede STN.

A representação STN foi apresentada em Kondili, Pantelides e Sargent (1993). Ela foi desenvolvida originalmente para descrever processos químicos complexos, pois elimina as ambiguidades que podiam conter no fluxograma tradicional de processos químicos, mas a sua forma clara de representar processos produtivos, permite que ela seja usada na indústria em geral, tanto em processos contínuos, semi-contínuos ou batelada (RODRIGUES, 2000). A STN tem sido utilizada frequentemente em problemas de planejamento e programação da produção (RODRIGUES et al., 2004; MARAVELIAS, 2009; SHAIK et al., 2009; BOSE; BHATTACHARYA, 2009; MONIZ; BARBOSA-POVOA; SOUSA, 2013; HARJUNKOSKI et al., 2014). A STN é descrita aqui utilizando o exemplo de aplicação apresentado em Papageorgiou e Pantelides (1996).

As matérias-primas, produtos intermediários e produtos finais são denominados "estados" e representados por "círculos". As "tarefas" produtoras e consumidoras são representadas por "retângulos". Os "estados" e "tarefas" são caracterizados por:

- Condições de armazenagens dos "estados": UIS, FIS e NIS;

- Política de transferência: sem limitações ou ZW;

- Quantidade de produção cada "tarefa";

- Tempo de processamento da cada "tarefa";

- Porcentagem dos "estados" produzidos e consumidos por cada "tarefa" como fração do tamanho da "tarefa".

As regras para construção da representação STN de um processo são:

- Uma "tarefa" tem a quantidade de "estados" de entrada (saída) igual ao número de materiais diferentes consumidos (gerados) pela "tarefa". 
- Duas ou mais entradas (saídas) em um "estado" são necessariamente de materiais iguais.

A Figura [E.1]apresenta um exemplo de representação STN. Ela mostra uma representação de sistema flexível de produção. Os "estados" ("círculos"), representam: matérias-primas ( $M p r 1$, $M p r 2, M p r 3, M p r 4, M p r 5$, e $M p r 6$ ), materiais em processo (produtos intermediários, $S 10$, $S 20, S 21, S 22, S 30, S 31, S 40, S 50, S 60, S 61, S 70, S 71$, e $S 72)$ e produtos finais (Pro1, Pro2, Pro3, e Pro4). Na parte de baixo dos "estados" são descritas as condições de armazenamento (UIS, FIS, e NIS), ou politica de transferência (ZW). Já as "tarefas" ("retângulos") (T10, T11, T20, T21, T22, T23, T30, T31, T32, T40, T41, T50, T51, T60, T61, T62, T70, $T 71$, e $T 72$ ) identificam a sequência das "tarefas" que são habilitadas para serem desenvolvidas em diferentes equipamentos, determinando assim as operações de produção necessárias para a manufatura dos produtos (intermediários ou finais).

Acima da "tarefa" é descrito o tempo de produção em unidade de tempo (u.t.). Abaixo da "tarefa" é' descrita a quantidade da produção. Nota-se que por meio desta representação todos os materiais necessários para a execução de uma "tarefa" ficam definidos.

Quando existem duas setas saindo de uma "tarefa" é necessário indicar a porcentagem que está saindo. Como exemplo, na T32 estão saindo duas setas, e em cada seta existe o valor de 0.50 , isto representa que $50 \%$ do material produzido por T32 vai para Int2 e 50\% vai para Int3. Reparar que o valor está na seta de saída da "tarefa". Quando não existe nenhum valor, significa $100 \%$.

Quando existir valor na entrada da "tarefa", este valor representa a porcentagem que a operação consome daquele material armazenado no estado de entrada. Como exemplo, a T21 consome $40 \%$ da Int2 e os outros $60 \%$ são consumidos pela $T 40$. 
Figura E.1 - Representação STN do exemplo.

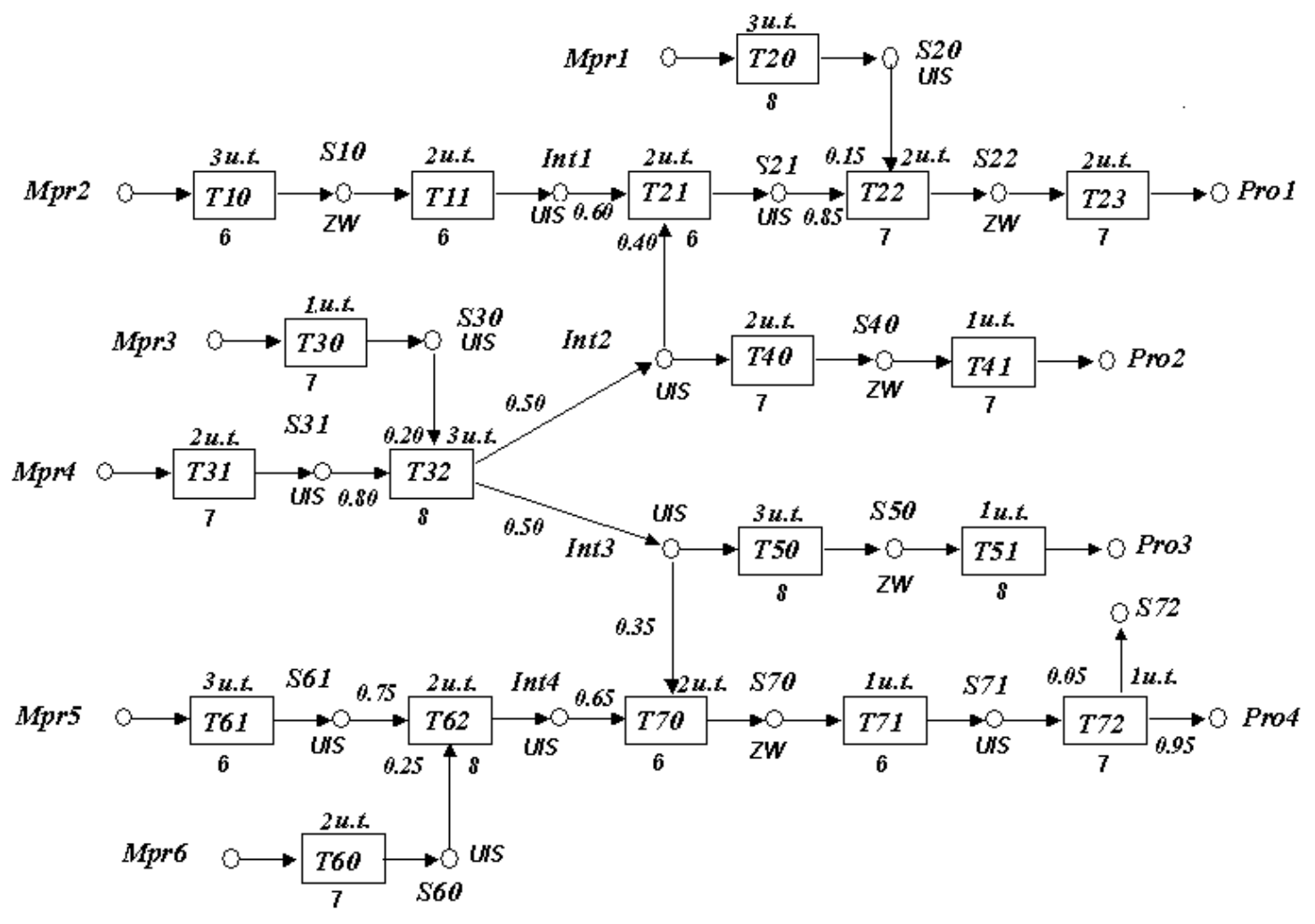

Fonte: (PAPAGEORGIOU; PANTELIDES, 1996)

\section{CONVERSÃO}

A STN é uma rede estática e não possibilita a sua simulação e nem o controle do processo, apenas a representação. Desta forma será apresentado o procedimento de conversão da STN em PFS. Possibilitando que as pessoas que utilizam o STN e desejam fazer a validação e o controle do processo apliquem o PFS.

As regras para construção da representação STN de um processo são:

- Uma "tarefa" tem a quantidade de "estados" de entrada (saída) igual ao número de materiais diferentes consumidos (gerados) pela "tarefa".

- Duas ou mais entradas (saídas) em um "estado" são necessariamente de materiais iguais.

A Figura E.2 já apresentada na seção 3.2, será utilizada novamente para demonstrar como ficará a passagem do STN para o PFS numa EV em que as EPs tenham relação de consumo. Nesta figura foi acrescentada as condições de estocagem e politica de transferência ZW para apresentar a conversão do STN para o PFS. No caso do UIS não é obrigatório colocar a condição na parte de baixo do estado, já que não tem nenhuma restrição. 
Figura E.2 - Exemplo de STN do processo produtivo de uma EV em que suas EPs tenham relação de consumo.

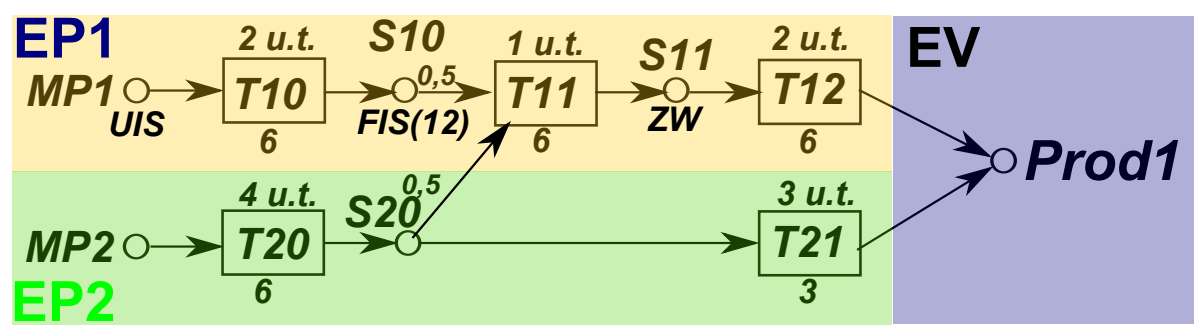

Para fazer a conversão do STN para PFS são necessários os seguintes passos:

1. Substituir as "tarefas" do STN pelo elemento "atividade" do PFS; colocar dentro do elemento "atividade" os valores referente ao respectivo nome da "atividade", o tempo de processamento em u.t., e quantidade de processamento (Figura E.3);

2. Verificar se existem duas setas saindo de um "estado" no STN (neste exemplo no S20). Caso positivo, é necessário tratar este "estado" antes de passar para o PFS. Como o PFS tem as características da RdP, quando existem dois "arcos" saindo de um "distribuidor", este caso representa um conflito, ou seja, que apenas um deles pode ser executado e a execução de um desses processos inibe a execução dos outros processos que estavam em conflito. No STN isto apenas representa que o material será consumido por duas "tarefas". Neste caso é necessário criar um elemento "atividade" e nomear como Distrib.(nome distribuidor), criar dois "arcos" saindo desta "atividade" indo para dois novos elementos "distribuidor", estes novos elementos é que farão a distribuição para as respectivas "atividades". Colocar a porcentagem dos "estados" produzidos/consumidos por cada "tarefa" do STN em cima do "arco" do PFS (Figura E.3). No exemplo apresentado no "estado" S20 saem dois "arcos", desta forma foi criado uma atividade com nome de "Distrib. S20". Substituir os "estados" do STN pelo elemento "distribuidor" do PFS: colocar acima do elemento "distribuidor" o respectivo nome do "distribuidor", e abaixo do elemento "distribuidor" a restrição de armazenagem ou de política de transferência (Figura E.4).

Figura E.3 - Passo 1 para a conversão do STN em PFS.

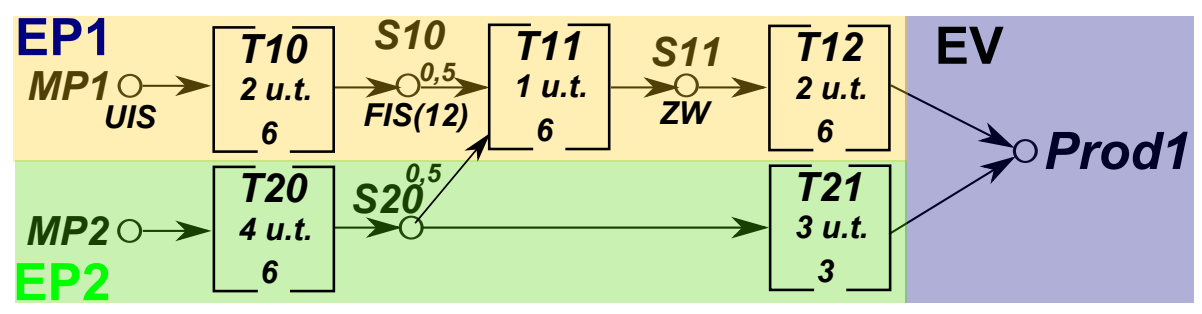


Figura E.4 - Passo 2 para a conversão do STN em PFS.

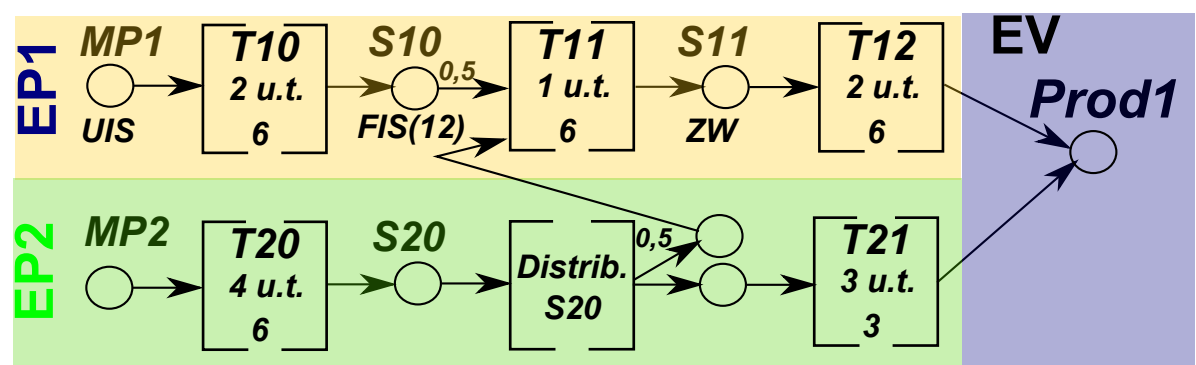

O valor que fica em cima do arco que sai da "atividade" distribuidora corresponde à porcentagem de material que será enviada para a próxima "atividade". Com o PFS final (Figura E.4), é possível fazer refinamentos sucessivos construindo um modelo de forma progressiva e estruturada, de modo que sejam preservadas as estruturas das atividades do nível superior e são descritos os detalhes num nível funcional. Este detalhamento pode gerar sub-grafos em RdP, podendo ser usado futuramente para análise e controle (MELO et al., 2008; MELO et al., 2010; MELO; JUNQUEIRA; MIYAGI, 2010). 